\title{
NEUTRON SPECTRUM MEASUREMENTS FOR RADIATION PROTECTION PURPOSES
}

\author{
D. R. Slaughter, D. W. Rueppe1 and D. A. Fuess
}

February 21, 1978

Work nerformed under the auspices of the US Department af

Energy of the UCLLL under contract number W-7405-ENG 48 .

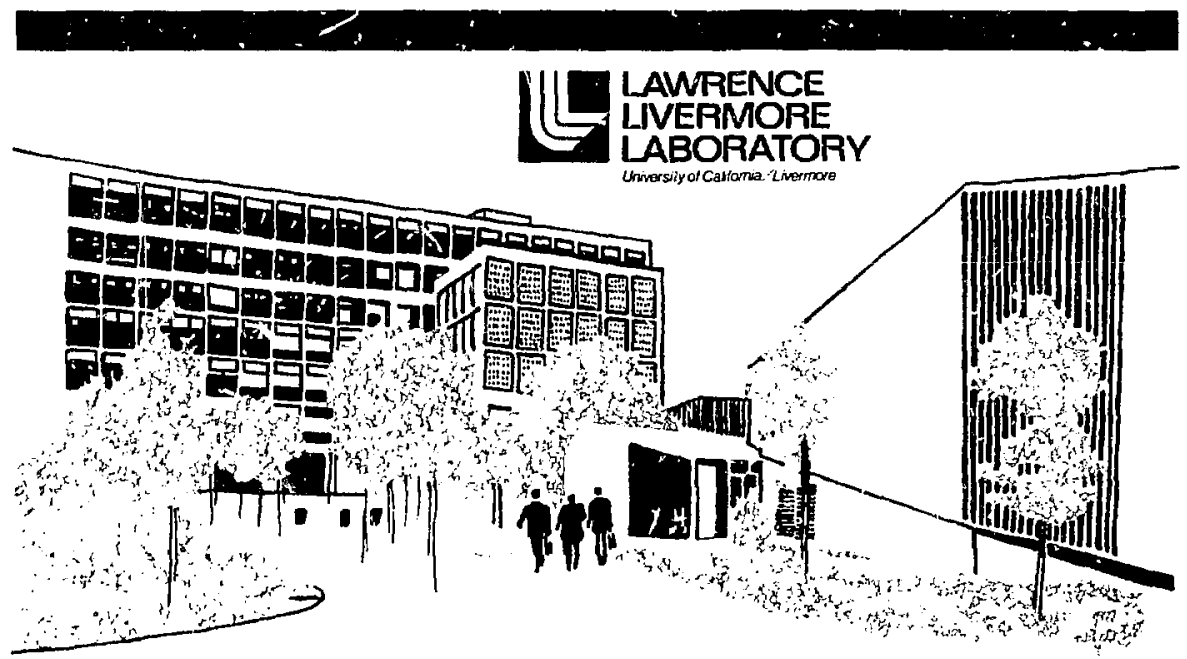

\section{MASIER}




\section{NoTICE.}

"This repost was prepared as an account of work iponsored by the United States Government. Neither the United States Hot the United States Departmez $t$ of Energy, noz any of their em. ployess, nor any of their contractors, subcon. tractors, or thest employees, makes an; warraniy. express or implied, or assumes any logal liability or responsibslity for the accuracy, completeness or usefulness of any information, appasatus. produci or process disclosed, or reptesents the 1 its use would not infringe privately-uwred righes."

\section{Motice}

Reference to a crimpany al product name does nol umply appresial or rectumendatuon of the product by the Universily of California of the U.S. Department of Encrey to the exclusion of others that inas be sultable.

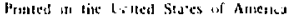
Avaltahle tr,im

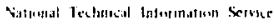

i s Depitrament il Commetce

szas line Rindal Ruat

Spunfliclil. VA :2lal

Penc fiancel cispls Mureltita $\$ 3.00$

\begin{tabular}{|c|c|c|c|c|c|}
\hline Poge & Range & $\begin{array}{c}\text { Domesilic } \\
\text { Price }\end{array}$ & Page & Range & $\begin{array}{c}\text { Domestic } \\
\text { Puce }\end{array}$ \\
\hline$\left.\left(I^{\prime}\right)\right]$ & 0129 & $(+t)[1]$ & $.32 \mathrm{t}$ & 350 & $\checkmark 12 .(3 t)$ \\
\hline 020 & $0<0$ & $4=31$ & .81 & 37 & 1250 \\
\hline 0.51 & $67^{2}$ & $5: 9$ & 370 & +100 & $1: 01]$ \\
\hline 076 & 100 & 600 & $4(1)$ & 435 & 1.325 \\
\hline 101 & 125 & 0.50 & 426 & 4.50 & 1400 \\
\hline 120 & 1.50 & 725 & +51 & 475 & 1450 \\
\hline 151 & 175 & K.HO & 476 & 500 & 1500 \\
\hline 176 & 310 & "I.(1) & 501 & 525 & 1528 \\
\hline 201 & 225 & 1125 & 5 . & 550 & 15.50 \\
\hline 226 & 250 & 150 & $\therefore 1$ & 575 & it 25 \\
\hline $2 \$ 1$ & 275 & 1075 & 570 & $(1,1)$ & $10.50]$ \\
\hline 276 & 100 & 11.00 & 601 & up & 1 \\
\hline 301 & 325 & 11.75 & & & \\
\hline
\end{tabular}

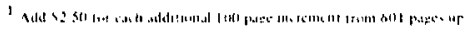




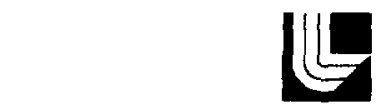

IAWRENCE IINERMORE I_ABORATORY

Unwersityof Caitorna Lvermore Caliorna 94550

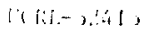

\title{
NEUTRON SPECTRUM MEASUREMENTS FOR RADIATION PROTECTION PURPOSES
}

\author{
1). R. Siambilu:r \\ is. $\therefore$ [aseppo] \\ 1). A. ruess
}

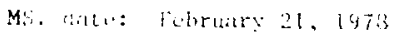

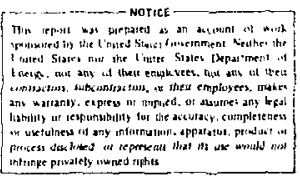




\section{CONTENTS}

Abstract . . . . . . . . . . . . . . . . . . . . . . . 1

Introduction ............................... 1

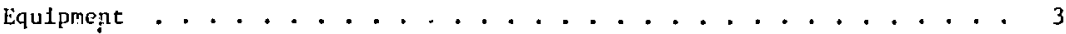

Organic Scintillation Detectors - NE213 and Stilbene . . . . . . . 4

Gas Proportional Counters $-\mathrm{CH}_{4}$ and $\mathrm{H}_{2}$. . . . . . . . . . . . . 10

Gas Proportional Counters $-{ }^{3} \mathrm{He}$. . . . . . . . . . . . . . . 15

Data Reduction to Obtain Differential Neutron Spectrum, $\phi(E)$. . . . . . 18

Organic Scintillation Detectors - NE213 and Stilbene . . . . . . . 18

Uncertainty Estimation - Scintillators . . . . . . . . . . . . . . 25

Gas Proportional Counters $-\mathrm{CH}_{4}$ and $\mathrm{H}_{2}$. . . . . . . . . . . . . . 30

High-Energy Response . . . . . . . . . . . . . . . 31

Low-Energy Response . . . . . . . . . . . . . . . 33

Unfolding . . . . . . . . . . . . . . . . . . . 37

Error Estimates. ....................... . . 39

Tests of the Method .................... . 0

Gas Proportional Counters $-3_{\mathrm{He}}$. . . . . . . . . . . . 49

Response Matrix... . . . . . . . . . . . . . . 43

Unfolding ...................... . . 47

Tests of the Method .................... . 48

Results . . . . . . . . . . . . . . . . . . . . . . . . 48

Display Format . . . . . . . . . . . . . . . . . . . 48 48

Laboratory Measurements . . . . . . . . . . . . . . . . . 51

Field Measurements . . . . . . . . . . . . . . . . . . 51

Conclusions . . . . . . . . . . . . . . . . . . . 55

References . . . . . . . . . . . . . . . . . . . . . . 60 60

Appendix A - Tabular Data - Moderated Sources . . . . . . . . . . . 65 


\section{NEUTRON SPECTRUM MEASUREMENTS FOK RADIATION PROTECTION PURPOSES}

\section{ABSTRACT}

At LLL we have measured the energy spectra of low-intensity neutron sources used for calibrating personnel neutron dose-rate meters and dosimeters, and for characterizing the neutron fields to which personnel are exposed. This report describes severai detector-analyzer systems that will neasure in the energy range $50 \mathrm{keV}$ to $20 \mathrm{MeV}$ at intensities from $10^{-1}$ to $10^{5} \mathrm{n} / \mathrm{cm}^{2}-\mathrm{s}$. The systems Include NE213 and stilbene organfc scintillators as well as $\mathrm{H}_{2}$, $3 \mathrm{He}$, and $\mathrm{CH}_{4}$ proportional counters. Also described are pulse-height analysis and pulseshape discrimination systems. An unfolding code, NUTSPEC, reduces the pulse-height data to an absolute differential neucron flux $\phi(E)$ for the above detectors. The code uses a derivative unfolding method for the scintillation detectors, and for the proportional counters it calculates a response matrix and uses $;$ il iterative unfolding method tc determine $\phi(E)$. The unfolded : tux distribution combined with published conversion factors produces differential neutron dose-equivaient and kerma rates. Spectral segment:s nbtained with different detectors from several measirements merge into a single differential flux spectrum over the range $50 \mathrm{keV}$ to $20 \mathrm{MeV}$, together with the corresponding differential kerma and neutron doseequivalent distributions. Also reported are spectrum measurements near ${ }^{252}$ Cf and ${ }^{238}$ Pube sources with various moderators.

\section{INTRODUCTION}

Biological tissut is damaged by neutrons when secondary charged particles are produced by interactions in hydrogen or carbon nucle1. or when gamma rays are produced followlug the capture of a neutron. The extent and nature of the effect is strongly Influenced by the tissue type and the linear energy transfer (LET) of tive secondary charged particles produced. To Infer the blological effect of a neutron exposi:re, th is necessary to determine the energy spectrum and intensity of a neutron field as well as the type and geometrical distribution of the tissue. It is reasonable 
to make general assumptions about tive tissue type and geometry for estimation of the effects due to personnel exposures, but the energy spectrum of the neutrons is highly dependent on the source type, shielding, and the environment around the source.

Several approaches may be used to estimate the biological effect of a particular neutron field on tissue exposed to it. The first is to devise a dosimeter or dose-rate-meter whose signal in a neutron field is proportional to the effect that field will have in tissue. Using general assumptions regirding charged particle production at various depths in man: organs, the ICRP has proposed a guide. ine for the neutron close-energy response for the whole body. 1

Several devices have been developed whose output due to neutron exposures approximates the prescribed doseenergy response. However, none of these devices follows the ICRP doseenergy response accurately at all neutron energies.

A second approach involves the direct neasurement of the LET spectra produced by secondary charged particles which result from neutron interactions in a tissue-like medium.

This work is currently being pursued at LLL and elseryere, but will not be discussed here.

A third method of inferring blological effect due to a neutron field is the direct measurement of neutron energy spectra and intensities, followed by calculation of the energy deposition in tissue or by application of an appropriate doseresponse relationship as in Ref. 1 . The work reported here is directed toward the last nethod. The Hazards Control Department at LLL inas constructed a calibration facility including a low-scatter cell. ${ }^{2}$ !'iere are several neutron sources available to simulate neutron fields of health physics interest, including ${ }^{238}$ puBe and ${ }^{252} \mathrm{Cf}$ with $\mathrm{H}_{2} \mathrm{O}, \mathrm{D}_{2} \mathrm{O}, \mathrm{CH}_{2}$ and aluminum moderators up to $25 \mathrm{~cm}$ thick. A neutron generator is also available which produces 2.5- or 14-MeV neutrons. Tinis Cacility is designed for caliurating neutron and gamma-ray monitoring instruments and dosimeters. Since most neutron monitoring devices have a response which only approximates the guideline dose response in tissue, it may be necessary to determine the neutron energy spectrum at the time of exposure.

Similarly, an Intrinsic Radiation Facility has been constructed at LLl. to measure the dose rate and spectra of radiation intrinsically emitted by nuclear weapons and their component parts. As a resul: of measurements made there, it is possible to forecast the radiation exposure to miltary personnel durlıg handling and storage of these weapons and the 
effect of changes in weapon design, shlelding, storagt configuration, or proximity of living quarters.

We have measured neutzon spectra in both of the facilities described above. These data are being used to assess shielding effects and the response of monitoring instruments, and also for comparing neutron transport calculations and experimental measurements. The measurements serve both to confirm the calculations and to determine the effects of complex geometries not easily simulated in a calculation. Some neutron energy spectrum measurements have been made in the field, and more are anticipated. These measurements are of interest as a means of verifying shielding calculations and to calibrate the response of various dosimeters used in work areas. One field measurement has already been reported ${ }^{3}$ using a modified version of tire 1aboratory spectrometer. A transportable system with high neutron sensitivity is now under construction.

The following sections describe the equipment used for labcratory and field measurements, and some of the important considerations in ctreosing appropriate detectors. The imporcant neutron interacticns in each detector are briefly discussed, and finally the data reduction methods used to obtain neutron spectra are described and their success is evaluated.

\section{EQUIPMENT}

Neutron spectra in the field or in tiıe facilities described earlier vary greatly in intensity and energy distribution. The intensttes of interest range from 0.1 co $10^{5} \mathrm{n} / \mathrm{cm}^{2} \mathrm{~s}$, and the energles range, roin thermal $(0.025 \mathrm{eV})$ to $20 \mathrm{MeV}$. Energy resolution must be at least as good as that in the transport calculations for purposes of veriflcation, and should be better if resonances or antiresonances in shielding materials are important. These requirements are difficult to meet and, as yet, there is no single detector system which covers the full energy and intersity range of interest.

A number of established methods are used to measure spectra in various regions of the above energy range including:

- Nuclear emulsions

- Threshold detectors using activation foils

- Moderated thermal or threshold detectors

- Time of flight

- Proton recoll spectrometers 
- ${ }^{3}$ He gas proportional counters

- ${ }^{3}$ He or ${ }^{6}$ Li semiconductor sandwich detectors.

While several of these methods are used to complement one another at LLL, ${ }^{4}$ only the proton recoil and ${ }^{3} \mathrm{He}$ gas proportional counter methods will be discussed below. The latter methods are restricted to a fairly narrow useful energy range, but offer the advantages of high sensitivity and good energy resolution.

The system to be described consists of several neutron detectors of different sensitivity and energy range. In combination, they may be used to measure spectra in the range $10 \mathrm{keV}$ to $20 \mathrm{MeV}$ over the whole incensity range described. There are several NE213 liquid scintillation detectors and a variety of ${ }^{3} \mathrm{He}, \mathrm{CH}_{4}$, and $\mathrm{I}_{2}$, proportional counters. spertral segments obtained with these detectors are merged into a mosaic displaying a continuous neutron energy spectrum. Spectra in the range $1-10 \mathrm{keV}$ are not measured routinely since our calculations indicate a sma11 contribution to the dose-equivalent in this range for the fields of interest.

Table 1 contains a list of detectors in the present inventory, and it gives some performance parameters. Generally, the scintillation detectors are used to measure the high-energy portion of a spectrum and the proportional counters the low-energy part. The scintillation detectors have much higher sensitivity in a given volume than the proportional councers, and may be operated at higher count rates. Thus, they are capable of useful measurements over a much wider range of intensities. However, only the proportional counters have been found useful at neutron energies below $0.5 \mathrm{reV}$. Since the physics principles, mode of operation, and data reduction for the scintilion detectors is Eundamentally - Eferent from those of proportional counters in tinis application, the following discussions ill consider scintillation and proportional counter measurements separately. ORGANIC SCINTILLATION DETECTORS NE213 AND STILBENE

Organic scintillators have been used for many years to measure fast neutron energy spectra, and there are several good reviews of this technique ${ }^{5-7}$ and many reported measurements. ${ }^{8-18}$ Materials used are generally pure hydrocarbons with maximum possible hydrogen content. Neutrons interact primarily by elastic scattering to produce recoil protons and carbon nuclei. The latter produce a very sma11 scintillation output because: (1) the recoil energy is at most $28 \%$ of the neutron energy, and (2) the light output of these scintillators decreases rapidly 
Trole 1. Detectors used for neutron spectrum measurements.

\begin{tabular}{|c|c|c|c|c|}
\hline $\begin{array}{l}\text { Detector } \\
\quad \text { No. }\end{array}$ & Scint1llators & $\begin{array}{l}\text { Energy } \\
(\mathrm{MeV})\end{array}$ & $\begin{array}{l}\text { Energy } \\
\text { resolution } \\
(\%)\end{array}$ & $\begin{array}{l}\text { Useful } \\
\text { neutron } \\
\text { intensity } \\
\left(\mathrm{n} / \mathrm{cm}^{2}-\mathrm{s}\right)\end{array}$ \\
\hline 101 & $5.08 \times 11.4 \mathrm{~cm}$ diam NE213 & $0.5-20$ & 7 & $0.1-10^{3}$ \\
\hline 103 & $7.6 \times 3.8 \mathrm{~cm}$ diam NE213 & $0.5-20$ & 7 & $0.5-10^{4}$ \\
\hline 105 & $5.08 \times 5.08 \mathrm{~cm}$ diam NE213 & $0.5-20$ & 7 & $0.5-10^{4}$ \\
\hline 104 & $2.5 \times 2.5 \mathrm{~cm}$ oiam NE213 & $0.5-20$ & 7 & $5-10^{5}$ \\
\hline 102 & $1.3 \times 1.3 \mathrm{~cm}$ d1am $\mathrm{NE} 213$ & $0.5-20$ & ? & $50-10^{6}$ \\
\hline 401 & $\begin{array}{l}1.0 \times 1.3 \mathrm{~cm} \text { dlam Stilbene } \\
\text { Proportional counters }\end{array}$ & $0.5-20$ & 7 & $50-10^{6}$ \\
\hline 201 & $20 \times 3.8 \mathrm{~cm}$ diam $3 \mathrm{~atm} \mathrm{H}_{2}$ & $0.01-0.8$ & 5 & $30-3000$ \\
\hline 204 & $46 \times 5.1 \mathrm{~cm}$ diam 1 atm $\mathrm{H}_{2}$ & $0.02-1.0$ & 5 & $5-500$ \\
\hline 206 & $91 \times 15.2 \mathrm{~cm}$ dram $0.5 \mathrm{~atm} \mathrm{H}_{2}$ & $0.02-1.0$ & & $1-100$ \\
\hline 208 & $91 \times 15.2 \mathrm{~cm}$ diam 1 atm $\mathrm{H}_{2}$ & $0.05-1.5$ & 5 & $0.5-50$ \\
\hline 207 & $\begin{array}{r}91 \times 15.2 \mathrm{~cm} \text { diam } 1 \text { atm } \mathrm{H}_{2}+ \\
1 \text { atm } \mathrm{Kr}\end{array}$ & $0.1-2.0$ & & $0.5-50$ \\
\hline 604 & $91 \times 15.2 \mathrm{~cm}$ diam 1 atm $\mathrm{CH}_{4}$ & & & $0.2-25$ \\
\hline 602 & $\begin{array}{r}91 \times 5.1 \mathrm{~cm} \text { diam } 2 \text { atm } \mathrm{CH}_{4}+ \\
4 \text { atm Kr }\end{array}$ & $0.5-10$ & & $0.5-50$ \\
\hline 301 & $\begin{array}{r}46 \times 5.1 \mathrm{~cm} \text { diam } \\
4 \mathrm{~atm}{ }^{3} \mathrm{He}+ \\
3 \text { atm } \mathrm{Ar}\end{array}$ & $0.2-3.0$ & 6 & $5-500$ \\
\hline 303 & $46 \times 4.1 \mathrm{~cm}$ diam 4 atm ${ }^{3} \mathrm{He}+$ & & & \\
\hline & 3 atm $\mathrm{Kr}$ & $0.2-3.0$ & 6 & $5-500$ \\
\hline 302 & $15 \times 2.5 \mathrm{~cm} \mathrm{dfam} 3$ atm ${ }^{3} \mathrm{He}$ & $0.1-1.0$ & 4 & $50-5000$ \\
\hline
\end{tabular}

as the speciflc Ionization of the charged particle increases, resultIng in very small scintillation output due to recoll carbon nuclel.

There are two important difficulties in using these detectors.
First, organic srintillators are sensitive to gamma rays. Photons in the energy range $100 \mathrm{keV}-10 \mathrm{MeV}$ interact in the scintillator primarily by Compton scattering. Cumpton electrons are produced which cause 
fluorescence and contribute to the output pulse-height spectrum. Figure 1 shows the light output from NE213 liquid as a function of charged particle energy. Two features are important:

1. Compton electrons at ahout $1 \mathrm{MeV}$ produce as much light as a recoil proton at 3 ilev. Thes a significant portion of the pulse-height spectrum may be obscured by gamma-ray interactions.

2. The fluorescent output of organic scintillators is dependent not only on the energy deposit ad by charged particles, but on the specific ionization of those particles. Higher specific ionization results in reduced fluorescence. Thus, light output due to recoil protons is not linear with energy. To analyze recoil protons over the energy range $0.5-20 \mathrm{MeV}$ (dynamic energy range $40: 1$ ), pulse height must be analyzed over a dynami : range $300: 1 .^{19}$ This imposes stringent requirements on the electronics used for pulseheight analysis.

Fortunatel.y, rome organic scintillators such as NE213 and Stilbene fluoresce via several de-excitation modes with time constants ranging from a few nanoseconds to a few hun- dred nanoseconds. ${ }^{20}$ The relative amplitude for each mode depends on the specific ionization of the charged particle, and thus the shape of the light pulse in time depends on whether the charod particle was an ei -..tron or a proton. Pulseshape descrimination (PSD) is used to distinguish gamma ray and neutron interactions in the scintillator. The scintillation output is viewed by an RCA 3575 photomultiplier tube whose base is conrected as shown in Fig. 2. Several fyatures of this base are inportant. The linear signai obtained from the 10th dynode is used for pulse-.eight analysis. Signals obtained nearer the anode were found to be not linear witi energy for lars,e-amplitude signals. In addition, the signal at the $10 \mathrm{th}$ dynode is linear only as long as the photomultiplier tube is operated at reasonrbly low gain; i.e., up to about $2600-1700$ walts on the anode. Finally, the inportance $c i$ the highcapacitance bypass capacitors on the last dynodes canno: be over emf'ר:sized since the large nonlinear signal at the anode is rearily coupled to the 10th dynode through the voltage divider resistors if the dynodes are noi adequately bypassed to sround.

Figure 3 shows a block diagram of the pulse processing electronics used. Two functicns are carsied out 


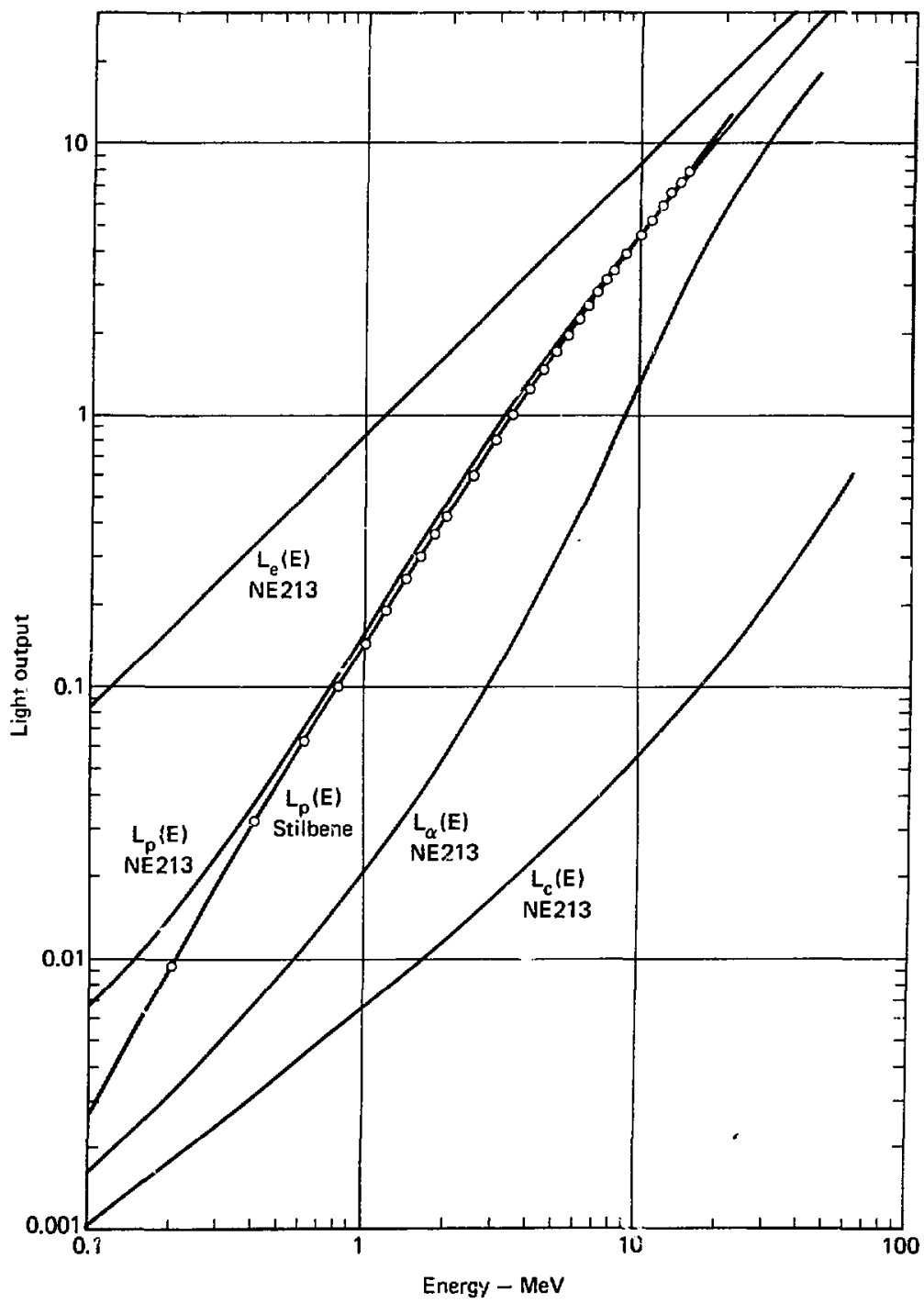

F1g. 1. LIght output in NE213 and St1lbene. I $\mathrm{J}_{\mathrm{e}}$ is the 1ight output due to electrons, $I_{i j}$ the.11ght output due to protons, $L_{\alpha}$ the light output due to alpha particles, and $\mathrm{L}_{\mathrm{c}}$ the light output due to recoil carbon nuclei. Data are taken from Refs. 7 and 7.9. 


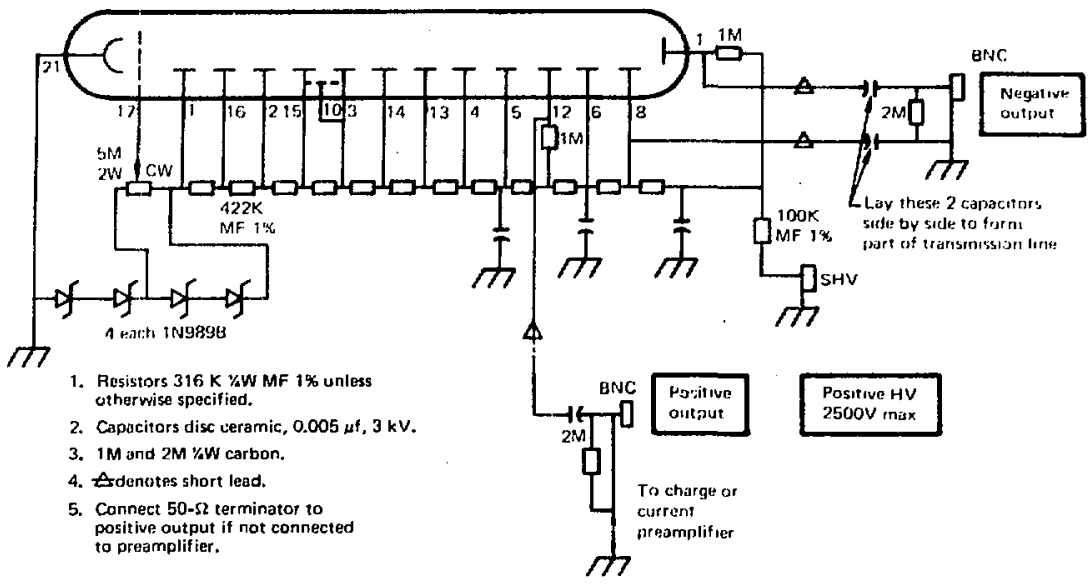

Fig. 2. Circuit diagram of PM tube base.

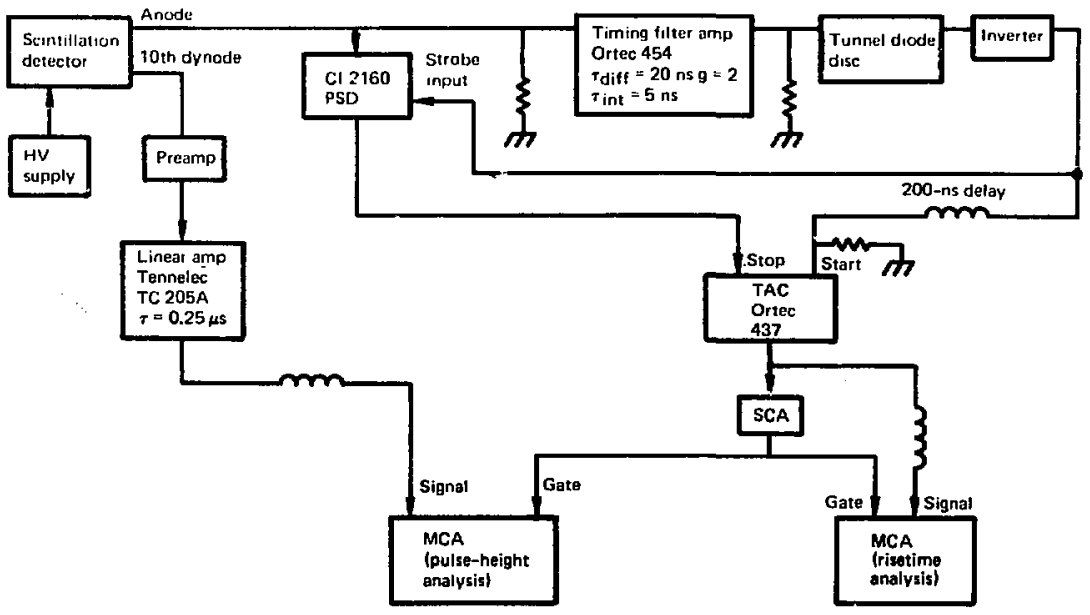

Fig. 3. Block dlagram of scint11.lation spectrometer system. 
sinultaneously. A signal derived from the anode of tire P:i tube is analyzed for siape, and a gate signat is generated if the risetine is consistent with that of a neutron event. Another signal derived from the 10tin dynode of the $\mathrm{RCA} 3575 \mathrm{PM}$ tube is amplified and used for pulseheight analysis.

The performance of the system shown is Iimited at low energies by its ability to distinguish neutron and ganna-ray interactions. At present the useful energy range is $0.5-$ 20 Mut since the pulse-shape dis:crimination begins to fail for pulses less than about 0.003 of full scalc. Simlarly, the maximum neutron intensity in wixich a given fecector may be used is Limited to approximately $10^{5}$ counts/s above which the PSB system begins to fail. It should also be noted that this count rate limit includes both ganma and neutron interactions so that a high gamma-ray background further reduces the maximum acceptable neutron intensity.

Data acquisition with these detectors requires: (1) establishing suitable pulse-shape discrimination to reject gamma-ray interactions and ${ }^{12} \mathrm{C}(\mathrm{n}, \alpha)$ reactions; (2) establishing an energy scale for the detector linear signal; and (3) collection of a pulse-hefght spectrum from the linear signal avallable at the $10 \mathrm{th}$ dynode. The energy scalle is determined by pulse-hujght analysis of a ganma-ray spectrum due to ${ }^{22}$ Na or other simple gamma-ray source. Gamma rays interact in the scintillator to produce a distribution of Compton scattered electrons. The relationship between the light output due to protons and electrons at the same energy is well known, 19 and has been shown in Fig. 1. Recoil proton energies may be determined from the pulse-height distribution due to Compton scattered electrons as follows: The most energetic Compton scattered electrons due to the 1.275-MeV gamma ray emitted by ${ }^{22} \mathrm{Na}$ have energy $1.062 \mathrm{MeV}$. The $0.511-$ $\mathrm{MeV}$ annihilation photons produce Compton electrons up to $0.34 \mathrm{~L} \mathrm{MeV}$. These two end-point energies occur as sharp edges in the ${ }^{22} \mathrm{Na}$ pulseheight spectrum shown in Fig. 4. Since the light output produced by energetic electrons is essentially linear with energy as shown in Fig. 1 , the fluorescence output, or light untt, is defined in terms of an equivalent electron energy deposition and 1 ts value is based on the data of Ref. 19.

$$
\begin{aligned}
\text { One 11ght unit } \equiv & \text { the light output } \\
& \text { due to the depo- } \\
& \text { sition of } 1.19 \\
& \text { MeV by an electron. }
\end{aligned}
$$

Thus, any simple gamma-ray source may be used to establish the energy scale 


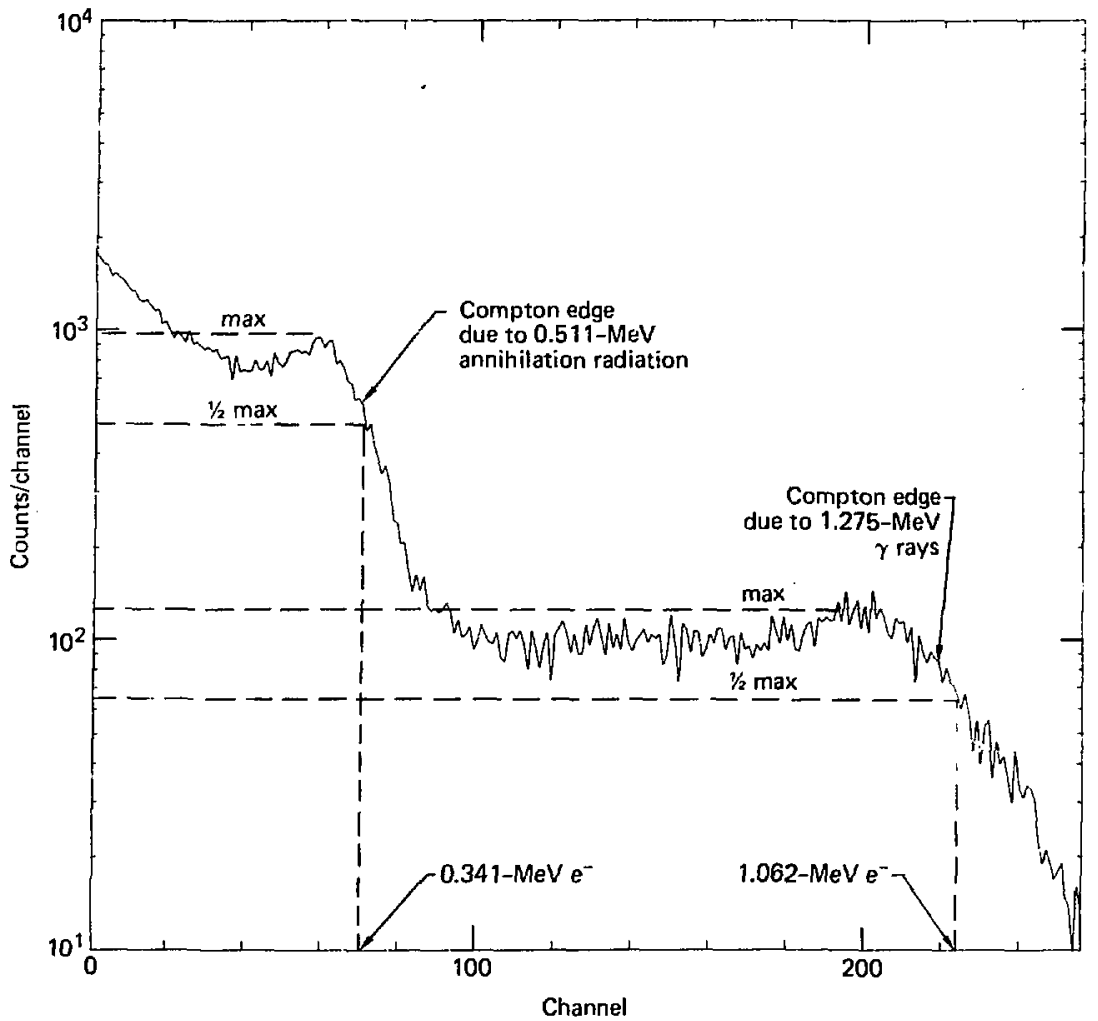

Fig. 4. Pulse-height spectrum due to ${ }^{22} \mathrm{Na}$ gamma rays in NE213. Location of electron edges at 0.341 and $1.062 \mathrm{MeV}$ are shown.

for the pulse-height distribution in light units. Then the relationship displayed in Fig. 1 is used to infer recoll proton energy corresponding to any given pulse height.
GAS PROPORTIONAL COUNTERS $-\mathrm{CH}_{4}$ AND $\mathrm{H}_{2}$

Hydrogen and methane proportional counters have been used by many to measure neutron spectra in the energy 
range of interest here. ${ }^{21-39}$ Good reviews of this technique are given in Refs, 26, 38 and 39. Proton recoils are produced in a hydrogenous gas proportional counter, and these are pulse-height analyzed to infer the neutron spectrum using an unfolding technique described in a later section. The electronics configuration used for this analysis is shown in Fig. 5.

There are a few important limitations on the performance of these detectors. First, the density of hydrogen is a great deal lower than in scintillators for practical gas pressures, and so the neutron sensitivity is much lower (see Table 1) even for very large proportional counters. Second, the charge collection time in a proportional counter is very long, i.e., on the order of 2-10 $\mathrm{\mu s} .40$ A proportional counter connot be operated at a high count rate $\left(>10^{3} \mathrm{c} / \mathrm{s}\right.$ ) and preserve good pulse-height resolution. As a result, the dynamic range is useful neutron intensity is narrow compared to the scintillator. Third, the pulseheight resolution is sensitive to the charge-collection efficiency and diameter of the anode wire in a proportional counter. Attempts to increase detector sensitivity by increasing the gas pressure in the detector generally result in:

(1) Reduced charge collection efficiency due to increased partial pressures of impurities in the gas and increased charge trapping in the primary aas; and (2) a requirement to reduce the anode wire diameter to maintain sufficient gas multiplication at practical anode voltages. Tolerances on the uniformity of anode wire diameter for very thin wires become critical since small variations in diameter cause large variations in

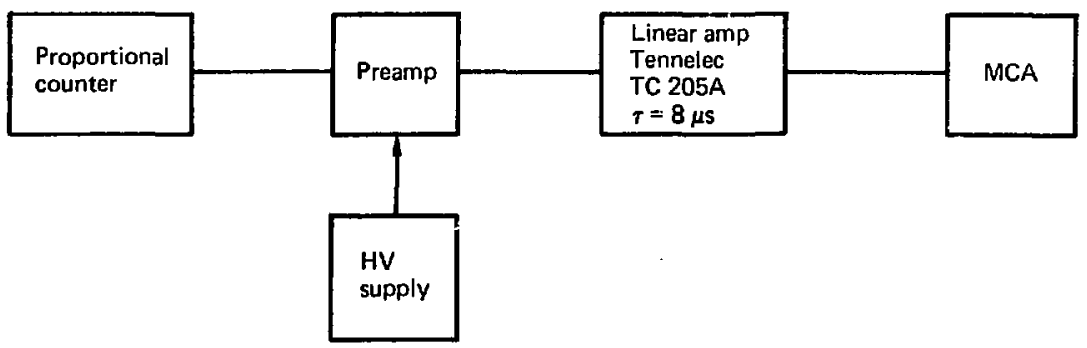

Fig. 5. Block diagram of proportional counter spectrometer system. 
gas multiplication and poor resolution.

Finally, the useful energy range of a proportional counter is determined by the stopping power of the gas fill and detector size. At the upper bound, useful spectrum measurements cannot be made $t$, hen the energy of a recoll proton is so large that its range in the gas exceeds the detector dimensions. At low energies, the pulse-height spectrum is distorted by photoelectron events in the detector walls and gas. Typically, the range of a photoelectron in the gas is Jong compared to detector dimensions so that energy deposition depends only on stopping power of the gas, its density, and the detector dimensions.

Increasing the gas dimensions or pressure, or introduction of a high-Z stopping gas will extend the useful energy range to more energetic neutrons by allowing analysts of more energetic protons, but this is done at the expense of greater energy deposition by photoelectrons generated in the detector wall. As a result, interference due to gammaray interactions obscures a greater portion of the low-energy spectrum.

It is posstble to reduce gammaray interference by rejecting long risetime evcnts (Refs, 26, 28-30, 32, $35-36,39-43)$. However, this technique has not been incorporated into the present system. The additional complexity associated with this technique Joes not appear to be warranted in the neutron fields investigated thus far.

We have made some effort to optimize detector dimensions and gas fill for measurements in the energy range $1 \mathrm{keV}$ to $3 \mathrm{MeV}$. Several proportional counter envelopes have been constructed with an active length of $91 \mathrm{~cm}$ and inner diameter of 5.1 and $15.2 \mathrm{~cm}$. Each has a spring-tensioned 0.051-mm-diameter anode wire and a fill tube to allow replacement of the gas. A gas handling system has been constructed (see Fig. 6) which supplies up to 6 atm of $\mathrm{H}_{2}, \mathrm{CH}_{4}, \mathrm{Ar}$, $\mathrm{Kr}$, or ${ }^{3}$ He with less than a few ppm water vapor or oxygen. The importance of removing electro-negative

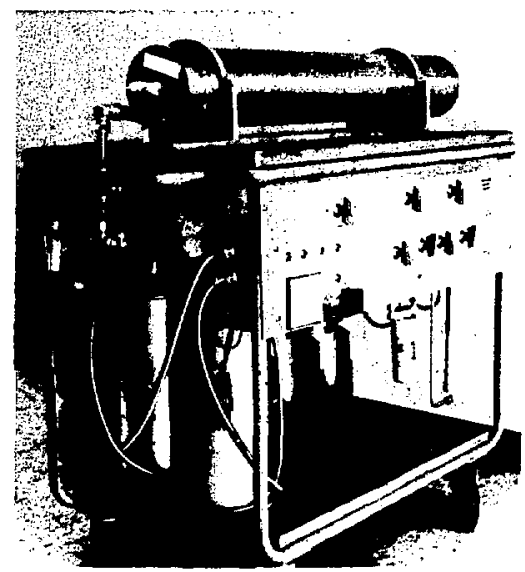

Fig. 6. Gas handling system used to refill gas proportional counters. 
or polar impurities has been discussed before. 33,44 The arrangement of gas filters and supplies is shown in Fig. 7.

The proper gas fill and detector geometry for a particular measurement is enosen on the asis of the desired sensitivity, energy range, and resolution. Energy resolution is determined by the uniformity of the multiplication process and efficiency of charge collection. Since charge collection efficiency depends on the relative concentration of chargetrapping species and on the number of charge mean-free-paths between anode and cathode, this requirement dictates the lowest possible gas presm sure. On the other hand, ligh sensitivity and good performance at high energies require higher gas pressures. The rationale used to balance these competing requirements is as follows: Assuming a fixed number of charge mean-free-paths from anode to cathode, the sensitivity of a cylindrical detector is directly proportional to the product of its length and diameter while that of a spherical detector varies as the diameter is squared. This is seen as follows: Note that

$$
\lambda \sim \frac{1}{\text { pressure }} .
$$

For a cylinder of diameter $2 \mathrm{R}$ and $M$ mean-free-paths over the anode-cathode distance $R$,

$$
R=\mathbf{M} \lambda \sim \frac{\mathbf{M}}{\mathrm{P}},
$$

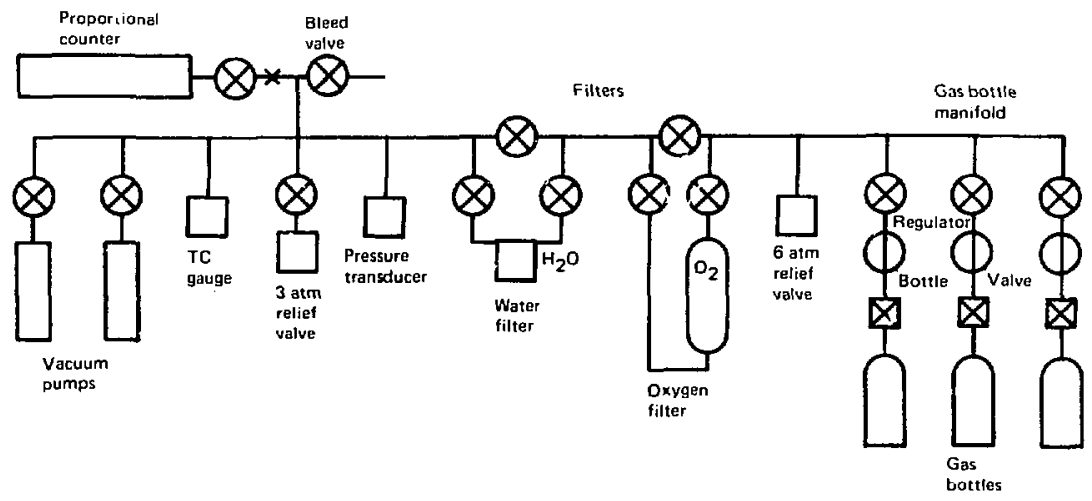

Fig. 7. Schematic of gas handling system used to refill gas proportional counters. 
and since

$$
\text { sensitivity } \approx \mathrm{PV} \text {, }
$$

then

$$
\begin{gathered}
S \sim \frac{M}{R} \pi R^{2} L \\
\sim M R L .
\end{gathered}
$$

For a spherica1 detector of diameter 2R,

$$
\begin{aligned}
\text { sensitivity } & \sim \mathrm{PV}, \\
& \simeq \frac{\mathrm{M}}{\mathrm{R}} \frac{4}{3} \pi \mathrm{R}^{3}, \\
& \backsim \mathrm{MR}^{2} .
\end{aligned}
$$

It must be noted that the pressure is reduced inversely as the radius in the above calculations. Figure 3 shows a plot of detector sensitivity versus detector radius where it is assumed that the number of mean-freepaths between anode and cathode (represented by the product of pressure and radius) is fixed. Inspection of the figure shows that proportional counters to be used in environmental neutron fields of $1 \mathrm{n} / \mathrm{cm}^{2} \mathrm{~s}$ or less must have diameters on the order of $15 \mathrm{~cm}$ or larger if the product $\mathrm{P} \times \mathrm{R}$ is 1 imited to $10 \mathrm{~atm}-\mathrm{cm}$. Another important consideration is the fact that a cylindrical proportional counter with $\mathrm{L}>2 \mathrm{R}$ has greater volume than a spherical detector of the same diameter, and is more

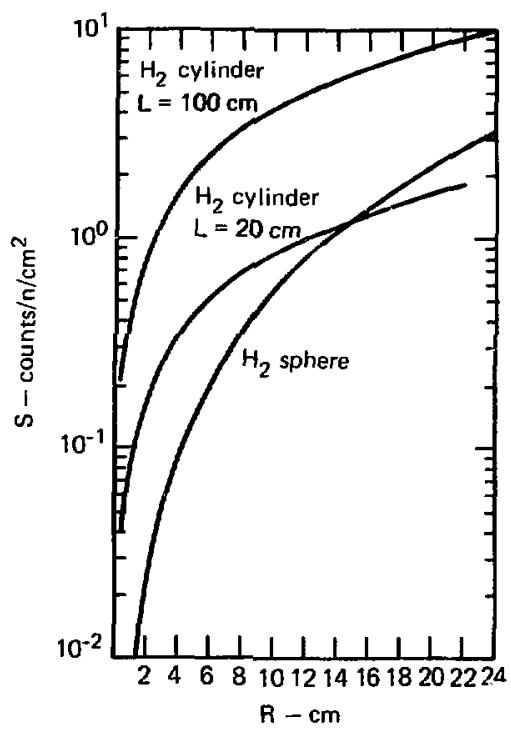

Fig. 8. Proportional counter sensitivity assuming pressure $x$ radius $=10$ atm-cm,

sensitive. However, the spherical detector has an isotropic response whlle the cylinder does not.

For a given gas fill and detector diameter, the useful energy range is bound at the top by the range of a recoil proton In the gas. When the range is on the order of the detector diameter, the response function becomes complex and the data reduction is difflcult. Figure 9 shows proton range for several gasses plotted against energy. The plot is based on the data of Northcliffe 45 and Parker. ${ }^{46}$ We have observed, as 


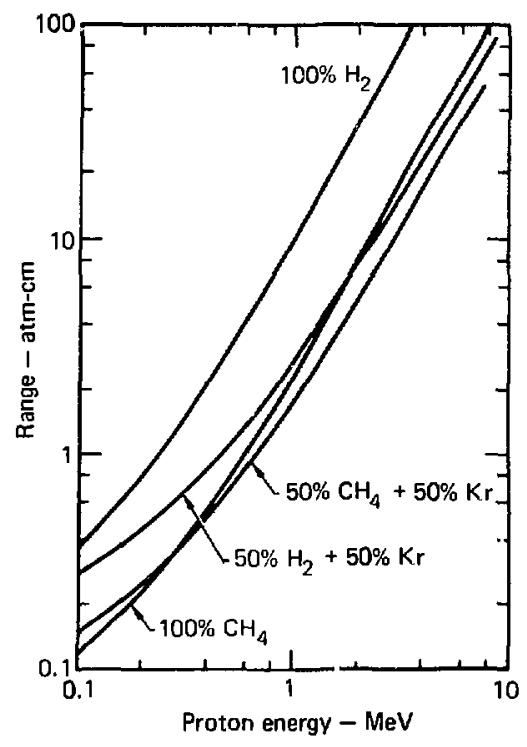

Fig. 9. Proton range in various gas mixtures as a function of energy.

others have ${ }^{25}$ that resolution begins to worsen appreciably when the anodecathode distance exceeds 10-20 atm-cm. Consequent $1 y$, it is clear from the figure that detectors filled primar1ly with hydrogen are limited to measurement of low-energy spectra, i.e., below about $1 \mathrm{MeV}$. Proportional counters for use in the range 1-5 MeV generally ins:lude either $\mathrm{Kr}, \mathrm{CH}_{4}$, or both as a stopping gas.

Calibration of the pulse helghtenergy scale is accomplished by either of two mechanisms. The counter gas f111 may contain small amounts of $\mathrm{N}_{2}$ or ${ }^{3}$ He which interact with thermal neutrons according, to ${ }^{14} \mathrm{~N}(\mathrm{n}, \mathrm{p}){ }^{14} \mathrm{C}$ or ${ }^{3} \mathrm{He}(n, p) \mathrm{T}$. The first reaction produces charged particles depositing about $606 \mathrm{keV}$, and the second $764 \mathrm{keV}$. These reactions will produce a peak in the pulse-height spectrum whose location establishes the recoil proton energy scale. Alternatively, the detector gas multiplication may be determined as a function of anode voltage. Then deposition of a known amount of charge on the anode wire by a test pulser wall produce a peak in the pulse-height spectrum whose location, together with the detector gas multiplication factor, is used to establish the energy scale. Curves of gas multiplication versus anode voltage have been determined for several detectors. The data were obtained ry locating the edge of the proton recoil distribution produced by a monoenergetic neutron source and comparing the pulse height to that produced when a known charge was placed on the anode wire. Figure 10 shows gas mi?iplication curves for several detectors.

GAS PROPORTIONAL COUNTERS $-{ }^{3} \mathrm{He}$

${ }^{3}$ He gas proportional counters are used in a tashion similar to that of $\mathrm{CH}_{4}$ and $\mathrm{H}_{2}$ detectors. Good reviews of their characteristics may be found in Refs. 47 and 48. There are two principle neutron interactions of interest: (1) ${ }^{3} \mathrm{He}(n, p)$ which has a 


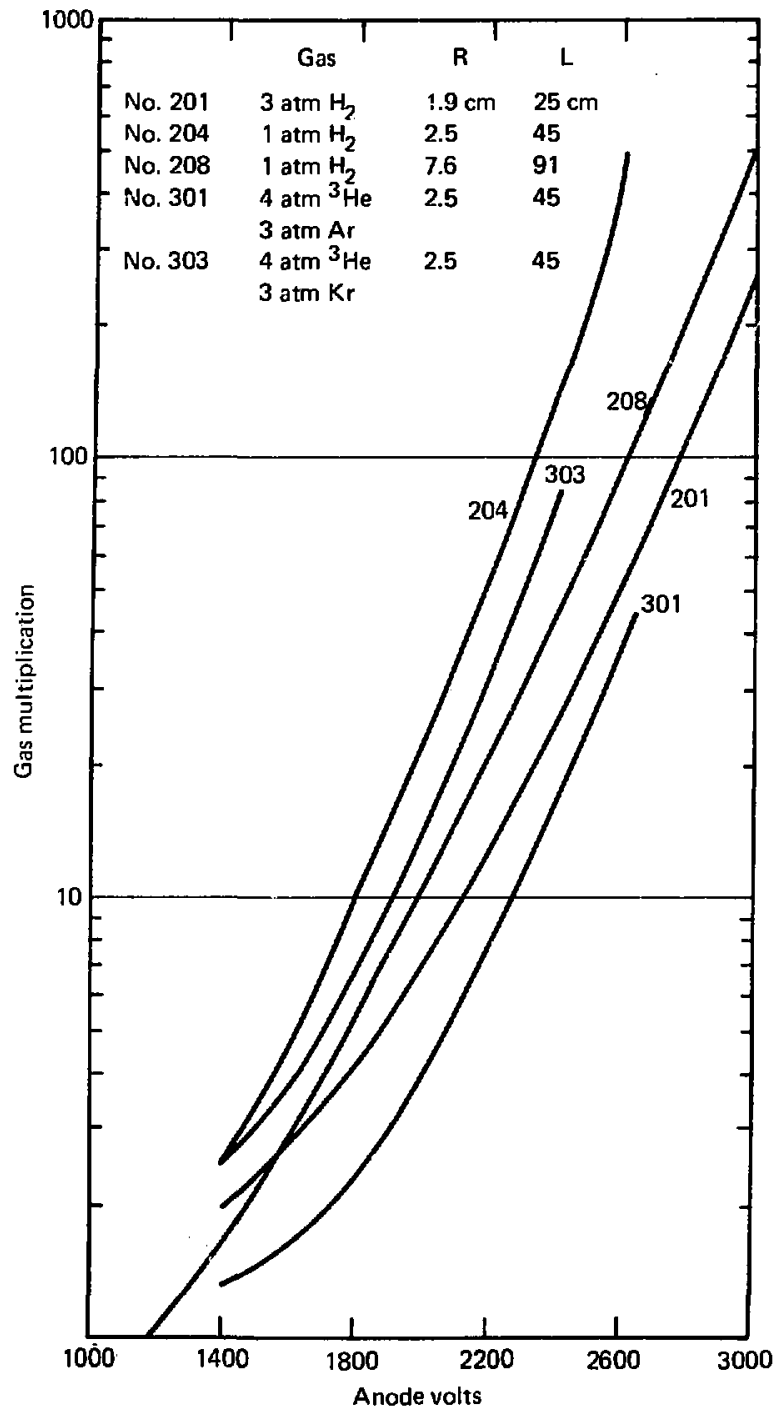

F1g. 10. Gas multiplication factor versus anode voltage for several gas proportional counters. 
$Q=+0.764 \mathrm{MeV}$, and (2) elastic scattering. As a result of the positive $Q$ for the $(n, p)$ reaction, these pulse-height spectra exhibit a $0.764-\mathrm{MeV}$ bias. Neutrons deposit $\mathrm{E}=\mathrm{E}_{\mathrm{n}}+0.764 \mathrm{MeV}$. There is no bias for the elastic scattering reaction in which the maxtmum energy deposition s $75 \%$ of the neutron energy. As a result, elastic scattering reactions interfere with the pulse-height spectrum due to $(n, p)$ reactions on $1 y$ at neutron energies greater than $\frac{0.764}{0.75}=$ $1.02 \mathrm{Me}$. Above that energy, the $3_{\text {He recoil distribution complicates }}$ the unfolding process, as will be described later.

Little interfarence due to gamna rays occurs in these detectors because of the $0.764-\mathrm{MeV}$ bias mentioned earlier, and energy scale calibration is accomplished simply by locating the always prominent peak due to thermal neutron capture.

The princlple characteristics which limit the use of these detectors are:

- The low-energy performance is limited since a portion of the pulse-height spectrum produced by very low-energy neutrons is obscured by the rather broad peak produced by thermal neutrons. For a resolution of $5 \%$, the thermal peak is $0.05 \times 764=$ $38 \mathrm{keV}$ wide, and thus obscures the lowest $50 \mathrm{keV}$ or so of the neutron spectrum.

- The $(n, p)$ cross section for thermal neutrons is about 5,00 barns while that for fast neutrons is on the order of $I$ barn. Thus, a small intensity of thermal neutrons may dominate the detector count rate and cause distortion of the pulseheight spectrum due to pulse pile-up.

- At energies above $1.02 \mathrm{MeV}$, the recoil distribution due to elastic scattering overlaps and interferes with the $(n, p)$ pulseheight distribution. Analysis of recoil events may be suppressed by $\mathrm{F}$ i.jse-shape discri-mination, 49,50 however, this is accomplished at considerable expense in sensitivity, and the resulting lower efficiency is extremely sensitive to small changes in the pulse-shape discriminator.

- The $(n, p)$ cross section falls rapidly above $1 \mathrm{MeV}$ and is exceeded by elastic scattering at about $80 \mathrm{kev}{ }^{51}$

- The upper bound on the useful energy range is limited primarlly by the same proton rangeversus-detector dimension considerations as were encountered in hydrogenous proportional counters. 


\section{DATA REDUCTION TO OBTAIN DIFFERENTIAL NEUTRON SPECTRUM, $\phi(E)$}

Three detector types have been described previously. In each case, a pulse-height spectrum is obtained and is related to the neutron spectrum through the pulse-height energy scale and the detector response function. A computer program called NUTSPEC $^{52}$ has been developed which

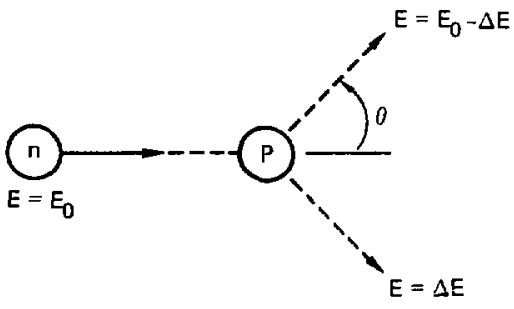

Fig. 11. Neutron-proton elastic scattering.

will transfer energy $\triangle D$ to the target. nucleus given by

$$
\Delta \mathrm{E}=\mathrm{E}_{0}\left(\frac{2 \mathrm{~A}}{(\mathrm{~A}+1)^{2}}\right)(1-\cos \theta)
$$

$$
\begin{aligned}
\text { where } A= & \frac{\text { mass of target }}{\text { mass of neutron }} \\
e= & \text { scattering angle measured } \\
& \text { in the laboratory coordin- } \\
& \text { ate system. }
\end{aligned}
$$

In the case where the target is the nucleus of a hydrogen atom in an organtc scintillator, $A \approx 1$ and the energy transfer for $(n, p)$ scattering Is

$$
\Delta E=\frac{1}{2} E_{0}(1-\cos \theta) .
$$


For neutron energies up to about 10 MeV, ( $n, p)$ elastic scattering is spherically symetric ${ }^{55}$ in the centerof-mass coordinate system. A simple geometric argument shows that the probability distribution of $\mathrm{P}(\cos \theta)$ is constant in this case, i.e.,

$$
\mathrm{P}(\cos \theta)=\text { const }
$$

so that the probability distribution of recoil proton energies is constant up to the maximum proton energy,

$$
\begin{aligned}
& E_{p}=E_{0} \text {, from Eq. (10). } \\
& P\left(E_{0}\right)=\left\{\begin{array}{l}
\frac{1}{E_{0}} 0 \leq E_{p} \leq E_{0} \\
0 \quad E_{p}>E_{0}
\end{array}\right.
\end{aligned}
$$

This distribution is drawn in Fig. 12.

The ralue of the constant is known since the area of the distribution must be unity. Thus, monoenergetic neutrons at energy $E_{0}$ will produce a

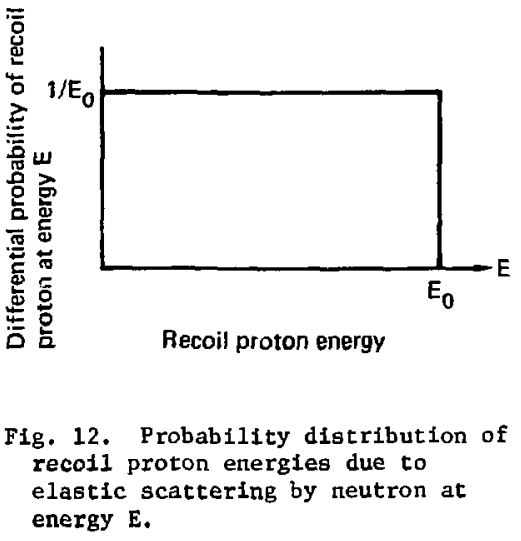

recoil proton dislribution in wich recoil proton energies are equally probable in the range $0<E_{p} \leq E_{0}$. Generalizing this result to the case where there is a continuous spectrum of source neutrons whose intensity is given by $\phi\left(\mathrm{F}_{0}\right)$, the recoil proton distribution is obtained by integrating the neutron scattering rate over all source energies which could produce : recoll proton at energy $E$ :

$$
\begin{aligned}
P(E)= & n_{H} v T \int_{E}^{\infty} \sigma_{n p}\left(E_{0}\right) \frac{\phi\left(E_{0}\right) \mathrm{dE}_{0}}{E_{0}} \quad \text { (13) } \\
\text { where } \quad \mathrm{V}= & \text { detector volume }\left(\mathrm{cm}^{3}\right), \\
\mathrm{T}= & \text { duration of exposure (s), } \\
\mathrm{n}_{\mathrm{H}}= & \text { density of target protons } \\
& \text { (H atoms } \left./ \mathrm{cm}^{3}\right), \\
\sigma_{\mathrm{np}}= & \mathrm{n}-\mathrm{p} \text { elastic scat tering } \\
& \text { cross section }\left(\mathrm{cm}^{2}\right),
\end{aligned}
$$

and the recoil proton distribution function $1 / \mathrm{E}_{0}$ has been insluded. Differentiation of Eq. (13) gives

$$
\frac{d P(E)}{d E}=\frac{-V T n_{H}}{E} \sigma_{n p}(E) \rho(E) \text {. }
$$

Then solving for $\phi(E)$,

$$
\phi(E)=\frac{-E}{V T n_{H}} \frac{}{\sigma_{n P}(E)} \frac{d P(E)}{d E} .
$$

The neutron spectrum is related directly to the first derivative of the proton recoll distribution, $P(E)$. Parameters $V$ and $T$ are determined at the time of measurenent while $n_{H}$ 
depends on whethor Stilbene or NE213 is selected for the detector. The $(n, p)$ scattering cross section is given by Gamme $1^{56}$ as

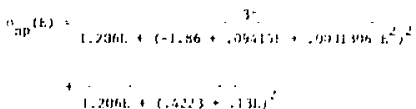

where $E=$ neutron energy in $\mathrm{MeV}$, $\begin{aligned} \sigma_{n p}= & \text { differential scattering } \\ & \text { cross section in barns. }\end{aligned}$

The $f$ actor $\frac{d P(E)}{d E}$ is obtained from the experimental data. A proton energy scale is established as described earlier.

Referring back to Fig. 1, recall that scintillation outpuc due to recoil protons is significantly reduced by their high LET, and is much smasler than that due to electrons of the same energy. The reduction in scintillation output is most severe for low-energy protons so that light output for protons is highly nonlinear. Verbinski ${ }^{19}$ has studied the response of NE213, and Swartz and Owen ${ }^{7}$ have tabulated proton scintillation yleld in Stilbene. These data were plotted in Fig. 1 and show the scintillation output for electrons as well as alpha particles and recoil carbon nuclei for comparison. To simplify the light-versus-energy relation for computational purposes, these data have been fitted with B-spline Interpolation functions subject to the constraints that the functional form be continuous ard its first and second derivatives are continuous. The functions $L_{p}$ (E) which satisfy these constraints and fit the data over the whole energy range within $\pm 2 \%$ are given in Table $2 \mathrm{~A}$. The function takes on different parameter values in each of several energy ranges separated by "knots." Each parameter set yields a function which joins smoothly with tile function in the adjacent energy regions. Lvaluation of $L_{p}(E)$ at any proton energy yields the scintillation output in light units "L.U." as defined earlier. Finctions used to obtain the inverse, i.e., $E\left(L_{p}\right)$, are given in Table $2 \mathrm{~B}$.

A detection system with amplification factor $g$ (channels/light unit) and bias $\mathrm{x}_{0}$ (channel location corresponding to zero scintillation output) will yield a pulse-height spectrum where it ie relationship between channe1 number $X$ and proton energy $E$ Is

$$
X(E)=x_{0}+g L_{p}(E)
$$

where $X_{0}$ and $g$ are determined by $a$ ${ }^{22} \mathrm{Na}$ or other gamma-ray calibration as described earlier. 
Table 2A. Piecewise polynomial representation of scintillator light output due to protons.

$$
L_{p}(E)=a_{0}+a_{1}\left(E-E_{0}\right)+\frac{a_{2}}{2 !}\left(E-E_{0}\right)^{2}+\frac{a_{3}}{3 !}\left(i-E_{0}\right)^{3} \text { for } E \geq E_{0}
$$

\section{$\mathrm{E}_{0} \quad \mathrm{E}_{\max }$}

(MeV)

$a_{0}$

$a_{1}$

$a_{2}$

$2.4964 \times 10^{-1}-9.9712 \times 10^{-2}$

NE213

$\begin{array}{llllll}0.100 & 1.09 & 6.7729 \times 10^{-3} & 6.4924 \times 10^{-2} & 2.4964 \times 10^{-1} & -9.9712 \times 10^{-2} \\ 1.092 & 3.17 & 1.7787 \times 10^{-1} & 2.6356 \times 10^{-1} & 1.5070 \times 10^{-1} & -6.1466 \times 10^{-2} \\ 3.170 & 40.0 & 9.5905 \times 10^{-1} & 4.4402 \times 10^{-1} & 2.2969 \times 10^{-2} & -1.0129 \times 10^{-3}\end{array}$

Stilbene
0.200
1.146
$9.3996 \times 10^{-3}$
$9.4224 \times 10^{-2}$
$2.1801 \times 10^{-1}-1.1671 \times 10^{-1}$
$1.146 \quad 2.59$
$1.7967 \times 10^{-1}$
$2.4826 \times 10^{-1}$
$1.0757 \times 10^{-1}-2.5032 \times 10^{-2}$
$2.592 \quad 4.52$
$6.3824 \times 10^{-1}$
$3.7759 \times 10^{-1}$
$7.1395 \times 10^{-2}$
$-1.6803 \times 10^{-2}$
$4.519 \quad 15.0$
$1.4784 \times 10^{0}$
$4.8397 \times 10^{-1}$
$3.3014 \times 10^{-2}$
$-3.5576 \times 10^{-3}$

To obtain $\frac{d P(E)}{d E}$, we note first that

$$
P(E)=P(X) \frac{d X}{d E},
$$

then

$\frac{d P(E)}{d E}=\frac{d P(X)}{d X}\left(\frac{d X}{d E}\right)^{2}+P(X) \frac{d^{2} X}{d E^{2}}$

Substitution of $X(E)$ from Eq. (17) gives

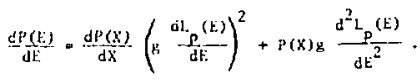

The neutron spectrum $\phi(E)$ is obtained from Eqs. (15) and (20):

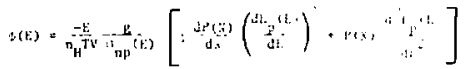

where $P(X)=$ pulse-height spectrum of recoil protons (counts/channel), $\frac{d P(X)}{d X}=$ slope of the pulseheight spectrum,

$L_{p}(E)=1$ ight output siven by the piecewise polynomials in Táble $2 \mathrm{~A}$.

Two important problems remain before a reliable estimate of $\phi(E)$ may be obtained. First, a suitable means must be found to obtain the slope of the pulse-height distribution without amplifying the statistical noise present or distorting the 
Table 2B. Plecewise polynomial representation of proton energy for given scintillation light output.

$$
E\left(L_{p}\right)=a_{0}+a_{1}\left(L_{p}-L_{0}\right)+\frac{a_{2}}{2 !}\left(L_{p}-L_{0}\right)^{2}+\frac{a_{3}}{3 !}\left(L_{p}-L_{0}\right)^{3}+\frac{a_{4}}{4 !}\left(L_{p}-L_{0}\right)^{4} \text { for } L_{p} \geq L_{0}
$$

$\begin{array}{llllll}L_{0} \text { I } L_{\text {max }} & a_{0} & a_{1} & a_{2} & a_{3} & a_{4} \\ \text { (Light Units) }\end{array}$

NE213

$\begin{array}{llllllll}0.006710 & 0.300 & 1.0233 \times 10^{-1} & 1.2433 \times 10^{1} & -1.6697 \times 10^{2} & 1.9023 \times 10^{3} & -9.7458 \times 10^{3} \\ 0.3004 & 0.950 & 1.5637 \times 10^{0} & 4.2897 \times 10^{0} & -2.8616 \times 10^{1} & 1.8903 \times 10^{2} & -4.9693 \times 10^{2} \\ 0.9460 & 1.92 & 3.2500 \times 10^{0} & 2.9227 \times 10^{0} & -1.0137 \times 10^{1} & 4.3826 \times 10^{1} & -7.3901 \times 10^{1} \\ 1.9148 & 3.70 & 5.2524 \times 10^{0} & 2.4704 \times 10^{0} & -2.3466 \times 10^{0} & 4.1566 \times 10^{0} & -3.2480 \times 10^{0} \\ 3.6894 & 24.8 & 8.4722 \times 10^{0} & 1.8257 \times 10^{0} & -3.5913 \times 10^{-2} & 1.3413 \times 10^{-2} & -1.0787 \times 10^{-3}\end{array}$

Stillbene

$\begin{array}{llllllll}0.009400 & 0.104 & 2.0000 \times 10^{-1} & 9.4015 \times 10^{0} & -8.5642 \times 10^{1} & 7.7967 \times 10^{2} & -\cdots \\ 0.1043 & 0.320 & 8.1770 \times 10^{-1} & 4.7348 \times 10^{0} & -1.1634 \times 10^{1} & 4.4121 \times 10^{1} & -- \\ 0.3129 & 1.0 & 1.6294 \times 10^{0} & 3.3173 \times 10^{0} & -2.4322 \times 10^{0} & 2.6991 \times 10^{0} & -\cdots \\ 1.0430 & 2.82 & 3.5783 \times 10^{0} & 2.2609 \times 10^{0} & -4.6155 \times 10^{-1} & 1.9055 \times 10^{-1} & \ldots \\ 2.816 & 10.0 & 7.0383 \times 10^{0} & 1.7421 \times 10^{0} & -1.2367 \times 10^{-1} & 2.4282 \times 10^{-2} & \ldots\end{array}$


data. Second, pulse-iedith speetrat nisst be compensited for distortions due to: (1) recoil protons which do not deposit all of their enerpy in the sensitive voiume of the detector; (2) neutrons which scatcer nore than once in the detector, producing two or more recoil proton events which are not resolved in time by ti:e detection system; and (3) secondary reactions such as inelastic scatering or $(n, 2)$ reactions in carbon.

A suitable digital filter has been designed 3 which finds the slope of the pulse-height data. If a parabola is least-squares fitted to $2 \mathrm{~N}+1$ data points, its slope at the midpoint may be obtained by a simple digital

filter. The digital filter computes the slope of the pulse-height parabola as follows:

$$
\left(\frac{d P}{d X}\right)_{k}=\sum_{i=1}^{N} W_{i}\left(P_{k+i}-P_{k-i}\right)
$$

where $P_{(k+i)}=$ counts in the $(k+i)$ th bin of the pulse-height distribution.

$$
\begin{aligned}
& w_{i}=c_{N} i, \\
& c_{N}=\frac{1}{2 \sum_{l=1}^{N} \ell^{2}},
\end{aligned}
$$

are the welght functions.

Expanding the width, $N$, of this filter has the effect of smoothing out statistical noise, but does so at the expense of resolution loss in the data. Une mast be cautious since Johnson 57 has found that sharp edges in the data will produce peaks in the unfolded spectrum whose centroids are shiffed loward higher energies.

Some distortion:s in the pulseheight data may be partially compensated. Loss of proton counts duc to riultiple scattering of one neutron in a thick detector may be treated by calculating the self atzenuation of the detector. 7 The detector efficiency is effectively reuced by the factor $f$,

$$
f(a L)=\frac{1-e^{-a L}}{a L} \text {, }
$$

where $L=$ detector thickness $(\mathrm{cm})$,

$$
a=n_{H} \sigma_{H}+n_{c} \sigma_{c} \text {, }
$$

and

$$
\begin{aligned}
n_{H}, n_{C}= & \text { atom densities of hydrogen } \\
& \text { and carbon, } \\
\sigma_{H}, \sigma_{C}= & \text { total cross sections of } \\
& \text { hydrogen and carbon. }
\end{aligned}
$$

In the work reported here, the carbon cross section is obtained by linear interpolation of the data given in Table 3.

$$
\text { Generally, multipie scatcering }
$$
produces two or more coincident proton events whose scintillation output is sumned by the detection system. Thus a distortion occurs, tending to increase the apparent rate of more 
Table 3, $c(n, n)$ elastic scattering cross section.

\begin{tabular}{llll}
\hline$E$ & $\sigma$ (barns) & $E$ & $\sigma$ (barns) \\
\hline .0 & 4.85 & 6.2 & 1.1 \\
0.5 & 3.4 & 6.3 & 2.7 \\
1.0 & 2.7 & 6.5 & 1.0 \\
2.7 & 1.6 & 7.15 & 0.75 \\
2.95 & 3.1 & 7.7 & 2.3 \\
3.03 & 1.0 & 8.4 & 1.1 \\
3.5 & 2.5 & 10.0 & 1.2 \\
4.15 & 1.8 & 11.0 & 1.4 \\
4.25 & 2.1 & 20.0 & 1.6 \\
5.32 & 1.1 & 40.0 & 1.1 \\
\hline. & .6 .0 & & \\
\hline
\end{tabular}

energetic protons. Countering this effect is the loss of energetic prorons which escape the detector active volume before depositing all of their energy. A semi-empirical formula due to Broek and Anderson 58 has been used with considerable success in those cases where the multiple scatter and escape corrections are not large. The correction is given below:

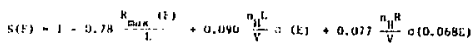

whert

$$
\begin{aligned}
\mathrm{R}_{\max } & =\text { range of protons }(\mathrm{cm}), \\
\mathrm{L} & =\text { detector thlckness, } \\
\mathrm{R} & =\text { detector radius, } \\
\mathrm{V} & =\text { detector volume, }
\end{aligned}
$$

and the range is obtalned using the empirical formula?

$$
\text { Range }=\frac{0.00178}{\rho}(E-0.119)^{1.815}
$$

where $\rho=\operatorname{density}\left(\mathrm{g} / \mathrm{cm}^{3}\right)$.

Incorporating these corrections into the expression for $\phi(E), E q .(21)$, gives:

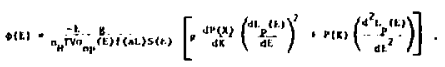

Tr 1 s expression is evaluated by the code NUTSPEC when reducing NE213 or Stilbene pulse-height data. All cross-section data are maintained in a parameter library internal to the code. Detector dimensions, elemental composition and density are also maintained within the parameter l1brary and are filed under the appropriate ID number for a particular detector. Reference 52 contains an operating manual for the code. 
Generally, it is necessary to divide the energy range $0.5-20 \mathrm{MeV}$ into two segments to maintain an approximately uniform resolution. This is because the bin width or energy width per pulse-height channel varies by near 1 y a decade over the 0.5 - to $20 \mathrm{meV}$ range due to the highly nonlinear relation between proton energy and scintillation output.

UNCERTAIITY ESTIMATION - SCINTILLATORS

Three sources of uncertainty are considered in the estimation of $\delta \phi(E)$, the uncertainty in spectral intensity. They are: (1) energy calibration errors, (2) statistical errors in pulse-height intensity, and (3) statistical errors in determination of the slope of the pulse-height distribution. These errors are assumed to be independent and are added in quadrature. Then

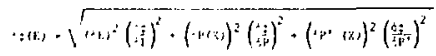

where

$$
\begin{aligned}
& \frac{\delta \phi}{\delta E} \cong \frac{\phi(E)}{E}, \\
& \frac{\delta \phi}{\delta P}=\frac{-E}{n_{H^{T V} \sigma_{n p}} f S}\left(\frac{\mathrm{d}^{2} L_{p}(E)}{\mathrm{dE}^{2}}\right)^{2}, \\
& \frac{\delta \phi}{\delta \mathrm{P}^{\prime}}=\frac{-E \mathrm{~g}^{2}}{\mathrm{n}_{\mathrm{H}} \mathrm{TV \sigma}_{\mathrm{np}} \mathrm{fS}}\left(\frac{\mathrm{dL}(\mathrm{E})}{\mathrm{dE}}\right)^{2},
\end{aligned}
$$

and assuming Poisson statistics,

$$
\begin{aligned}
& (\delta P(x))^{2}=P(x), \\
& \left(\delta P^{\prime}\left(X_{k}\right)\right)^{2}=\sum_{i=1}^{N} w_{i}^{2}\left(P_{k+1}+P_{k=i}\right),
\end{aligned}
$$

$$
\begin{aligned}
S E= & \text { estimated calibration } \\
& \text { uncertainty. }
\end{aligned}
$$

The analysis described above has been used to obtain neutron spectra from pulse-height data in a variety of detector systems and a variety of neutron fields. Three phenomena are not included in the foregoing calculation: (1) anisotropy in the $n-p$ scattering, (2) inelastic reactions in carbon, and (3) elastic scattering in carbon.

Anisotropy in the n-p scattering cross section causes less than $10 \%$ variation in the differential cross section at 14 and $22.5 \mathrm{MeV}{ }^{59}$ This has been neglected in the ana-ysis above, although an empirical expression due to Gamme $1^{56}$ could be incorporated. Neutrons which scatter inelastically in carbon are neglected here, and caution must be exercised In the interpretation of reduced spectra. Similarly, $(n, \alpha)$ and $(n, p)$ reactions are neglected since their cross sections are less than onetenth that due to $(n, p)$ scattering at energies up to $20 \mathrm{MeV}$ and have energy thresholds at 6.2 and 13.6 
MeV. Nevertheless, caution must be exerclsed in the Interpretation of reduced neutron spectra where the predominant intensity consists of neutrons above $10 \mathrm{MeV}$. These reactions and their thresholds are listed in Table 4.

A crude attempt is made to remove the effects of neutrons scatcered elastically in carbon. Figure 1 shows that the scintillation output due to a recoil ${ }^{12} \mathrm{C}$ nucleus is negligible. However, in a thlck detector a neutron which loses up to $28 \%$ of its energy scattering elastically in carbon may then produce a proton recoil before leaving the detector. The reduced data then show a continuous distribution of Table 4. Neutron reactions in ${ }^{12} \mathrm{C}$.

\begin{tabular}{lr}
\hline Reaction & $\begin{array}{c}\text { Neutron energy } \\
\text { threshold (MeV) }\end{array}$ \\
\hline$\left(n, n^{\prime} \gamma\right)$ & 4.8 \\
$(n, \alpha)$ & 6.2 \\
$(n, 9 B e)$ & 6.2 \\
$(n, n \alpha)$ & 8.0 \\
$(n, p)$ & 13.6 \\
$(n, d)$ & 14.8 \\
\hline
\end{tabular}

neutrons ranging in energy from $\mathrm{E}_{0}$ to $0.72 E_{0}$ where $E_{0}$ is the source energy. This is seen clearly in Fig. 13 where detectors of varlous thicknesses have been exposed to 2.5- and $14-\mathrm{MeV}$ neutrons and the data have been reduced. Note that the relative intensity of the scattered neutrons increases as the ratio of detectur thickness to neutron mean-free-path increases.

In the approach used here, the neutron energy distribution obtained from Eq. (29) is taken as a first approximation to that which would exist in the absence of carbon elastic scattering. Partlal compensation for the spectral distortion due to undetected elastic scattering in carbon is accomplished by calculating the energy spectrum of carbon-scattered neutrons and subtracting that from the solution to Eq. (29). This is carried out as follows:

$$
\phi(E)=\phi_{0}(E)-\phi_{c}(E)
$$

where

$$
\begin{aligned}
\phi_{0}= & \text { solution to Eq. }(29), \\
\phi_{c}= & \text { spectral intensity of neu- } \\
& \text { trons elastically scattered } \\
& \text { by }{ }^{12} \mathrm{C} \text { nuclei in the detector. }
\end{aligned}
$$


$\times 10^{3}$

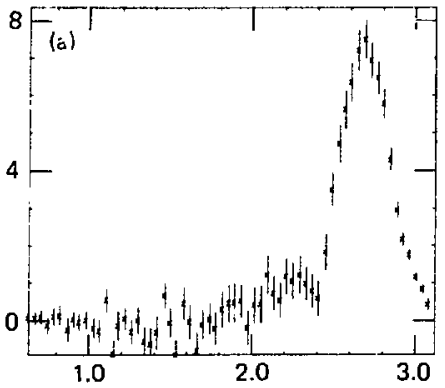

$x i 0^{2}$
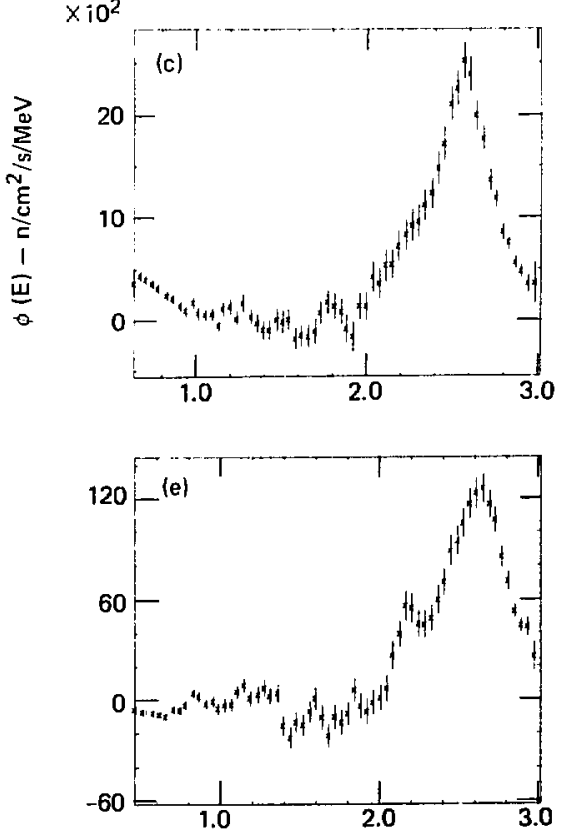

$\times 10^{3}$

(b)
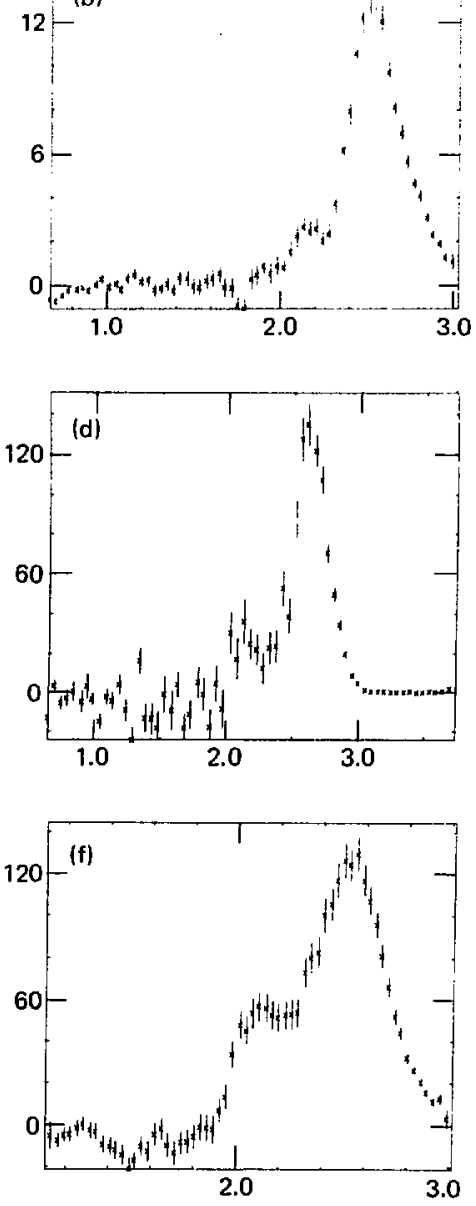

Neutron energy - MeV

F1g. 13. Unfolded neutron spectra obtained with several different NE213 detectors exposed to 2.5- and 14-MeV neutrons. (a) 401 at $2.5 \mathrm{MeV}$, $(\mathrm{R}=0.75 \mathrm{~cm}, \mathrm{~L}=1.0 \mathrm{~cm})$; (b) 102 at $2.5 \mathrm{MeV}, \quad(\mathrm{R}=0.65 \mathrm{~cm}, \mathrm{~L}=1.3 \mathrm{~cm})$; (c) 104 at $2.5 \mathrm{MeV},(\mathrm{R}=1.27 \mathrm{~cm}, \mathrm{~L}=2.54 \mathrm{~cm})$; (d) 103 at $2.5 \mathrm{MeV}$, $(\mathrm{R}=1.9 \mathrm{~cm}, \mathrm{~L}=7.6 \mathrm{~cm}) ; \quad$ (e) 105 at $2.5 \mathrm{MeV},(\mathrm{R}=2.54 \mathrm{~cm}, \mathrm{~L}=5.08 \mathrm{~cm})$; and (f) 101 at $2.5 \mathrm{MeV},(R=5.7 \mathrm{~cm}, \mathrm{~L}=5.1 \mathrm{~cm})$. 

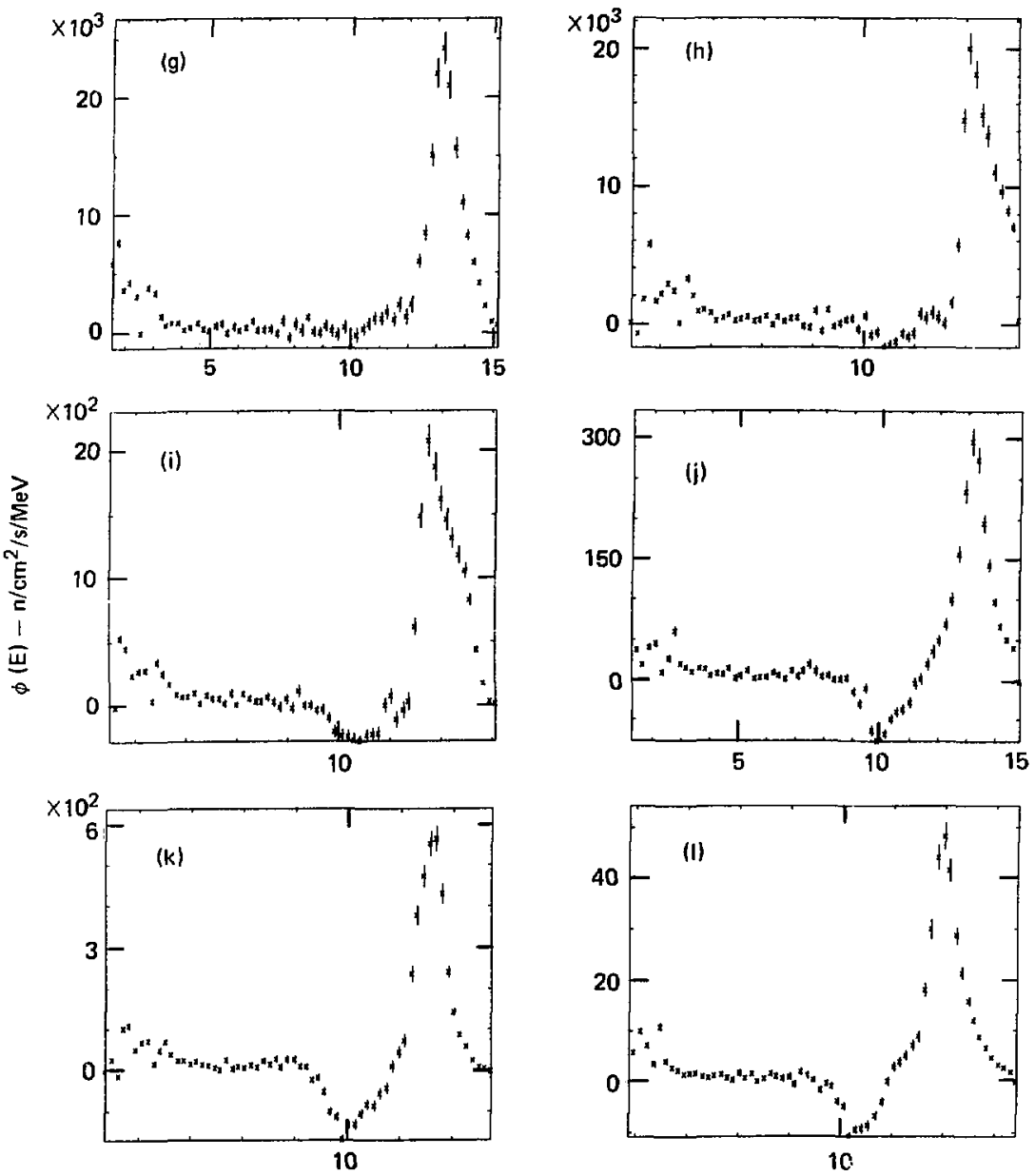

Neutron energy - MeV

Fig. 13. Continued. (g) 401 at $14 \mathrm{MeV}$, (h) 102 at $14 \mathrm{MeV}$, (1) 104 at $14 \mathrm{MeV}$, (j) 103 at $14 \mathrm{MeV}$, (k) 105 at $14 \mathrm{MeV}$, and (1) 101 at $14 \mathrm{MeV}$. 
An estimate of $\phi_{C}(E)$ is made by calculating the scattering rate due to the best current estimate of the neutron spectrum, $\phi_{0}$, 1.e.,

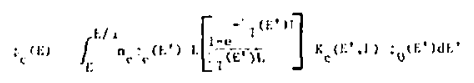

where $\alpha=\left(\frac{A-1}{A+1}\right)^{2}$,

$$
\begin{aligned}
\mathrm{n}_{\mathrm{c}}, \mathrm{o}_{\mathrm{c}}= & { }^{12} \mathrm{C} \text { atom density and } \\
& \text { elastic scattering cross } \\
& \text { section, }
\end{aligned}
$$

$$
\begin{aligned}
\Sigma_{T}=n_{c} \sigma_{c}+n_{H_{H}}= & \text { total cross } \\
& \text { section, }
\end{aligned}
$$

$K_{C}\left(E^{\prime}, D\right) d E=$ probability that a neutron scattering elasti.cally in ${ }^{12} \mathrm{C}$ at energy $E^{\prime}$ will have final energy $\varepsilon$ such that $\mathrm{E} \leq \mathrm{E} \leq \mathrm{E}+\mathrm{d} \mathrm{E}$.

The probability distribution $k_{c}$ is obtained from the angular distribution of elastically scattered neutrons in the laboratory and the kinematics given in Eq. (9),

$K_{c}\left(E^{\prime}, E\right)= \begin{cases}0 & \text { for } E<\alpha_{c} E^{\prime} \\ \frac{P(\cos \theta)}{\left(1-\alpha_{c}\right) E^{\prime}} & \text { for } \alpha_{c} E^{\prime} \leq E \leq E^{\prime} \\ 0 & \text { for } E>E^{\prime}\end{cases}$ where $\mathrm{P}(\cos \theta)=$ angular distribution in the laboratory and

$\theta=\cos ^{-1}\left[1-\frac{(A+1)^{2}}{2 A}\left(1-\frac{E}{E^{T}}\right)\right]$.

The angular distribution, $P(\cos \theta)$ was represented in the form of Legendre polynomials obtained from the LLL ENDF/B neutron cross-section library (1973) due to Howerton. 60

Figure 14 shows neutron spectra which have been compensated using

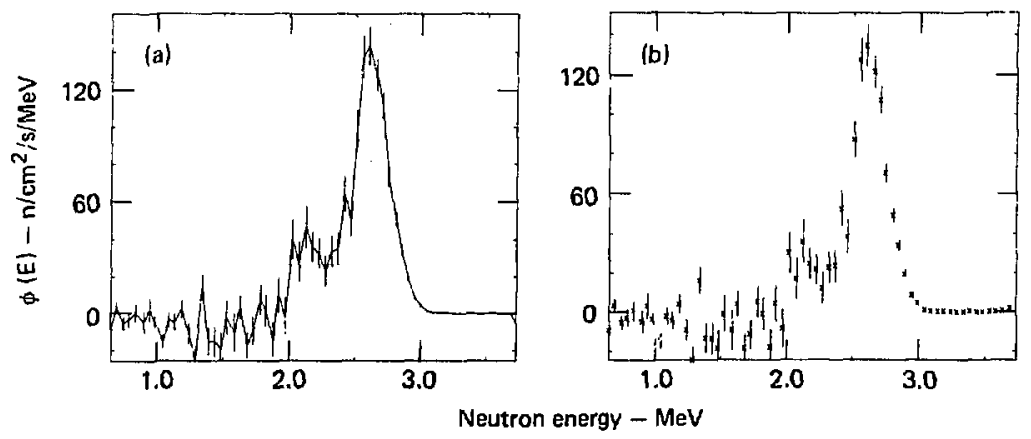

Fig. 14. Unfolded neutron spectrum showing the effect of compensation for ${ }^{12} \mathrm{C}(n, n)$ elastic scattering; (a) without compensation, (b) with compensation. 
Eqs. (36) and (37). It is clear from the figures that subtraction of neutron intensity due to single scattering in carbon results in Incomplete compensation. A complete removal of the effects of detector size can only be obtained by a response function unfolding method. However, the simple derivative unfolding method has been used satisfactorily to reduce data taken near various monoenergetic sources. Results shown in Figs. 13 and 14 are typical. In addition, the integral of these spectra is in good agreement with the total intensity indicated by a calibrated long counter. 61

GAS PROPORTIONAL COUNTERS $\mathrm{CH}_{4}$ AND $\mathrm{H}_{2}$

Reduction of proportional counter pulse-height data is substantlally more complex than was the case with organic scintillators. Like the scintillator, the $\mathrm{H}_{2}$ and $\mathrm{CH}_{4}$ gas proportional counters are proton recoll devices, However, at normal gas pressures of a few atmospheres, the range of recoll protons is comparable with the detector dimensions at energies of only about $1 \mathrm{MeV}$. As a result, many recoil protons deposit significant amounts of energy outside the detector sensitive volume, and the pulse-height distribution is distorted.
Several approaches have been used in the past to obtain neutron spectra from proportional counter pulsehelght spectra. Some have used derivative unfolding methods 26,35 with appropriate corrections to the pulseheight data before differentlation, while others use a response matrix unfolding approach. $24,28,39,62,63$ The work described below employs a combination of these two techniques to reduce pulse-height spectra as efficlently as possible.

The data reduction problem for gas proportional counters is defined as follows :

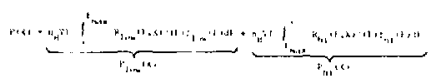

where

$$
\begin{aligned}
P(X)= & \text { experimental-pulse height } \\
& \text { distribution, } \\
X= & \text { energy deposited within } \\
& \text { detector-sensitive volume } \\
& (\text { MeV), } \\
n_{H}= & \text { hydrogen atom density } \\
& \text { within sensitive volume } \\
& \left(\text { cm }^{-3}\right. \text { ), } \\
V= & \text { sensitive volume (cm }{ }^{3}, \\
T= & \text { duration of exposure (s), } \\
= & \text { an energy at which the } \\
& \text { proton range is a low mul- } \\
& \text { tiple of the detector } \\
& \text { radius, } \\
\sigma= & n, P \text { elastic scattering } \\
& \text { cross section (cm }{ }^{2} \text { ), }
\end{aligned}
$$




$$
\begin{aligned}
\phi_{\text {low }}= & \text { neutron spectrum at ener- } \\
& \text { gies below } E_{\text {max }}, \text { which is } \\
& \text { to be determined, } \\
\phi_{\mathrm{ni}}= & \text { neutron spectrum at energies } \\
& \text { above } \mathrm{E}_{\text {max' which has }} \\
& \text { already been determined } \\
& \text { independently, } \\
\mathrm{R}(\mathrm{E}, \mathrm{X}) \mathrm{dX}= & \text { probability that a neutron } \\
& \text { scattering in hydrogen at } \\
& \text { energy } \mathrm{E} \text { will produce a } \\
& \text { recoil proton which depos- } \\
& 1 t s \text { energy } \varepsilon \text { within the } \\
& \text { sensitive volume such that } \\
& \mathrm{x}<\varepsilon<\mathrm{x}+\mathrm{dx} \text {. }
\end{aligned}
$$

Reduction of pulse-height data is carried out in the following sequence:

1. Calculate the detector response matrix, $\mathrm{R}_{h i}$, for interactions at energies above $\mathrm{E}_{\max }$.

2. Evaluate the second term in $\mathrm{Eq}$.

(41); t.e., the high-energy pulse-height response:

$$
P_{h i}(X)=n_{H} V T \int_{E_{\max }}^{\infty} R_{h i}(E, X) \sigma(E) \phi_{h i}(E) d E
$$

3. Subtract the high-energy response from the experimental pulse-height data to obtain the low-energy residual:

$$
P_{\text {low }}(X)=P(X)-P_{h i}(X) \cdot
$$

4. Calculate the detector response matrix, $\mathrm{R}_{\text {low, for interactions }}$ at energies below $\mathrm{E}_{\max }$.
5. Hake an initial estimate of the neutron spectrum, $\phi_{10 w}(E)$, using a derivative unfolding method based on Eq. (15).

6. Unfold the low-energy neutron spectrum, $\phi_{\text {low }}(E)$, from the residual:

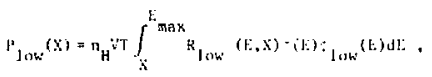

using an iterative unfolding procedure to be described below. Details of these calculations are described in the following sections.

\section{High-Energy Response}

The pulse-height response of several hydrogen proportional counters tn energetic neutrons has been determined empirically. It is asiumc 1 here that recoil protons yield a pulse whose amplitude is proportional to the energy deposited within the detector sensitive volume. Figures 15(a) and 15(b) show pulse-height spectra cbtained when $a$ hydrogen proportional counter ( $3 a t m H_{2}, R=$ $1.9 \mathrm{~cm}, \mathrm{~L}=20 \mathrm{~cm}$ ) was irradiated with 2.5- and 14-MeV neutrons. A response of the form

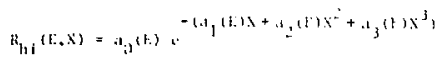

where

$$
\begin{aligned}
& \mathbf{X}= \text { energy deposited within sen- } \\
& \text { sitive volume (MeV), and } \\
& E= \text { neutron source energy. } \\
& \text { fits the data reasonably well. }
\end{aligned}
$$




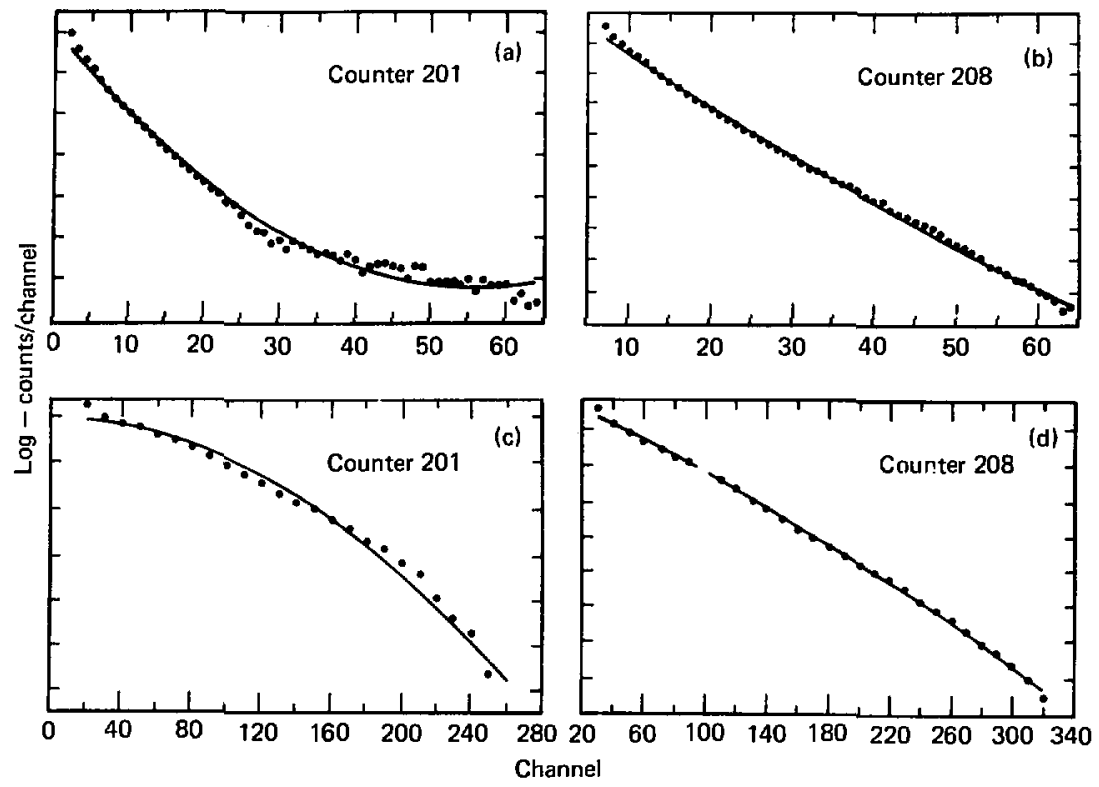

Fig. 15. Pulse-selght distribution, measured with hydrogen proportional counters, due to $14-\mathrm{MeV}$ neutrons (a) and (b); and $2.5-\mathrm{MeV}$ neutrons (c) and (d).

Clearly, the parameters $a_{0}, a_{1}, a_{2}$ and $a_{3}$ are functions of the detector construction, the source energy, and the angular distribution of the neutrons incident on the detector.

Table $\boldsymbol{5}$ contains parameter values at 2.5 and $.24 \mathrm{MeV}$ for two detectors irradiated by a point source which Illuminated the detector normal to its axis. Unfortunately, the energy dependence of the parameters is not we11 established by only two data points. Nevertheless, in the absence of measured or calculated responses at other energies, spectra have been unfolded where the parameters were obtained by linear interpolation between the $2.5-$ and $14-\mathrm{MeV}$ data points. This procedure could readily lead to serlous errors in the estimation of the pulse-height response to neutrons at energies intermediate between 2.5 and $\mathrm{J} 4 \mathrm{MeV}$. However, this approach has been used in a varlety of measurements with two different proportional counters to remove events from the pulse-height spectra due to energetic neutrons. The 
Table 5. Proportional counter response tó high-energy neutrons.

$$
\mathrm{R}_{\mathrm{hi}}(E, X)=\frac{a_{0}(E) e^{a_{1}(E) x+a_{2}(E) x^{2}}+a_{3}(E) x^{3}}{\int_{0}^{\infty} e^{a_{1} x+a_{2} x^{2}}+a_{3} x^{3}} d x
$$

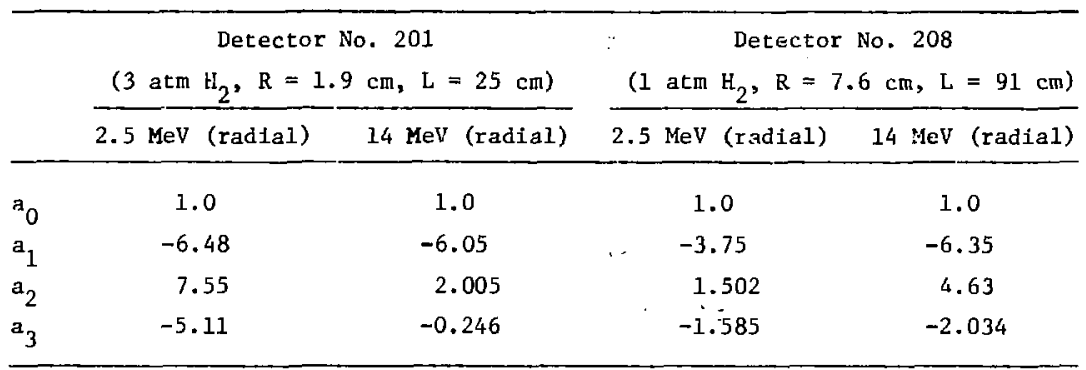

unfolded results obtained in these measurements are not in good agreement with calculated spectra in every case. However, the estimation of $\mathrm{P}_{\mathrm{h} 1}(\mathrm{X})$ generally merges with the experimental pulse-height spectrum at $1 \mathrm{t}, \mathrm{h}$ igh-energy end. The measured and calculated pulse-helght intensttles at $E_{\text {max }}$ agree within a factor of 2 In every case, and generally fall within $\pm 25 \%$.

Since the shape of the pulseheight spectra at 2.5 and $14 \mathrm{MeV}$ are very similar, it is assumed here that the relative pulse-helght distribution is estimated with greater accuracy than the absulute pulseheight distribution. Consequently, a tegt is made during the unfolding process to crmpare the calculated pulse-height intensity at $\mathrm{E}_{\max }$ to the measired intensity. The calculated pulse-helght distribution, $P_{h i}(A)$, is then renormalized by the ratio of these Intensities so that $P_{h i}(X)$ merges with $P(X)$ at the high end in every case. Figure 16 shows a typical pulse-height spectrum together with $\mathrm{P}_{\mathrm{hi}}(\mathrm{X})$ after renormalization.

\section{Low-Energy Response}

A low-energy neutron spectrum, $\phi_{\text {low }}(E)$, is obtalned by an iterative matrix unfolding method following removal of the pulse-height response to energetic neutrons, as described 


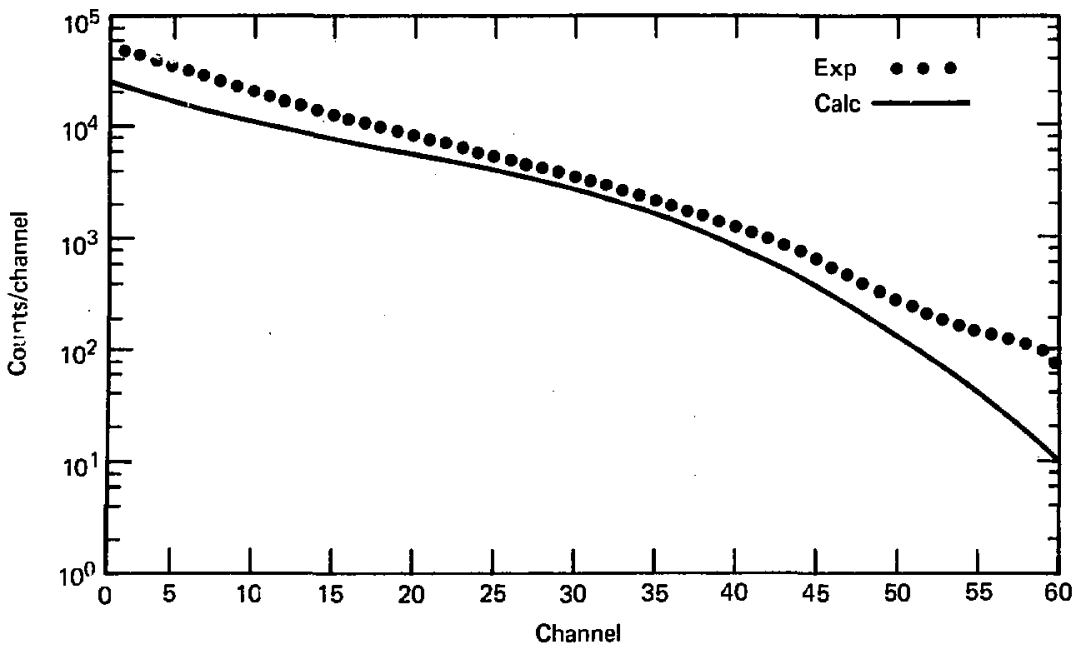

Fig. 16. Experimental pulse-height spectrum in hydrogen proportional counter due to $238 \mathrm{PuBe}$ source and calculated response to neutrons above $\mathrm{E}_{\mathrm{max}}$.

before. The unfolding problem has been reduced to

$$
R_{\text {low }}(E, X)=\frac{1}{E}
$$

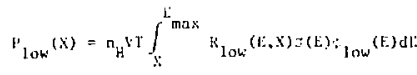

where

$$
\begin{aligned}
\mathrm{R}_{\text {low }}(\mathrm{E}, \mathrm{X}) \mathrm{d} \mathrm{x}= & \text { probability that a } \\
& \text { recoil proton pro- } \\
& \text { duced by neutron of } \\
& \text { energy } \mathrm{E} \text { will deposit } \\
& \text { energy } E(\mathrm{x} \leq \varepsilon \leq \mathrm{x}+\mathrm{dx}) \\
& \text { within the detector } \\
& \text { sensit tve volume. }
\end{aligned}
$$

In an ideal, wall-less detector the response function would be simple; 1.e.,
However, there are several important distortions to this simple response function. They are:

- Recoll protons which leave the sensitive volume with significant energy.

- Recoil protuns which deposit significant amounts of energy before entering the sensitive volume, such as in end regions of the detector.

- Recoll protons suffering both 1 and 2 above. 
- Events depositing energy in a region of the detector where the gas anpliflcation is low or the charge collection is poor; i.e., the pulse-height ssectrum may not be Identical to the Ionization spectrum.

A11 of the detectors used in this work are long cylinders; 1.e., $\frac{L}{R}>10$. Consequently, the gas amplification and charge collection are reasonably uniform, and the "end volumes" are very small compared to the sensitive volume. In all of the discussiciss which follow, the lonization distribution and the pulse-height distribution will be considered identical. Only recoil protons which deposit significant amounts of energy in the walls are considered in calculating the detector response function. The analytical functions due to Snidow and Warren ${ }^{64}$ are used to calcuiate the detector response, distorted by "wall events." A "gaussian" filter is then used to smooth the response. Detector pulse-height response functions are calculated at up to 64 neutron energies. Each energy deposition spectrum constitutes cine column of the detector response matrlx. Figure 17 shows a typical pulse-height spectrum extending to about $1 \mathrm{MeV}$ and Fig. 18 shows the response inatrix calculated to unfold the data. The elements of the response

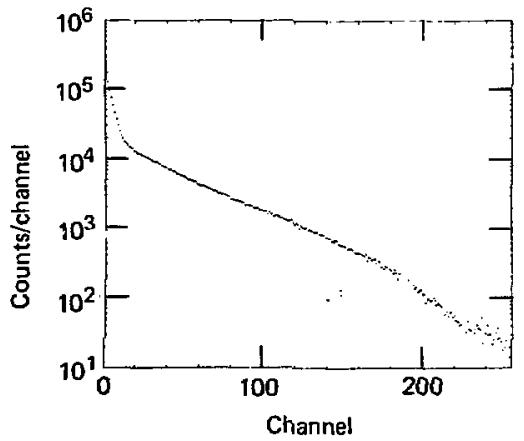

Fig. 17. Pulse-height distribution tue to hydrogen proportional counter (201) exposed to $238 \mathrm{PuBe}$ neutron source. Full scale corresponds to $1 \mathrm{MeV}$ deposition.

matrix $R_{j i}$ are defined by (48) below:

$$
P_{j}=\sum_{i=j}^{M} n_{H} V T E_{j i}^{\prime} \Delta X_{j} \sigma_{i} \phi_{i} \Delta E_{i}
$$

where

$$
\begin{aligned}
\mathbf{P}_{j}= & \text { number of events counted } \\
& \text { in bin } \mathrm{j} \text { of the pulse- } \\
& \text { height spectrum, } \mathrm{P}_{\text {low }}(\mathrm{X}), \\
\mathrm{M}= & \text { number of columns in } \mathrm{R}^{\prime}, \\
\mathrm{n}_{\mathrm{H}}= & \text { number of hydrogen atoms in } \\
& \text { detector sensitive volume } \\
& \left(\mathrm{cm}^{-3}\right. \text { ), } \\
\mathrm{V}= & \text { detector volume (cm } \left.{ }^{3}\right), \\
\mathrm{I}= & \text { duration of measurement } \\
& \text { (sec), } \\
\Delta \mathrm{x}_{j}= & \text { energy width of pulse- } \\
& \text { height bin } \mathrm{j} \text { (Mev), } \\
\sigma_{i}= & n, \mathrm{p} \text { elastic scattering } \\
& \text { cross section at energy } \\
& E_{1} \text { (cm }{ }^{2} \text { ), }
\end{aligned}
$$



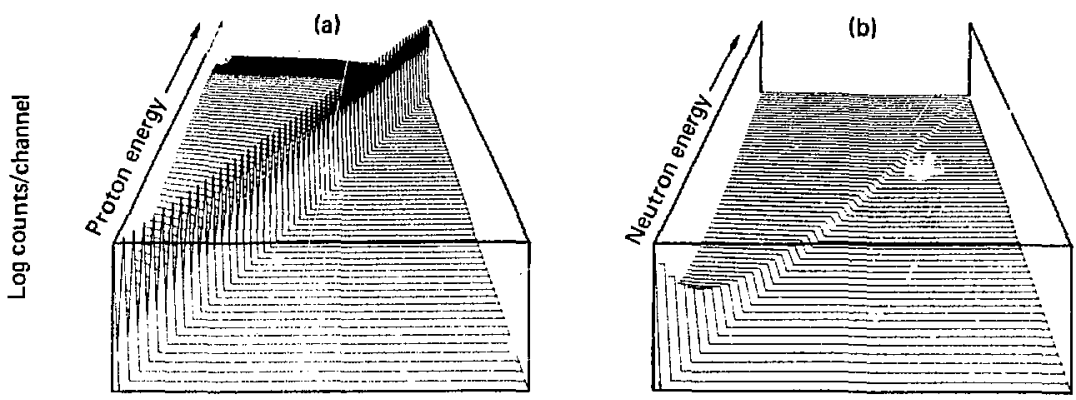

Energy deposited - MeV

Fig. 18. (a) Proton ionization response matrix, D, for hydrogen proportional counter 201. (b) Ionization response produced by neutrons in a hydrogen proportional counter.

$$
\begin{aligned}
\phi_{i}= & \text { neutron differential inten- } \\
& \text { sity at output bin } i \\
& \left(n / \mathrm{cm}^{2}\right. \text {-sec-MeV), } \\
\Delta E_{i}= & \text { energy width of output bin } \\
& i(M e V),
\end{aligned}
$$

and $R_{j i}^{\prime} \Delta X_{j}=$ probability that a recoil proton produced by

a neutron with energy

$E_{i}$ will deposit energy

E within detector sensitive volume such that $\mathrm{Y}_{j-1}<\varepsilon \leq \mathrm{X}_{j}$.

The detector response matrix, $R^{\prime}$, may be factored further Into an Ideal response matrix and a distortion matrlx where the pulse-ix Ight distribution due to monoenergetic recoll protons is calculated. As mentloned earlier in Eq. (12), the Ideal response to monoenergetic neutrons at energy $E$ in the absence of wall events is:

$$
R_{j i}^{\prime}=\left\{\begin{array}{l}
\frac{1}{E_{i}} \text { for } x_{j} \leq E_{i} \\
0 \text { for } x_{j}>E_{i}
\end{array} .\right.
$$

The matrix $R_{j i}^{\prime}$ then contains the distribution of recoil protons due to monoenergetic neutrons. Define the distortion matrix, $\underline{D}$, to be the matrix containing the pulse-height distributions due monoenergetic protons.

$$
\text { If } \begin{aligned}
D_{j i} \Delta X_{j}= & \text { probability that a } \\
& \text { recoil proton of energy } \\
& E_{i} \text { will deposit energy } \\
& \varepsilon \text { in the detector sen- } \\
& \text { sitive volume such that } \\
& x_{j-i}<\varepsilon \leq X_{j},
\end{aligned}
$$


then

Unfolding

$$
R_{j i}^{\prime}=\frac{1}{E_{i}} \sum_{k=j}^{i} D_{j k} .
$$

Clearly, the ideal response is obtained in the special case where the distortion matrix, $D$, is just the unit matrix. Generally, the detector response to monoenergetic nrotons, D, is not a unit matrix at energies of interest here, and it is calculated according to the analytical relations given by Snidow and Warren. For the purposes of that calculation, the ratio of recoil proton range to the detector length and diameter are calculated. The proton range is approximated by polynomials fitted to the range-versus-energ data contained in Ref. 45. Ta'sle 6 contains the polynomial coefficients which are used.
Following removal of events from the pulse-height spectrum due to neutrons at energies above $E_{\max }$ and the calculation of the low-energy response matrix $R^{\prime}$ defined above, tho lowenergy neutron spectrum is unfolded from E.q. (47) according tos the algorithm described below. For ease of calculation, a detector response matrix $R$ is defined as follows:

$$
\begin{aligned}
R_{j i} & =n_{H} \operatorname{TVAX}_{j} \Delta E_{i} \sigma_{i} R_{j i}^{\prime} \\
& =\frac{n_{H} V T \Delta x_{j} \sigma_{i} \Delta E_{i}}{E_{i}} \sum_{k=j}^{i} D_{j k} .
\end{aligned}
$$

Then, from E.q. (47), the unfolding problem is thit of finding the solutio: vector $\Phi$ to the matrix equation,

$$
\underline{\mathrm{P}}=\underline{\mathrm{R}} \dot{t},
$$

\begin{tabular}{|c|c|c|c|c|}
\hline \multicolumn{5}{|c|}{$\begin{array}{l}R(E)=a_{0}+a_{1} E+a_{n} E^{2}+a_{3} E^{3} \\
\text { where } E=\text { proton fonergy (MeV) } \\
\left.R=\text { range (mg/cm }{ }^{2}\right)\end{array}$} \\
\hline Gas & $a_{0}$ & ${ }^{a} 1$ & $a_{2}$ & $a_{3}$ \\
\hline Hydrogen & 0.0947 & -0.0325 & 0.602 & -0.00691 \\
\hline Helium & 0.179 & 0.586 & 1.25 & -0.0123 \\
\hline \multicolumn{5}{|l|}{ Methane } \\
\hline Argon & $-2.79 \times 10^{-5}$ & 3.09 & 1.83 & -0.0256 \\
\hline Krypton & -0.0197 & 5,16 & 2.24 & -0.0312 \\
\hline
\end{tabular}

Table 6. Proton range in gasses. 
Biver the response matrix R and input vector P. In principal, this problem has a taiglue solut jon which may be obtained by the inversion of the response matrix; 1.e.,

$$
i=(R)^{-1 !} \text {. }
$$

However, R normally contains minor systemitic errors and is frequently i]l ronditirnet. 55 in addition, p contains stochast ic notse and sysLemalli: cerrors due to the removal of $l_{h i}(x)$. The result is frequently nomplysical and nolsy solution vectors, 65,66

It is claimed, apriorl, that the solution vector f cannot have any negat i ve components; i.c., neutron intensities are non-negative. The approach taken here is to start with a reasonably good first estimate of the low-encergy neutron spectrum, and to refinc that estimate iteratively until a convergence criterion is satisfied. A first estimate of the low-energy neutron spectrum is obtained using a derivative unfolding method,

$$
\phi_{0}(E)=\frac{-E}{n_{H} \text { TVO }(E)} \frac{d P_{\text {low }}(X)}{d X} \text {, }
$$

\footnotetext{
where $\frac{\mathrm{dP}_{10 \mathrm{w}}(\mathrm{X})}{\mathrm{dx}}$ is obtained using a parabolic digital filter described earlier.
}

A trial pulse-belgint spectrum corresponding to the first estimate spectrum is then calrulated asing the response mat 1 ix $\underline{R}$ as follows:

$$
r_{0}=\underline{k}_{0} .
$$

Flgure 19 shows a typical calculated pulse-helght spectrum l'a, compared to the experimental data, "low.

A convergence parameter $x^{2}$ is then calculated to determine the adequacy of the current estimate, $t_{0}$,

$$
x_{\phi}^{2}=\frac{1}{M} \sum_{i=1}^{M} \frac{\left(p_{10 w}\left(x_{i}\right)-\left(P_{0}\right)_{i}\right)^{2}}{P_{10 w}\left(x_{i}\right)} \text {. }
$$

The next estimate of $t$ is oilained by a mulciplicative procedure,

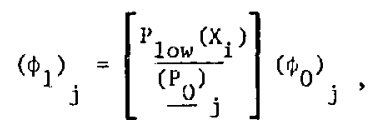

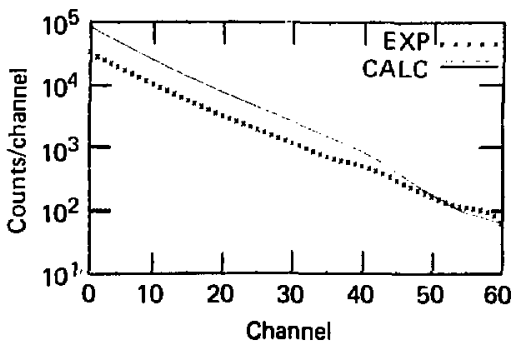

F1g. 19. Experimental pulse-height spectrum compared to that calculated by refolding initial estimate of neutron spectrum. 
fullowed by calculation or i? and its corresponding anverpence parateter, $\stackrel{2}{1}$. If the valut of $\frac{2}{2}$ is less than the value which ineets the convergence criteria, then the iterative procedure is stopped and $: \ldots$ is reported as the solution vector. in the event $x^{2}$ fatis to decrease on four successive icerations, the unfolding is seopped and like most recent $\mathrm{r}$ is reported with an error indicalion.

The procedure deseribed abuve iats been used before $67-70$ to unfold pammaray energy distribulions. One of it:s primeiple advantages is that, since $P$ and $k$ are non-negative, the solution vector $i x$ will also be nonneygative ats long as the initial estimate 0 is. Secondly, with a suitable initial estimate, the procedure converges very rapidiy.

Starting with an initial estimate which gave the $P_{0}$ shown in Pig. 19 , the unfolding procedure produced a $x^{2}$ of 2.3 in only seven iterations. The final $P_{N}$ is shown in Fig. 20 superimposed on the experimental data.

\section{Error Estimates}

Estimates of the uncertainty in spectral intensity are not easily obtained when an iterative procedure such as that above is used. No error matr $1 x$ is avallable as in the case of a least-squares fitting procedure or a true response matrix inversion.
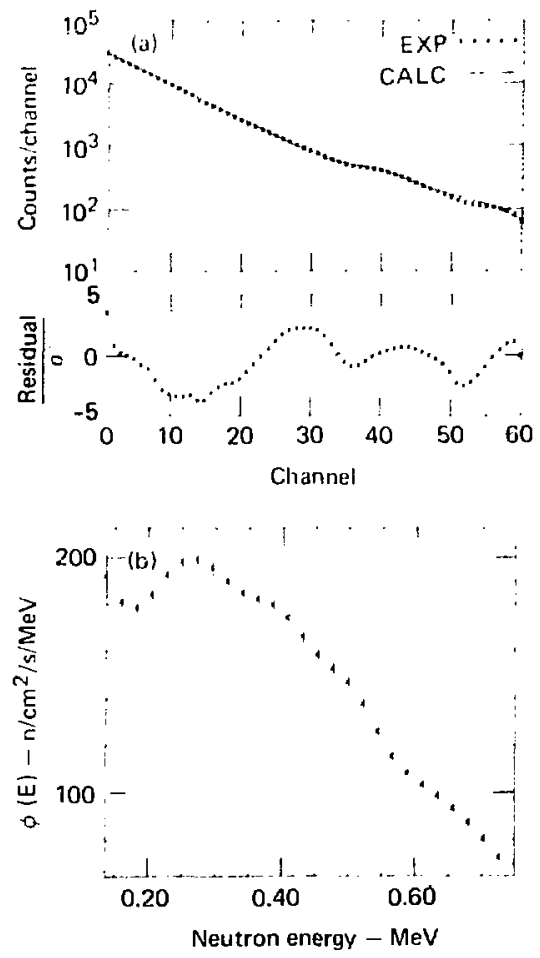

Fig. 20. (a) Refolded pulse-height spectrum calculated from estimated spectrum $\phi(E)$ compared to experimental pulse-height spectrum. (b) Unfolded neutron spectrum obtained with a hydrogen proportional counter exposed to $238 \mathrm{PuBe}$ neut ron source.

No serious effort is made here to estimate the true uncertainty, but some assessment of tis lower bound may be made on the basis of the residuals between $P_{\text {low }}(X)$ and $P_{N}$. 
The output vector, $\Phi_{N}$, is zccompanied by a convergence vector $\delta \phi_{N}$ defined by

$$
\left(\delta \phi_{N}\right)_{j}=\frac{P_{10 w}\left(x_{j}\right)-\left(P_{N}\right)_{j}}{P_{10 w}\left(X_{j}\right)} \times \frac{\left(\phi_{N}\right)_{j}}{.} .
$$

This vector is not intended to reflect uncertainties in the response matrix, $\underline{R}$, or stochast $1 \mathrm{c}$ errors in the pulseheight data, but instead provides some measure of the agreement between $P_{\text {low }}$ and $P_{\text {is }}$ over the spectrum.

\section{Tests of the liethod}

Several measurements have been made where hydrogenous proportional counters have been exposed to nearly monoenergetic neutrons produced by the $7_{\mathrm{Li}}(\mathrm{p}, \mathrm{n})$ reaction. Source energy dispersion was about $12 \mathrm{keV}$. Data at various energies between $23 \mathrm{keV}$ and $1.0 \mathrm{MeV}$ were obtalned and unīulted according to the procedure above. The pulse-height data and unfolded spectra are shown in Fig. 21. It was not necessary to remove events due to energetic neutrons from these data. Spectra obtained near energetic sources w1ll be discussed later where the subtraction of $P_{h i}(x)$ is 1mportant. All of the spectra shown In F1g. 21 show good erergy resolution (except at $23 \mathrm{keV}$ where the
12-keV source dispersion is important) and are relatively free of spurious oscillations. Integration of each spectrum indicates an Intensity In good agreement with that measured by a calibrated long counter. 61

GAS PROPORTIONAL COUNTERS $-{ }^{3}$ He Conceptually, pulse-height data obtained using ${ }^{3}$ He proportional counters is unfolded in exactly the same way as using the hydrogenous proportional counters; i.e., by calculating the response matrix, making an initlal estimate of the neutron spectrum, $\Phi_{0}$, and solving Eq. (52). However, the similarity ends there. The principle reaction of interest is the ${ }^{3} \mathrm{He}(n, p) T$ reactIon with $Q=0.764 \mathrm{MeV}$. An Inttial estimate of the neutron flux is made assuming there are no other competing reactions and that all proton and triton energy is deposited within the detector sensitive volume. Then,

$$
\phi_{0}(E)=\frac{P(E+0.764)}{n_{\mathrm{He}} V T \sigma_{n p}(E)}
$$

where

$$
\begin{aligned}
P(E)= & \text { pulse-helght distribution } \\
& \text { (counts } / \mathrm{MeV}) \text { at energy } \\
& \text { deposition } E, \\
\sigma_{\mathrm{np}}(E)= & 3 \text { He }(n, p) \text { reaction cross } \\
& \text { section. } \quad .
\end{aligned}
$$



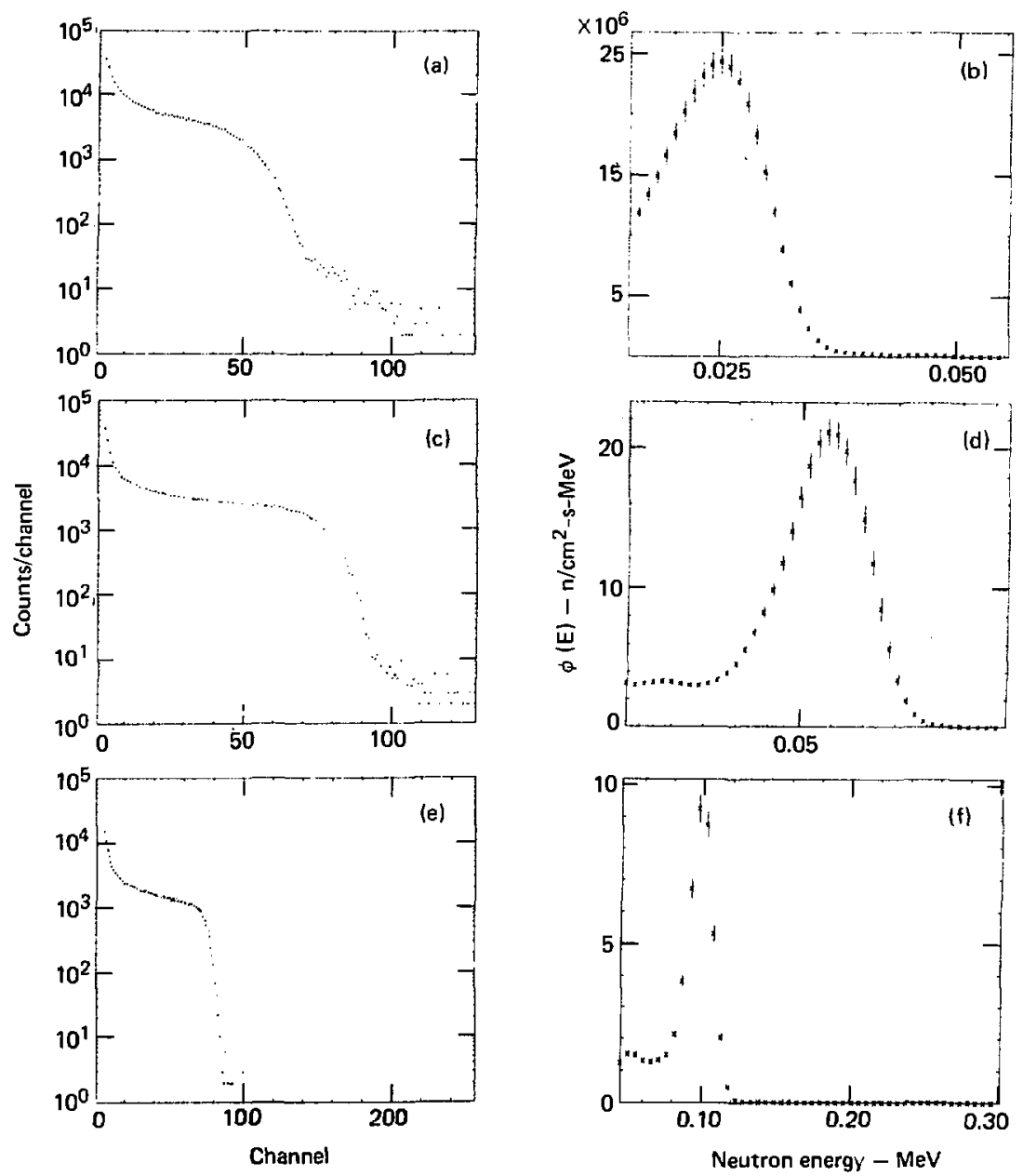

FIg. 21. Response to monoenergetic neutrons in the energy range 0.025-1.0 MeV. Plots show pulse-helght spectra and corresponding unfolded neutron spectra at neutron energles: $25 \mathrm{keV}$ - (a) pulse-helght data, (b) unfolded spectrum; $54 \mathrm{keV}$ - (c) pulse-helghe daca, (d) unfolded spectrum; $100 \mathrm{keV}$ - (e) pulsehelght data, (f) unfolded spectrum. 

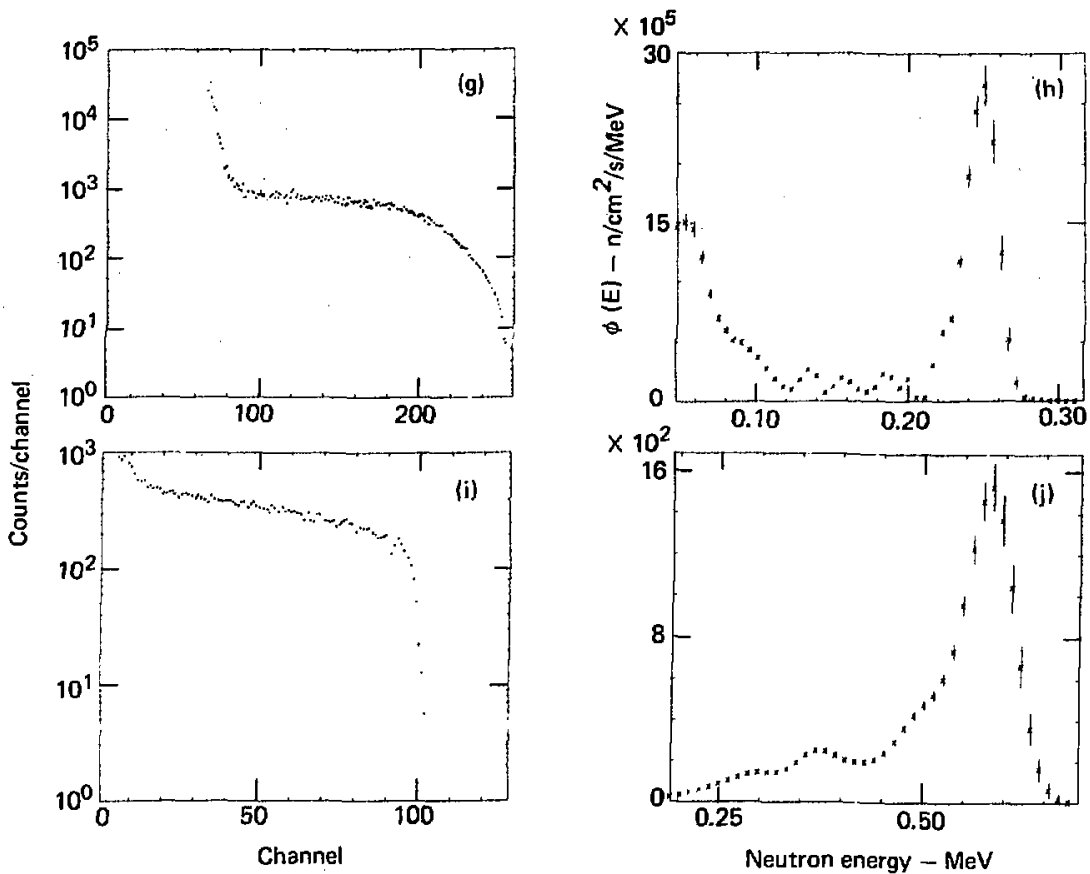

Neutron energy - MeV

Fig. 21. Continued. $250 \mathrm{keV}-(g)$ pulse-height data, (h) unfolded spectrum; $567 \mathrm{keV}$ - (i) pulse-height data, (j) unfolded spectrum.

Infolding the àctual neutron spectrum is complicated by several distortions:

- Many $(n, p)$ reactions produce protons or tritons which deposit some of their energy outaide the detector active volume.

- Elastic scattering in ${ }^{3}$ He by neutrons at energies above 1.02 $\mathrm{MeV}$ produce recolls which interfere with the low-energy portion of the pulse-height spectrum.

- ${ }^{3} \mathrm{He}(n, d)$ reactions whose threshold is $4.36 \mathrm{MeV}$.

- ${ }^{3} \mathrm{He}(\mathrm{n}, \mathrm{pn})$ reactions whose threshold is $7.37 \mathrm{MeV}$. An excellent review of these interferences and some of the efforts to deal with them is given by Batchelor and Morrison ${ }^{48}$ and by Bair. 47 


\section{Response Matrix}

The calculation of the response matrix to be described here is simpler than some of those used previously; $47,48,71,72$ and seems to be adequate in most cases. Basically, the pulse-height response to monoenergetic neutrons is decomposed into three components. These are fllustrated on the pulse-height spectrum slown in Fig, 22. The three components are:
1. Peak due to ${ }^{3} \mathrm{He}(n, P)$ where charged particles deposit all of their energy in the sensitive volume.

2. Recoil distribution due to ${ }^{3} \mathrm{He}\left(n, n^{\prime}\right)$ elastic scattering.

3. Continuum due to charged part1cles which deposit significant energy outside the sensttive volume.

The three individual components are calculated, acicied together, then

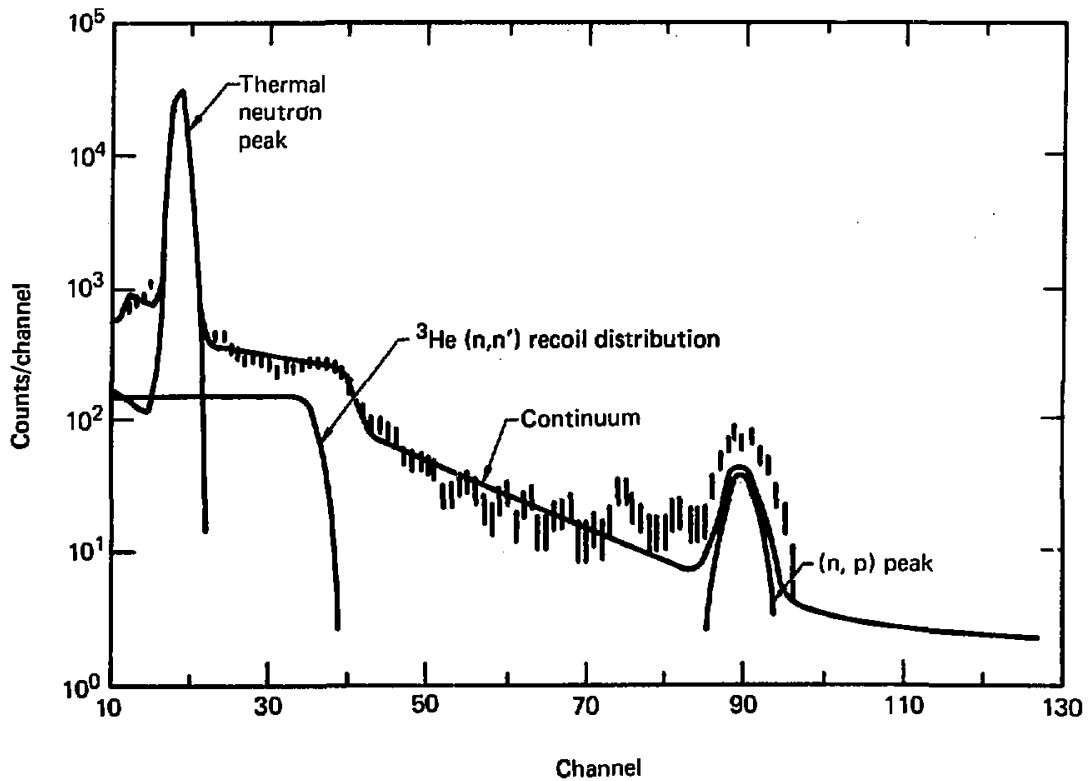

F1g. 22. Pulse-height distribution in ${ }^{3}$ He detector due to $2.3-M e V$ neutrons. 
smoothed with a gaussian filter to provide a pulse-helght response function at each neutron energy; 1.e., for each column of the response matrix. Each of the three components has been empirically parameterized 73 using experimental pulse-helght spectra obtalned near monoenergetic sources. The sources were produced by ${ }^{7} \mathrm{Li}(\mathrm{p}, \mathrm{n})$ and $T(p, n)$ reactions on a van de Graaf accelerator, and were monitored using a calibrated long counter. ${ }^{61}$ Parametric descriptions of each component are given below:

$$
\begin{aligned}
R(E, x)= & R_{\text {peak }}(E, x)+R_{\text {rec }}(E, x) \\
& +R_{\text {cont }}(E, x) .
\end{aligned}
$$

A peak corresponding to Eull energy deposition in the sensitive volume by a ${ }^{3} \mathrm{He}(\mathrm{n}, \mathrm{p})$ reaction is represented by a delta function at the proper energy,

$$
R_{\text {peak }}(E, x) d x=n_{H} V T \sigma_{n p}(E) \varepsilon(E) d x
$$

where

$$
\begin{aligned}
n_{H}= & \text { atom density of }{ }^{3} \mathrm{He}\left(\mathrm{cm}^{-3}\right), \\
\sigma_{n p}= & { }^{3} \mathrm{He}(\mathrm{n}, \mathrm{p}) \text { differential cross } \\
& \text { section }\left(\mathrm{cm}^{2}\right), \\
E= & \text { the prohability that an } \\
& (\mathrm{n}, \mathrm{p}) \text { reaction at energy } E \\
& \text { will result in full energy } \\
& \text { deposition within the sen- } \\
& \text { sitive volume of the } \\
& \text { detector. }
\end{aligned}
$$

The efflciency function, $E$, for two ${ }^{3}$ He proportional counters has been measured, and the data are shown in Fig. 23. For each detector, a function of the form

$$
\varepsilon(E)=\varepsilon_{0} e^{-\varepsilon_{1}(E+Q)-\varepsilon_{2}(E+Q)^{2}}
$$

has been fitted to the data. The fits are shown for comparison.

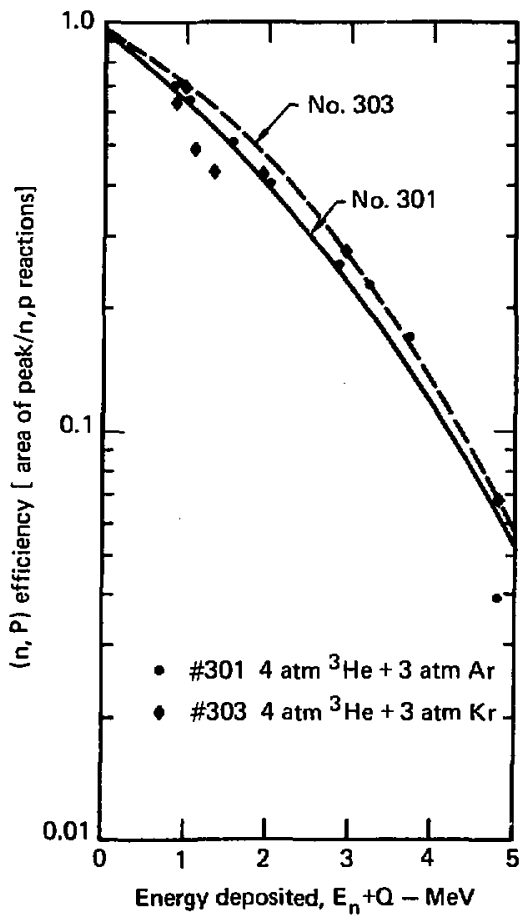

Fig. 23. ${ }^{3}$ He $(n, p)$ reaction peak efficiency. 
The energy distribution of recoll ${ }^{3}$ He nucle. produced by elastic scattering is determined by the scattered neutron angular distribution. $A 1-$ though an adequate description of that distribution exists, 71,72 an empirical method is used here where the recoll distribution is represented by two straight lines, as shown in Fig. 24. The parameters $\mathrm{H}_{\mathrm{H}}$ and $\mathrm{H}_{\mathrm{L}}$ determine the slope of the distribution over the top portion. Parameters $\mathrm{C}_{\mathrm{I}}$, and $\mathrm{C}_{\mathrm{H}}$ determine the rate of fall to zero, and are also used to compensate for the fact that a ${ }^{3} \mathrm{He}$ recoil produces less collected charge in the counter than coes an $(n, p)$ reaction depositing the same energy. The recoll response function then takes the form,

$R_{\text {rec }}(E, X) d x-n_{H} V T \sigma_{s}(E) S(E, x) d X$

where $n_{11}=$ atom density of ${ }^{3} \mathrm{He}\left(\mathrm{cm}^{-3}\right)$ $a_{s}={ }^{3}$ He $(n, n)$ elastic scattering cross section $\left(\mathrm{cm}^{2}\right)$

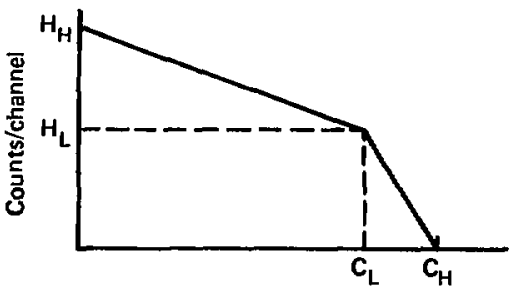

Chanrel

FIg. 24. Simple representation of ${ }^{3}$ He $(n, n)$ recoll distribution. and

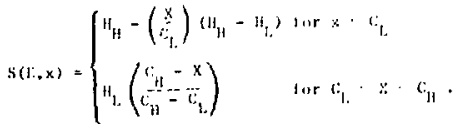

The parameters are given as a function of neutron energy by

$$
\begin{aligned}
& \mathrm{C}_{\mathrm{H}}=\mathrm{C}_{0}(1-\alpha) \mathrm{E}, \\
& \underset{U_{H}}{C_{L}}=C_{1}+C_{2} E+C_{3} E^{2}, \\
& \frac{\mathrm{H}_{\mathrm{H}}}{\mathrm{H}_{\mathrm{L}}}=\mathrm{h}_{1}+\mathrm{h}_{2} \mathrm{E} \text {, } \\
& H_{L}=\frac{h_{0}}{\frac{1}{2} c_{H}\left(1+\frac{H_{H}}{H_{L}} \frac{C_{L}}{C_{H}}\right)} \text {. }
\end{aligned}
$$

Table 7 gives the parameter values used for two ${ }^{3}$ He gas proportional counters. Note that the constant $h_{0}$ Is the area of the recoil distribution due to a single scattering event.

The continuum distribution obtained in many pulse-height spectra due to monoenergetic neutrons is observed to be nearly exponential up to the point where the continuum joins the gaussian peak at its low-energy stde. Figure 25 shows the form of the response assumed here for the continum due to $(n, p)$ events which deposit significant energy outside the detector active volume. For $\mathrm{X} \leq \mathrm{C}_{\mathrm{L}}$, 
Table 7. ${ }^{3}$ He response function parameters.

\begin{tabular}{|c|c|c|}
\hline Parameter & $\begin{array}{c}\text { Detector No. } 301 \\
\left(4 \operatorname{atm}{ }^{3} \mathrm{He}, 3 \operatorname{atm~Ar}\right) \\
(\mathrm{R}=2.5 \mathrm{~cm}, \mathrm{~L}=46 \mathrm{~cm})\end{array}$ & $\begin{array}{c}\text { Detector No. } 303 \\
(4 \text { atm } 3 \mathrm{He}, 3 \mathrm{~atm} \mathrm{Kr}) \\
(\mathrm{R}=2.5 \mathrm{~cm}, \mathrm{~L}=46 \mathrm{~cm})\end{array}$ \\
\hline$\varepsilon_{0}$ & 0.95 & 0.93 \\
\hline$\varepsilon_{1}$ & 0.356 & 0.203 \\
\hline$\varepsilon_{2}$ & 0.0448 & 0.072 \\
\hline$c_{0}$ & 0.91 & 0.95 \\
\hline$c_{1}$ & 0.6 & 0.75 \\
\hline $\mathrm{C}_{2}$ & 0.159 & 0.02 \\
\hline$c_{3}$ & -0.021 .2 & 0 \\
\hline $\mathrm{h}_{0}$ & 0.3 & 0.3 \\
\hline $\mathrm{h}_{1}$ & 0.2 & 0.3 \\
\hline $\mathrm{h}_{2}$ & 0 & 0 \\
\hline$\delta_{1}$ & -0.357 & -0.357 \\
\hline$\delta_{2}$ & -0.774 & -0.774 \\
\hline$\delta_{3}$ & 0.04 & 0.04 \\
\hline$\delta_{4}$ & -0.015 & -0.010 \\
\hline$\delta_{5}$ & 0 & -0.002 \\
\hline$\delta_{6}$ & 0 & 0 \\
\hline$\delta_{7}$ & 0 & 0 \\
\hline$\delta_{8}$ & 0 & 0 \\
\hline$\delta_{9}$ & 0 & 0 \\
\hline$\delta_{10}$ & -1.43 & -1.43 \\
\hline$\delta_{11}$ & -0.613 & -0.613 \\
\hline$\delta_{12}$ & 0 & 0 \\
\hline$\delta_{13}$ & -0.05 & -0.05 \\
\hline$\delta_{14}$ & 0.0075 & 0.0075 \\
\hline$\delta_{15}$ & 0 & 0 \\
\hline
\end{tabular}




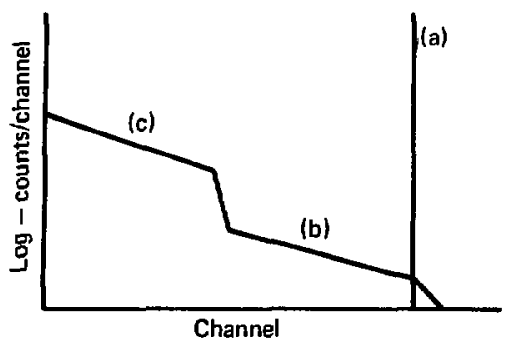

F1g. 25. Simple representation of ${ }^{3} \mathrm{He}$ pulse-height distribution before smoothing, showing: (a) delta function representation of $(n, p)$ reaction peak; (b) continum due to incomplete charge collection; and (c) continuum plus 3 He $(n, n)$ recoil distribution.

$r_{i, g n t}(1 ., x) d x=n_{H 1} v T n_{n p} d x e^{r_{1}+r_{2}\left(x-c_{1}\right)+r_{3}\left(x-c_{1}\right)^{2}}$

where

$$
\left.\begin{array}{l}
r_{1}=\delta_{1}+\delta_{2} E+\delta_{3} E^{2} \\
r_{2}=\delta_{4}+\delta_{5} E+\delta_{6} E^{2} \\
r_{3}=\delta_{7}+\delta_{8} E+\delta_{9} E^{2}
\end{array}\right\} \text { for } x \leq C_{1} .
$$

Parameter values for $\delta_{1}-\delta_{9}$ are also Included in Table 7. For energy depositions $x \geq c_{1}$, the continuum is assumed to fall toward : $: 0$ with greater slope, so that for $x>c_{1}$,

$$
R_{\text {cont }}(E, X) d x=n_{H} V T \sigma_{n p} d x e^{r_{4}+r_{5} x}
$$

where

$$
\begin{aligned}
& r_{4}=\delta_{10}+\delta_{11} E+\delta_{12} E^{2} \\
& r_{5}=\delta_{13}+\delta_{14} E+\delta_{15} E^{2} .
\end{aligned}
$$

Full-width at half-maximum (FWIM) of the gaussian reaction peak has been measured as a function of energy for two detectors. The data are plotted in Fig. 26. A straight line passing through these data is used to infer the resolution width of the detector response as a function of neutron energy. $A$ gaussian filter of the same width is used to srooth the response function calculated $\overline{\mathbf{r}}$ rom the three components described above. A smoothed pulse-helght response function is calculated for each column of the detector response matrix. Figure 27 displays a response matrix calculated for neutrons up to $2.3 \mathrm{HeV}$.

\section{Unfolding}

An initial estimate of the neutron spectrum is made from Eq. (59).

Following this and the calculation of the response matrix, a neutron spectrum is unfolded from the pulseheight data using the same procedure as for hydrogenous proportional counters. 


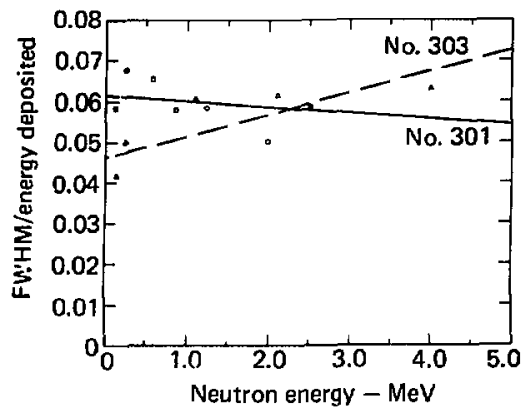

Fig. 26. ${ }^{3}$ He detector pulse-height resolution versus neutron energy.

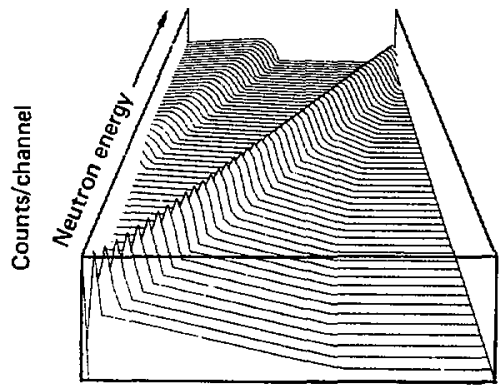

Energy deposited - MeV
Tests of the Method

A varlety of pulse-height spectra have been obtained near neutron sources using ${ }^{7} \mathrm{LI}(\mathrm{p}, \mathrm{n})$ and $\mathrm{T}(\mathrm{p}, \mathrm{n})$ reactions. These have been unfolded as described above. Figure 28 shows sone typical experimental data and the corresponding neutron spectra. It is clear that most of the interferences described earlier have been properly accommodated by the response matrix in spite of several simplifications. However, at heutron energies of $2 \mathrm{MeV}$ and greater, the recoll distribution is not properly represented by the response matrix, and there remains a small peak in the low-energy spectrum due to the systematic errors in the response matrix.

F1g. 27. Response matrix for ${ }^{3}$ He proportional counter.

\section{RESULTS}

\section{DISPLAY FORMAT}

Neutron spectral data are obtained from experimental pulse-helght data using organic scintillators, hydrogenous gas proportlonal counters, and ${ }^{3}$ He gas proportional counters.
Each detector is useful in a rather narrow portion of the energy range of Interest. Spectral segments are obtained using the LLL unfolding code NUTSPEC. 52 The spectral output from NUTSPEC appears in both graphic and tabulated form. The tabular output 

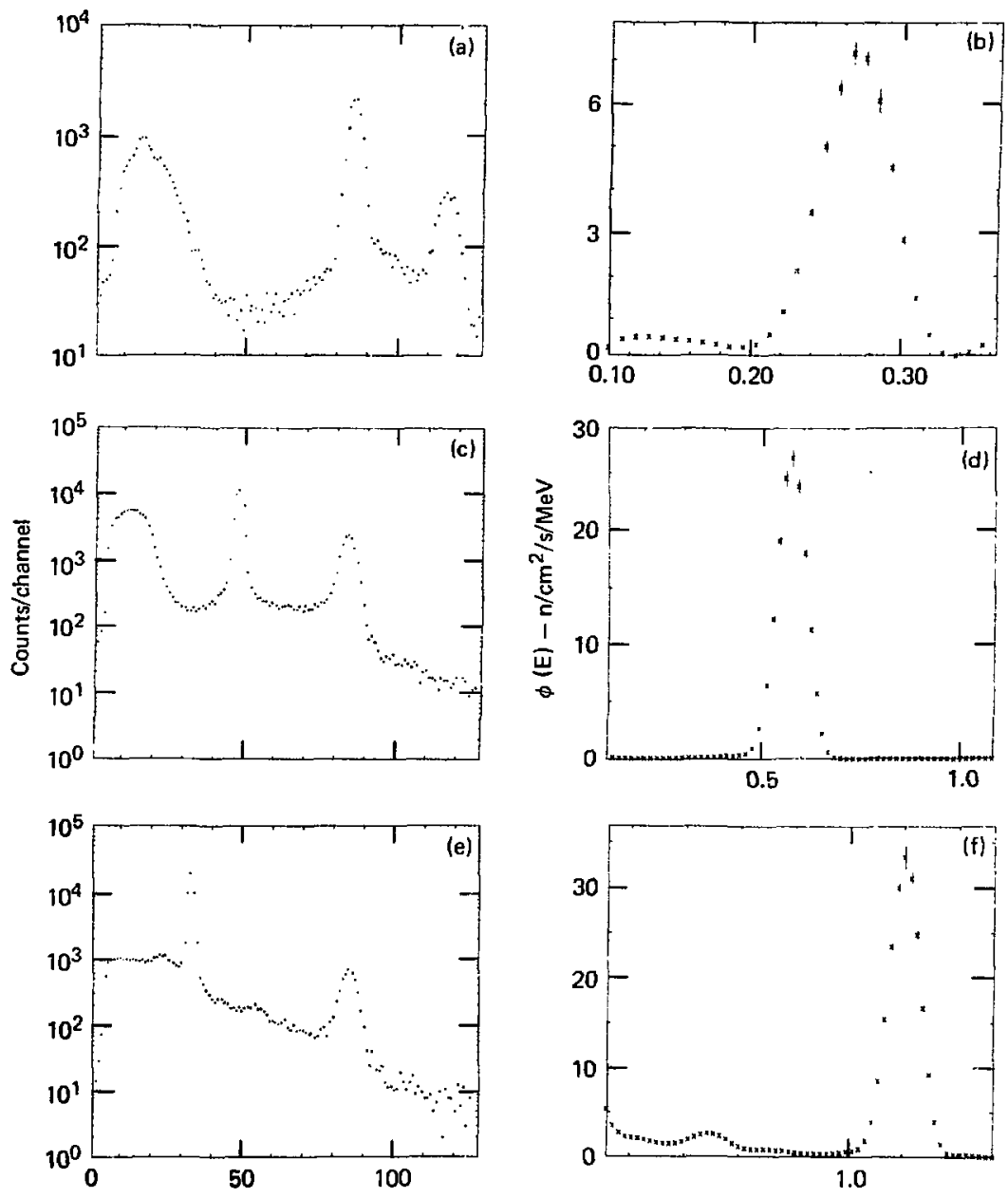

Channel

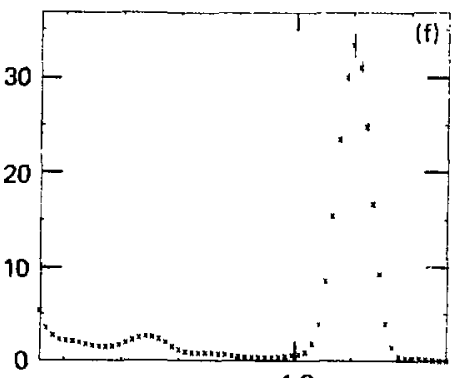

1.0

Neutron energy - MeV

Fig. 28. ${ }^{3}$ He proportional counter exposed to monoenergetic neutrons:

(a) pulse-helght spectrum, 268-keV source; (b) unfolded energy spectrum, 268-keV source; (c) pulse-helght spectrum, 567-keV source; (d) unfolded energy spectrum, 567-keV source; (e) pulse-helght spectrum, 1.2-MeV source; and (f) unfolded energy spectrum, 1.2-MeV source. 


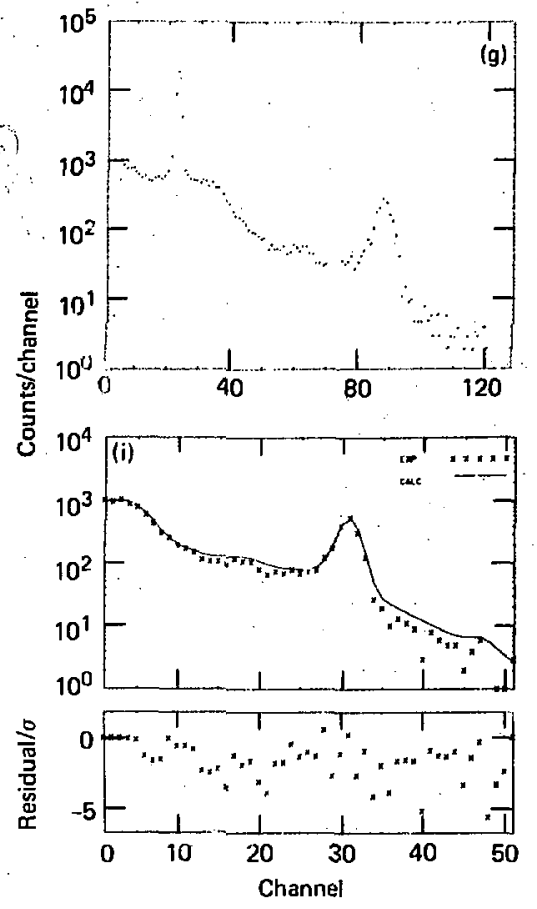

gives spectral Intensity, $\phi(E)$, (neutrons $/ \mathrm{cm}^{2}-\mathrm{s}-\mathrm{MeV}$ ) as well as the uncertainty. $\delta \phi(E)$. In addition, the spectral intensity is multiplied by a neutron dose-equivalent conversion factor ${ }^{74}$ at energy $E$ to obtain the neutron differential dose-equivalent rate, $D(E),(m R / h r-H e V)$ and by a suitable conversion factor ${ }^{75}$ to obtain differential neutron kerma rate, $K(E)$, (erg/g-s-MeV). Finally,

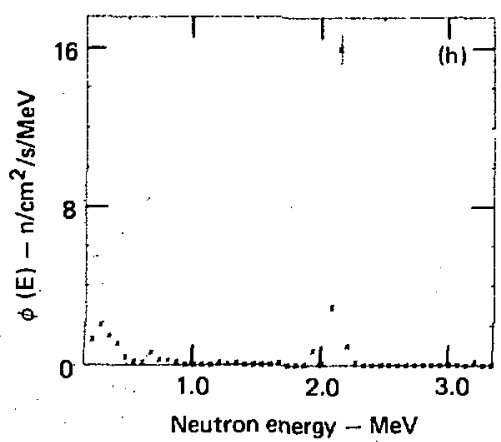

Fig. 28. Continued. (g) pulseheight spectrum, $2.03-\mathrm{MeV}$ source, (h) unfolded energy spectrum, 2.03$\mathrm{MeV}$ source, and (i) refold pulseheight spectrum compared to experimental data, 2.03-MeV source.

integrals of $\phi, \dot{D}$, and $K$ are given as functions of energy; i.e.,

$$
I_{\phi}(E)=\int_{E}^{\infty} \phi\left(E^{\prime}\right) d E^{\prime} .
$$

Graphical data are also given showing the experimental pulse-helght data, the refolded pulse-helght spectrum compared to the experimental data, the unfolded neutron spectrum $\phi(E)$, 
and differential dose-equivalent

rate $D(E)$. Spectral segments ubtained using several detectors are merged together Into a mosalc using an LLl. code called RESULTS. 52

\section{LABORATORY MEASUREMENTS}

A series of measurements has recently been completed in the LLL. low-scater facility. ${ }^{2,4}$ Neutroa spectra at 1 and $2 \mathrm{~m}$ from sources of ${ }^{252} \mathrm{Cf}$ and ${ }^{238}$ PuBe were made following the procedures described earlier. Each source was exposed bare, and enclosed by various spherical moderators of $\mathrm{H}_{2} \mathrm{O}, \mathrm{CH}_{2}, \mathrm{D}_{2} \mathrm{O}$, or $\mathrm{Al}$. The results of these measurements are tabulated in Appendix $A$ and plotted in FIgs. 29-32.

Differential neutron energy spectra are given in Figs. 29 and 30 for ${ }^{252} \mathrm{Cf}$ and ${ }^{238} \mathrm{PuBe}$ souicus, respectively. The integral of these spectra, from Eq. (76), are plotted in Figs. 31 and 32 . These measurements may be uscod to assess the limits on the present methods of spectral determination. All of the spectra exhibit a depression or gap In the 0.5 to $0.3-\mathrm{MeV}$ region which Is an Instrumental effect. It is caused by the absence of overlap between the useful energy ranges of the $\mathrm{r}_{2}$ proportional counter and the NE213 detectors. The proportional counter used in these measurements Is a low-pressure (1 atm) detector where wall events predominate above about 0.7 MeV. Scintillation measurements were limited by the very high count rates where PSD was effective only for recoil protons at energies greater than about $0.8-0.9 \mathrm{MeV}$. Aside from the gap in these measurements, the measured spectra for unmojerated ${ }^{252} \mathrm{CF}$ and ${ }^{238}$ PuBe sources are in good agreement with the work of others. 76,77 Fission temperature inferred from a Maxwellian $f$ it to the bare ${ }^{252} \mathrm{Cf}$ data in the range 2-10 MeV yields a temperature of $1.40 \mathrm{MeV}$ which is in good agtement with Guenther, et al. ${ }^{78}$ who measured $1.42 \mathrm{MeV}$.

\section{FIELD MEASUREMENTS}

Only one measurement has been made outside the laboratory to date. 79 It was carried out using two large detectors and with the laboratory pulse-processing electronics system. A neutron spectrum was measured over a period of about 16 hours in a neutron field whose total intensity was about $5 \mathrm{n} / \mathrm{cm}^{2}-\mathrm{s}$ (whlch produced a dose-equivalent rate of about $0.5 \mathrm{mR} / \mathrm{hr}$ ). The experience gained from that measurement indicates that spectral data may be obtained at neutron intensities as low as $0.1 \mathrm{n} / \mathrm{cm}^{2}-s$ with some sacrifice in statistical accuracy if it Is possible to accumulate data over 

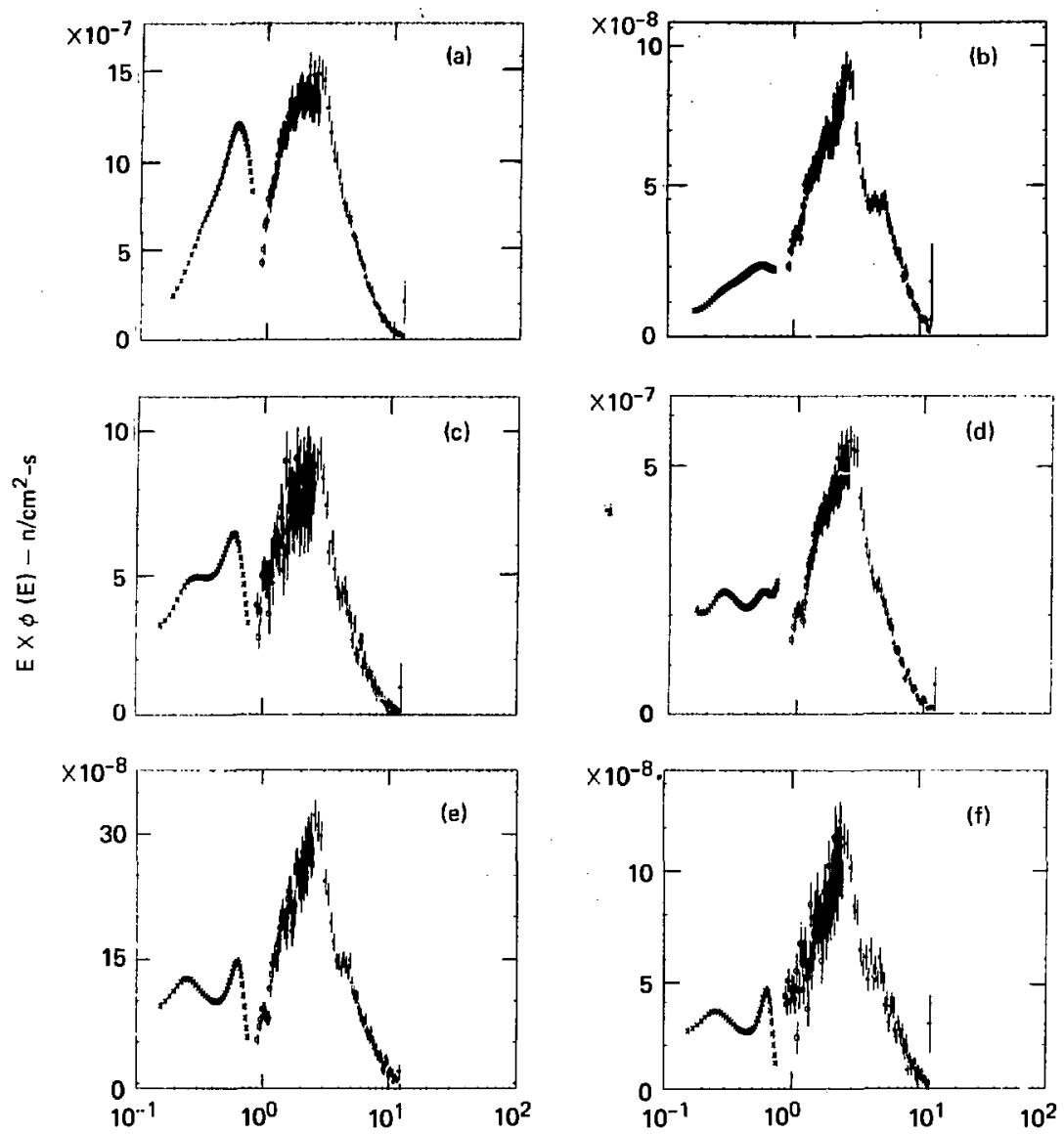

Neutron energy - MeV

Fig. 29. Neutron spectra measured $2 \mathrm{~m}$ from a ${ }^{252} \mathrm{CF}$ source. Al1 data are normalized to $1-\mathrm{n} / \mathrm{s}$ source Intensity. (a) Bare, (b) 25-cm $\mathrm{H}_{2} \mathrm{O}$ moderation, (c) $5-\mathrm{cm} \mathrm{D}_{2} \mathrm{O}$, (d) $10-\mathrm{cm} \mathrm{D}_{2} \mathrm{O}$, (e) $15-\mathrm{cm} \mathrm{D}_{2} \mathrm{O}$, and (f) $25-\mathrm{cm} \mathrm{D}_{2} \mathrm{O}$. 


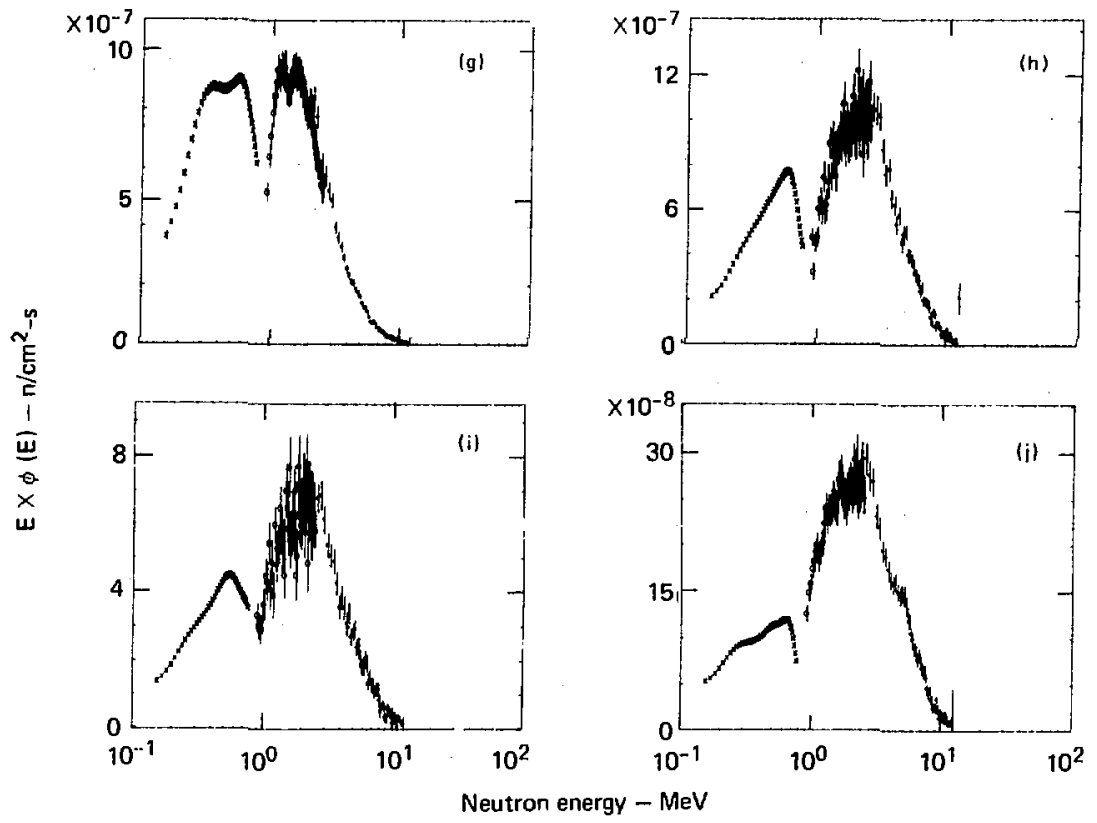

Fig. 29. Continued. (g) $20-\mathrm{cm}$ aluminum, (h) $2-\mathrm{cm}$ polyethylene, (i) $5-\mathrm{cm}$ polyethylene, and (j) $10-\mathrm{cm}$ polyethylene.

24-48 hours. Data with good statistics during which good data may be accumumay be obtained during this time period at intensities of $1 \mathrm{n} / \mathrm{cm}^{2}-5$. lated. Interference due to energetic cosmic-ray protons also become important as neutron intensities decresse. At the present time, a fleld spectrometer is being built which will monitor a built-in $\gamma$ ray source to stabilize the system for measurements using organic scintillators. 

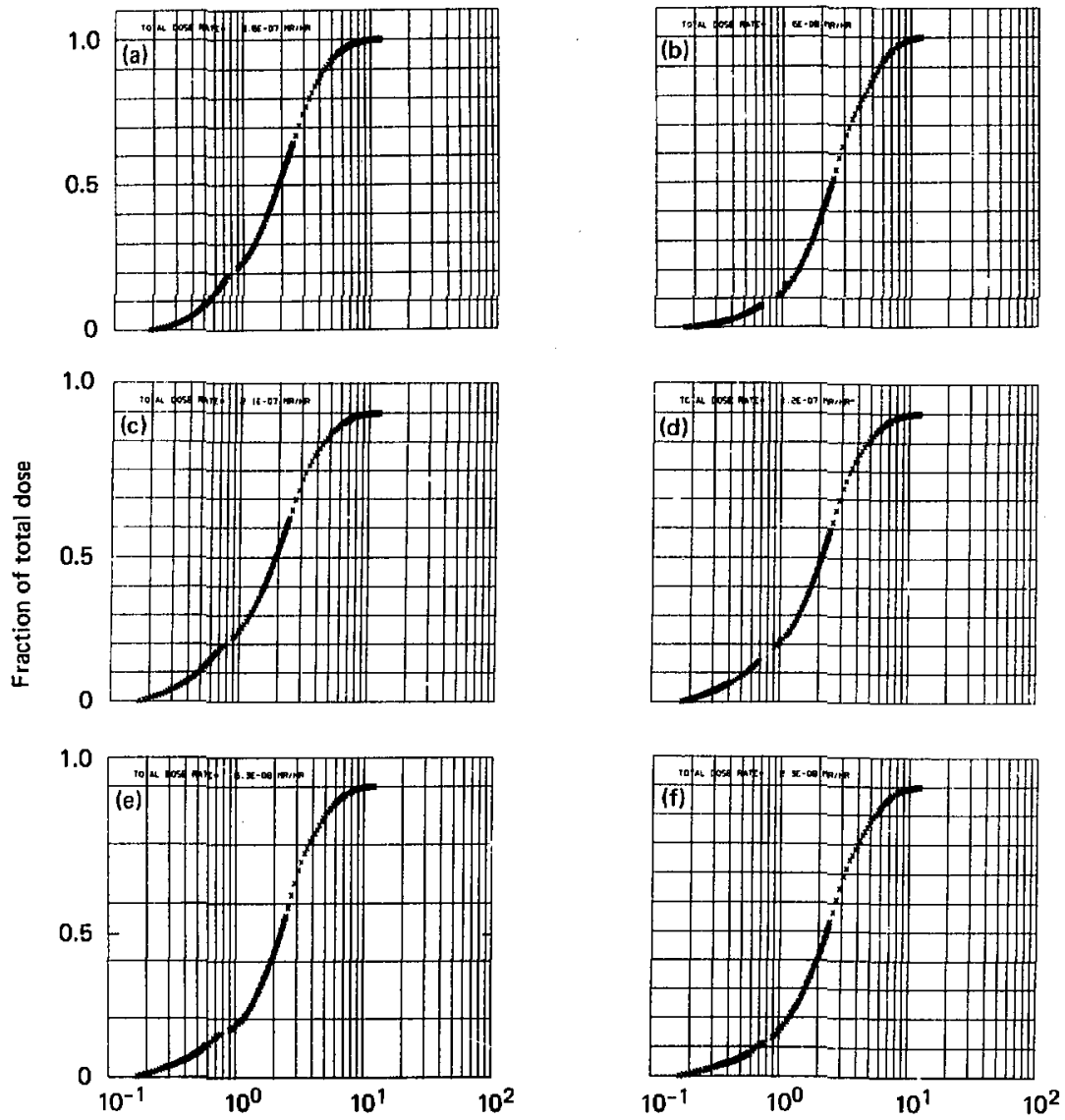

Neutron energy - MeV

Fig. 30. Dose-equivalent spectrum at $\mathrm{R}=2 \mathrm{~m}$ for ${ }^{252} \mathrm{Cf}$ integrated from threshold energy $E$ to infinity. Data normalized to $1-n / s$ source. (a) Bare, (b) $25-\mathrm{cm} \mathrm{H}_{2} \mathrm{O}$ moderation, (c) $5-\mathrm{cm} \mathrm{D}_{2} \mathrm{O}$, (d) $10-\mathrm{cm} \mathrm{D}_{2} \mathrm{O}$, (e) $15-\mathrm{cm} \mathrm{D}_{2} \mathrm{O}$, and (f) $25-\mathrm{cm} \mathrm{D}_{2} \mathrm{O}$. 


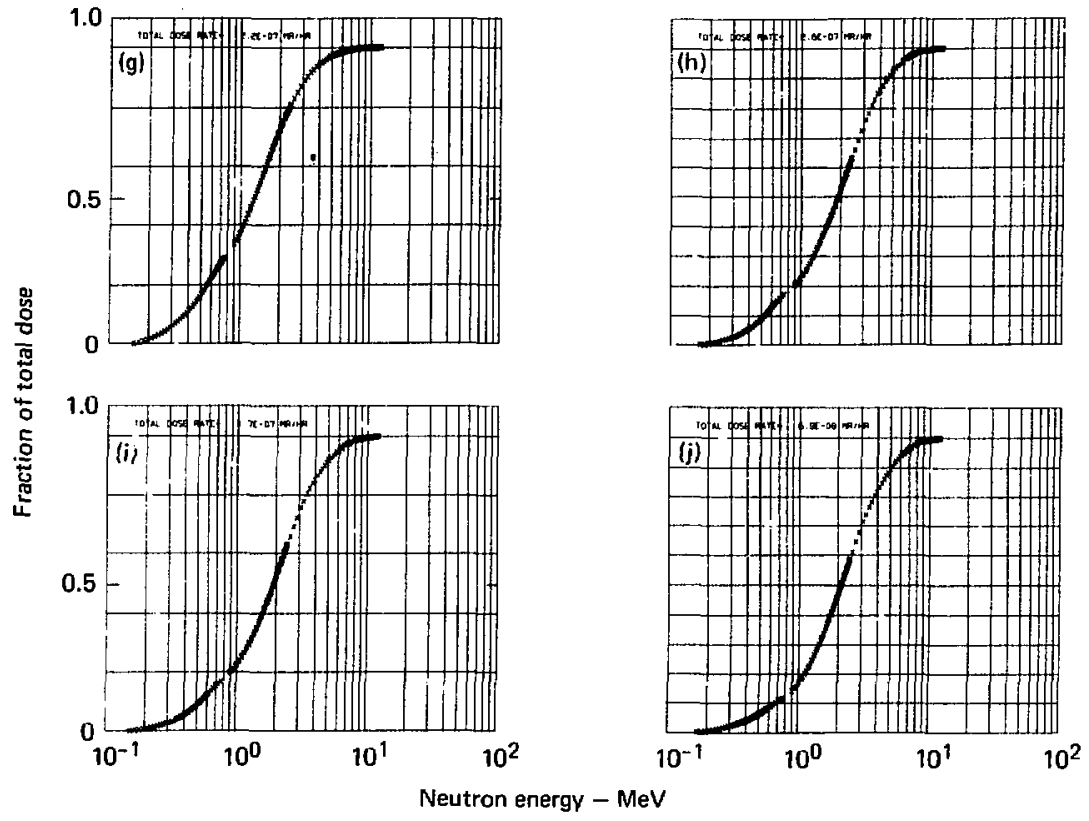

Fig. 30. Continued, (g) 20-cm aluminum, polyethylene, and (j) 10-cm polyethylene.

(h) 2-cm polyethylene,

(i) $5-\mathrm{cm}$

\section{CONCLUSIONS}

Spectrometer systems for both laboratory and fleld measurements have been constructed and evaluated. Simple unfolding methods have been investigated and found to be efficlent, and quite adequate for dosimetry, shielding, and verification of theoretical calculations. Hydrogen gas proportional counters have been used routinely for low-energy measurements, wh1le NE213 liquid scintillation detectors have been used for measurements above $1 \mathrm{MeV}$. These systems have been found 

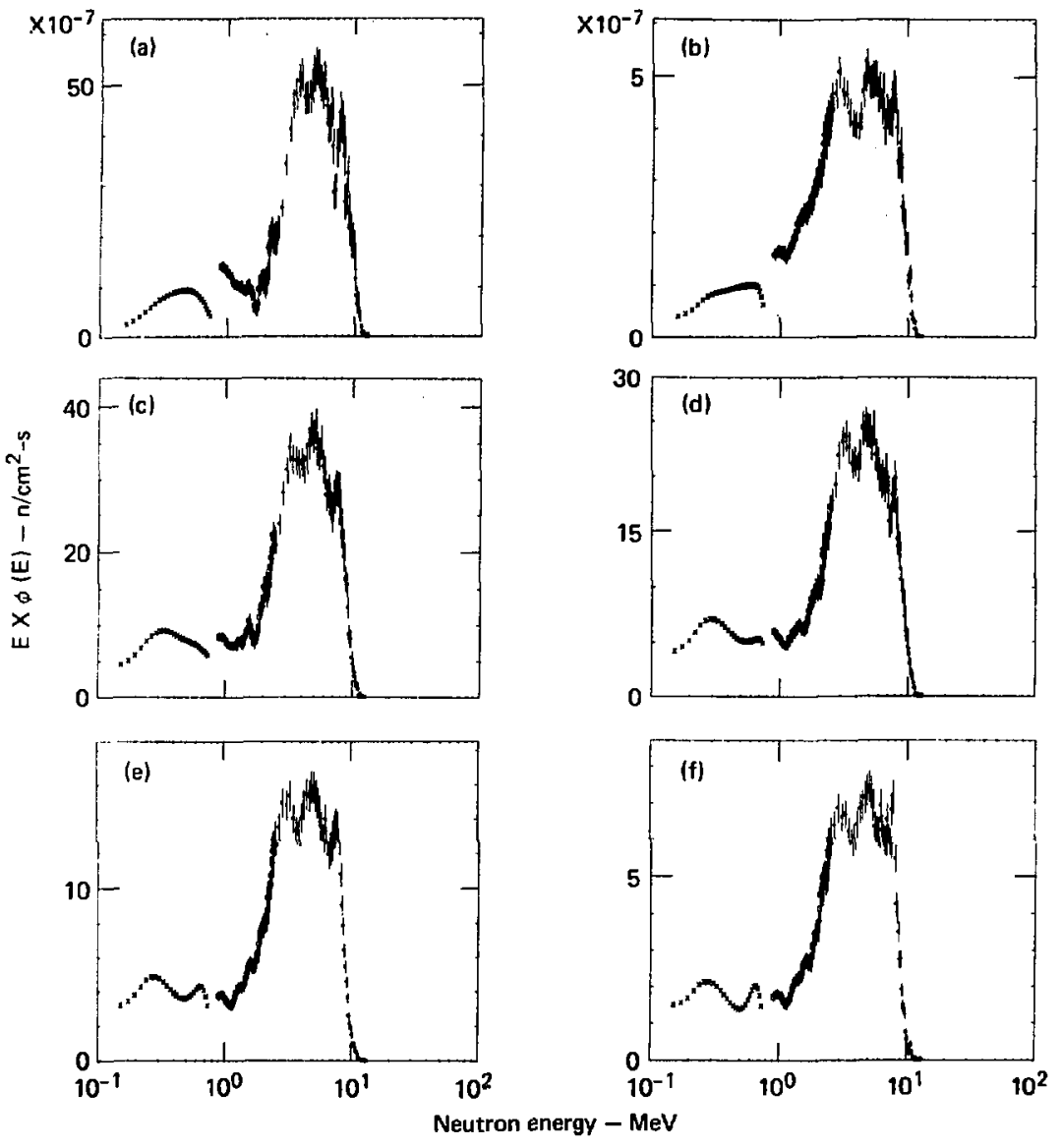

Fig. 31. Neutron spectra measured at R=1M from a ${ }^{238}$ PuBe neutron source. A.11 data are normalized to $1-\mathrm{n} / \mathrm{s}$ source strength. (a) Bare, (b) $25-\mathrm{cm} \mathrm{H}_{2} \mathrm{O}$ moderation, (c) $5-\mathrm{cm} \mathrm{D}_{2} \mathrm{O}$, (d) $10-\mathrm{cm} \mathrm{D}_{2} \mathrm{O}$, (e) $15-\mathrm{cm} \mathrm{D}_{2} \mathrm{O}$, and (f) $25-\mathrm{cm}$ $\mathrm{D}_{2} \mathrm{O}$. 


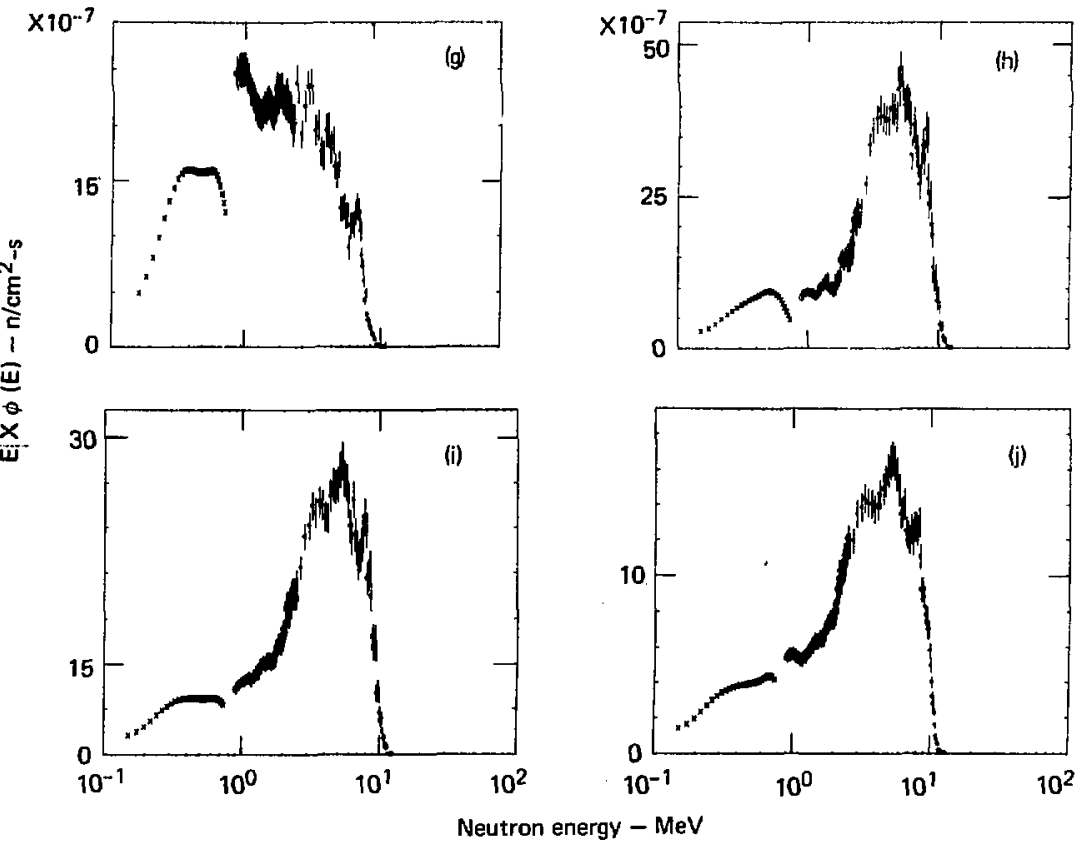

F1g. 31. Continued. (g) $20-\mathrm{cm}$ aluminum, (h) $2-\mathrm{cm}$ polyethylene, (i) $5-\mathrm{cm}$ polyethylene, and (j) $10-\mathrm{cm}$ polyethylene.

adequate for the intensity range $10^{-1}$ to $10^{6} \mathrm{n} / \mathrm{cm}^{2}-\mathrm{s}$ and an energy range nominaliy 0.05 to $20 \mathrm{MeV}$.

The most significant problem remaining is that of closing the spectral gap due to the fallure of the proportional counter and scintillator responses to overlap. In princ1ple, the ${ }^{3}$ He proportional counters should bridge this gap readily. Response functions for several such detectors have been determined in the range $0.2-4 \mathrm{MeV}$. However, the large count rate due to thermal neutrons in the fields of Interest have caused serious distortions in the response functions due to pulse pile-up in the detector and processing system. As a result, an echo of the thermal peak appears in the pulse-height spectra. Unfolded results have been unrellable In many cases of interest. These detectors may yot prove usef'll if an 

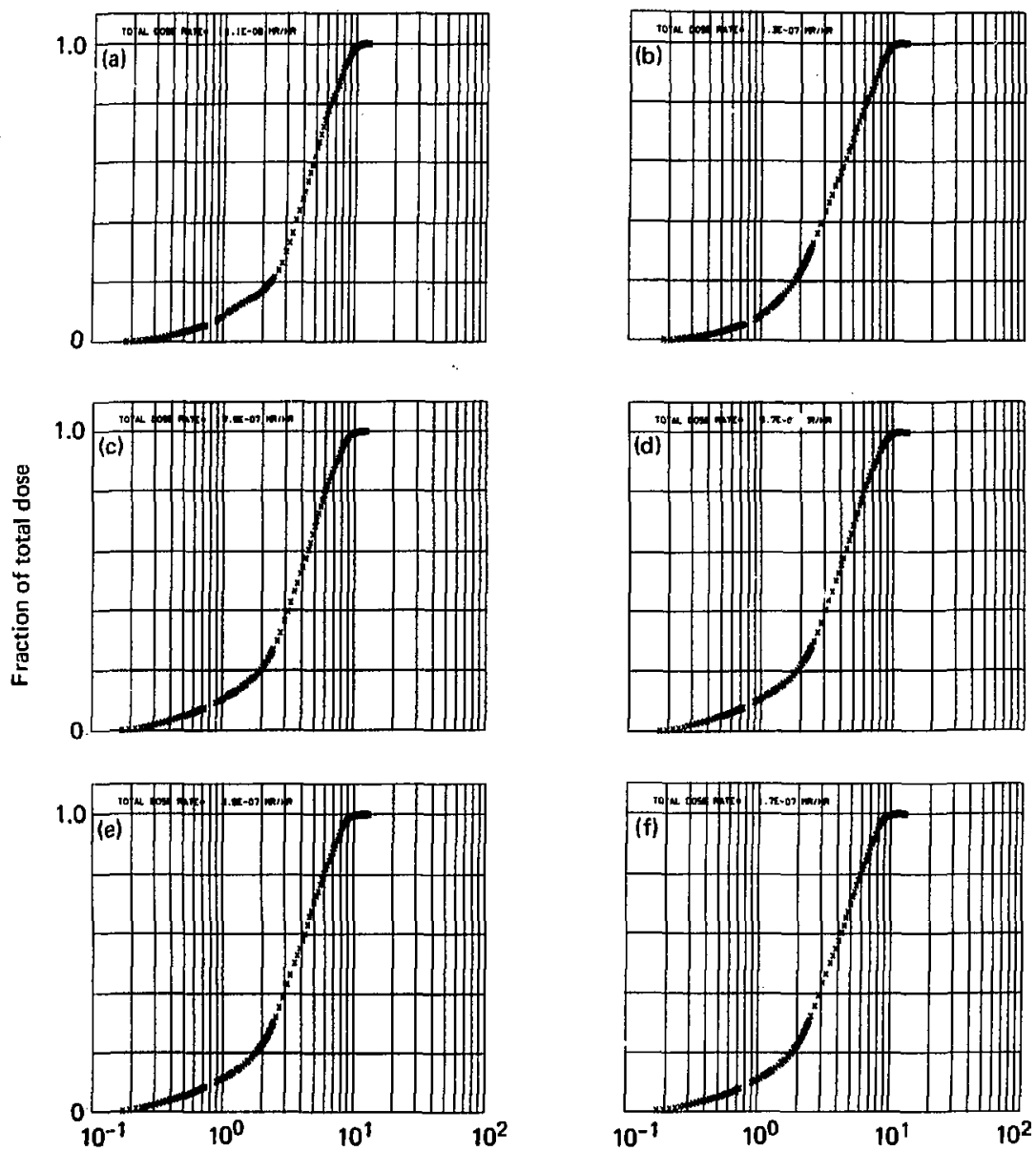

Neutron energy - MeV

F1g. 32. Dose-equivalent spectra at $\mathrm{R}=1 \mathrm{M}$ for ${ }^{238} \mathrm{PuBe}$ source, integrated from threshold energy $E$ to Infinity. Data normallzed to $1-n / s$ source. (a) Bare, (b) $25-\mathrm{cm} \mathrm{H}_{2} \mathrm{O}$ moderation, (c) $5-\mathrm{cm} \mathrm{D}_{2} \mathrm{O}$, (d) $10-\mathrm{cm} \mathrm{D}_{2} \mathrm{O}, \quad$ (e) $15-\mathrm{cm} \mathrm{D}_{2} \mathrm{O}$, and (f) $25-\mathrm{cm} \cdot \mathrm{D}_{2} \mathrm{O}$. 


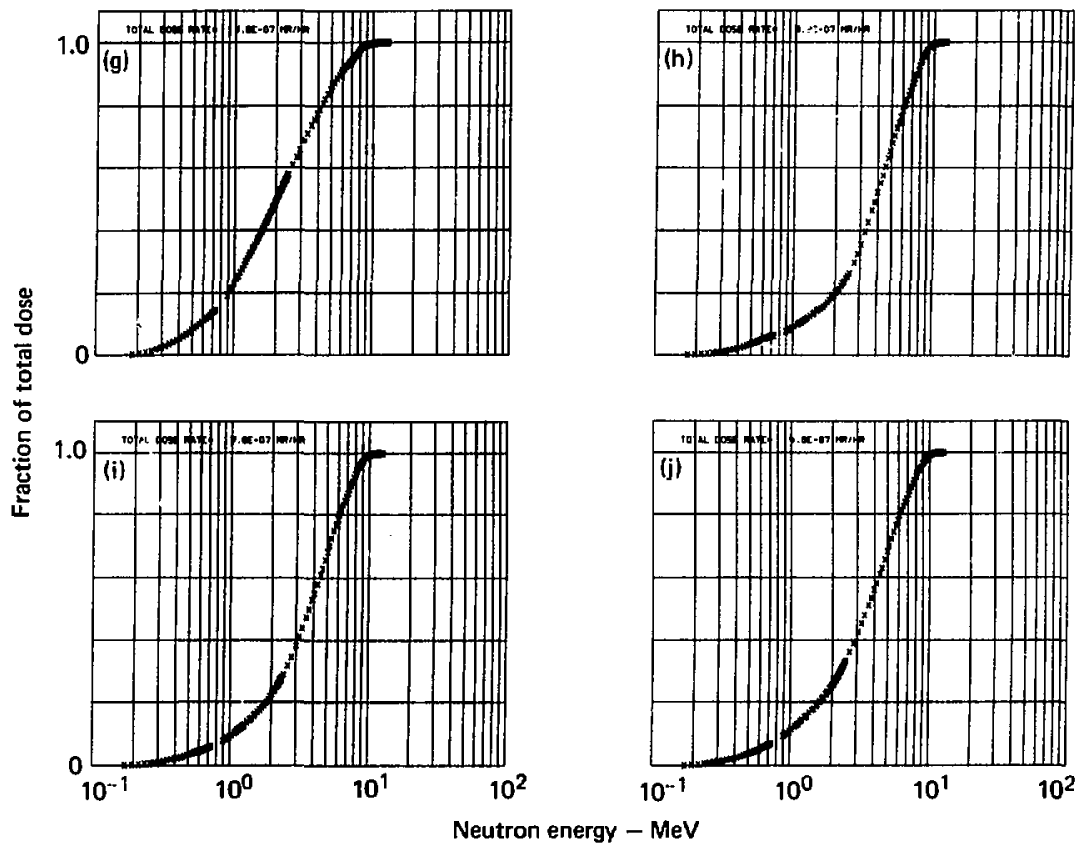

F1g. 32. Continued. (g) 20-cm aluminum, (h) $2-\mathrm{cm}$ polyethylene, (i) $5-\mathrm{cm}$ polyethylene, and (j) 10-cm polyethylene.

effective thermal neutron shield may be designed for them.

Alternatively, the useful energy range of hydrogen and methane gas proportional counters may be extended to higher energles by Introducing a stoppling gas or Increasing the fill pressure. Th1s work 1a now in progress. As yet, electronegative Impurities Introduced during the f111 process limit the formance of high stopping power detectors.

Measurements made thus far have provided enough information about the neutron spectra of Interest that shielding and dosimetric conclusions may be drawn. The gap in the measured spectra, although 1 t often occurs in a region of high intensity, is narrow and an estimate of the spectral shape 
may be based on transport calculations without Introducing large errors. Thus, the methods described here may be implemented to provide a simple and efficient means of neutron spectroscopic measurements. Imple- mentation on a mini-computer or micro-computer is stralghtforward, and the quality and completeness of the result has been found adequate for the purposes described in the Introduction.

\section{REFERENCES}

1. Data for Protection Against Ionizing Radiation from External Sources, ICRP Publication 21 (Pergamon Press, Oxford, 1971).

2. J. V. Boggs, Neutron Scatteming in the Hazards Control Low-Saatter Cell, Hazards Control Progress Report No. 34, UCRL-50007-69-2 (1969).

3. D. R. Slaughter and D. W. Rueppel, Environmental Neutron Spectmu Outside the LLL High Intensity 14-MeV Neutron Facility, Lawrence L1vermore Laboratory, Rept. UCRL-78946 (1977).

4. R. V. Griffith, D. R. Slaughter, H. W. Patterson, J. L. Beach, E. G. Frark, D. W. Rueppel and J. C. Fisher, "Mult1-Technique Characterization of Neutron Fields from Moderated ${ }^{252} \mathrm{Cf}$ and ${ }^{238}$ PuBe Sources," IAEA Symp. National and International Standardization of Radiation Dosimetry, Atlanta, Georgla, December 5-9, 1977 (Preprint UCRL-79483).

5. J. Cerny, Nuclear Spectroscopy and Reactions, Part B (Academic Press, New York, 1974).

6. H. Schraube, W. Eck1, K. Kolbe and G. Burger, "The Spectrometry of Neutrons with Different Methods," First Symp. Neutron Dosimetry in Bfology and Medicine, Jeuherberg/Munchen May 15-19, 1972, EUR-4896 d-f-e.

7. C. D. Swartz and G. E. Owen, "Recoll Detection In ScIntillators," Fast Neutron Physics, Part I (Interscience Publishers, London, 1960).

8. M. J. Coolbaugh, "Fast Neutron Spectroscopy In Aquecus Media UsIng an NE213 Proton Recoll Neutron Spectrometer System," Nuclear EngIneering Dept., University of Kansas, c00-2049-7 (1971).

9. D. W, Jones and M. E. Toms, "A Neutron Spectrometer Using Organic Scintillators," Naval Research Laboratory, Washington, D.C., NRL-7324 (1971).

10. Yu A. Kazanski, A. A. Van'Kov and E. I. Inyutin, Atomic Energy Rev. 13, ISS 4, 807 (1975). 
11. W. R. Young, "Neutron Spectra from an Organic Scintillator," University of Calif., UCRL-16149 (1965).

12. M. E. Toms, Nuc1. Instr. Meth. $\underline{92}, 61(19 / 1)$.

13. R. S. Reynolds, Trans. Amer. Nucl. Soc. 19, 419 (1974).

14. R. H. Johnson, B. W. Wehring, J. J. Dorning, "NE-213 Neutron Spectrometry for Measurements to $15 \mathrm{MeV}$," Nuctear Cross Sections and Technolog?: Vol. $I$, Proceedings of Conference, National Bureau of Standards, Wash. D.C., March 3-7, 1975.

15. Time-Dependent Fast Neutron and Secondrry Gamma Ray Spectrum Measurements in Concrete, Gulf General Atomic, San Diego, Calif. DASA-2401-1 (1969).

16. W. Eckl, Determination of Transfer Matrix of a Scintizlation Spectromete.' for Neutrons and Deconvolution of Neutron Spectra, PhD Thesis, Technische Universitat Munchen, Germany (1974).

17. J. L. Butragueno Casada, Neutron Spectroscopy with Organic Scintizzators, Junta de Energia Nuclear, Madrid, Spain, JEN-249 (1972).

18. J. S. Liu and B. G. Olcman, Liquid Scintizlator Analysis of Neutron Spectra, Radiological Physics Div. Annual Report July 1969 - June 1970, Argorıne National Laboratory, ANL-7760, Part I (1970).

19. V. V. Verbinski, W. R. Bürrus, T. A. Love, W. Zobel, N. W. Hill and R. Textor, Nucl. Instr. Neth, 65, 8 (1968).

20. F. T. Kuchnir and F. J. Lynch, IEEE Trans. Nucl. Sci. NS-15, No. 3, 107 (1968).

21. V. V. Badyayev, Yu A. Yegorov, V. A. Kulagin and Yu. V. Pankratyev, Voprosy Eiziki Zashehity Reaktorov No. 6, 152-158 (1974).

22. E. F. Bennett, A Study of the $1 / E$ Slowing Down Neutron Spectrum Using $4 \pi$ Recoil Proportional Counters, Argonne National Laboratory, ANL-6897 (1964).

23. P. W. Benjamin, C. D. Kemshall and J. Redfearn, Nucl. Instr. Meth. 59, 77 (1968).

24. P. W. Benjamin, C. D. Kemsiall and A. Brickstock, The Analysis of Recoil Proton Spectra, UKAEA, AJVE Re. No. 0-9/68 (1968).

25. E. F. Bennett and T. J. Yule, Nucl. Instr. Meth. 93, 393 (1972).

26. E. F. Bennett, Nucl. Sci. Eng. 27, 16-27 (1967).

27. E. F. Bennett, Nucl. Sci. Eng. 27, 28-33 (1967).

28. G. K. Borgonovi and G. E. Bromley, Proton Recoil Data Analyses ar Gulf Radiation Technology, Gulf-RT-10487 (1971).

29. A. K. Broomfleld and M. D. Carter, Proton Recoil Techniques in Zebra, UKAEA, AEEW-M905 (1969). 
30. A. Capgras, C. Ronteix and M. Sueur, "Spectrometrie de Nutrons et Etalonnage de Sources," First Syinp. Neutron Dosimetry in Biology and Medicine, Neuherberg/Munchen, May 15-19, 1972, EUR-4896-d-f-e (1972).

31. G. Fieg, J. Nuct. Energy 26, 585 (1972).

32. T. Ichimori, M. Obu, K. Shirakata, Measuring Fast Neutron Spectra with a Recoil Proton Proportional Counter, Japan Atomic Energy Research Institute, KURRI-TR-89, 80-86 (1975). Also Nuct. Instr. Meth. 127, 571 (1975).

33. D. Albert, H. Koepernik and W. Voge1, Kemergie 16, ISS 9, 287 (1973).

34. C. D. Kemsha11, Use of Spherical Proportional Counters for Neutron Measurements, UKAEA Weapons Group, Aldermaston, AWRE-0-31-73 (1973).

35. C. D. Livengood, C. K. Paulson and H. E. Hungerford, NucZ. Sci. Eng. 52, 254-266 (1973).

36. J. E. PowerII and J. W. Mathews, A Proton Recoil Spectrometer for Neutron Spectmum Measurements in the Sandia Pulsed Reactor-II Facility, Sandia Laboratories, SC-RR-71 0453 (1971).

37. H. Werle and H. Bluhm, J. Nucl. Energy 26, 165 (1971).

38. H. Werle, Nucl. Instr. Meth. $\underline{99}, 295$ (1972).

39. V. V. Verbinski and R. Giovanninni, Nuel. Insir. Meth. 114, 205 (1973).

40. A. I. M. Ritchie and A. Rose, Nucl. Instr. Meth. 127, 237 (1975).

41. E. Mathieson and T. J. Harris, Nucl. Instr. Meth. 88, 181 (1970).

42. G. R. Ricker and J. J. Gomes, Rev. Sci. Instr. 40, 227 (1968).

4.7 L. F. Bennett and T. J. Yule, Techniques and inxlyses of Fast Reactor Neutron Spectroscopy with Proton Recoil Proportional Counters, Argonne National Laboratory, ANL-7763 (1971).

44. B. B. Rossi and H. H. Staub, Ionization Chambers and Counters (McGrawHill, New York, 1949).

45. L. C. Northcliffe and R. F. Schllling, "Range and Stopping Power Tables for Heavy Ions," Nuclear Data Tables A7, 233-463 (1970).

46. J. B. Parker, P. H. White and R. J. Webster, Nucl. Instr. Meth. 25, 61 (1963).

47. W. A. Bair, An Improved Heliwm-3 Neutron Spectrometer, Lawrence Berkeley Laboratory, UCRL-96595 (1966).

48. R. Batchelor and G. C. Morrison, "Hellum-3 Neutron Spectrometers," Fast Neutron Physice, Part I, J. B. Marion, J. L. Fowler, Eds. (Interscience, New York, 1960). 
49. A. E. lvans and L. V. East, Evaluation of a Gridded ${ }^{3}$ He Spectrometer Tube for Safeguards and Other Analysis Applications, Los Alamos Scientific Laboratory, LA-5291-PR (1973).

50. J. Cutler, Y. Dagan and S. Shalev, Trans. Amer. Nucl. Soc. 14, 417 (1971).

51. D. I. Garber and R. R. Kinsey, Neutron Cross Sections Volume II, BNL-325, Third Ed, Vo1 II (1976).

52. D. R. Slaughter, NUTSPEC: A Program for Unfolding Neutron Spectral Data Obtained with Scintillation Detectors and Gas Proportional Counters, Lawrence Livermore Laboratory, UCID-17713 (1978).

53. D. R. Slaughter, "A Simple Method to Unfold NE213 and Stilbene Neutron Spectral Data," Radiation Energy Spectra Unfolding, Oak Ridge National Laboratory, ORNL-RSIC-40 (1976).

54. D. R. Slaughter, "NUTSPEC, A Code for Unfolding Neutron Pulse-Height Data," Hazards Control Progress Report No. 51, Lawrence Livernore Laboratory, UCRL-50007-75-2 (1976).

55. A. M. Weinberg and E. P. Wigner, The Physical Theomy of Neutron Chain Reactors (University of Chicago Press, Chicago, 1958), PP. 279-284.

56. J. L. Gamme1, "The n-p Total and Differential Cross Sections in the Energy Range 0-40 MeV," Fast Neutron Physics Part II, J. B. Marion and J. L. Fowler, Eds. (Interscience, New York, 1963), page 2209.

57. R. H. Johnson, "Improvements in Differentiation Unfolding of Radiation Spectra," Radiation Energy Spectra Unfolding, Oak Ridge National Laboratory, ORNL/RSIC-40 (1976).

58. H. W. Broek and C. E. Anderson, Rev. Sei. Instr. 31, 1063 (1960).

59. D. I. Garber, L. G. Stromberg, M. D. Goldberg, D. E. Cullen and V. M. May, Angular Distributions in Neutron Induced Reactions, Volume $I, 2-1$ to 20 , Brookhaven Nationa1 Laboratory, BNL-400, Third Ed. (1970).

60. R. J. Howerton, W. J. Cahil1, K. L. Hil1, D. W. Thompston and S. T. Perkins, Lawrence Livermore Laboratory, UCRL-50400.

61. D. R. Slaughter and D. W. Rieppe1, Nucl. Instr. Meth. 145, 315 (1977).

62. W. R. Burrus and V. V. Verbinsk1, Nucl. Instr. Meth. 67, 181 (1969).

63. H. Werle, Spectrum Measurements of Radioactive Neutron Sources in the $10 \mathrm{keV}-10 \mathrm{MeV}$ Energy Region with Proton Recoil Proportional Counters. Karlsruhe Nuclear Research Center, INR-4170-25 (1970) (Trans1. ORNL-TR2415).

64. N. 1. Snidow and H. D. Warren, Nuct. Instr. Meth. 51, 109 (1966). 
65. B. W. Rust, "Mathematical Foundations Underlying the Burrus Techniques of Spectra Unfolding," "adiation Spectra Unfolding, ORNL/RSIC-40 (1976).

66. W. R. Burrus, "FERD and FERDO Type Unfolding Codes," Radiation Spectra Unfolding, Oak RIdge National Laboralory, ORNL/RSIC-40 (1976).

67. N. E. Scofield, "A Technique for Unfolding Gamma-Ray Scintillation Spectrometer Pulse-Helght Distributions," U.S. Naval Radiological Defense Laboratory, USNRDL-TR-447 (1960).

68. C. V. Smith and N. E. Scofield, A Computer Program for Unfolding PuzseHeight Distributions, U.S. Naval Radlologlcal Defense Laboratory, USNRDL-TR-829 (1965).

69. W. J. O'Conne11, A Computer Program for Unfolding Detector Response Effects from a Continuous Cama Ray Spectrum, Lawrence Livermore Laboratory, UCID-30079 (1973).

70. J. F. Mollenauer, A Computer Analysis J. Tomplex Sodium Iodide Gomma Spectra, Lawrence I.1vermore Laboratory, * '9] -9748 (1961).

71. W. K. Brown, Nuci. Instr. Meth. 26, 1 (196i

72. H. T. Wang, Inversion Matrix for a ${ }^{3}$ He Fast Neutron Spectrometer, Lawrence Berkeley Laboratriry, UCRL-10770 (1963).

73. D. R. Slaughter, "A Parameterized Pulse-Height Response Matrix for a ${ }^{3}$ He Proportional Counter," Hazards Control Progress Report No. 5z, Lawrence Livermore Laboratory, UCRL-50007-76-1 (1976).

74. Radiativn Protection, ICRP Publication 21, Pergamon Press, 1971.

75. Protection Againat Neutron Radiation, National Counc1l on Radiation Protection, NCRP Report No. 38, 1971.

76. W. Meyer, Trans. Amer. Nucl. Soc. 19, 480 (1974).

77. A. Kumar and P. S. Nagarajan, Nucl. Instr. Meth. 140, 175 (1977).

78. P. Guenther, D. Have1, R. Sjoblom and A. Smith, A Remark on the Prompt Eission Neutron Spectrum of ${ }^{252}$ Cf, Argonne National Laboratory, ANL/ NDM-19 (1976).

79. D. R. Slaughter and D. W. Rueppel, "Environmental Neutron Spectrum Outside the LLL High Intensity $14 \mathrm{KeV}$ Neutron Factlity," Health Physics Soclety 22nd Annual Meeting, Atlanta, Georgia, July 3-8, 1977 (Also UCRL-78946). 


\section{APPENDIX A - TABULAR RESULTS FOR NEUTRON SPECTRUM MEASUREMENTS NEAR VARIOUS MODERATOR-SOURCE CONFIGURATIONS}

Data are given in two forms for each configuration. First, spectral results are given where absolute intensitles are normalized to a source strength of $1 \mathrm{n} / \mathrm{s}$. Second, these tabular results are integrated over the 30 energy groups used by MORSE-L to give 30 group results. The first table for each configuration includes the absolute differential intensity $\left(\mathrm{n} / \mathrm{cm}^{2} \mathrm{~s}-\right.$ MeV) and its uncertainty (one-sigma). The table also includes differential neutron dose-equivalent rate $(\mathrm{mR} / \mathrm{hr}-\mathrm{MeV}$ ) and differential Kerma rate (erg/ g-s-MeV). Finally, the table shous the integrals $\int_{E^{\infty}}^{\infty}\left(E^{\prime}\right) d E^{\prime}$ and $\int_{E^{\infty}}^{\infty} D\left(E^{\prime}\right) d E^{\prime}$. The second table for each configuration gives, for each group:

- The differential flux $\phi(E)$, averaged over the group.

- The group flux, i.e., $\phi(E)$ integrated over the group.

- The differential flux per untt lethargy $\phi(U)=E \phi(E)$, averaged over each group. 
'CF-252 BARE AT R=2M (FOR $1.0 \mathrm{~N} / \mathrm{SEC}$ )

TIME AND DATE OF DATA REPORTING ENEROY (NEUT/CM2-SEC-MEV) DEL-PHI

\begin{tabular}{|c|c|c|}
\hline 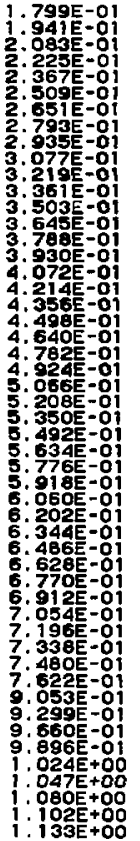 & 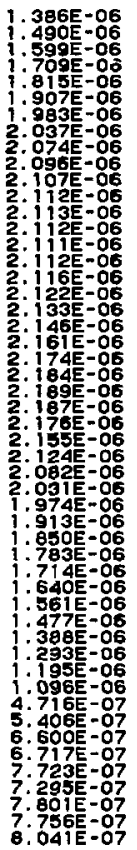 & 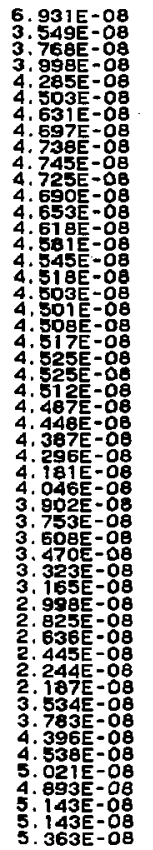 \\
\hline
\end{tabular}

$10 / 18 / 77 U^{10: 26: 574} 10 / 18 / 77$

DOSE

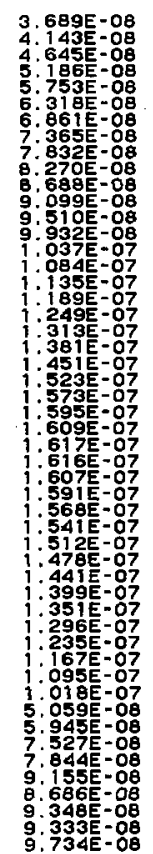

(ERG/GMRMA

$1.079 E-13$
$1.197 E-13$
$1.327 E-13$
$1.464 E-13$
$1.605 E-13$
$1.742 E=13$
$1.869 E-13$
$1.963 E-13$
$2.084 E-13$
$2.175 E-13$
$2.258 E-13$
$2.337 E-13$
$2.413 E-13$
$2.491 E-13$
$2.571 E-13$
$2.655 E-13$
$2.747 E-13$
$2.845 E-13$
$2.952 E-13$
$3.067 E-13$
$3.186 E-13$
$3.311 E-13$
$3.435 E-13$
$3.521 E-13$
$3.559 E-13$
$3.582 E-13$
$3.589 E-13$
$3.577 E-13$
$3.548 E-13$
$3.501 E-13$
$3.442 E-13$
$3.375 E-13$
$3.300 E-13$
$3.219 E-13$
$3.129 E-13$
$3.029 E-13$
$2.917 E-13$
$2.792 E-13$
$2.653 E-13$
$2.500 E-13$
$2.339 E-13$
$2.168 E-13$
$1.048 E-13$
$1.226 E-13$
$1.541 E-13$
$1.599 E-13$
$1.859 E=13$
$1.760 E=13$
$1.890 E-13$
$1.864 E-13$
$1.960 E-13$

(NETEGRAL

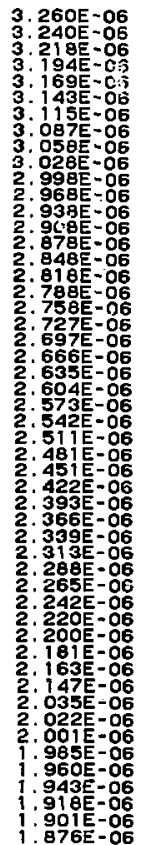

(NT =DOSE

FILE-ID

\begin{tabular}{|c|c|}
\hline & 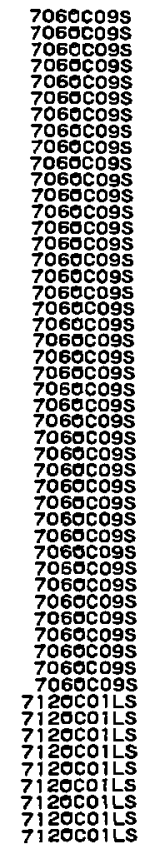 \\
\hline
\end{tabular}



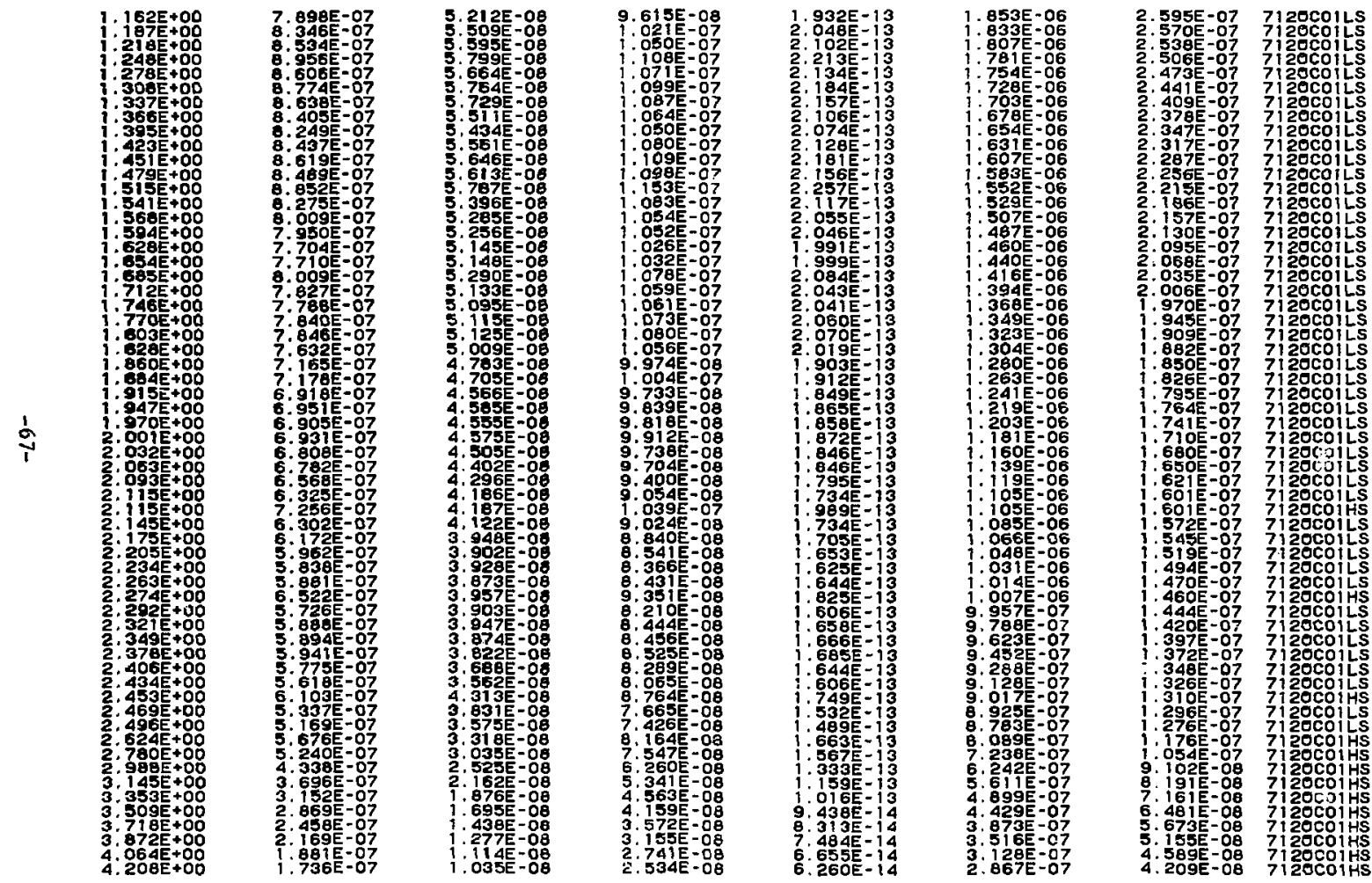

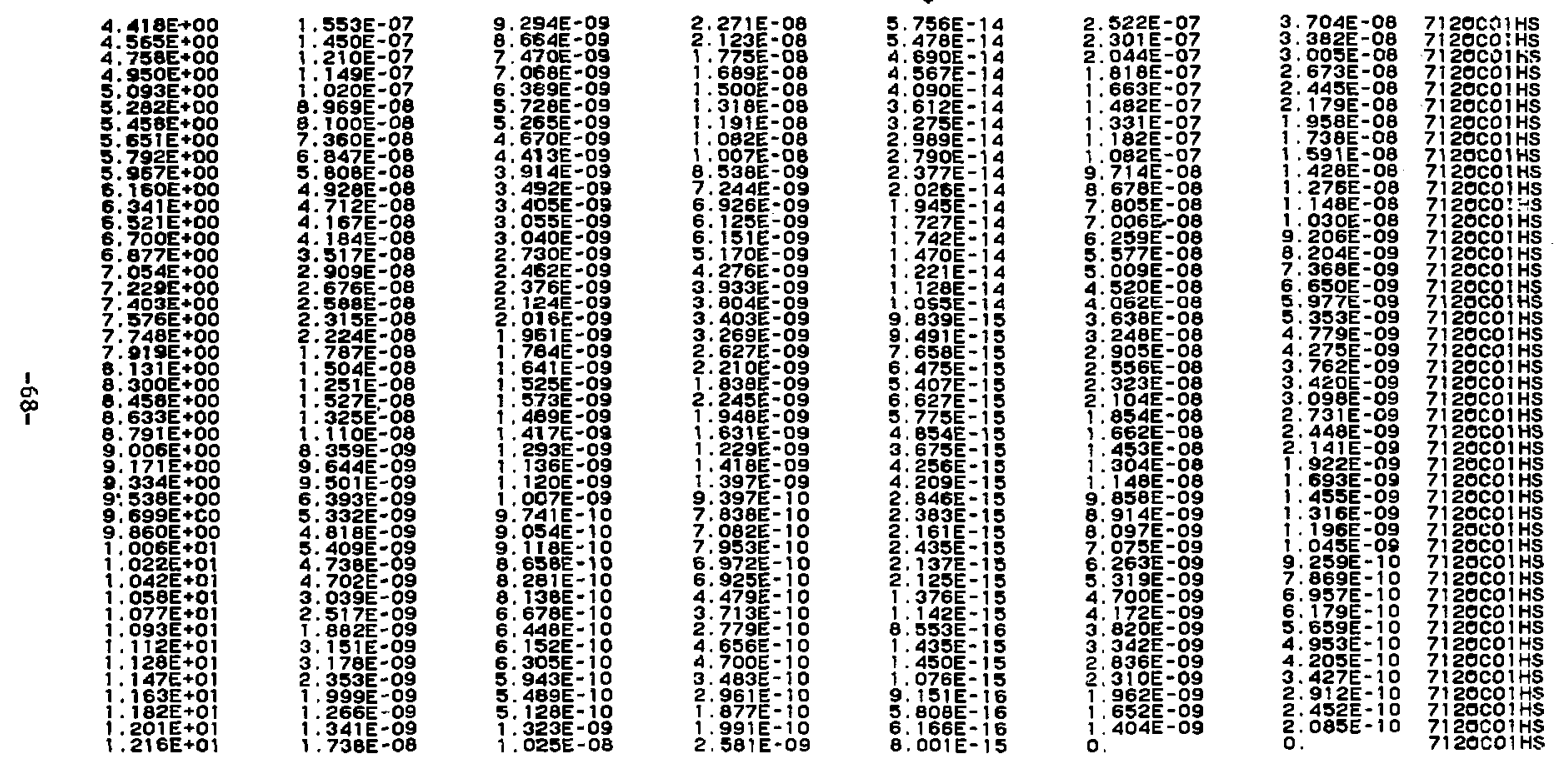


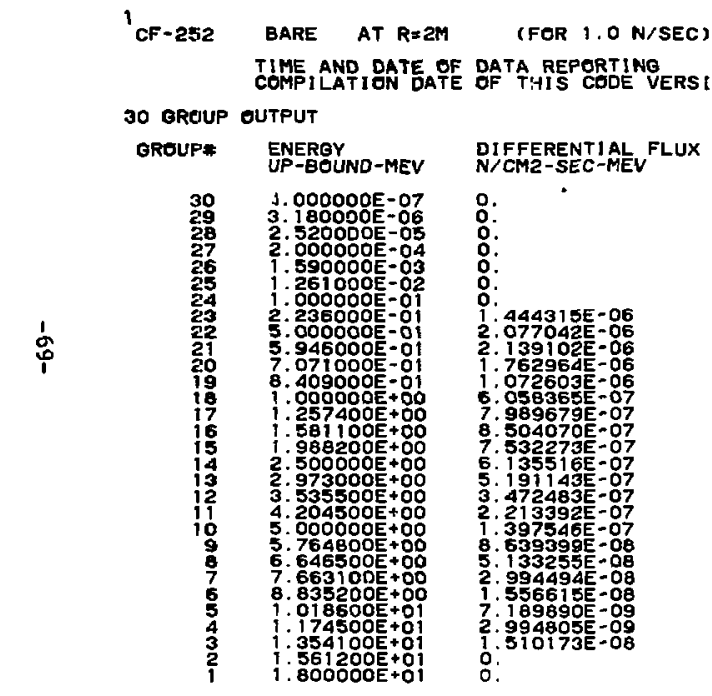

(FER 1.0 N/SEC)

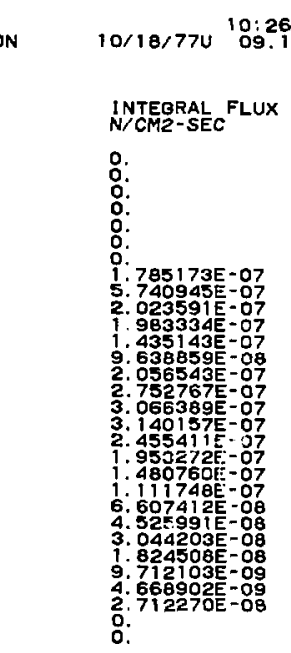

FLUX PER UNIT LETHAROY

o.

o.

o.

2. $336901 E-07$

. $170731 E-06$

$1.147425 E-06$

. $301950 E-07$

O1705-2 -07

.206940E-06

. 344247E-06

$1.376871 E-06$

. 130033 E-06

$8.565829 \mathrm{E}-07$

6. $431855 E-07$

3. $185519 E-07$

2. $142501 \mathrm{E}^{-07}$

1. 284075 E -07

$3.283954 E-08$

1.9093IIE-O7

$\stackrel{\circ}{\circ}$ 

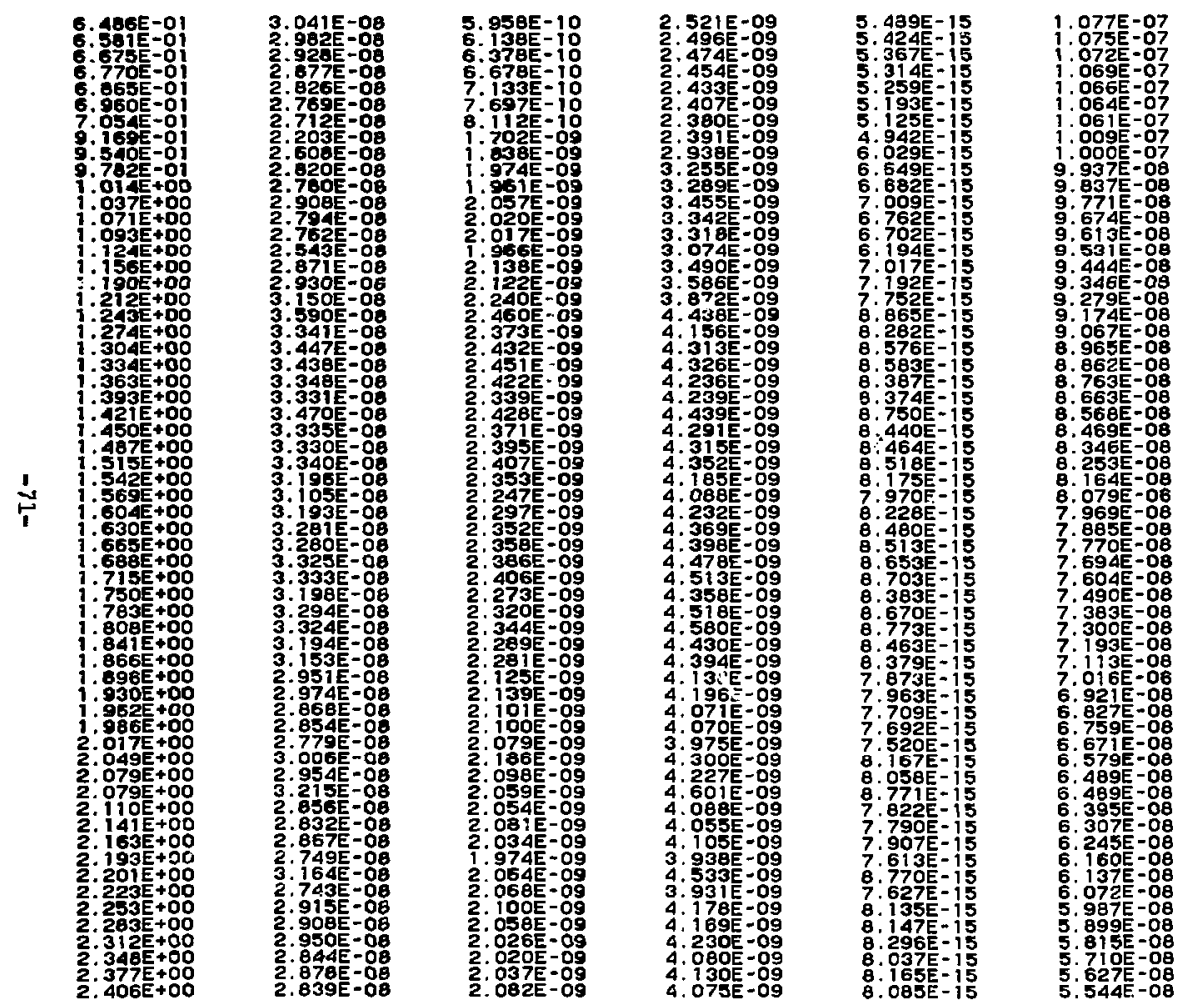

\begin{tabular}{|c|c|}
\hline$=0$ & 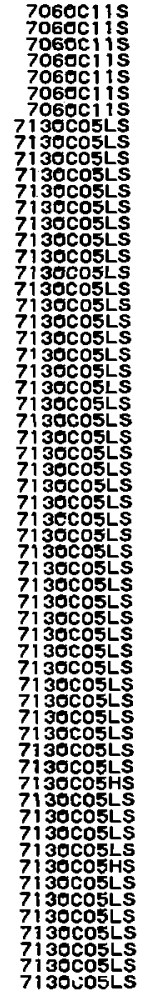 \\
\hline
\end{tabular}



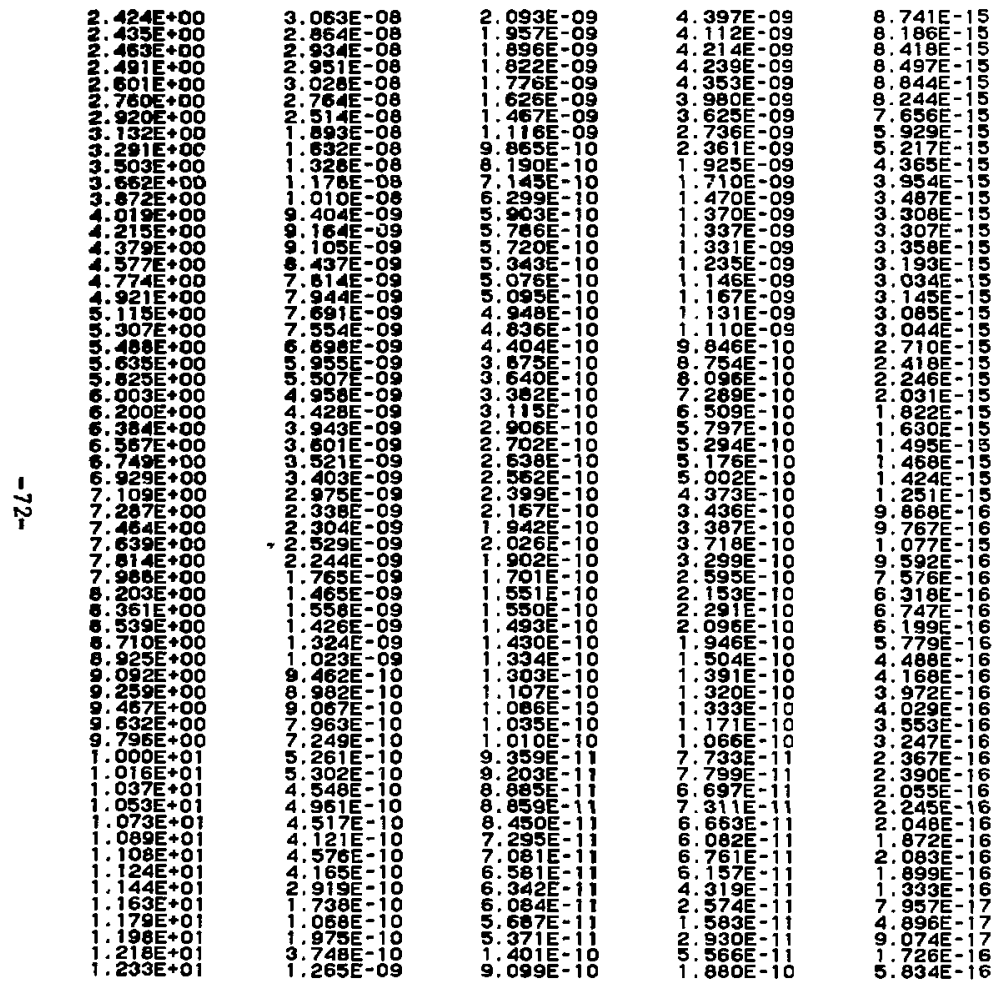

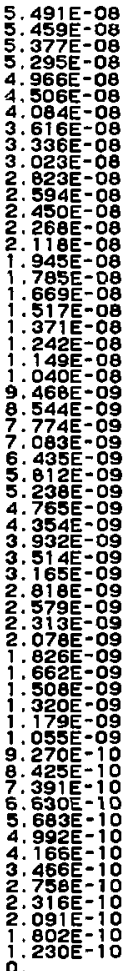

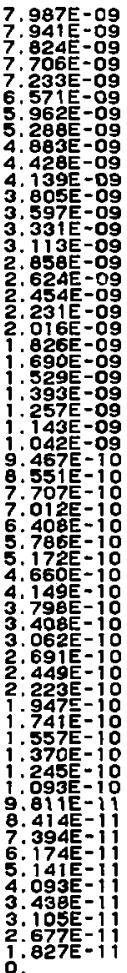

$7130 \mathrm{coshs}$ 7130cosLS $7130 \mathrm{cos} \mathrm{LS}$ $7130 \mathrm{cos} H$ $713 \mathrm{gcos} H \mathrm{~s}$ $7130 \mathrm{cos} H \mathrm{~s}$ $7130 \mathrm{cos} H \mathrm{~s}$ $7130 \mathrm{cos} H \mathrm{~S}$ $7130 \mathrm{cosh}$ $7130 \mathrm{cos} H \mathrm{~S}$ $7130 \mathrm{cos} H \mathrm{~s}$ $7130 \mathrm{coshs}$ $7130 \mathrm{coshs}$ $7130 \mathrm{coshs}$ $7130 \mathrm{cosh}$ 713000545 $3130 \mathrm{cos} H \mathrm{HS}$ $7130 \mathrm{cos} H$ $7130005 H$ $7130 \mathrm{cos} H \mathrm{HS}$ $7130 \mathrm{cos} H \mathrm{~s}$ $7130 \mathrm{cos} \mathrm{HS}$ $7130 \mathrm{cos} A \mathrm{~s}$ $7130 \mathrm{cos} H$ $7130 \mathrm{cos} \mathrm{HS}$ $7130 \mathrm{coshs}$ $7130 \mathrm{cos} H \mathrm{H}$ $7130 \mathrm{cos} H \mathrm{~S}$ $7130 \mathrm{cos} H \mathrm{~S}$ $713 \mathrm{gcOSHS}$ $7130 \mathrm{cos} H \mathrm{~S}$ $7130 \mathrm{cos} \mathrm{HS}$ $7130 \mathrm{coshs}$ $7130 \mathrm{cos} H \mathrm{~S}$ $7130 \mathrm{cos}$ s $7130 \mathrm{cos} H \mathrm{H}$ $7130 \mathrm{cos} H \mathrm{~S}$ $7130 \mathrm{cosH}$ 713005 $7130 \mathrm{cos} H$ $7130 \mathrm{cos}$ S 7 30costs $7130 \mathrm{cos}$ S 


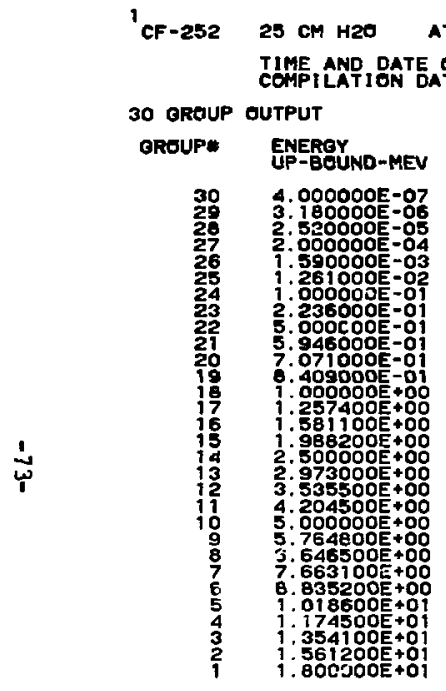

(FOR $1.0 \mathrm{~N} / \mathrm{SEC}$ )

GATE OFTA RIEPORTINO CODE VERSION

DIFFERENTI AL FLUX

$\therefore$.

.

:

:

4. $535209 \mathrm{~g}-08$

4. $465368=08$

3. $046967 E-08$

2. $454223 E-0 B$

2. $922120 \mathrm{~T}-0 \mathrm{~B}$

3., 166617 - 08

2. $799004 \mathrm{E}-\mathrm{OB}$

1. $732578 \mathrm{E}-08$

. $049425=08$

6.968494 E -99

$4.465524 E-09$

1 .681591E-OS

B. $103622 E-10$

1. $014119 \mathrm{E}-09$

o.

$10 / 10 / 770$ 10:28:36U

1 NTEGRAL FLUX
N/CM2-SEc

0.

o.

:

.

5. 605519E-09

$1.234228 \mathrm{E}-09$

3.526927E-09

3. $904668 E-09$

7.521551 -og

$1.081917 \mathrm{~F}=08$

$1.289130 E-08$

1. $313996 \mathrm{E}=08$

7 . 020651E-09

$6.713477 \mathrm{E}-09$

$5.329505 E-09$

2.

. 92734 -09

1.947637 -

$6.145435 E-10$

o:
FLUX PER UNI T LETHARGY

$\circ$.

o.

:

o.

7: $3379695-99$ 2. $040473 \mathrm{E}-08$

2. 258989E-08

3. $298203 \mathrm{E}-08$

4. $7436211 \mathrm{E}-08$

5. 651303 E

$7.602008 \mathrm{E}-08$

5.638242E-08

$4.061273 \mathrm{E}-08$

.

2. $771148 \mathrm{E}-\mathrm{os}$

2 . 060235

$1.370671 \mathrm{E}-\mathrm{O}$

7.707031E-09

4. $322499 E-09$

o. 
CF-252 5 CM D2O AT R=2M (FER $1.0 \mathrm{~N} / \mathrm{SEC}$ )

TIME AND DATE OF OATA REPORTING DEL-PHI ENEROY (NEVT/CME-SEC-MEV)

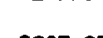

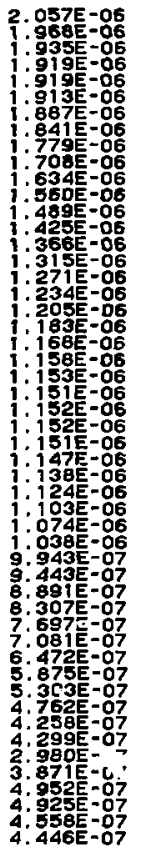

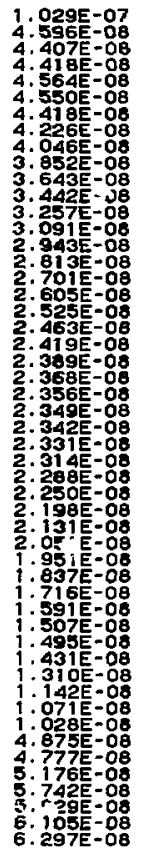

Dese (MR/HR-MEV)

5. 087E-08

5. $223 \mathrm{E}-08$

. $413 \mathrm{~B}-08$

5. $8961 \mathrm{E}-08$

6. $073 E-D 8$

$6.248 E-08$

$6.265 E-08$

6. $262 \mathrm{E}-0 \mathrm{~B}$

, $249=-08$

6. $228 E-08$

. $240 E=08$

$6.338=-08$

6. $429 \mathrm{E}-08$

$6.558 \mathrm{E}-0 \mathrm{~B}$

6. $726 \mathrm{E}-0 \mathrm{~B}$

6. $935 E-08$

7. $165 \mathrm{E}=08$

$7: 798 E-08$

. $152 E-08$

. $319 E-08$

. $434 E-08$

$8.580=08$

8. 594E-08

8. $450=-08$

$8.281=08$

8. $048 E-08$

$7.754 E-08$

$7.4065-08$

6. $597 \mathrm{E}-08$

5. $156 E=08$

5. 255E-08

4. $812 E-08$

3.976 -08

4. $604 E-08$

3. $2725=8$

4. $358 E-08$

5. 7811 - 08

5. $317 \mathrm{E}-\mathrm{OB}$
(ERG/GM-SEC-MEV) (NEUT/CML-SEC) (HT-DOSE

FILE-ID

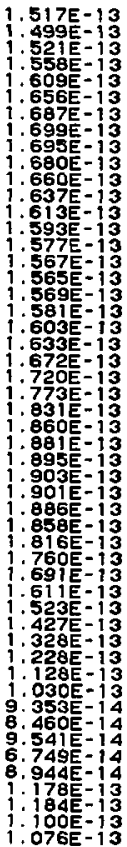

\begin{tabular}{|c|c|c|}
\hline 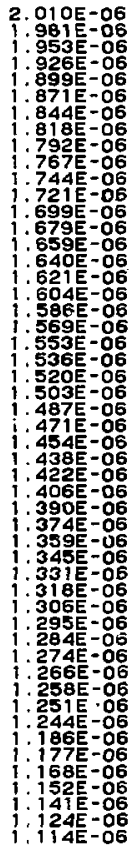 & 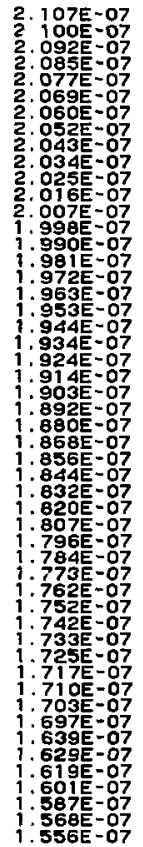 & 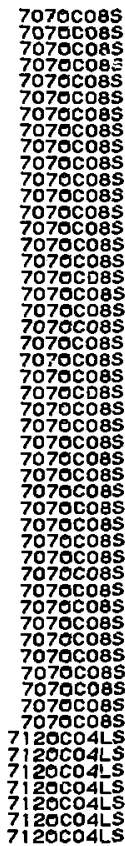 \\
\hline
\end{tabular}



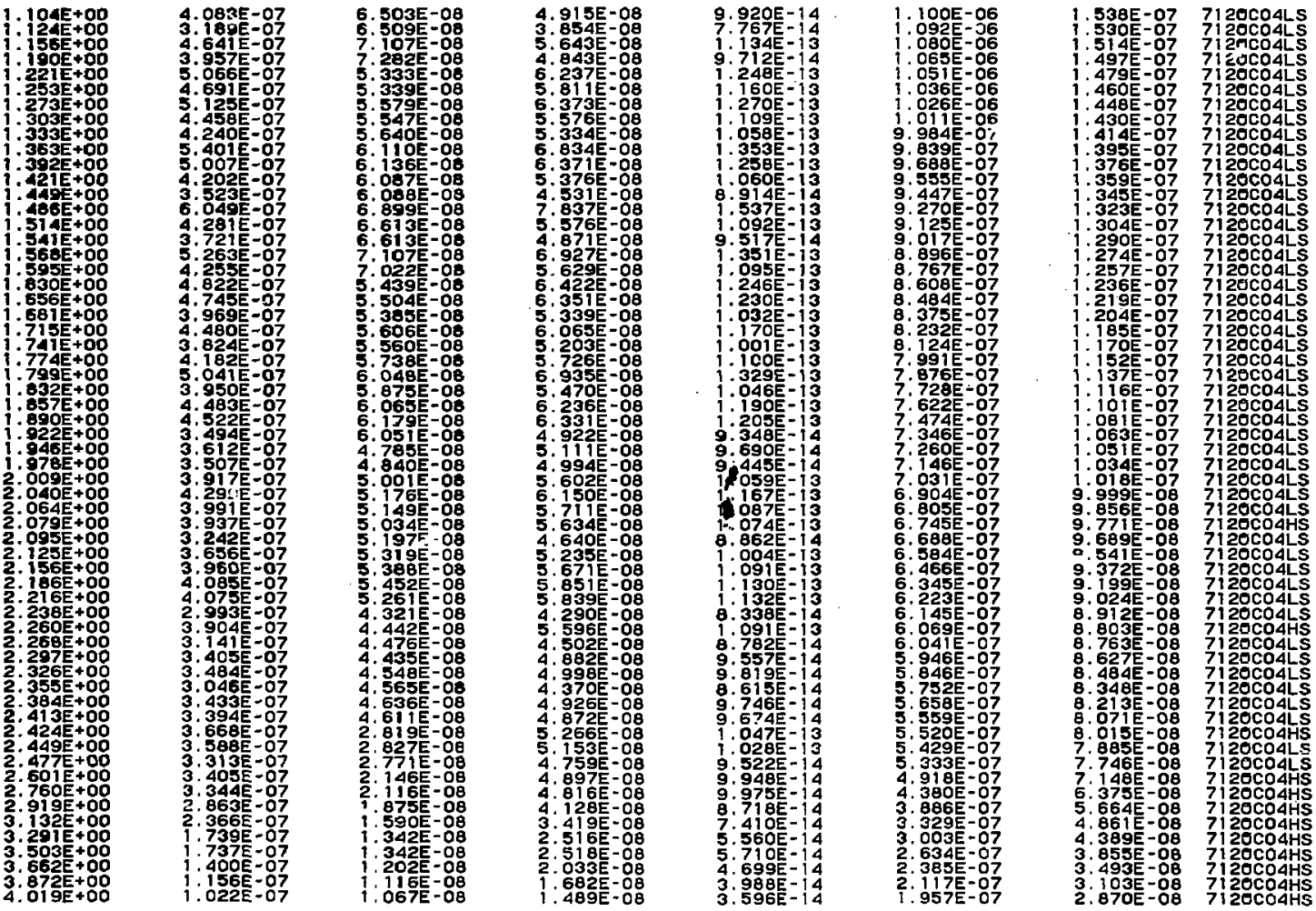


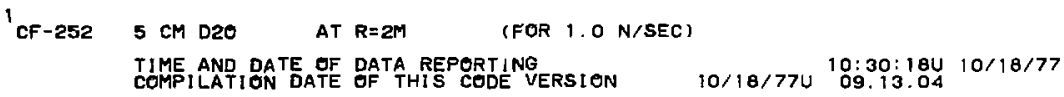

30 BREUP OUTPUT

\begin{tabular}{|c|c|c|}
\hline GROUF= & $\begin{array}{l}\text { ENERGY } \\
\text { UP-BOUND-MEV }\end{array}$ & $\begin{array}{l}\text { DIFFERENT IAL } \\
\text { N/CM2-SEC-ME }\end{array}$ \\
\hline $\begin{array}{l}30 \\
29 \\
28 \\
27 \\
26 \\
25 \\
24 \\
23 \\
22 \\
21 \\
20 \\
19 \\
16 \\
17 \\
16 \\
15 \\
14 \\
13 \\
12 \\
11 \\
10 \\
9 \\
8 \\
7 \\
6 \\
5 \\
4 \\
2 \\
1\end{array}$ & 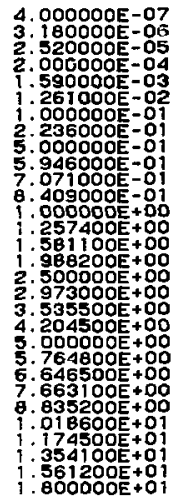 & 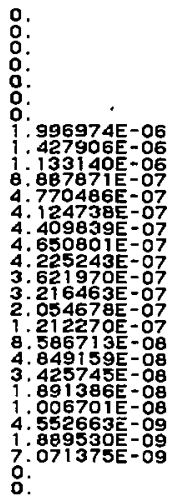 \\
\hline
\end{tabular}

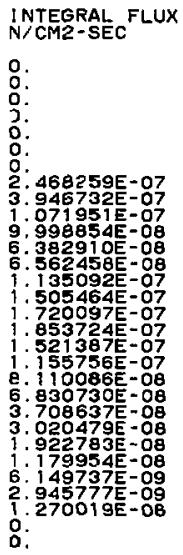

FLUK PER UNIT LETHAROY

o.

o:

:.

3. $231103 E-07$

$5.166164 E-07$

6.ㅜㄴ.201677 -

$3.692356 \mathrm{E}-07$

$4.977305 E-07$

$600649 \mathrm{E}-07$

7. 540500

$8.801850 \mathrm{~K}-07$

6. $686436 \mathrm{E}-07$

$4.691485 E-07$

$3.951820 \mathrm{E}-07$

2.610012E.07

2. $125897 \mathrm{-O}$

$1.353249 \mathrm{E}-07$

8. $304228-08$

4.

. $940340 \mathrm{E}-06$

o. 
CF-252 $10 \mathrm{cM}$ D20 AT R=2M (FOR $1.0 \mathrm{~N} / \mathrm{SEC}$ )

TIME AND OATE OF OATA REPQRTING

10:32:05U 10/18/77

ENEROY (NEUT/CM2-SEC-MEV)

DEL-PHI

(MR/HR-MEV)

1. 664E-01

1. 854 垈-

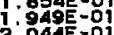

2. 139 E-O1

234E-aj

2. 4 年 $=01$

2. $319 \mathrm{OE}-01$

2. $709 \mathrm{E}-01$

2.7094-0

g.

2. 994 -

3. 184 E $=1$

3. 280 -

3. $375 \mathrm{~T}-\not$
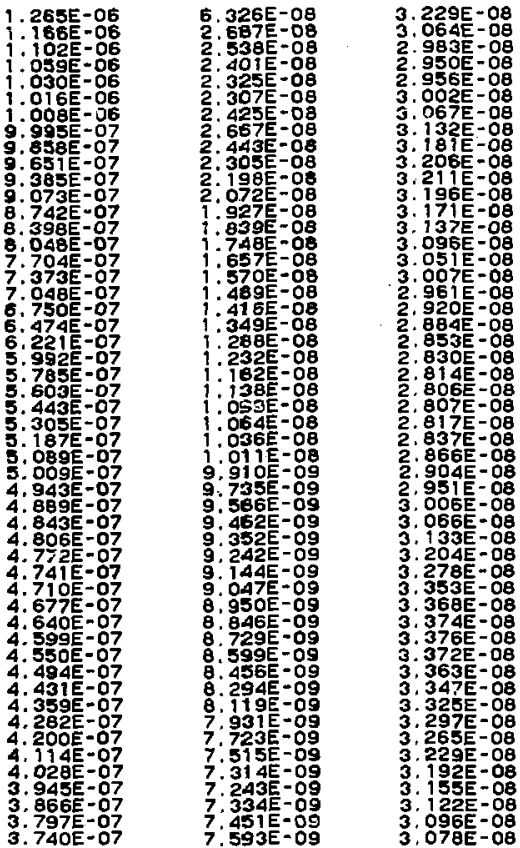

KERMA

( INTEGRAL

9. $548 E-14$

. $692 \mathrm{z}-14$

. 520E-ia

. $469 \mathrm{~g}-14$

8. $532 E-14$

8. 763 E - 14

9.83 IE- I4

8.831E- 14

8. 666E-14

\%.53OE-14

8. i $66=14$

. $015 E-14$

$7.837 E-14$

$7.4905-14$

$7.339 E-14$

7. $205 E-14$

7. $089 \mathrm{~g}=14$

6. $919 E-14$

6.86 - 14

$6.831 \mathrm{E}=14$

6. 831 IE- 14

6. 884 - 14

6. $940 \mathrm{E}-14$

7. $013 E-14$

7. $0965-14$

7. 299 这 4

7. 410 O -14

$7.5205-14$

7. 534E- 14

7. 525E- 14

7. $503 E-14$

$7,468 \mathrm{E}-14$

$7.419 E-14$

7. $2825-14$

7. $04 \mathrm{E}-14$

7. ôिE-

6.918E- 14

6. 832E- 14

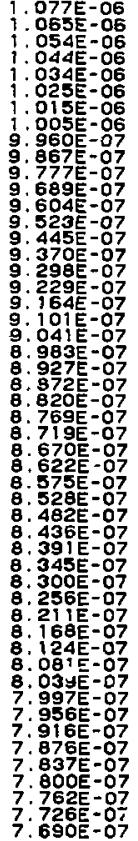

(ARTHR)

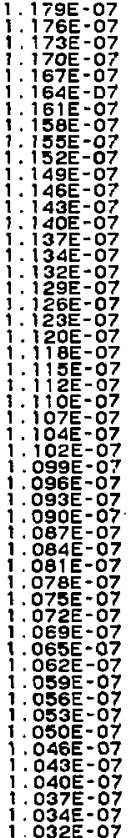

$100 \mathrm{cozs}$

$7100 c 02 s$

$7100 \mathrm{cos}$

$7100 \mathrm{coss}$

$7100 \mathrm{coss}$

7100 cons

$7100 \mathrm{cozs}$

7 oocozs

710 cos

$7100 \mathrm{cos}$

$7100 c 025$

$7700 \mathrm{cozs}$

$7100 \mathrm{co} 2 \mathrm{~s}$

$7100=025$

7 i ogcozs

$7100 \mathrm{cozs}$

$7100 \mathrm{co} 2 \mathrm{~s}$

7 1 goco2s

$7100 \mathrm{cozs}$

$7100 \mathrm{cozs}$

$7100 \mathrm{cos}$

$7100 \mathrm{co} 2 \mathrm{~s}$

$7100 \mathrm{coes}$

$7100 \mathrm{cozs}$

$7100 \mathrm{coz}$

$7100 \mathrm{cos}$

7 ijoco2s

$71, \mathrm{co} 2 \mathrm{~s}$

$7100 \mathrm{co2s}$

7 ouco2s

$7100 c 02 s$

71000025

$7100 \mathrm{cos}$

$7100 \mathrm{cozs}$

710 cos

710 cons

$7100 \mathrm{gens}$

71 a.co2s

$7100 \mathrm{co2s}$

7100 cons

$7100 \mathrm{cc} 2 \mathrm{~s}$

$7100 \mathrm{co} 2 \mathrm{~s}$

7100 cons 


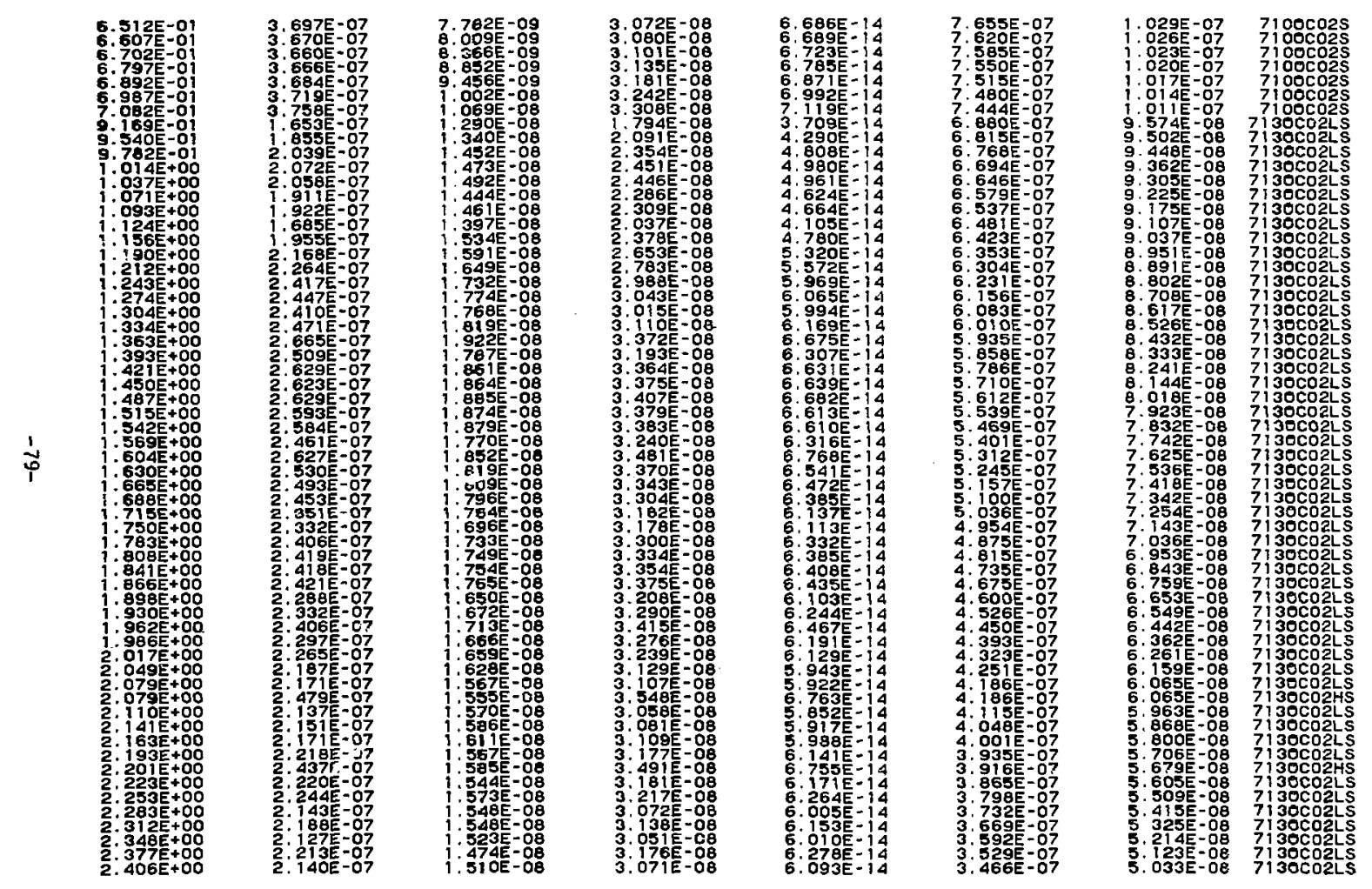



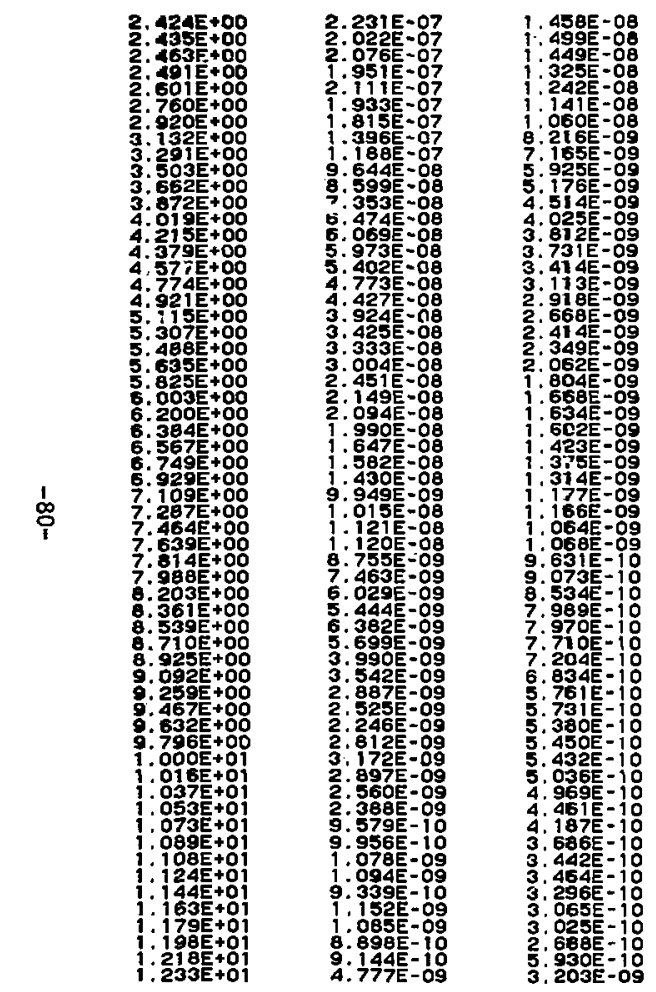

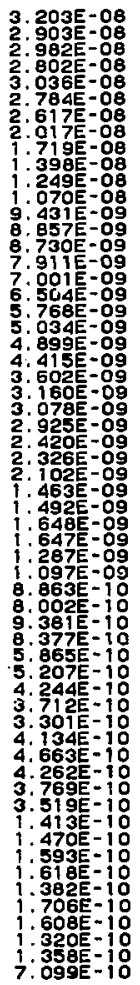
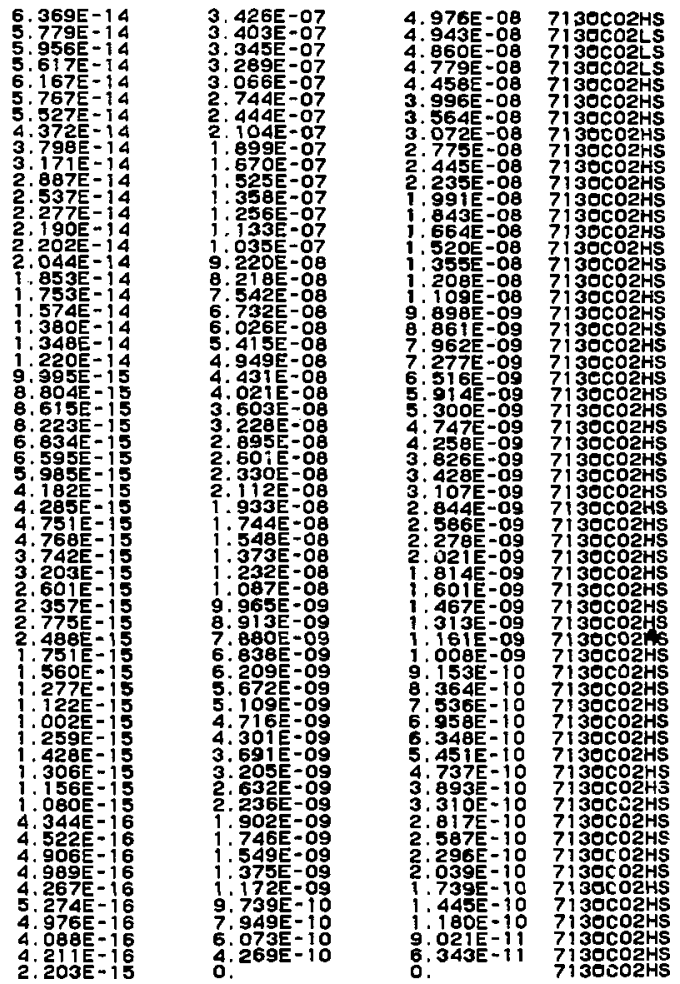

'CF-252 $10 \mathrm{cM}$ D20 AT R=2M (FOR $1.0 \mathrm{~N} / \mathrm{SEC}$ )

TIME AND DATE OF DATA REPORTING

$10 / 18 / 770$ 10:32:05U

30 GROUP OUTPUT

\begin{tabular}{|c|c|c|c|}
\hline GROUP* & $\begin{array}{l}\text { ENEROY } \\
\text { UP-BOUND-MEV }\end{array}$ & $\begin{array}{l}\text { DIFFERENTIAL FLUX } \\
\text { N/CM2-SEC-MEV }\end{array}$ & $\begin{array}{l}\text { INTEORAL FLUX } \\
\text { N/CM2-SEC }\end{array}$ \\
\hline $\begin{array}{l}30 \\
29 \\
28 \\
27 \\
25 \\
25 \\
24 \\
23 \\
22 \\
21 \\
20 \\
19 \\
10 \\
17 \\
16 \\
15 \\
14 \\
13 \\
11 \\
10 \\
9 \\
8 \\
7 \\
6 \\
5 \\
4 \\
3 \\
2 \\
1\end{array}$ & 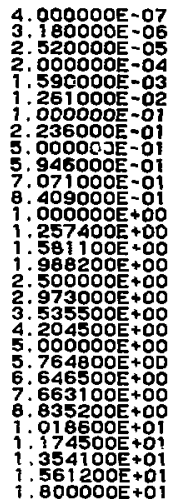 & 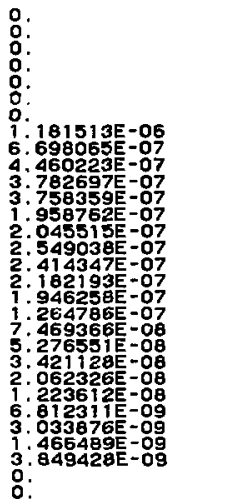 & 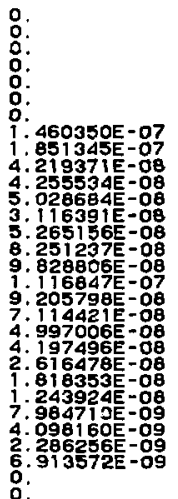 \\
\hline
\end{tabular}

FLUX PER UNI T LETHARGY

o.

o.

o.

I. $911688 E-07$

2,441080 - -07

2. $461968 \mathrm{E}-07$

.

. 802943

.30773E-07

300764 - 97

$897050 \mathrm{E}-07$

. 325934E-O7

$4.15930 E-97$

428401 E-o

. $41388 \mathrm{E}-07$

$279608 \mathrm{E}-07$

. 6146

1 $539 \mathrm{E}-O$

,60日07日E-08

o. 
1

CF-252 $15 \mathrm{cM}$ D2O AT R:2M (FOR $1.0 \mathrm{~N} / \mathrm{SEC}$ )

TIME AND DATE OF DATA REPORTING

$$
\text { 10/18/770 10:33:210 10/18/77 }
$$

ENERGY PHI DEL-PH:

$15625-$

6. $037 \mathrm{E}^{-07}$

704E-OI

986 =01

2. $273 \mathrm{E}-\mathrm{g}$

2.273

2.699-

2.841 -

3. $125 E-a 1$

$3.267 \mathrm{~F}-91$

.55

$693 E-01$

3.835E-01

119 -o1

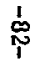

(MR/HR-MEV)

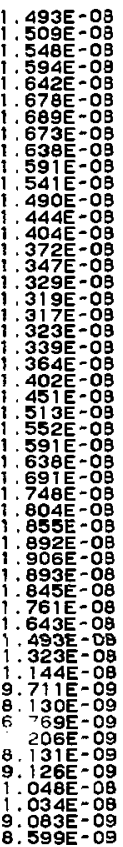

(ERG/GM-SEC-MEV)

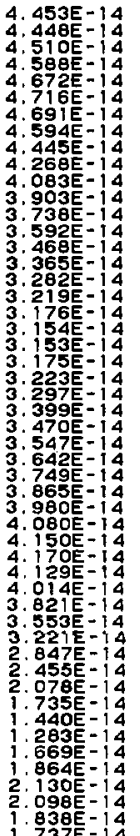

(NNEEGRALL-SEC)

5. $653 \mathrm{E}-07$

5. $486 \mathrm{E}-07$

5. $405 \mathrm{E}-07$

5. $247 \mathrm{E}-07$

. $171 \mathrm{E}-07$

5. $098 \mathrm{E}-\mathrm{O} 7$

4. $966 \mathrm{E}-07$

4. $907 \mathrm{Z}-07$

4. $852 E-07$

$4.801 E-07$

$4.754 E-07$

668 - 07

. $529 \mathrm{E}-07$

552 -07

.

$4.491 \mathrm{E}-07$

$4.428 \mathrm{E}-07$

4. $39 \mathrm{EE}-\mathrm{O} 7$

4. $337 \mathrm{E}=07$

4. 306E -07

$4.273 E-07$

. $211 \mathrm{E}-07$

4. $179 \mathrm{ge}-\mathrm{O}$

4. $112 E-O 7$

4. $078 \mathrm{BE}-07$

4. 013 उE -07

3. $982 \mathrm{E}-07$

3. 954 - -07

3. 920 - 0 ?

3. $905 \mathrm{E}-\mathrm{O}$ ?

$3.869 \mathrm{E}-07$

3. $855 \mathrm{E}-07$

3. 844 E- 07

.722E-

. 7OUE-O?

3. $674 \mathrm{E}-07$

$3.626 E=07$
INT-DOSE FILE-1D

6. 265E-08 7070604S

$6.243 E-00 \quad 70706045$

6. $199 \mathrm{E}-0 \mathrm{~B}$

6.176E-08 70700045

6. $153 \mathrm{E}-08$ 7070504S

6. $129 \mathrm{E}-08$ 7070c04S

6. $105 E-08$ 7070C04S

6.058 - 08 7 707045

$6.036 \mathrm{E}-08 \quad 7070 \mathrm{CO} 4 \mathrm{~s}$

$6.015 E-08$

5.994E-08 7070c04S

$5.974 E-08 \quad 7070 \mathrm{CO} 45$

$5.935 E-08 \quad 7070 \mathrm{COC4S}$

$7070 \mathrm{cosS}$

$5.878 \mathrm{~g}-08 \mathrm{O} 7070 \mathrm{CO} 4 \mathrm{~S}$

.859E-08 70700045

. $7070 \mathrm{COS}$

: 201 -O 707045

1.781E-08 $7070 \mathrm{CO} 4 \mathrm{~S}$

.760E-08 $7070 \mathrm{CO} 4 \mathrm{~S}$

3.738E-08 $7070 \mathrm{CO} 4 \mathrm{~S}$

.716E 70700045

.670E-08 70700045

$7070 \mathrm{coss}$

$\begin{array}{ll}5.620 \mathrm{E}-08 & 7070 \mathrm{CO4S} \\ 5.594 \mathrm{E}-08 & 7070 \mathrm{CO} 045\end{array}$

.567E-08 7070C04S

$513 \mathrm{E}-\mathrm{OB} \quad 7070 \mathrm{COS}$

587 - 08 7070COS

5. $461 \mathrm{E}-08$ 7070C045

. $437 \mathrm{E}-08 \quad 7070 \mathrm{CO} 4 \mathrm{~S}$

$5.415 E-08 \quad 7070 \mathrm{CO} 4 \mathrm{~S}$

$5.395 \mathrm{E}-08 \quad 7070 \mathrm{CO} 4 \mathrm{~S}$

$5.377 E-08$ 7070C04S

5.362E-08 7070C04S

$5.349 E-08 \quad 70706045$

. 339E 7070045

5. $242 E-08 \quad 7130 C 04 L S$ 5 . 5. $159 E-08$ 7130COALS 5.1005

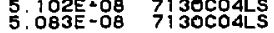




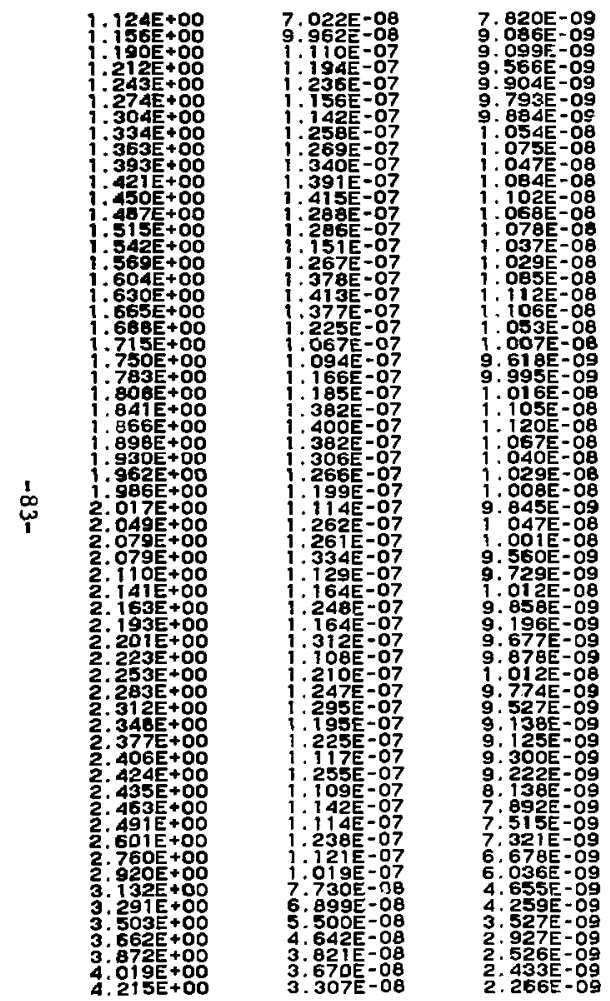

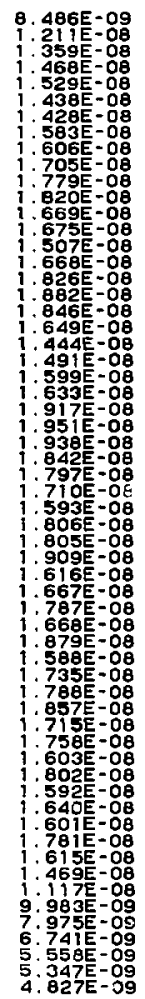

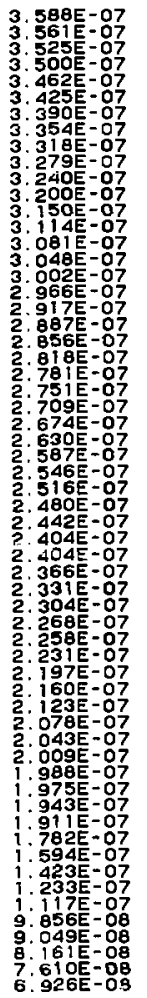

$5.056 \mathrm{E}-08$

$5.023 \mathrm{E}-08$ $4.979 E-0$ $4.902 E-08$ 4.813E-O $4.768 E-08$ $4.722 \mathrm{E}-08$ $4.672 \mathrm{E}-08$ $4.571 \mathrm{E}-\mathrm{O}$ 4. $506 \mathrm{E}-\mathrm{O}$ $4.417 \mathrm{~B}$ $4.374 \mathrm{E}-0$ $4.313 E-08$ 4 . $199 \mathrm{E}-08$ 4. $1595-08$ $4.17 \mathrm{~F}=08$ $4.015=-08$ $3.974 \mathrm{E}-08$ 3. $916 \mathrm{E}-08$ 3. $8055-08$ 3. $745 \mathrm{E}-08$ $3.644 \mathrm{E}-08$ 3. $593=08$ 3. $539 \mathrm{E}^{-08}$ 3. $485 E-08$ $3.430=-08$ 3. $379 \mathrm{E}-\mathrm{O}$ 3. $341 \mathrm{E}-0 \mathrm{0}$ $289 E-08$ . $237 \mathrm{E}-0 \mathrm{O}$ 3. 187 E -08 3. 082 E -08 3. $017 \overline{7}-08$ 2. $9671-08$ 2. 887 - 08 2. $869 \mathrm{E}-0 \mathrm{\theta}$ 2. $778 \mathrm{E}-00$ 2. $592 \mathrm{E}-0$ . $322 \mathrm{E}-\mathrm{O}$ 1.01 $633 E-08$ $4435-0$

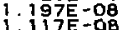
1. $017 \overline{71}-08$

$7130004 \mathrm{LS}$ $7130 \mathrm{CO} 4 \mathrm{LS}$ $7130 \mathrm{co} 4 \mathrm{~L}$ $7130 \mathrm{coALS}$ $7130 \mathrm{COLLS}$ $7130 \mathrm{CO} 4 \mathrm{LS}$ $7130 \mathrm{COALS}$ $7130 \mathrm{co4} 4 \mathrm{~s}$ $7130 \mathrm{CO} 4 \mathrm{LS}$ $7130 \mathrm{cosis}$ $7130 \mathrm{CO} 4 \mathrm{~L}$ 730 7130 $7130 \mathrm{co} 4 \mathrm{~s}$ $7130 \mathrm{co} 4 \mathrm{LS}$ $7130 \mathrm{co} 4 \mathrm{LS}$ $7130 \mathrm{co} 4 \mathrm{LS}$ $7130 \mathrm{CO} 4 \mathrm{LS}$ $7130 \mathrm{COLLS}$ $7130 \mathrm{CO} 4 \mathrm{LS}$ $7130 \mathrm{couLS}$ $7130 \mathrm{coLLS}$ $7130 \mathrm{CO} L \mathrm{LS}$ $7130 \mathrm{CO} 4 \mathrm{LS}$ $7130 \mathrm{COLLS}$ $7130 \mathrm{couLS}$ $7130 \mathrm{cos} L \mathrm{~s}$ $7130 \mathrm{CO} 4 \mathrm{LS}$ $7130 \mathrm{co4} 4 \mathrm{~S}$ $7130 \mathrm{COAHS}$ $7130 \mathrm{co4} 4 \mathrm{~L}$ $7130 \mathrm{co} 4 \mathrm{LS}$ $7130 \mathrm{CO} 4 \mathrm{LS}$ $7130 \mathrm{co} 4 \mathrm{~L}$ $7130 \mathrm{CO} 4 \mathrm{HS}$ $7130 \mathrm{co} 4 \mathrm{LS}$ $7130 \mathrm{CO} 4 \mathrm{LS}$ 7130 co $4 L S$ $7130 \mathrm{COALS}$ $7130 \mathrm{co} 4 \mathrm{LS}$ $7130 \mathrm{CO} 4 \mathrm{HS}$ $7130004 \mathrm{~L}$ $7130 \mathrm{COLLS}$ 71 3aco $4 M S$ $7130 \mathrm{CO} 4 \mathrm{HS}$ $7130 \mathrm{CO} 4 \mathrm{HS}$ 7 3.c04HS $7130 \mathrm{co} 4 \mathrm{HS}$ $7130 \mathrm{co} 4 \mathrm{HS}$ $7130 \mathrm{CO} 4 \mathrm{HS}$ $7130 \mathrm{co} 4 \mathrm{HS}$ 

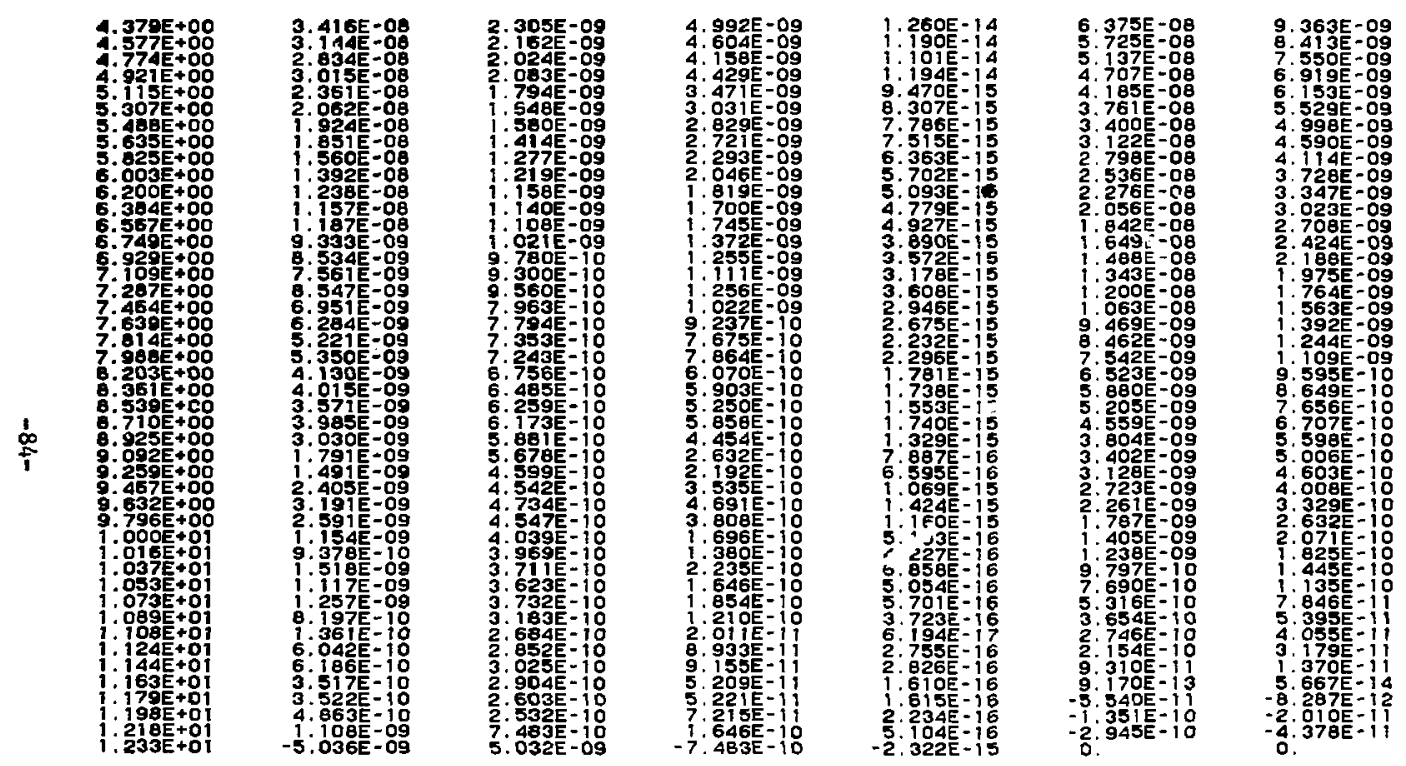

$7130004 \mathrm{HS}$ $7130 \mathrm{COAHS}$ $713 \mathrm{gcodHS}$ $7130 \mathrm{codHS}$ $7130 \mathrm{CO} 4 \mathrm{HS}$ 7 3oco 4 HS 7) $7130 \mathrm{cos}$ S $7130 \mathrm{co} 4 \mathrm{~S}$ $7130 \mathrm{cons}$ $7130 \mathrm{co4HS}$ 730c04HS 7) $30 \mathrm{CO} 4 \mathrm{HS}$ $7130 \mathrm{CO} 4 \mathrm{HS}$ $7130 \mathrm{CO} 4 \mathrm{HS}$ $7130 \mathrm{codHS}$ $7130 \mathrm{CO} 4 \mathrm{HS}$ $7130 \mathrm{CO} 4 \mathrm{HS}$ 7 i $30 \mathrm{CO} \mathrm{AHS}$ $7130 \mathrm{CO} 4 \mathrm{HS}$ $7130 \mathrm{CO} 4 \mathrm{HS}$ 7130cos 7ivocouts 71304 $730 \mathrm{H}$ 1 $7130 \mathrm{cos}$ $7130 \mathrm{CO} 4 \mathrm{HS}$ $7130 \mathrm{CO} 4 \mathrm{HS}$ $7130 \mathrm{cos}$ S $7130 \mathrm{CO} 4 \mathrm{HS}$ 71 3日co 4 H $7130 \mathrm{coshs}$ $7130 \mathrm{CO} \mathrm{HS}$ $7130 \mathrm{COHS}$ $7130 \mathrm{cos}$ $713004 \mathrm{H}$ $7130 \mathrm{co} 4 \mathrm{HS}$ $7130 \mathrm{cosHS}$ $7130 \mathrm{CO} 4 \mathrm{HS}$ $7130 \mathrm{CO} 4 \mathrm{HS}$ 

CF-2ER
15 CH DeO
AT $R=2 M$
(FOR 1.O N/SEC)

TIME ANO DATE OF OATA REPORTINO

30 erreup eutput

ENERGY

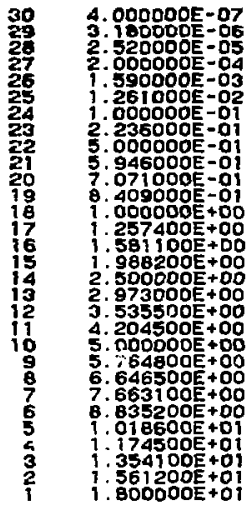

DIFFERENTIAL FLUX

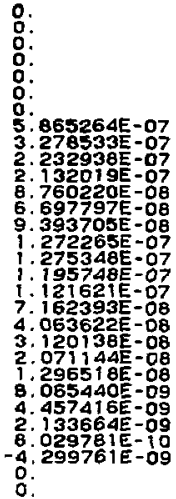

$10 / 18 / 770$ 10:33:214 $10 / 18 / 77$

INTEGRAL FLUX

o.

:

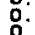

7.249466E-OB

$9.061866 \mathrm{E}-08$

2. $112360 \mathrm{E}-0 \mathrm{O}$

$1.172117 \mathrm{~T}-0 \mathrm{0}$

$1.065620 \mathrm{E}-08$

2.417940E-08

4. $118321 \mathrm{E}-08$

6. 199840-

. 17940 -

$4.028846 \mathrm{E}-08$

2.718563E-08

$2.482070 \mathrm{O}-\mathrm{OB}$

$1.584011 \mathrm{E}-\mathrm{OB}$

1. I $43140 E-08$

$5.199327 E-09$

$2.882153 \mathrm{E}-09$

$-7.7251843 \mathrm{E}-09$

0 .
FLUX PER UNIT LETHAROY

o.

o.

0 .

$\therefore 489997 \mathrm{E}-08$

$1.186173 \mathrm{E}-07$

$1.222087 E=07$

$1.387625 \mathrm{E}-07$
$.780410 \mathrm{E}-08$

. $164987 E-08$

$.060267 E-07$

. 80566ZE-07

$683 . ? 79 E-07$

0693 ? -07

330822E-07

32622E-07

$.435966 E-07$

$.045740 E-08$

$770651 E-0 A$

$676900 \mathrm{O}-0 \mathrm{~B}$

$029242 E-08$

. $805057 E-09$

○. 
1 CF

AT $R=2 M$

(FOR $1.0 \mathrm{~N} / \mathrm{SEC}$ )

TIME,AND DATE OF DATA REPORTING

10/18/770 10:59:41U 10/18/77

ENEREY (NEUT/CM2-SEC-MEV)

DEL-PH!

gOSE

$1.562 \mathrm{E}-01$

1. $711 \mathrm{E}-07$

B. $554 \mathrm{E}-09$

(MR/HR-MEV)

(ERG/GMR-SEC-MEV)

(INTEGRAL-SEC)

(NT-OOSE

FILE-ID

$4.232 \mathrm{E}-09$

$4.449 \mathrm{~K}-\mathrm{og}$

$4.592 E-09$

$4.705 E-09$

4.732 -09

4.650 - 99

4. $394 \mathrm{E}-\mathrm{O}$

$4.247 \mathrm{E}-09$

4. $101 \mathrm{E}-09$

$3.8395-09$

.732E-09

$3.580 \mathrm{E}-09$

3. $5425-09$

3.53E-09

3.548E-09

3.64 E -09

.

3. $950 \mathrm{0E}-09$

4. $051 \mathrm{E}=09$

4. 200 E -09

4.648 -09

4. $\rightarrow 36 \mathrm{EE}-09$

5. 521 -09

. $732 \mathrm{E}-09$

ᄀל

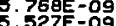

5. $109 \mathrm{E}-09$

$4.533 E-09$

3. $145 \mathrm{E}-09$

2. 478 -09

$1.9025-09$

. $127 \mathrm{E}-\mathrm{Og}$

4.644 E 09

5. $931 E-09$

4. $824 E-09$

5. $179 E-09$
$4.680 E-09$

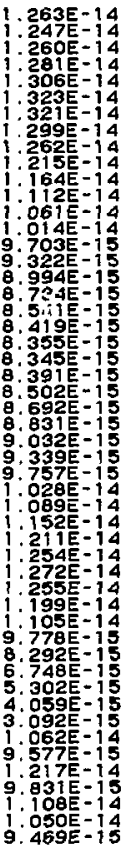

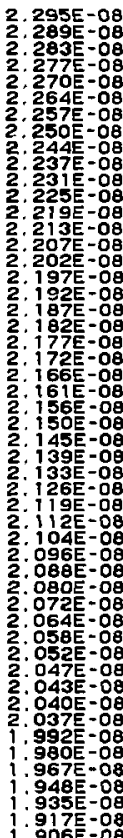

$7060 \mathrm{co7s}$

$7060 \mathrm{co7s}$

$706 \mathrm{cozs}$

$7060 \mathrm{co7}$

$7060 \mathrm{cops}$

$7060 \mathrm{co7s}$

$7060 \mathrm{co7s}$

$7060 \mathrm{co7s}$

$7060 \mathrm{co} 7 \mathrm{~s}$

$7050 \mathrm{co7s}$

$7060 \mathrm{co7s}$

$7060 \mathrm{co7s}$

$7060 \mathrm{co7s}$

$7060 \mathrm{co7s}$

$7060 \mathrm{co7s}$

7065

$7060 \mathrm{co} 5$

$700 \mathrm{cos}$

7060 c 75

70600075

$7060 \mathrm{co7s}$

$7050 \mathrm{co7s}$

$7060 \mathrm{co7s}$

$7060 \mathrm{co7s}$

$7060 \mathrm{co7s}$

$7060 \mathrm{co7s}$

$7060 \mathrm{co7s}$

7060 co7s

7060

7060

$7060 \mathrm{cos}$

706075

$7060 \mathrm{co} 5$

$7060 \mathrm{co} 5$

$7060 \mathrm{co} 7 \mathrm{~s}$

$7060 \mathrm{co7s}$

$7060 \mathrm{co7s}$

$7060 \mathrm{co7s}$

$7060 \mathrm{CO} \mathrm{TS}$

$7060 \mathrm{co} / \mathrm{s}$

$7120 c 05$

$7120 \mathrm{cos} L S$

$71206054 S$

$7120 \cos L S$

7120 cos

7120 cosLs 

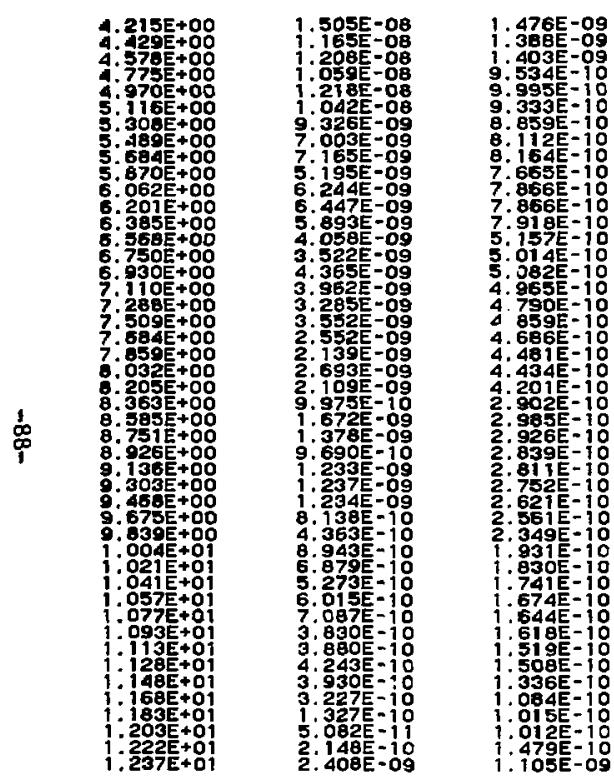

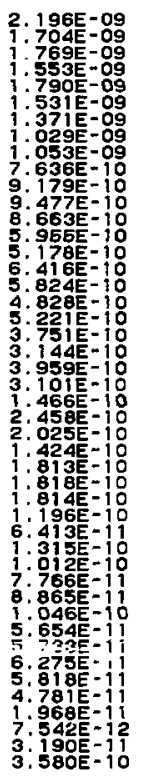

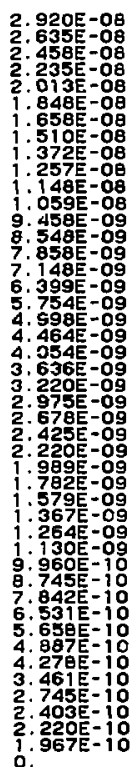

$7120 \mathrm{cos} H S$ $7120 \mathrm{cos} H \mathrm{~S}$ $7120 \mathrm{cos} H S$ $7120 \mathrm{cos} H \mathrm{~S}$ $7120 \mathrm{COSHS}$ $7120 \mathrm{cos} H \mathrm{~S}$ $7120 \mathrm{cos} H \mathrm{~S}$ $7120 c 05$ $7120 \mathrm{cos} H \mathrm{~S}$ $7120 \cos H S$ $7120 \mathrm{cos} 4 \mathrm{~S}$ $7120 \mathrm{cos} H \mathrm{~S}$ $7120 \mathrm{cos}$ H $7120 \mathrm{cos}$ $7120 \mathrm{COSHS}$ $7120 \mathrm{cos}$ $7120 \mathrm{cos} H$ $7120 \mathrm{COSHS}$ $7120 \mathrm{COSHS}$ $7120 \mathrm{COSHS}$ 7120 COSHS $7120 \mathrm{COSHS}$ $7120 \mathrm{cos} H \mathrm{~S}$ $7120 \mathrm{cos} H \mathrm{~S}$ $7120005 \mathrm{HS}$ 7120054 7 i $20 \mathrm{cos} H \mathrm{~S}$ $7120 \mathrm{coshS}$ $7120 \mathrm{cos} H \mathrm{~s}$ $7120 c 0545$ $7120 \mathrm{coshS}$ $7120 \mathrm{coshs}$ $7120 \mathrm{COSHS}$ $7120 \mathrm{coshs}$ 712005 712005 $7120 \mathrm{cos}+\mathrm{s}$ $7120 \mathrm{cos}$ $7120 \mathrm{coshs}$ 


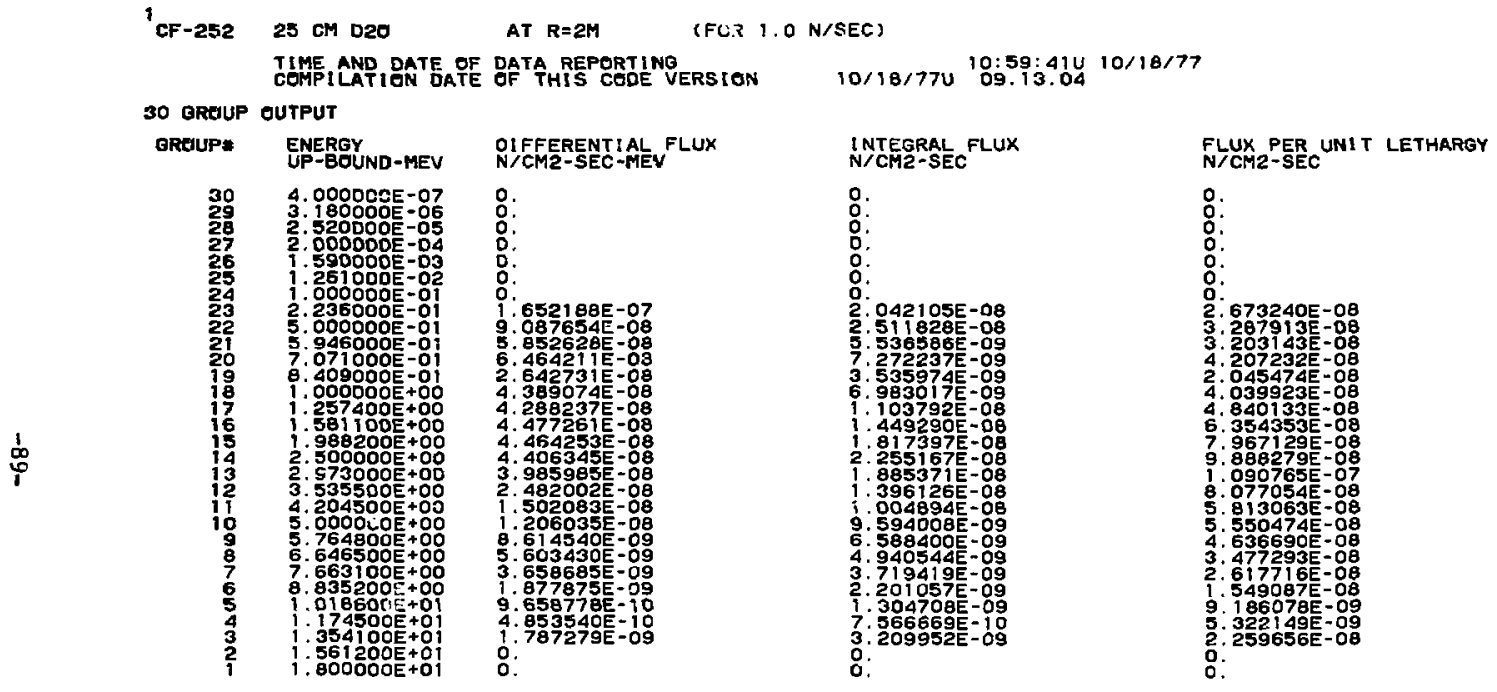



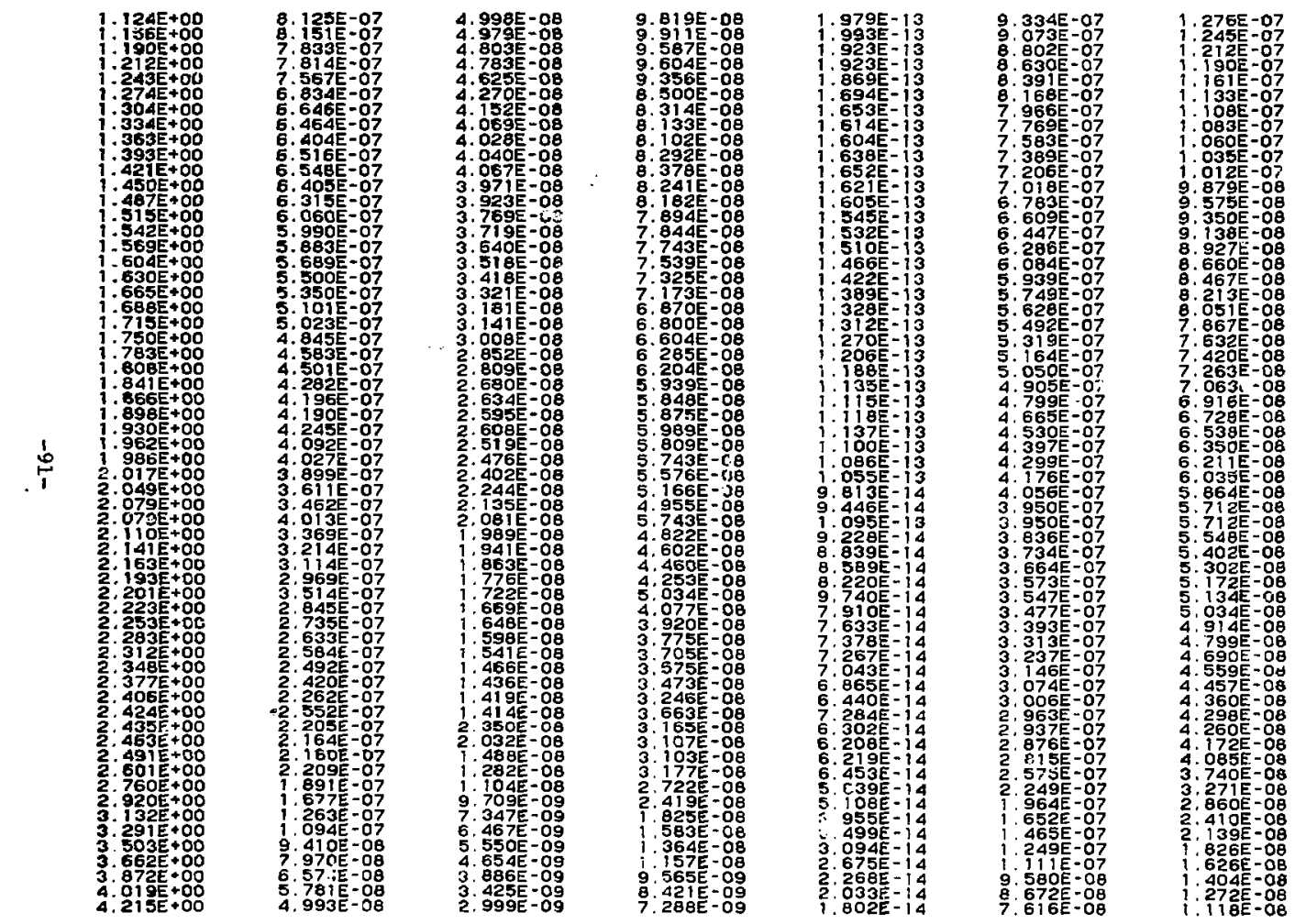

$7130 \mathrm{cos} s$ $7130 \mathrm{cos} L S$ $7130 \mathrm{CO} \mathrm{LS}$ $7130 \mathrm{CO} 3 \mathrm{LS}$ 713 co3LS 71 $7130 \mathrm{cos}$ LS 71 . $7130 \mathrm{co3LS}$ $7130 \mathrm{CO} L \mathrm{~L}$ $7130 \mathrm{COJLS}$ $7130 \mathrm{cojLS}$ $7130 \mathrm{cos} L \mathrm{~S}$ $7130 \mathrm{C03LS}$ 7130 ro3LS $7130 \mathrm{co3} \mathrm{LS}$ $7130 \mathrm{CO}$ LS 7 . $30 \mathrm{cos} \mathrm{LS}$ $7130 \mathrm{co3LS}$ $7130003 \mathrm{LS}$ $7130 \mathrm{CO} 3 \mathrm{LS}$ 71 cos $7130 \mathrm{cos}$ $7130 \mathrm{~s}$ $7130 \mathrm{cos} L$ $7130 \mathrm{co} 3 \mathrm{LS}$ $7130 \mathrm{CO} \mathrm{LS}$ $7130 \mathrm{cos} L \mathrm{~S}$ 7 i 30 co3Ls $7130 \mathrm{CO} H \mathrm{HS}$ $7130 \mathrm{CO} L \mathrm{LS}$ $7130 \mathrm{CO} L \mathrm{LS}$ $7130 \mathrm{CO} L \mathrm{LS}$ $7130 \mathrm{CO} L \mathrm{LS}$ $7130 \mathrm{cos} H \mathrm{~s}$ $713 . c 03 L$ $7130 \mathrm{cos}$ $7130 \mathrm{cos}$ $7130 \mathrm{cos} L \mathrm{~S}$ $7130 \mathrm{cos} L \mathrm{~s}$ $7130 \mathrm{CO} L \mathrm{LS}$ $7130 \mathrm{CO} 3 \mathrm{HS}$ $7130 \mathrm{Co} \mathrm{LS}$ $713 \mathrm{CCO} \mathrm{LS}$ $7 \mathrm{CO}$ Ls 7 socoshs $7130 \mathrm{cos} H \mathrm{~s}$ $7130 c 0345$ $7130 \mathrm{co}$ HS $7130 \mathrm{cos} \mathrm{HS}$ $7130 \mathrm{cos}^{3} \mathrm{HS}$ $7130 \mathrm{cos}$ s 71 agcoshs $7 \longdiv { 3 0 C O 3 H S }$ 

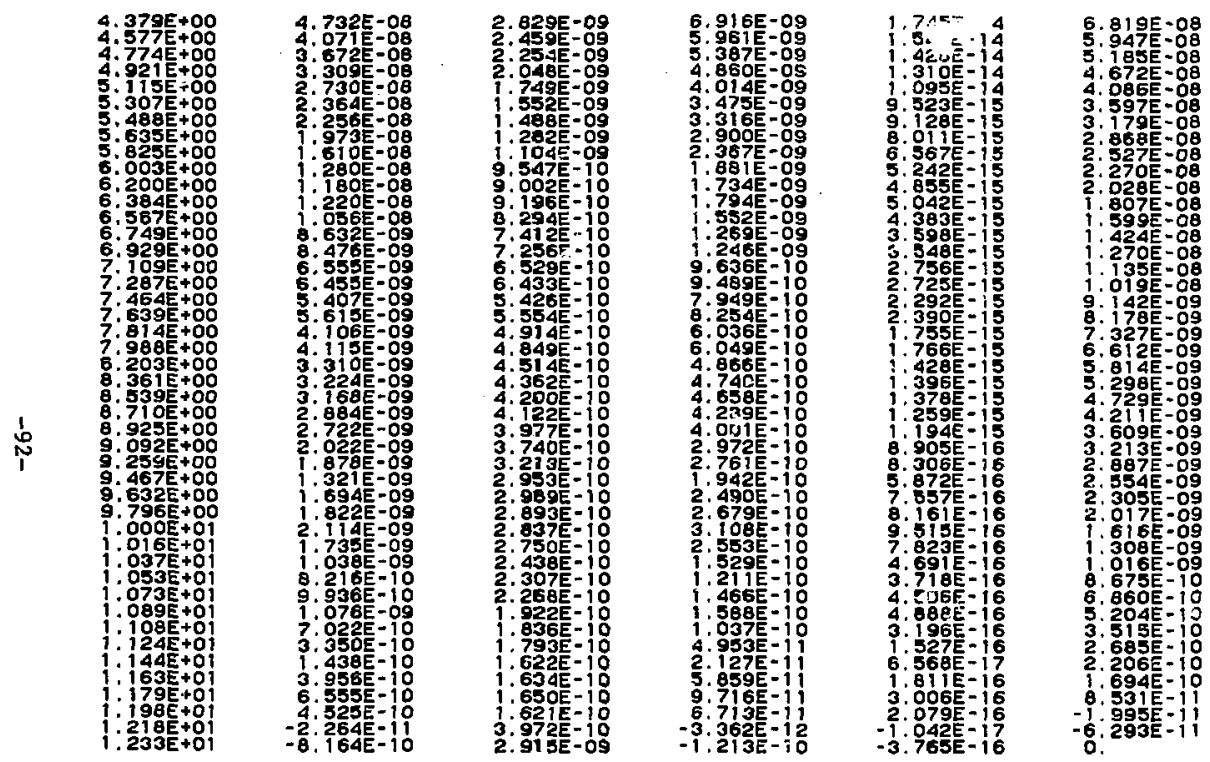

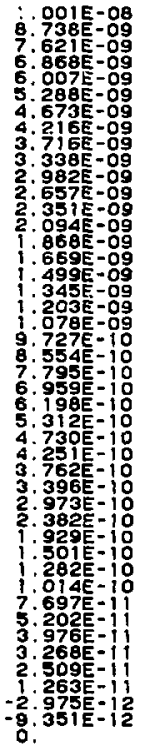

$7130 \mathrm{cos}$ $7130 \mathrm{cos} 3 \mathrm{HS}$ $7130 \mathrm{cos} H \mathrm{~s}$ $7130 \mathrm{Co} 3 \mathrm{HS}$ $7130 \mathrm{cos}$ H $713 \mathrm{coshs}$ $7130 \mathrm{cos} H \mathrm{~s}$ $7130 \mathrm{coshs}$ 71 1 7 . $7130 \mathrm{cos} H \mathrm{~S}$ $7130 \mathrm{cos} H \mathrm{HS}$ $7130 \mathrm{cos} H \mathrm{~s}$ $7130 \mathrm{cos} 3 \mathrm{~S}$ $7130 \mathrm{cos}$ H 7 i $30 \mathrm{cos} H \mathrm{HS}$ 7) $7130 \mathrm{cos}$ H $7130 \mathrm{cos}-4$ 7 i $30 \mathrm{cos} H \mathrm{HS}$ $7130 \mathrm{CojHS}$ $7130 \mathrm{cos} H \mathrm{H}$ $7130 \mathrm{cos} H \mathrm{~s}$ $730 \mathrm{CO} 3 \mathrm{HS}$ $7130 \mathrm{cojHS}$ $7130 \mathrm{cos} H \mathrm{HS}$ $7130 \mathrm{CO} 3 \mathrm{HS}$ $7130 \mathrm{cos} H \mathrm{HS}$ 7 7) $30 \mathrm{cos} 4 \mathrm{~s}$ $7130 \mathrm{cos} H \mathrm{~S}$ $7130 \mathrm{CO}$ HS $7130 \mathrm{cos}$ S $7130 \mathrm{CO} H \mathrm{HS}$ $7130 \leq 03 H 5$ $7130 \mathrm{cos} H \mathrm{~S}$ 
1 CF-252 $20 \mathrm{CM}$ ALUMINUM AT R=2M (FOR $1.0 \mathrm{~N} / \mathrm{SEC}$ )

$\begin{array}{lll}\text { TIME AND DATE OF DATA REPORTING } & 10: 58: 16 U 10 / 18 / 77 \\ \text { CEMPILATION DATE OF THIS CODE VERSION } & 10 / 18 / 770 \text { O9.13.04 }\end{array}$

30 GREUP OUTPUT

\begin{tabular}{|c|c|c|}
\hline GRDUP* & $\begin{array}{l}\text { ENERGY } \\
\text { UP-BGUND-MEV }\end{array}$ & $\begin{array}{l}\text { DIFFERENT IAL } \\
\text { N/CM2-SEC-ME }\end{array}$ \\
\hline $\begin{array}{l}30 \\
29 \\
2 ! 0 \\
27 \\
25 \\
25 \\
24 \\
23 \\
212 \\
21 \\
20 \\
19 \\
19 \\
17 \\
16 \\
15 \\
14 \\
13 \\
11 \\
10 \\
9 \\
8 \\
7 \\
6 \\
5 \\
.1 \\
3 \\
2 \\
1\end{array}$ & 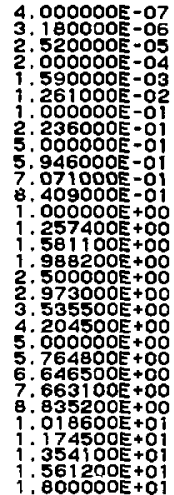 & 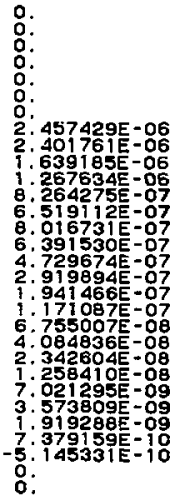 \\
\hline
\end{tabular}

INTEGRAL FLUX

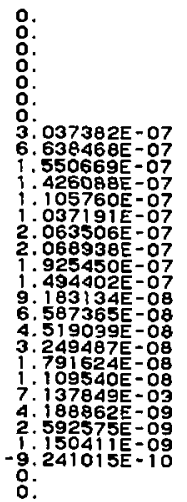

FLUX PER UNIT LETHARGY

:

0.

3. $976120 E-07$

8. $689572 E-07$

.971260E-07

. 250393E-07

. 396549E-07

9. 048484E-07

.

$552535-07$

$312822 E-07$

3.811010E-07

2.614188E-07

. 879944E-07

. $260883 E-07$

$7.809254 E-08$

. $948089 E-06$

.

-6.505242E-OS

o. 


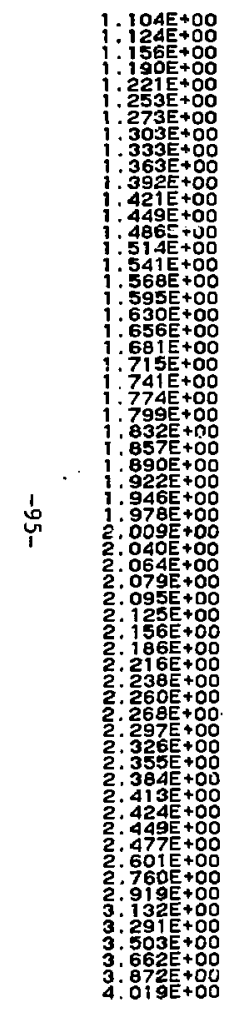

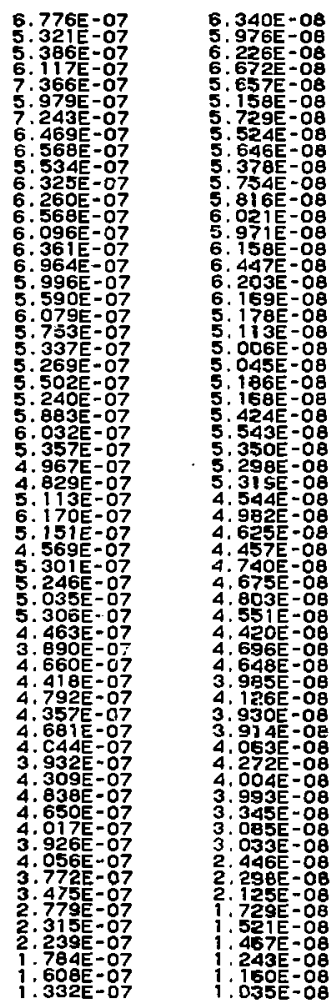

\begin{tabular}{|c|}
\hline 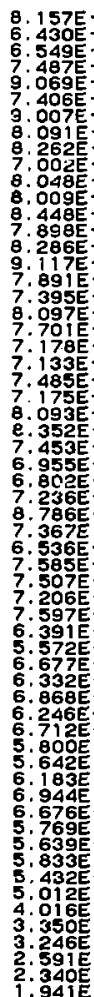 \\
\hline
\end{tabular}
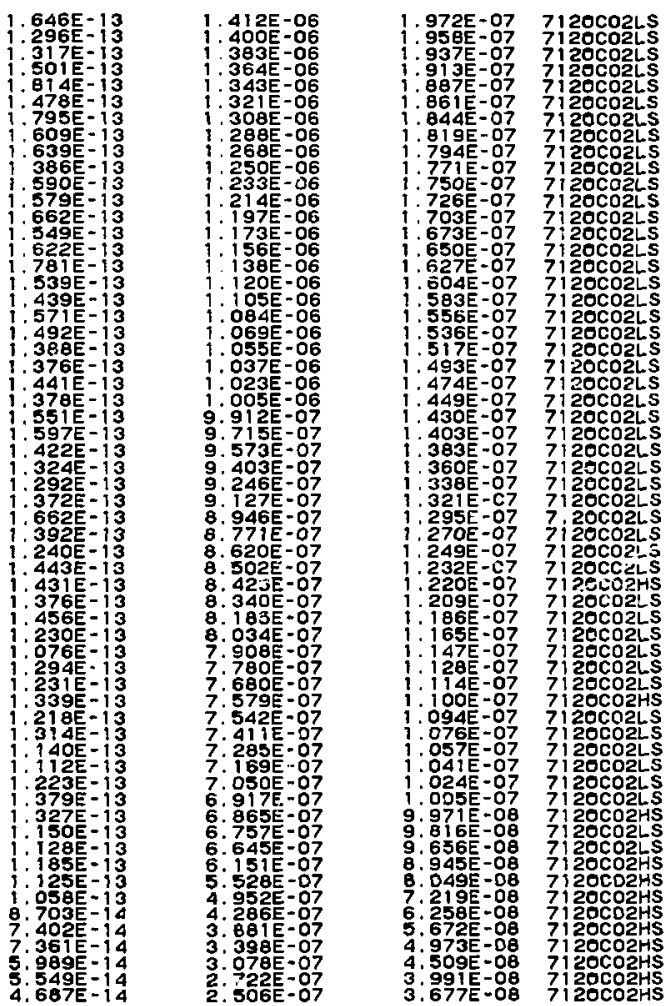

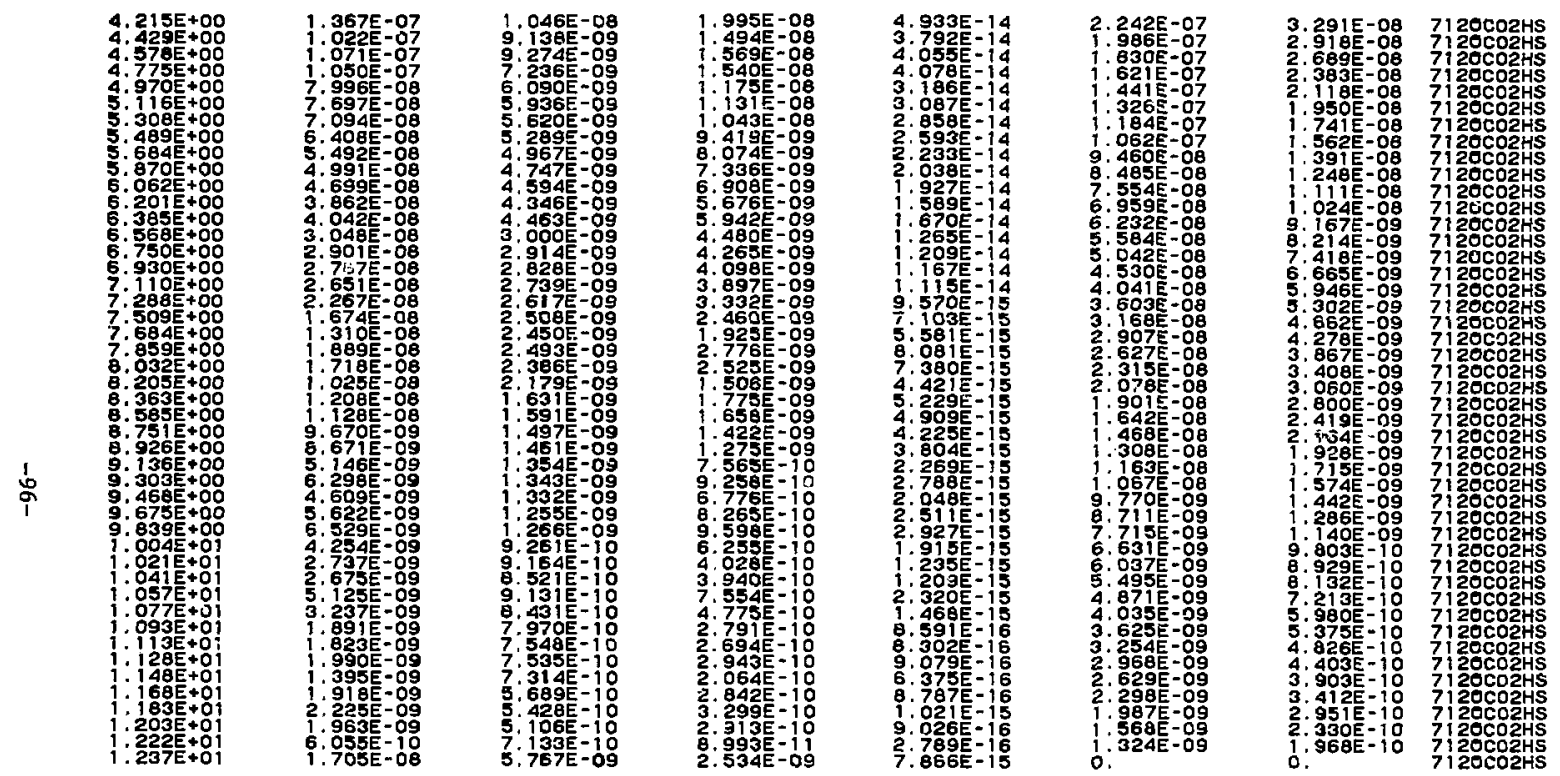

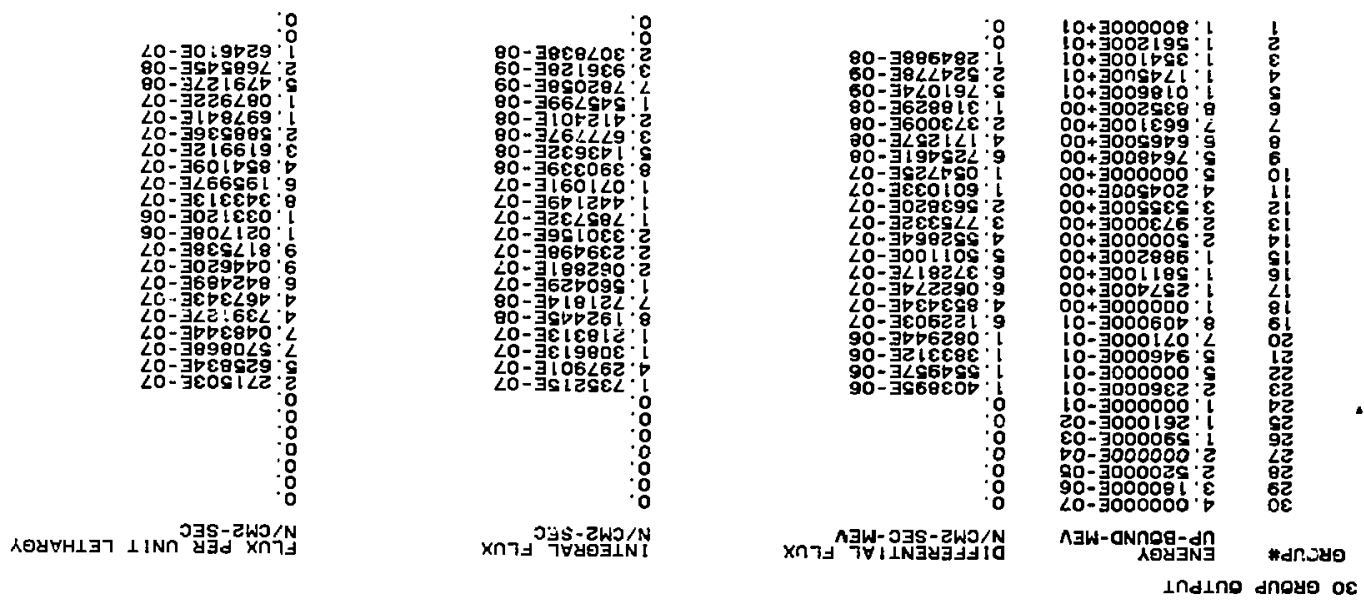

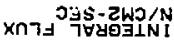

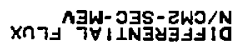
Indino dกoye os

$\angle L / 8$ L $/ 0$ คำ:

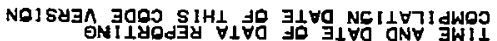



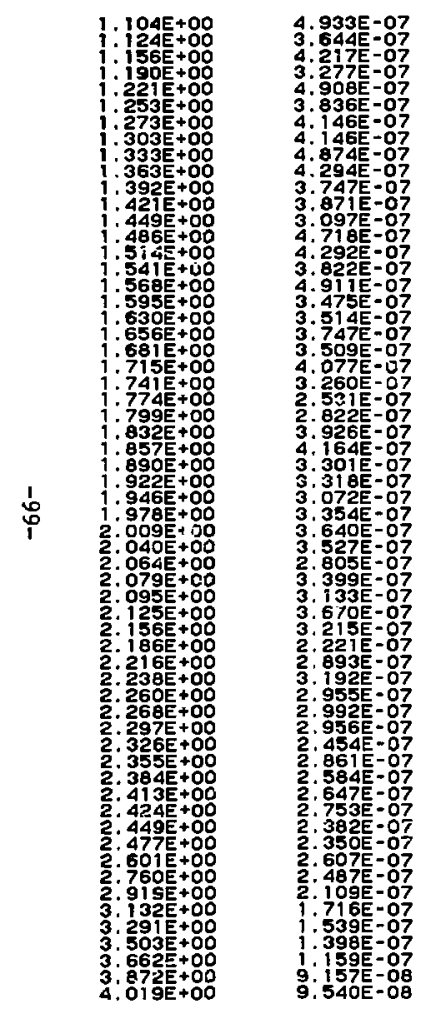

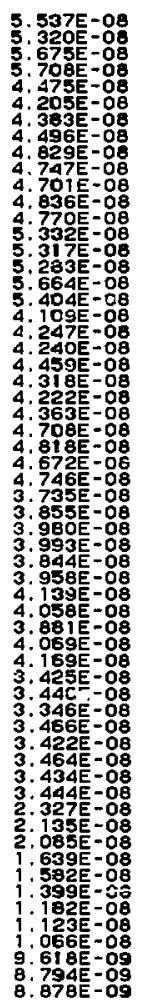
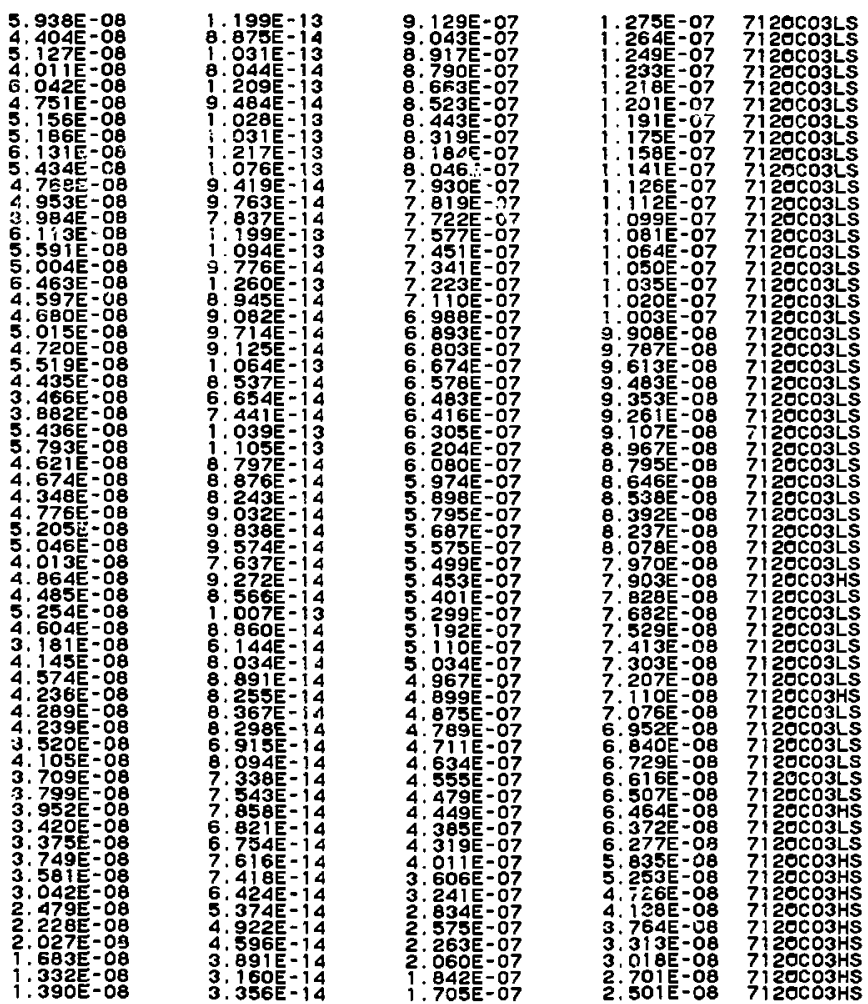

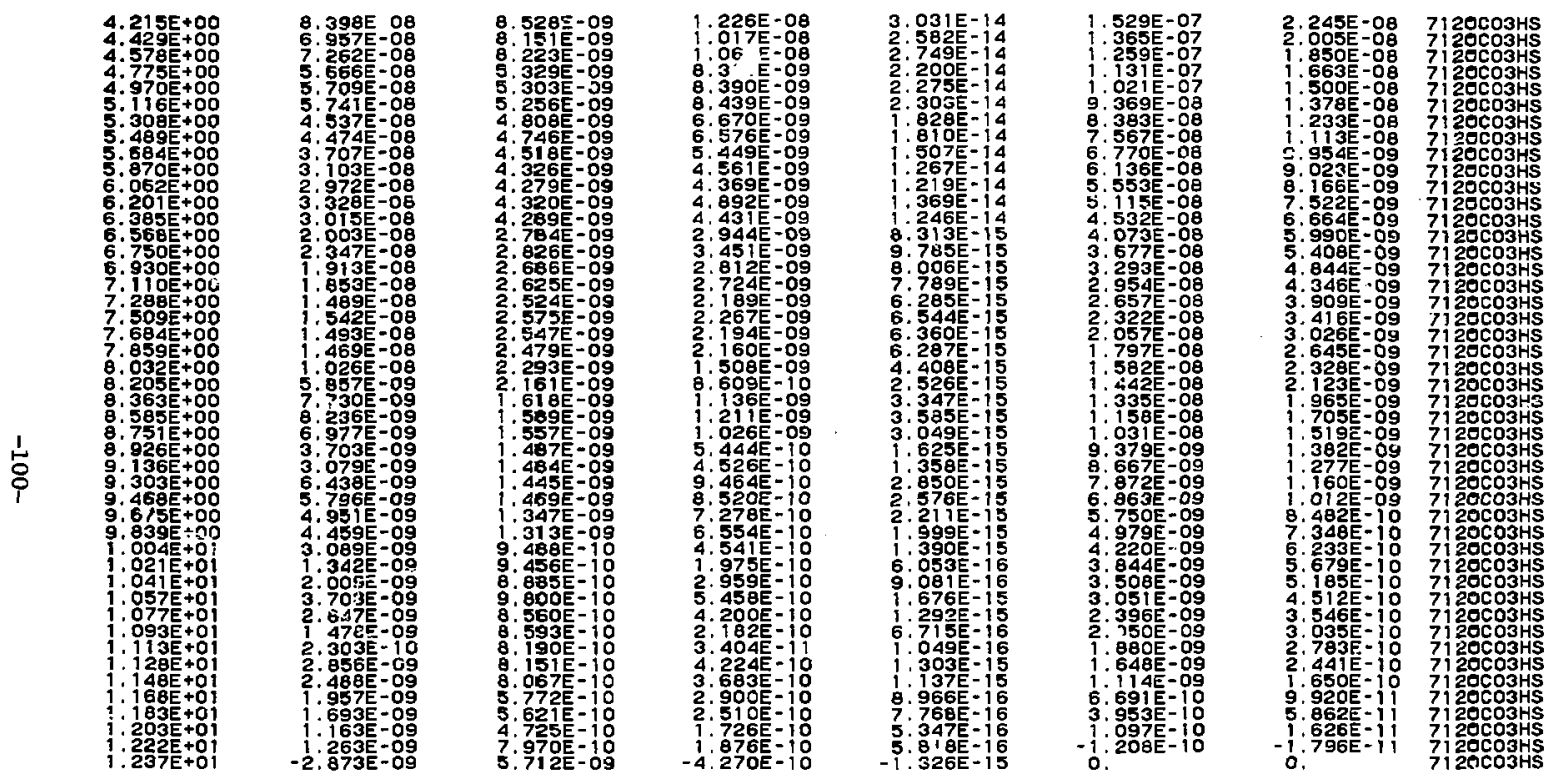


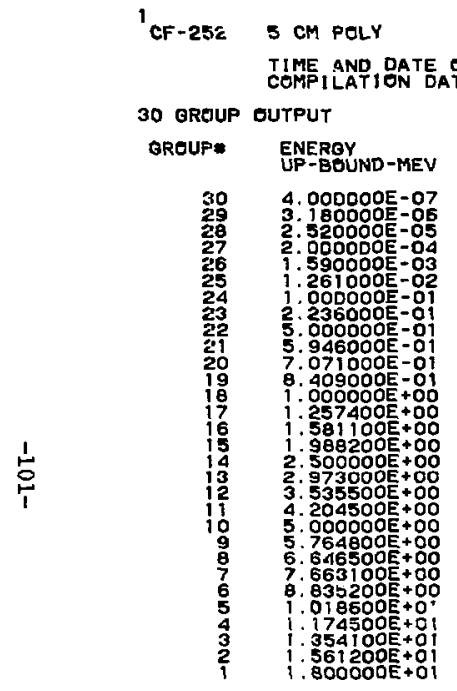

AT $R=2 M$ (FER $1,0 \mathrm{~N} / \mathrm{SEC}$ )

TIME AND DATE OF DATA REPORTING

DIFFERENTIAL F!-UX
N/CM2-SEC-MEV

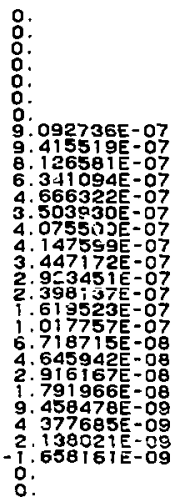

$10 / 18 / 770$ 11:03:55U

$10 / 18 / 77$
I NTEGRAL FLUX
N/CM2-SEC

o.

$:$

:

1: $123862 \mathrm{E}-07$

2. $602449 E-07$

$7.687746 \mathrm{E}-08$
$7.133731 \mathrm{E}-08$

7. $133731 E-08$

$6.243539 \mathrm{E}-08$

$049034 E=07$

. $403344 E-07$

$.403344 \mathrm{E}-07$

1. $134319 \mathrm{~g}-07$

9. $109817 E-08$

5. $808797 E-08$

3. $553217 \mathrm{E}-06$

1.821713E-0日

1. $108628 E-0$

3. $333174 \mathrm{E}-09$

- $2.978057 \mathrm{E}-09$

o.
FLUX PER UNIT LETHAROY

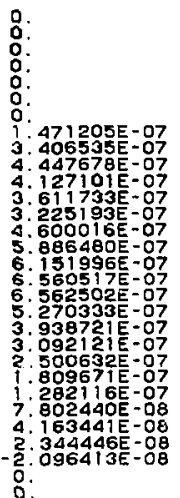




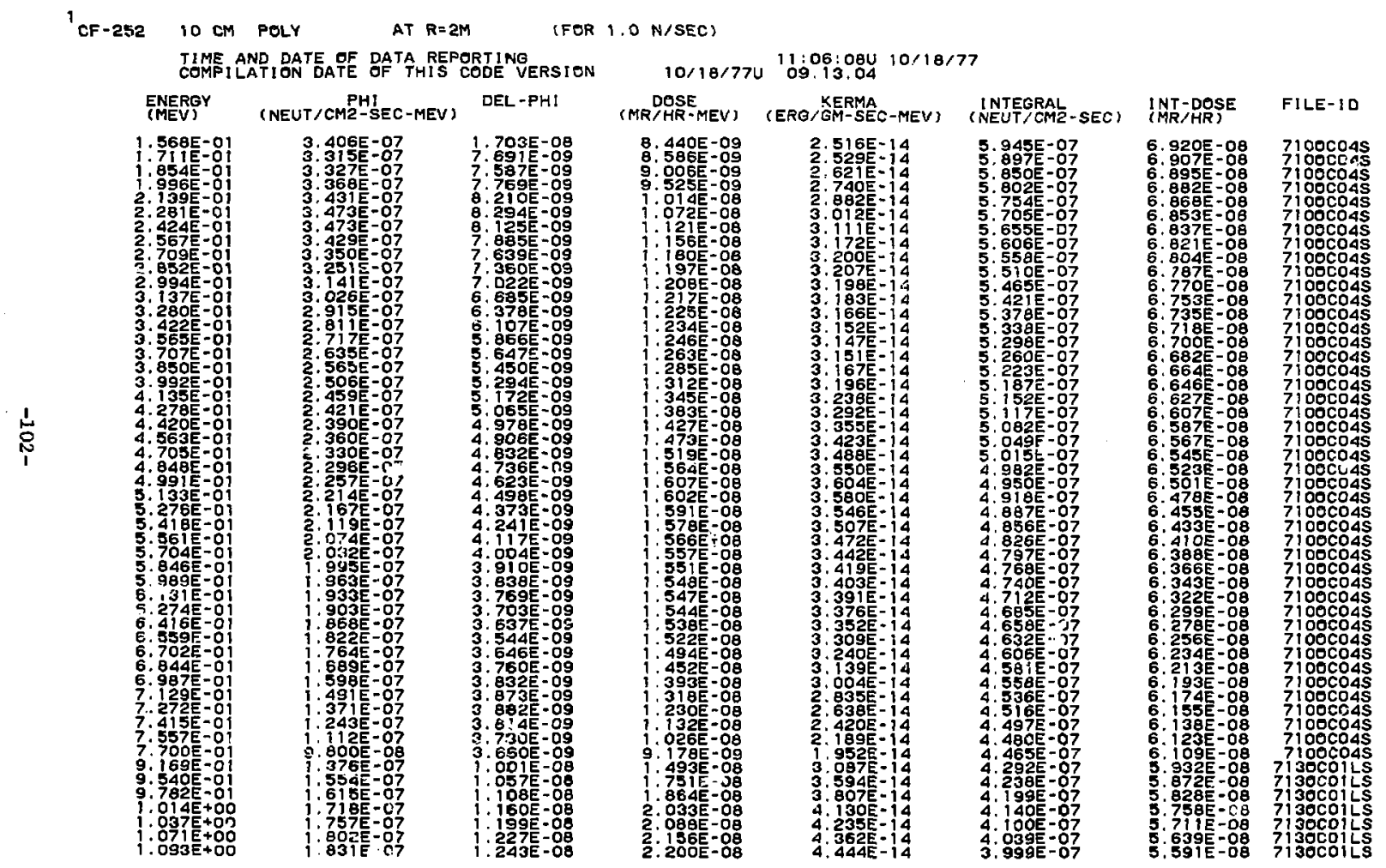



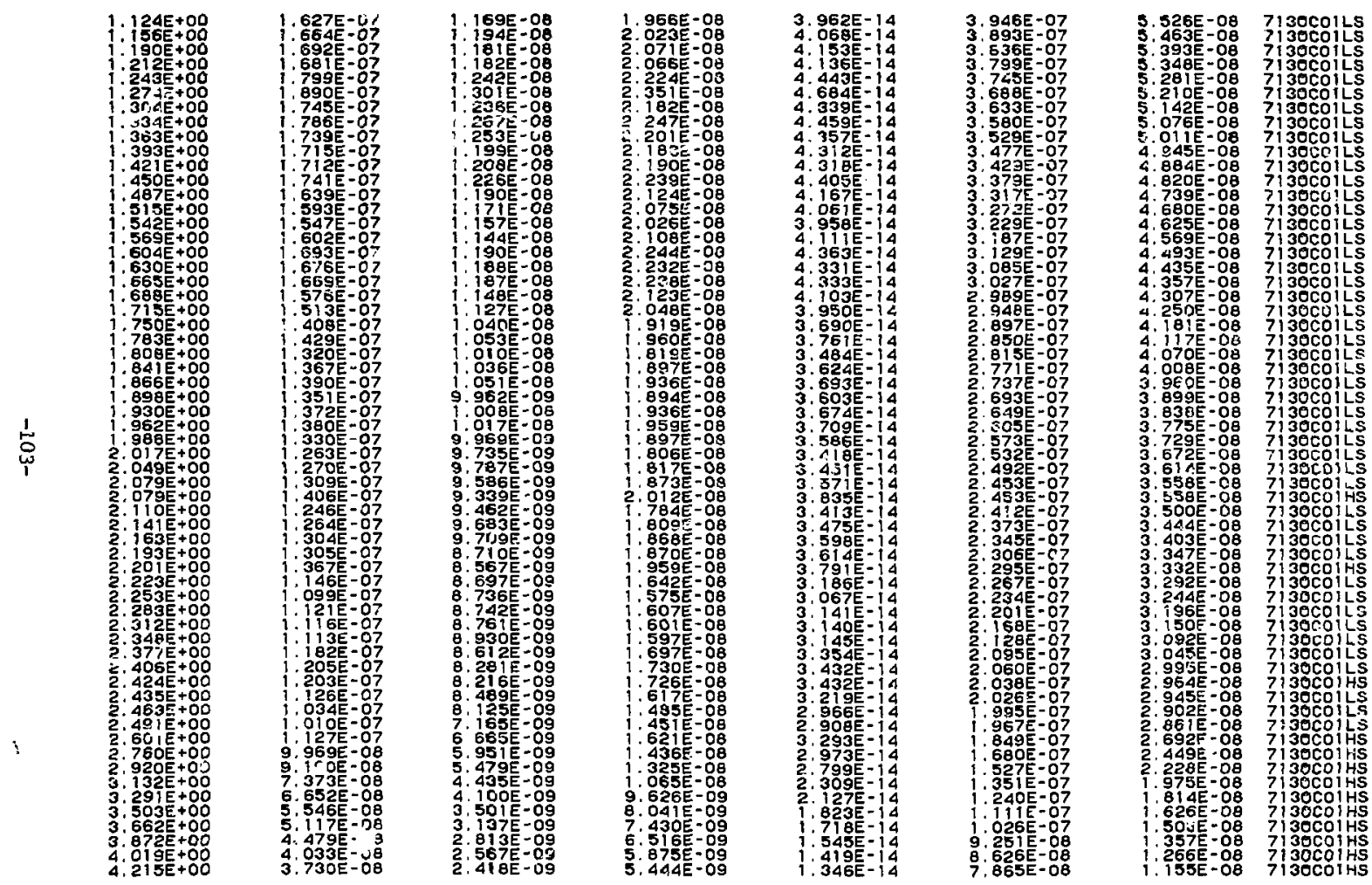

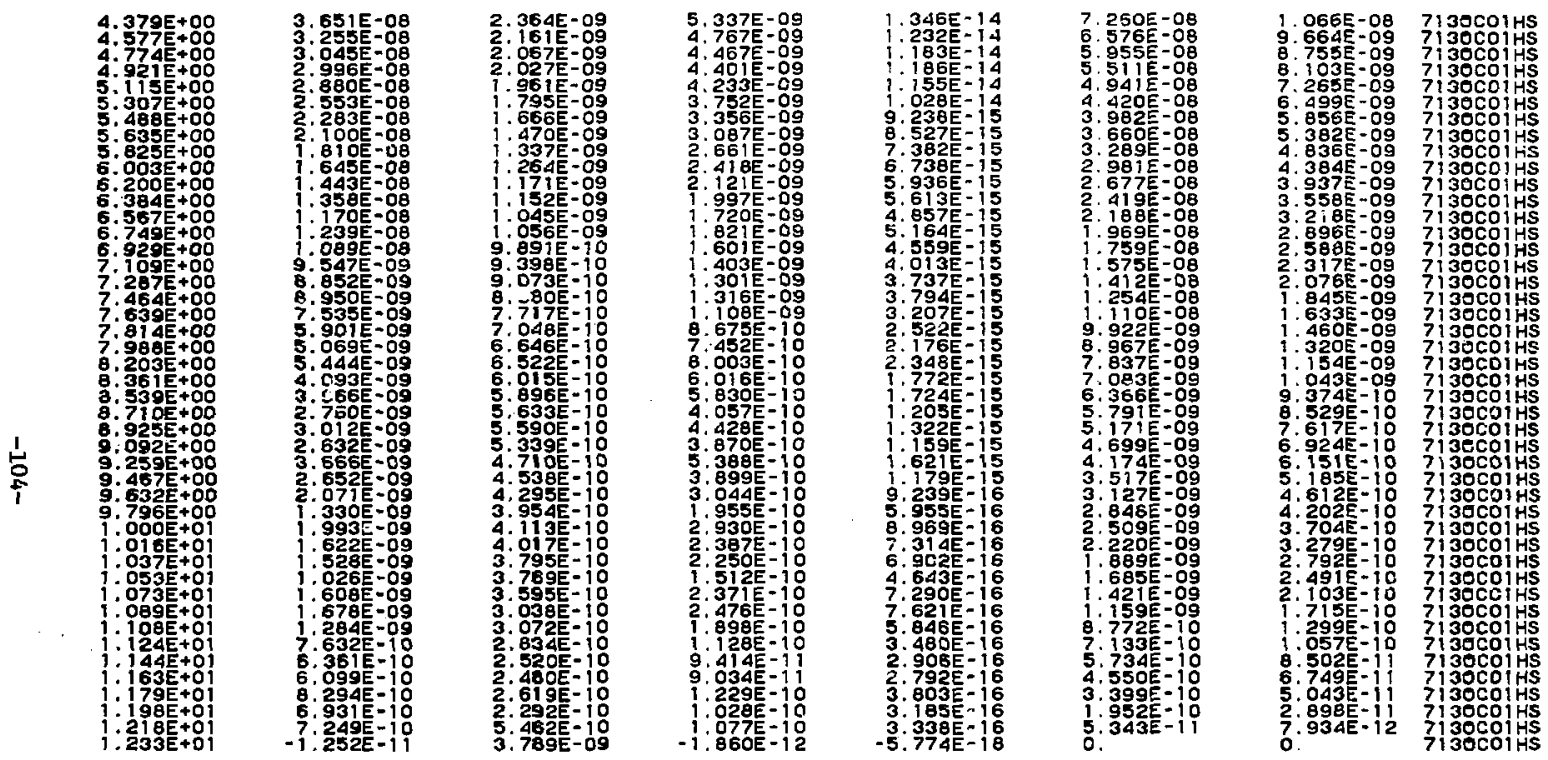


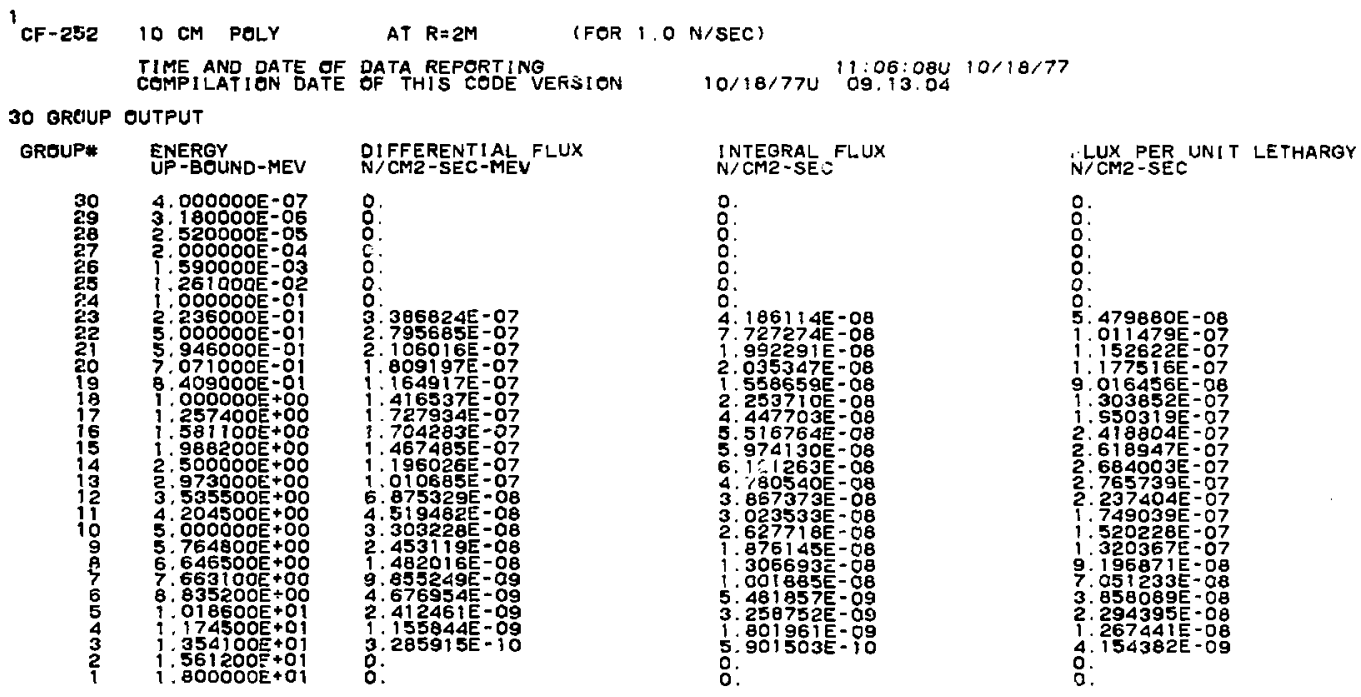


BARE AT R= IM (EOR $1.0 \mathrm{~N} / \mathrm{SEC}$ )

TIME, AND DATE OF DATA REPORTING

ENERGY

1, 642E-0

(NEUT / CM2-SEC-MEV)

DEL - PHI

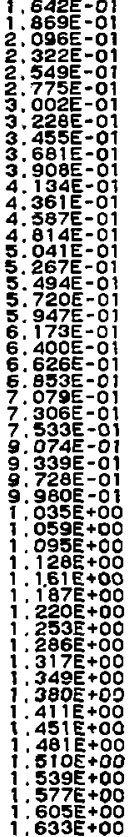

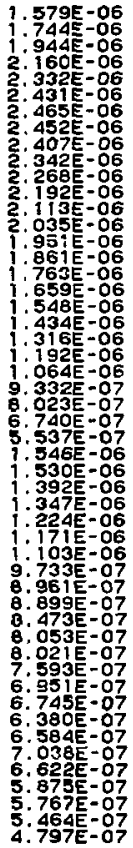

$10 / 14 / 770 \begin{array}{r}14: 44: 40 R \\ 16.05 .47\end{array}$ DOSE

$4.002 E-08$
$4.741 E-08$
$5.670 E-08$
$6.755 E-08$
$7.819 E-08$
$8.740 E-08$
$9.506 E-08$
$1.014 E-07$
$1.067 E-07$
$1.113 E-07$
$1.157 E-07$
$1.198 E-07$
$1.239 E-07$
$1.279 E-07$
$1.315 E-07$
$1.334 E-07$
$1.293 E-07$
$1.245 E-07$
$1.188 E-07$
$1.126 E-07$
$1.057 E-07$
$9.796 E-08$
$8.944 E-08$
$6.027 E-08$
$7.059 E-08$
$6.0675-08$
$5.099 E-08$
$1.662 E-07$
$1.690 E-07$
$1.596 E-07$
$1.567 E-07$
$1.454 E-07$
$1.397 E-07$
$1.325 E-07$
$1.177 E-07$
$1.0915-07$
$1.066 E-07$
$1.043 E-07$
$9.976 E-08$
$1.000 E-07$
$9.523 E-08$
$8.771 E-08$
$8.562 E-08$
$8.148 E-08$
$8.4725-08$
$9.109 E-08$
$8.619 E-08$
$7.689 E-08$
$7.603 E-08$
$7.242 E-08$
$6.392 E-08$

(ERG/GM-SEC-MEV) (NEUT/CML-SEC)

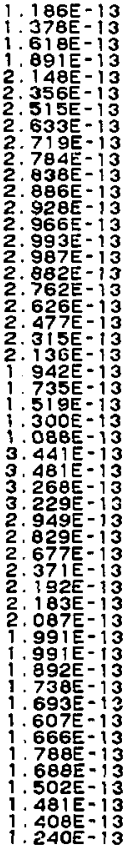

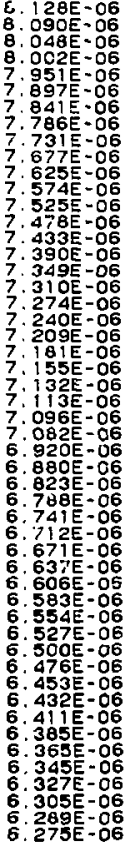

INT-DQSE

$1.067 \mathrm{E}-06 \quad 609 \mathrm{~N} 0025$

$.066 E-06$

. O6SE-06

$.062 E-06$

. OSOE- 05

056E-O

. O5 AE-

OSIE-06

. $446 E-06$

$.043 E=06$

$.037 \mathrm{E}-06$

$034 \mathrm{E}-06$

$.031 E-06$

O26E-OF

. $215-06$

. $016 \mathrm{E}-06$

. OI $A E-O G$

. OI $3 E=06$

. $10 \mathrm{O}-06$

. $931 E-07$

9. $823 E-07$

9. 782E-07

$9.726 E-07$

9. $643 \mathrm{E}-07$

9. $602 E-07$

$.564 E-07$

$9.501 E-07$

9. $467 E-07$

9. 404 - 07

9. 375 E- 07

9. $348 E-07$

. 322E-07

. $289 E-07$

.252E -07

$9.213 E-07$

9. 1 BAE-07

9. 1G3E-07 $144 E-07$
8NOO2

6OBNOO2S

$608 \mathrm{NOO} 2 \mathrm{~S}$

6 CANDO2S

$608 \mathrm{NOO} S$



ONOO2S

608N002S

60BNoO2S

$608 N O 025$

OBNOO2S

GoBNoOzS

OQNoO2S

608 NOO2S

08 NOO2S



600 NOO2S

GOBNOOLS

606Noozs

GO8NOOLS

ounoos

7 in

711 JAO ILS

7 IJAOILS

71 J JAOILS

7 J JAOILS

7 JAOILS

71 I JAOILS

$711 \mathrm{JAOLLS}$

7 IIJAOILS

71 JAOILS

719 JAOILS

7 II JAOILS 


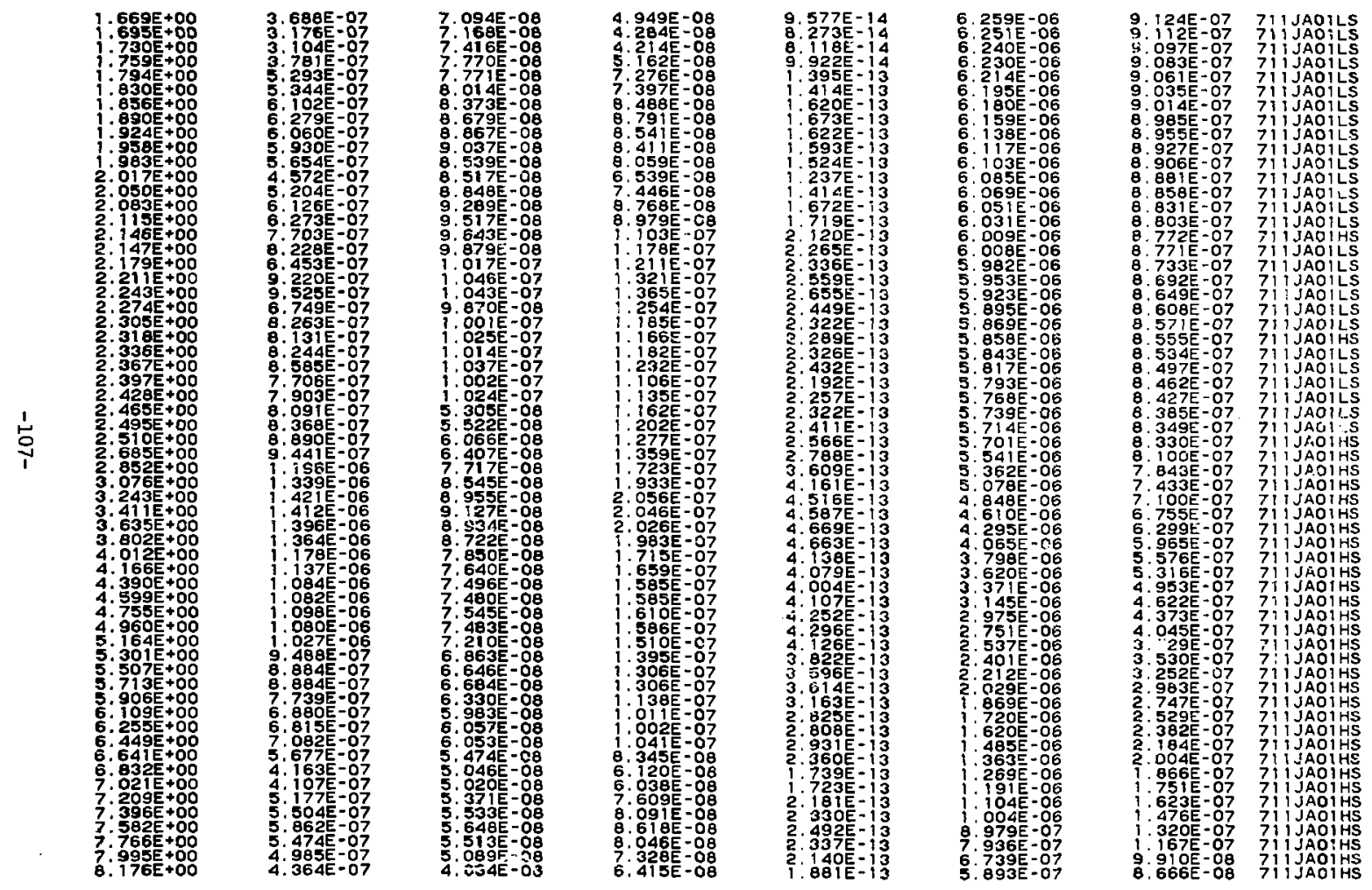



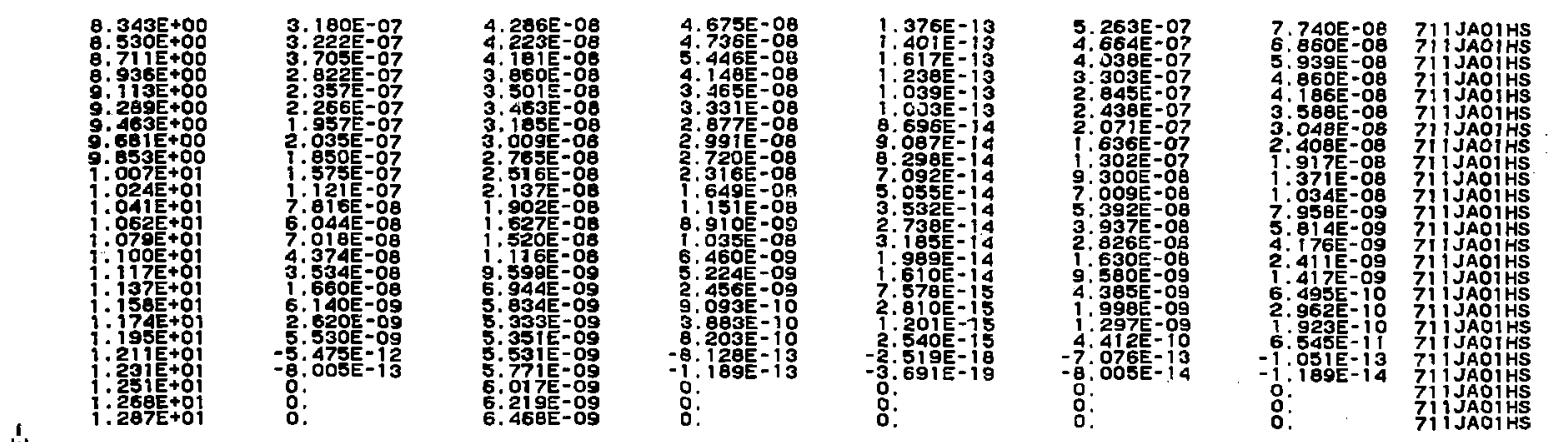

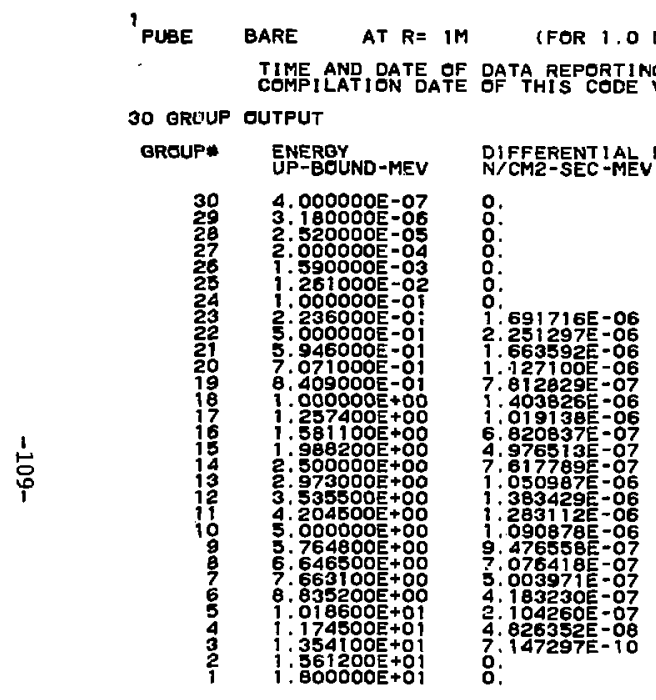

JNTEGRAL FLUX
N/CME-SEC

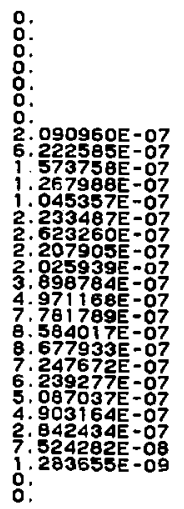

FLiiX PER UNIT LETHARGY

o.

:

:

.

2. 737 ; $96 \mathrm{E}-07$

8. $1451925-07$

9. 1048 A30E -07

$6.047130 \mathrm{E}-07$

. 29215 E

$9.150373 \mathrm{E}-07$

8. $881335 \mathrm{H}-\mathrm{O}$ ?

2.876026E -06

4.500

4.955642 - 06

5.020492 - 06

$5.100663 \mathrm{E}-06$

$4.391377-06$

3.500241 -05

2. 001277 E-OE g.: $036323 \mathrm{E}=07$ 


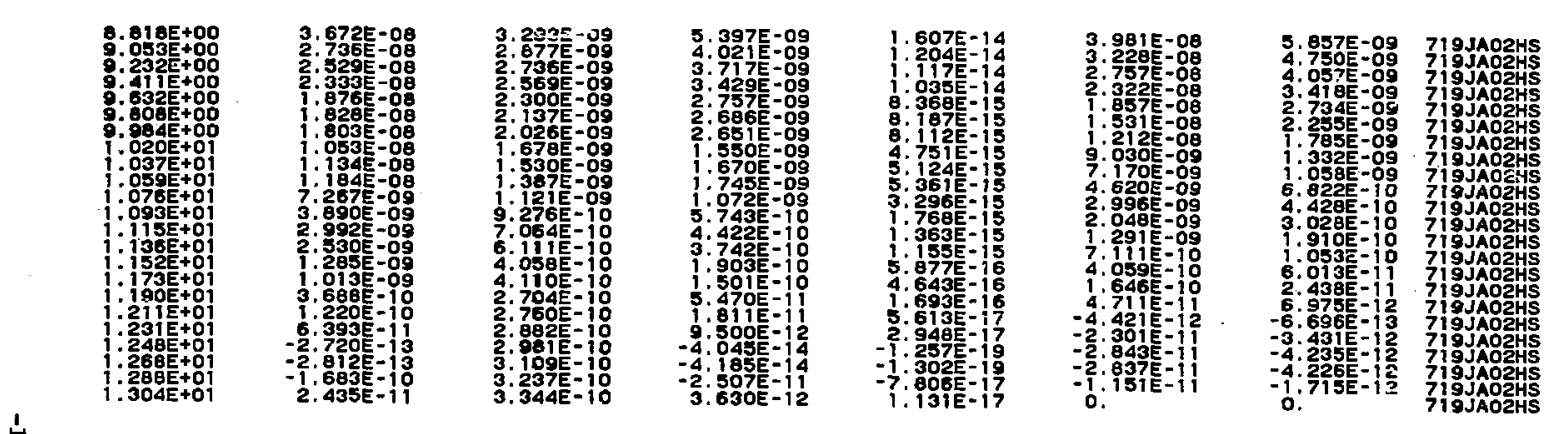




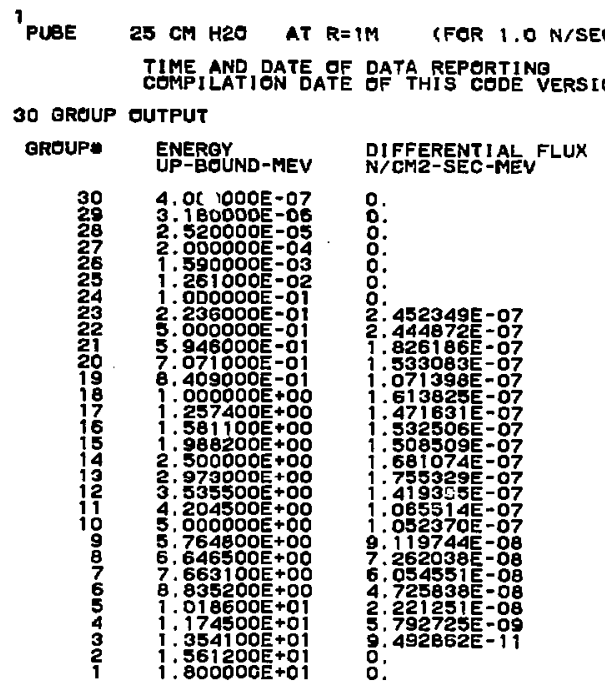

10/14/770 14:48:18R $10 / 17 / 77$

INTEGRAL FLUX FLUX PER UNIT LETHARGY

o.

D:

o.

3. $031103 E-08$

.757627E-O8

1,7247195

1:433531E-08

2. $567595 \mathrm{E}-08$

$3.787979 \mathrm{~g}-08$

4. $960723 \mathrm{E}-08$

6. 141140 -08

B. 302707 -

96E- 0

7. 371602 E -0

$6.974781 \mathrm{-}-08$

$6.402939=08$

$6.15015 E=08$

$3.000466 \mathrm{E}-08$

9. $030859 E-09$

o.

o.

。.

:.

:

3.967901E-08

9.845548E- -8

9.978073E-08

. $292622 E-08$

$1.661030 \mathrm{E}-07$

2. $175010 \mathrm{0}-07$

$2.692161 \mathrm{E}-07$

. 772497

$4.6190665-07$

$4.8432695-07$

4.

$4.331910 \mathrm{E}-\mathrm{O} 7$

$3.898415 \mathrm{E}-07$

2. $112543 E-07$

6. $352013 E-08$

o: 

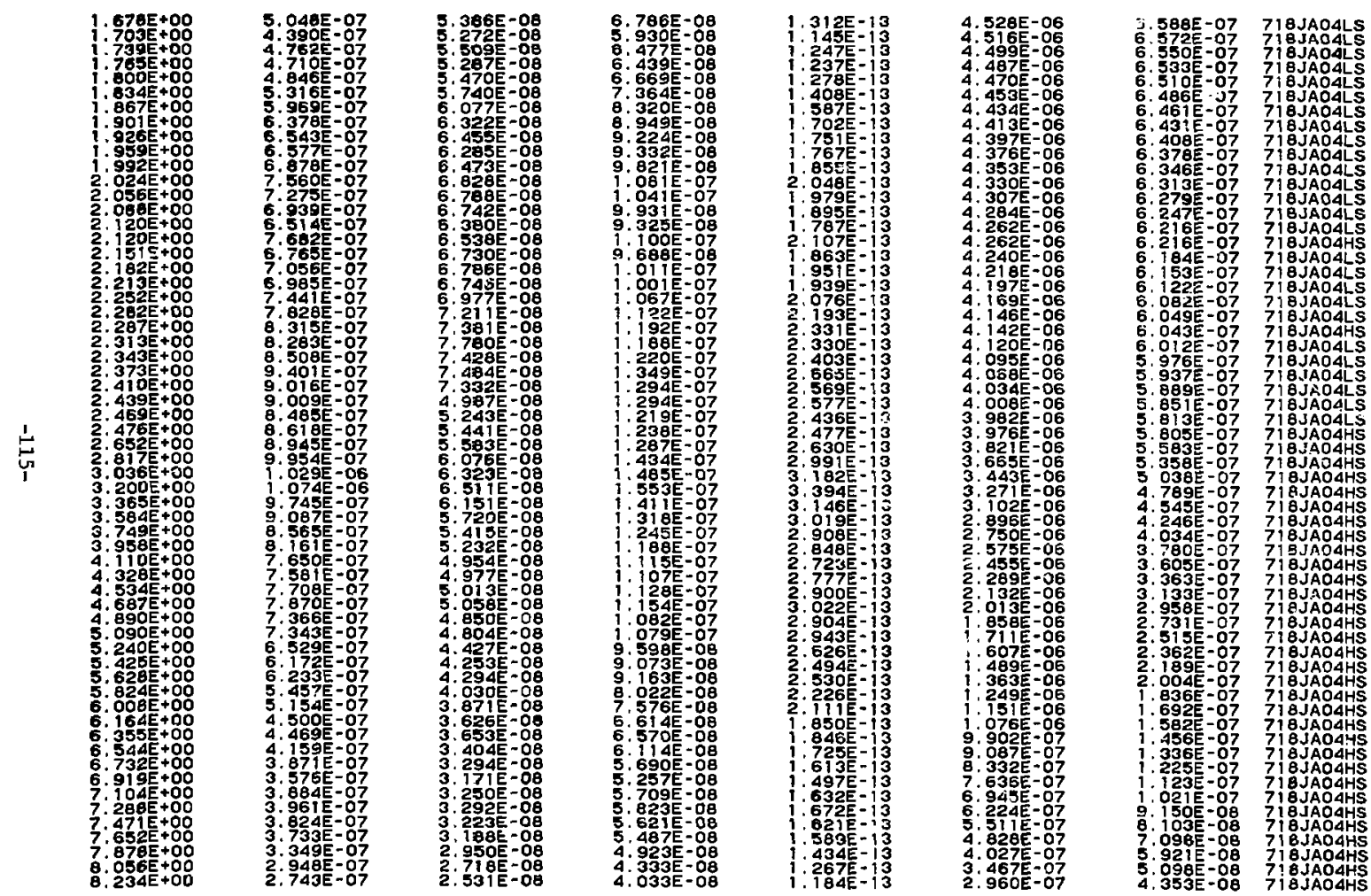

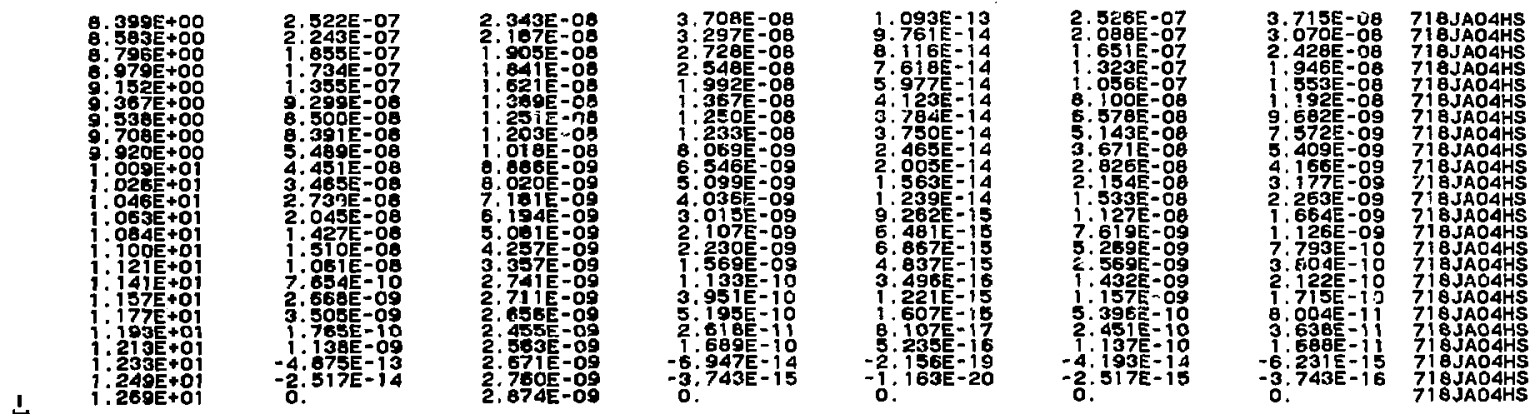


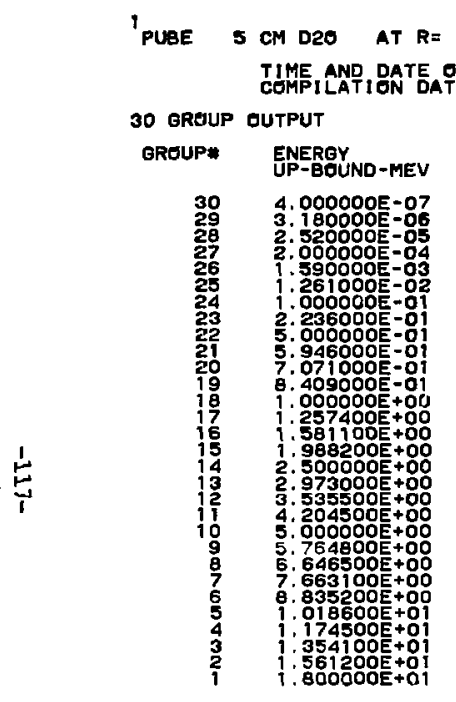

(FOR 1.O N/SEC)

TIME AND DATE OF DATS REPPORTING

$10 / 14 i 770 \begin{array}{r}14: 49: 42 R \\ 16.05 .47\end{array}$

30 GREUP OUTPUT

DIFFERENTIALLFLUK

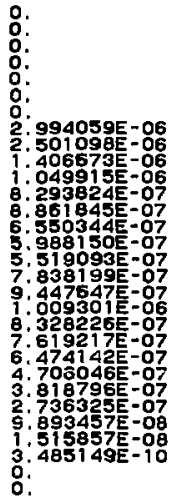

1NTEORAL FLUX
N/CM2-SEC

o.

o.:

o.

3. $700656 E-07$

6.913035E=-07

. $330712 E-67$

1 109714E-07

. $409920=07$

$938364 E-07$

$2.246823 E-07$

$4.458737 \mathrm{E}-\mathrm{D} 7$

$5.571583 E-07$

4.95107

$4.149321 E-07$

3. 8 83

3. $207247 \mathrm{E}-07$

$2.363201 E-08$
$0.359328 E-10$

:.
FLUX PER UNI T LETHAROY

o.

o.'

:

$4.844387 E-07$

$4.044387 E-07$

$7.69795-07$

$6.419420 \mathrm{E}-07$

$8.156885 E-07$

. $393373=-97$

. $499650=07$

1. $738970 \mathrm{E}-06$

.

(2)

3. 500554 E- 06

3. $484642 E-06$

$2.732272 \mathrm{E}-06$

$2.257236 \mathrm{E}-06$

9. 409271 - 07

4. $406274=09$

o. 


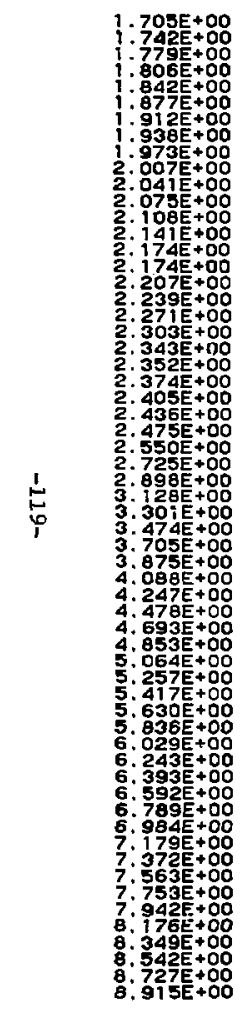

\begin{tabular}{|c|c|}
\hline 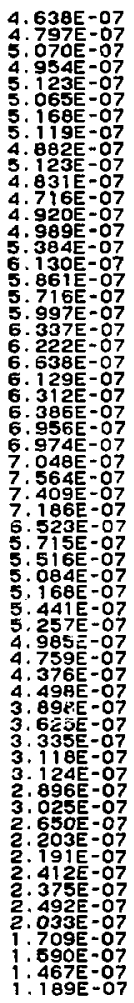 & 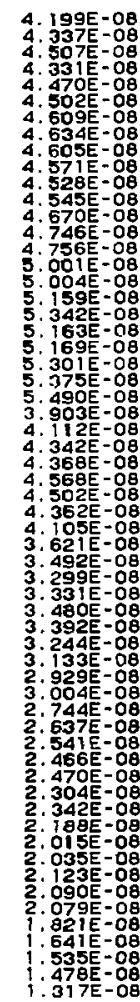 \\
\hline
\end{tabular}
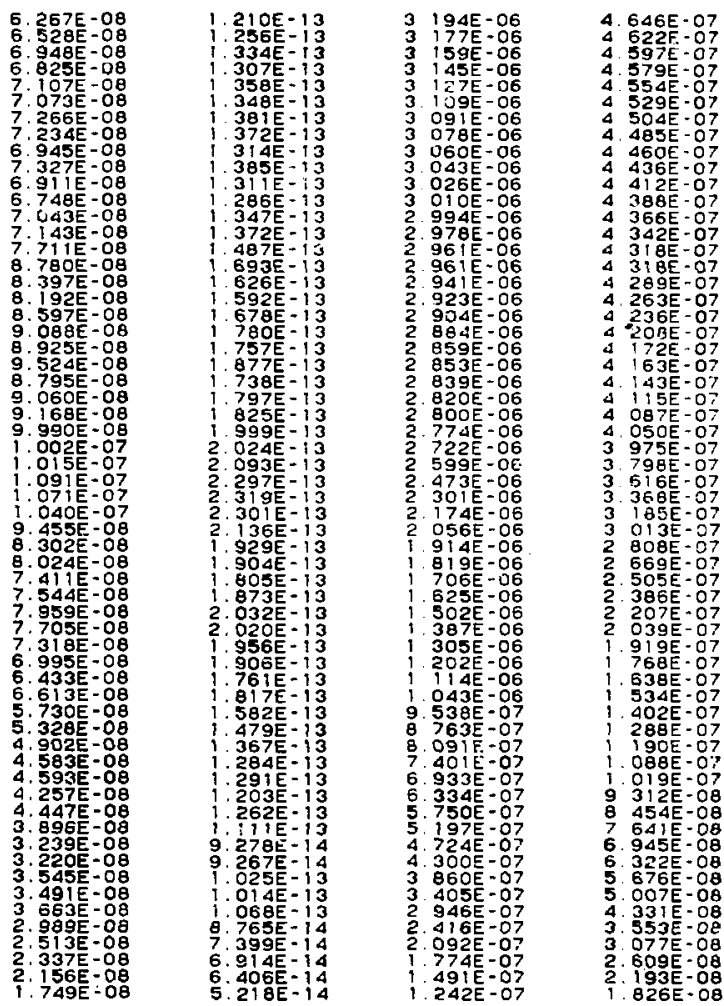

$720 J A 03 L S$

$720 J A 03 L S$

$720 \mathrm{JAOBLS}$

$720 \mathrm{JAOBLS}$

$720 J A O 3 L S$

$720 \mathrm{Aaz} \mathrm{LS}$

720 JAO3LS

$720 J A 03 L S$

7 JOJAO3LS

720 JAO3LS

$720 J A O 3 L S$

$720 \mathrm{JAO} 3 \mathrm{LS}$

7.

$720 J A 03 L$

$720 J A O 3 H S$

$720 J A O 3 L S$

720 JOO3LS

720 JaUzLs

$720 \mathrm{JAOJHS}$

$720 J A O 3 H S$

720 AO3HS

$720 J A 03 M S$

$720 J A 034 S$

$720 J A O J H S$

$720 J A O Z H S$

$720 J A 03 \mathrm{HS}$

$720 J A 03 H S$

$720 J A O 3 H S$

720 JAOJHS

$720 J A 03$ HS

$720 \mathrm{JAOBHS}$

7201903 HS

$7203 A 3 H$

$720 J A O B H S$

$720 \mathrm{JAOBHS}$

$720 \mathrm{JAO} 3 \mathrm{HS}$

$720 J A D 3 H S$

$720 \mathrm{JAO} H \mathrm{HS}$

$7201403 H S$

72003 A

$720 J A 03 H S$ 7 7.

$720 j a 03 H S$

T2OJAOJHS 

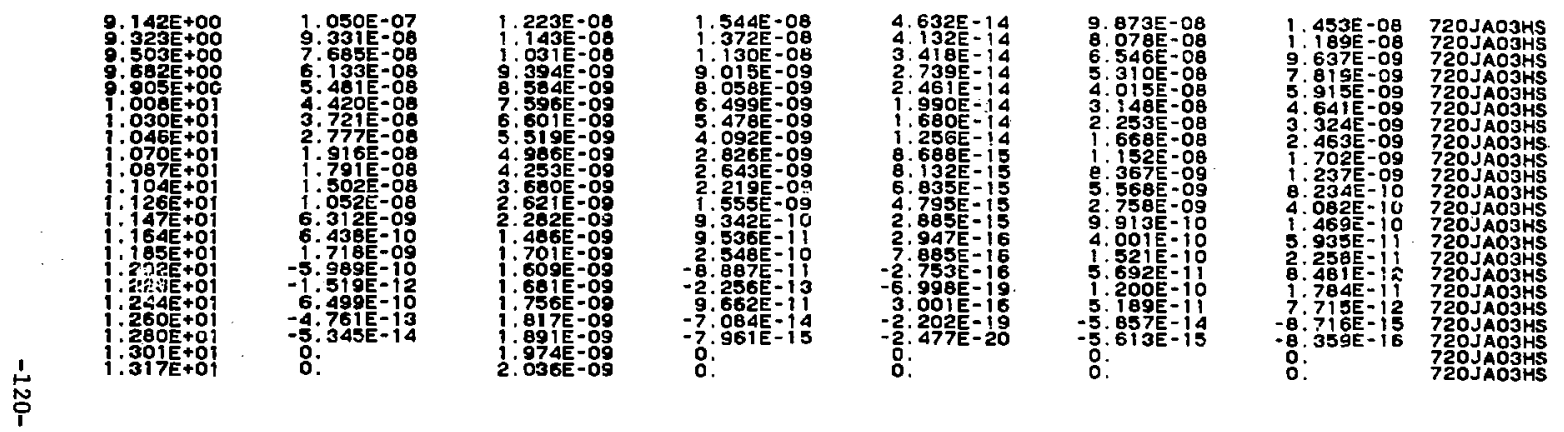
'puae

$10 \mathrm{CM}$ D2O AT R=1M

(FOR $1.0 \mathrm{~N} / \mathrm{SEC}$ ) TIME AND DATE GF OATA REPGRTING SO GREUP QUTPUT

\section{DIFFERENTIALFLUX}

:

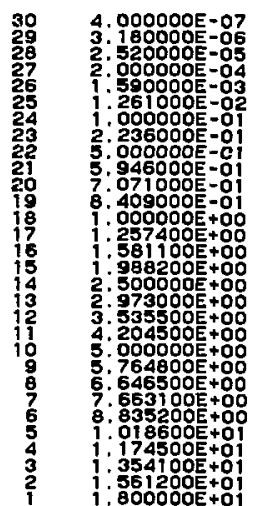

o.:

:

.

2. $683674 E-06$

$1.8731665-06$

. $351573 E-07$

$6.739293 E-07$

6. $243409 \mathrm{E}-07$

$4.415319 \mathrm{E}-07$

4.

. $198138 E-07$

.109828E- 07

5. 197791 - 07

.32243 07

.513338E-07

$1.944024 E-07$

7.931254 -O8

.694227E- 10 8 .

$10 / 14,774 \begin{array}{r}14: 51: 13 R \quad 10 / 17 / 77 \\ 16.05: 47\end{array}$

$$
\begin{aligned}
& \text { INTEGRAL FLUX } \\
& \text { N/CME+SEC }
\end{aligned}
$$

0 .

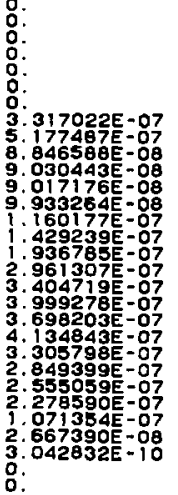

FLUX PER UNIT LETHAROY

o.

o.

o.

4. $342185 \mathrm{E}-07$ 6. 777160 -07

5. $118116 \mathrm{6}-07$ 224412E- 7 $746746 E-07$

$266442 E-07$

4 . $40501 E-07$

. 298450 - 06

. $969770 E-06$

.

2.392154 - 06

. 326507E-06

$72435-06$

. 5ก3654E - 06

5.13098E-O

1. $976156 E=07$

o. 
TIME AND DATE GF DATA REPQRTING

ENERGY

(NEUT/CME-SEC-MEV)

1. 529E-01

$.982 E-01$

2.2095-01

2. $662 E-01$

3. 11 1

. $341 E-01$

$705=01$

021 1 -01

.248E=01

.781E-01

$927 E-01$

$380-01$

5.6007E-0́1

$6.287 E-01$

$6.513 E=01$

$6.966 \mathrm{E}-01$

. $193 E-01$

. 419E-01

. 527 20 -01

. 79se-01

O18E+00

1 . O8 1 E +

. 151 IE+o0

- $18 B E+00$

$1.223 E+00$

- $246 E+00$

$324 E+00$

. 357E+00

. $421 E+00$

. $452 E+0 D$

$.493 E+00$

$553 \mathrm{E}+00$

$592 \mathrm{O} 00$

$.659 E+00$
$.685 E+00$
DEL-PHI

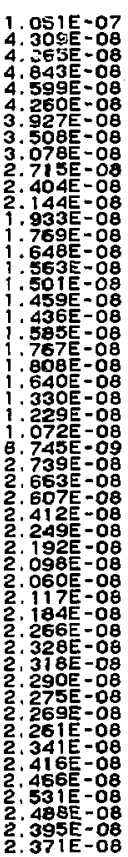
$10 / 14 / 770 \quad 14: 57: 44 R$

(MR/HR-MEV) (ERG/GERMAC-MEV)

(NNTEGRAL

(NT-DOSE FILE-10

5. $146 E-08$

$1.539 E-13$

5. $4075-08$

5. $868 \mathrm{E}-08$

5. $233 \mathrm{E}-08$

6. $363 \mathrm{E}=08$

6. 126 E-DQ

5. $877 \mathrm{E}-08$

5. $369 \mathrm{E}-0 \mathrm{a}$

5. $175 E-08$

$4.982=08$

, DOSE-OB

5. 1 2 12 IE-O8

5. 122E-OB

. $282 \mathrm{E}-0 \mathrm{~B}$

$5.282 E-08$

$5.499 E-08$

5. $400 E-08$

5. $100 E-08$

3. 926E-OB

4. $439 \mathrm{E}-08$

4. $503 E-08$

$4.199=08$

3. $866 \mathrm{E}-\mathrm{O}$

3. 776 E - 0

3. $3463=-08$

3. $5432=08$

3. $740 E-O 8$

$4.090 \mathrm{E}-0 \mathrm{~B}$

$4.032 E-08$

3. $982 E-08$

3. $952 E-08$

3. $975 \mathrm{E}-08$

$4.393 E=08$

4.695

$4.588 \mathrm{E}-0 \mathrm{~B}$

4. 399E-O̊

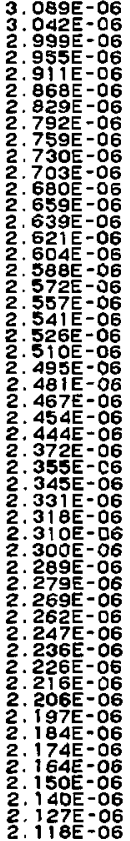

$602 N 0035$

$602 N 0035$

$602 N 0035$

Gu2NoOJs

602 NOO3S

60Nus

602 Nog

o2Nojs

$602 \mathrm{NOO}_{35}$

602 NOOJS

$602 N o b 3$

Go2No03s

$602 N 0035$

G02NOO3S

602 NoD 35

6on

$602 N 0035$

$602 N 0035$

602NOO3S

602NOO3S

725JAO3LS

72SJAO3LS

725JAO3LS

725JAO3LS

$725 \mathrm{JAO}$ LS

725 AO3LS

$725 \mathrm{JAO} L \mathrm{LS}$

$725 \mathrm{JAO} 3 \mathrm{LS}$

725 JAO3LS

$725 \mathrm{JAO} 3 \mathrm{LS}$

725JAO3LS

$725 \mathrm{JAO} \mathrm{LS}$

725JAO3LS

725 AOBLS

$725 \mathrm{JAO}$ L

725

$725 \mathrm{AO}$

$725 J A O 3 L S$

725 JAOOLS

725 JAOSLS 


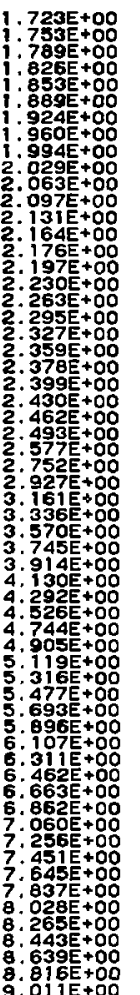



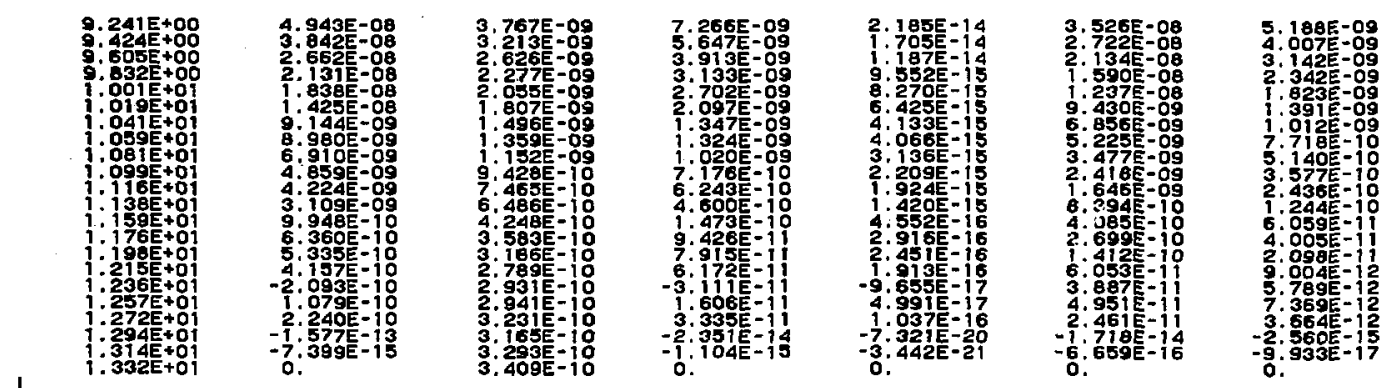

725JAO3HS 725 JAO3HS $725 \mathrm{JAO}$ HS 25JAO3HS 25JAO3HS $725 \mathrm{JAO}$ HS 25JAO3HS 25JAO3HS 25JAO3HS 政3 作 25.JAO3HS $725 \mathrm{JAOBH}$ 25JAO3HS 
'PuBE

$15 \mathrm{cM} D 20$ AT R=1M

(FOR $1.0 \mathrm{~N} / \mathrm{SEC}$ )

TIME AND DATE OF DATA REPORTING

30 GROUP OUTPUT

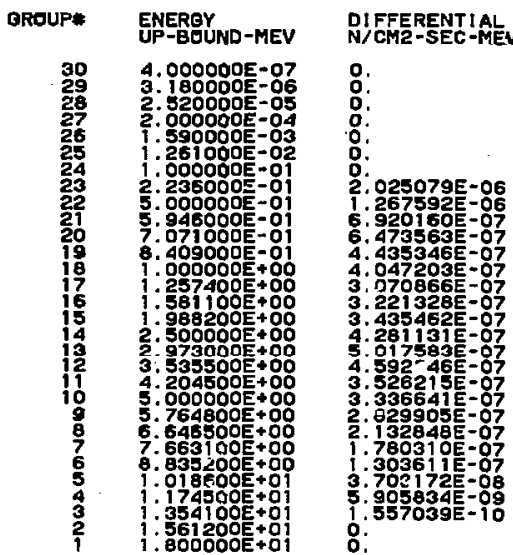

$10 / 14 / 77$ U 14:57;448 $10 / 17 / 77$

NTEGRAL FLUX

$\circ$.

o:

o.:

o.

. $502997 E-07$

$503623 E-57$

. 282775 -

5. $934493 \mathrm{E}-08$

6. 439100 -08

7:904410E-08

1.398577 -07

2. 193017 E:-07

.

$6542085-07$

$2.164311 \mathrm{E}-07$

. 8 o $32 E-07$

$1.827963 E-07$

$9: 207196 \mathrm{E}-09$

$6442 E-10$
FLUX PER UNIT LETHAROY

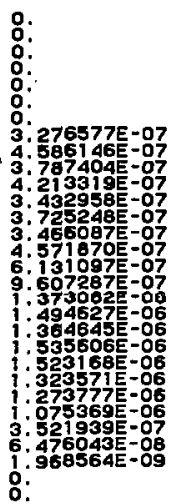


'PUBE

$25 \mathrm{cM}$ D20 AT R=1M (FOR $1.0 \mathrm{~N}$ /SEC)

TIME AND DATE OF OATA REPORTING

ENERGY

PHI

DEL-FHI

$14: 59: 20 R$
$10 / 14 / 770 \quad 15.05 .47$

$10 / 17 / 77$

(NEUT/CM2-SEC-MEV)

(MRIRRE-MEV)

(ERG/GMRMA

(NTEGRAL

INT-DOSE FILE-ID

1.529E-이

$\begin{array}{ll}9.862 E-07 & 4.931 E-08 \\ 8.908 E-07 & 1.973 E-08\end{array}$

2. $200 \mathrm{~K}-01$

$435-01$

2.662E-

3.31E-

.568E-O1

4.021E-व1

4.248E-01

$474=-01$

. 927 -

. $380 \mathrm{E}-\mathrm{D} 1$

2. $415 E-O 8$

$7.221 E-14$

1. $918 \mathrm{BE}-\mathrm{OB}$

$.546 \mathrm{E}-07$

. $432 E-07$

8. $006 \mathrm{E}-07$

2.003E- -08

$5.994 \mathrm{E}-07 \quad 1: 346 \mathrm{E}-\mathrm{O} 8$

$5.309 E-07 \quad$ I. $193 E-08$

4. 686 E⿱ -07

3. $672 \mathrm{E}-07$

3. $2965=07$

3. $014 E-07$

2. $704 \mathrm{E}-\mathrm{O} 7$

2.653E-07

$2.793 \mathrm{E}-07$

2. $921 \mathrm{E}-07$

3.033E-07

3:010E-07

$2.905 E-07$

2. $440 \mathrm{aE}-07$

. 980 E -07

$.869 \mathrm{E}-07$

. $868 \mathrm{EE}-07$

$1.716 \mathrm{E}-07$

$.513 E-07$

: $407 E-07$

$1.287 \mathrm{E}-07$

: 3651 - 3107

1.420E-07

.529E-07

- $605 \mathrm{E}-07$

$5365-07$

$.5345=07$

.577 -g7

:631E-0?

.660E-07

6 TOE-0?

9:064

7: $946 \mathrm{E}-09$

$7.068 \mathrm{E}-\mathrm{Og}$

6. $426 \bar{E}-09$

3. $696 \mathrm{E}-09$

$565 E-09$

5. $606 \mathrm{E}-09$

$137 \mathrm{k}-09$

$.546 E-09$

$134=09$

. $983 E-09$

$5.109 \mathrm{~g}-09$

.275E-08

.27 1E-OB

.136E-08

. $155 E-08$

:051

.

.02昆-08

. O87E-08

i60E-08

. 201 - 08

, 201틀

177E-08

$1.1825=08$

.2 $273 \mathrm{~K}-08$

.284E-08

. 267 E- 2308

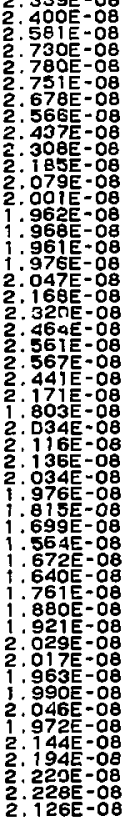

$6.912 \mathrm{E}-1$

$7.293 \mathrm{E}-14$

$7.571 E-14$

$7.566 \mathrm{E}-14$

$7.019 E-14$

6. 601 E 14

$5.716 E-14$

$4.959 E-14$

4.684 - 14

4. 508 E: 14

$4.380 \mathrm{E}-14$

$4.394 E-? 4$

$4.781 \mathrm{E}-14$

. O93E- 14

$5.573 E-14$

$5.562=14$

4. $5635-14$

3. 854 E -14

4.338 E -14

4. $356 E-14$

$4.000 \mathrm{E}-14$

3. $667 \mathrm{E}-14$

$3.145 E-14$

$3.352 \mathrm{E}-14$

3.5ा $4 E-14$

3.742E- 14

$4.019 \mathrm{E}-14$

3. $9706-14$

3.870E-14

$4.012 E-14$

3. $858 \mathrm{E}-14$

$4.271 E=14$

4.315e 14

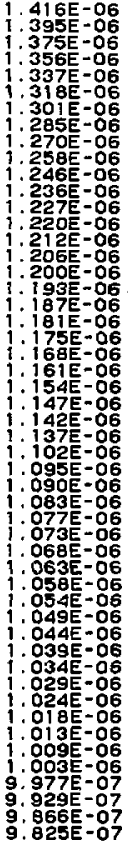

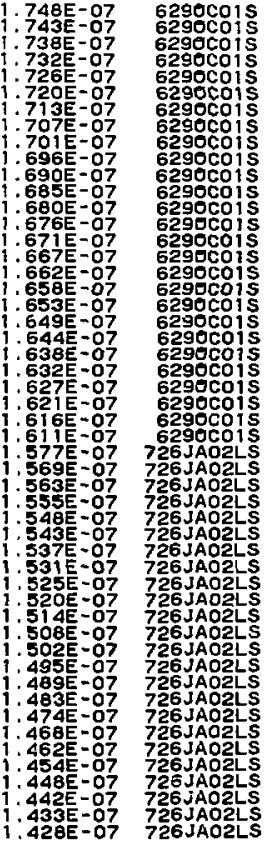




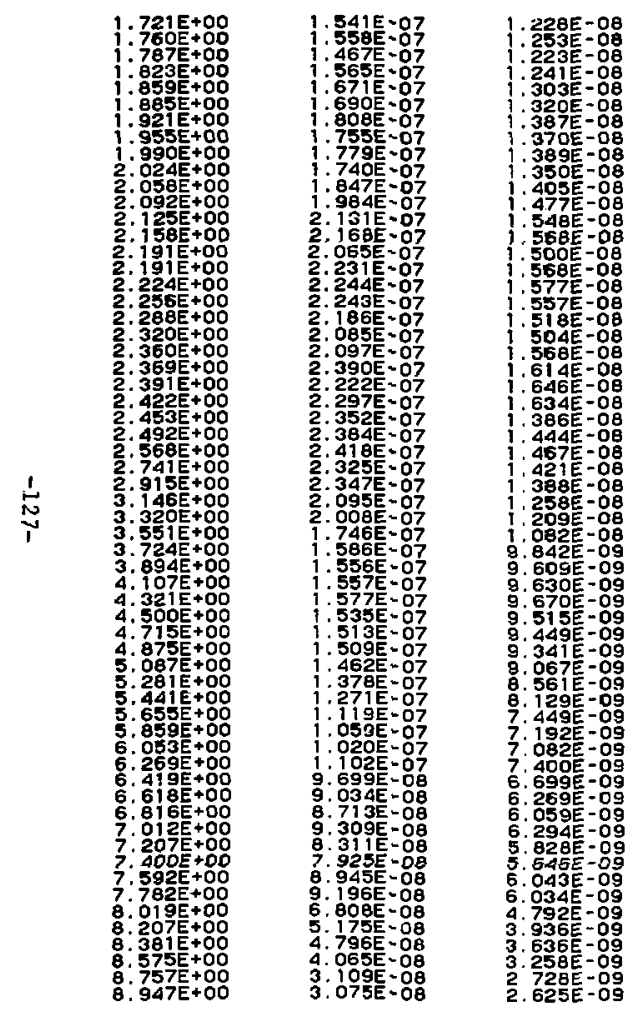

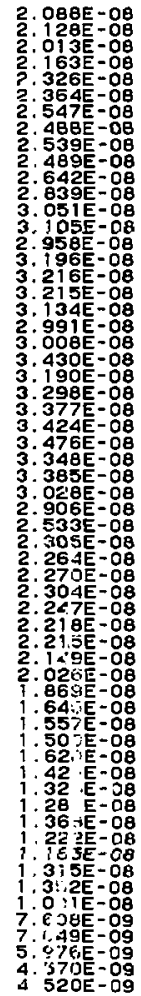
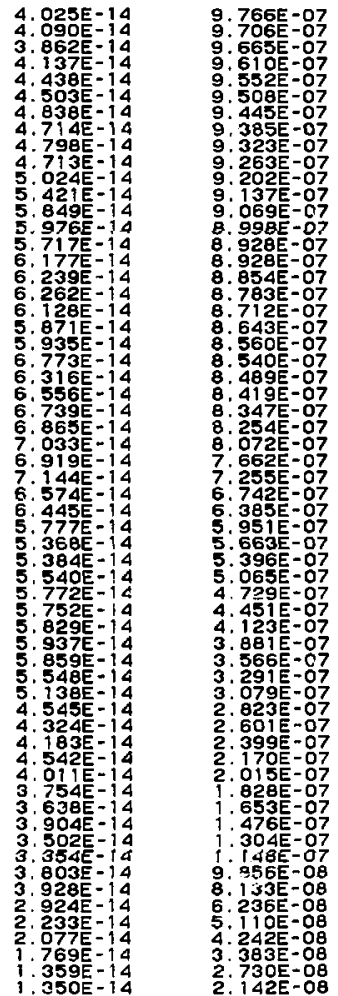

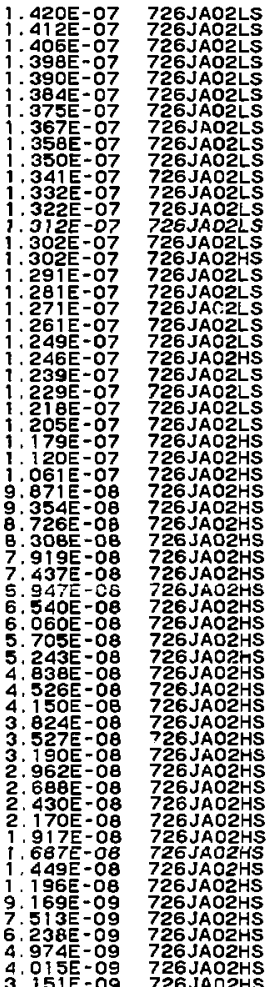



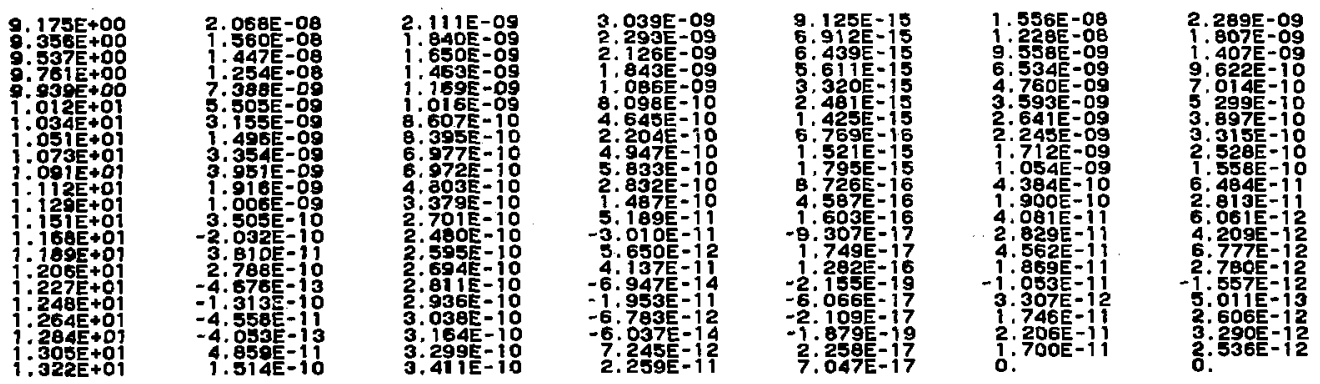

726JAO2HS 7 $726 J A C 2 H S$ $726 \mathrm{JAOZHS}$ $726 J A O 2 H S$ 7 6JAOLS

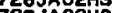
$7265 A 02 H S$ $726 \mathrm{JAO} 2 \mathrm{HS}$ 7 T5 $726 J A 02 \mathrm{HS}$ 726JAO2HS SJAO2HS $726 \mathrm{JAO}$ HS 726JAD2HS 


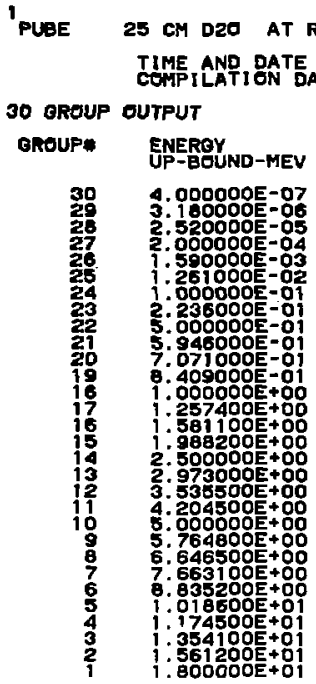

(FOR $1.0 \mathrm{~N} / \mathrm{SEC}$ )

\section{DIFFERENTIAL FLUX}

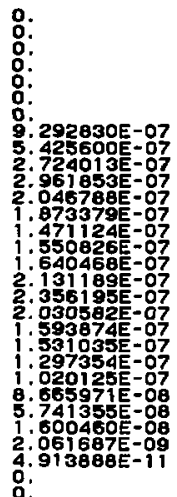

INTEGRAL FLUX

o.

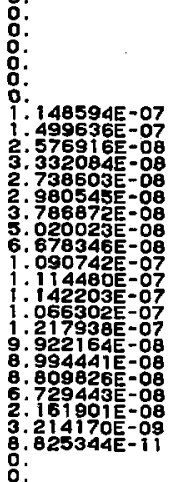

\section{FLUX PER UNIT LETHAROY}

o.

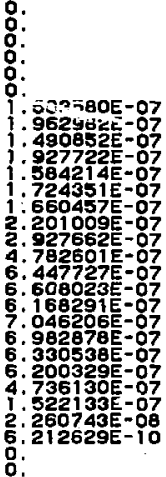


$10 / 14 / 77$ U $\begin{array}{r}14: 47: 07 R \quad 10 / 17 / 77 \\ 16.05,47\end{array}$ ENERGY (NEUT/CME-SEC-MEV) DEL-PHI

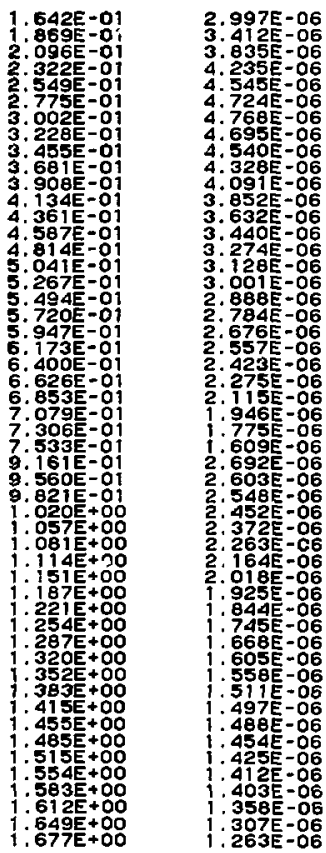
(MR/HRE $-M E V)$

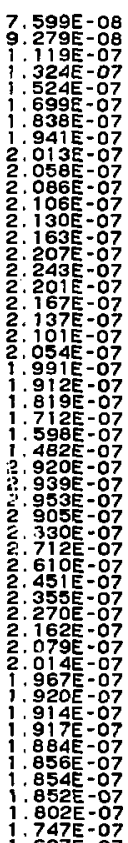

(ERG/GM-NEC-MEV) (NEUT/CML-SEC)

$\begin{array}{ll}2.251 E-13 & 6.759 E-06 \\ 2.698 E-13 & 6.686 E-06\end{array}$ 2. $698 \mathrm{E}-13$ $3: 191 \mathrm{E}^{-13}$ $4.188 E-13$ $4.5 \mathrm{SOE}-13$ $4.864 E-13$ 5. $130 \mathrm{E}-13$ 5: $145 \mathrm{E}-13$ 5. $118 \mathrm{E}-13$ $5.071 E-13$ $016 E-13$ $.024 E-3$ $4.021 \mathrm{E}^{-13}$ $4.907 \mathrm{E}-13$ $4.722 \mathrm{E}^{-13}$ $4.623 E-13$ $4.499 \mathrm{E}-13$ $4.152 E-13$ 3. 932 E -13 $3.685 \mathrm{E}-13$ 3. $425 \mathrm{E}-13$ 6.162) 13 $6.037 \mathrm{E}-13$ 6. $026 \mathrm{E}^{-13}$ . $432 \mathrm{E}-13$ 264 - 13

.930 - 13

$.724 E-13$ $4.315 E-13$ $4.140 \mathrm{E}-13$ $3.898 \mathrm{E}-13$ $3.794 \mathrm{E}-13$ 3. $774 E-13$ $3.769 \mathrm{E}-13$ 3.634 E $\{3$ $3.610 \mathrm{E}-13$ 3. 607 E -13 3. $502 \mathrm{E}-13$ 3. $28 \mathrm{EE}-13$
6. $604 \mathrm{E}-06$

6. 5 ! $3 E-06$

6. $308 \mathrm{E}-06$

6. $200 \mathrm{DE}-06$

6. $093 \mathrm{E}-06$

$5.989 E-06$

5. $793 \mathrm{E}-06$

. $703 \mathrm{E}-06$

$5.538 E-06$

5. 462 E -06

. $320 \mathrm{E}-06$

. $253 \mathrm{E}-06$

5. $127 \mathrm{E}-06$

. $012 \mathrm{E}-06$

$4.95 B E-06$

$4,909 \mathrm{E}-06$

4. $863 E=06$

4. 821 ह -06

$4.432 E-06$

. $326 E-06$

4 i 4 E -06

. $195-06$

3. $946 \mathrm{E}-06$

$3.869 \mathrm{E}-06$

3. $798 \mathrm{E}=06$

3. $734 \mathrm{E}-06$

3. 618 E-06

3. 564E-06

3.

. $466 \mathrm{E}=06$

3. $358 \mathrm{E}-06$

3. 314 E- 06

3. $271 \mathrm{E}-06$

3. $216 \mathrm{E}-06$

3. $175=06$

$3.086 \mathrm{E}-06$
3. $050 \mathrm{E}-0 \mathrm{0}$
INT-DOSE FILE-ID

$7.557 E-07$ 603NEO3S 7.538E-97 603NEO3S $7.515 E-07$ 603NOO3S 7. $487 \mathrm{E}=07 \quad 603 \mathrm{NEOBS}$ $7.419 E-07$ G03NEO3S 739E- 07 603NE03S 7.336E-07 603NOO3S $7.291 \mathrm{E}-07$ 603NOO3S 7.245E-07 603NOO3S 7.19日E-07 603NEO3S 7. $103 \mathrm{E}-07$ 603NEO3S $7.054 \mathrm{E}=07 \quad 603 \mathrm{NeO3S}$ 7. $004 \mathrm{E}-07$ 603NoO3S 6.954E-07 603NOO3S $6.904-07603 N 0035$ 6.805E-07 603NOO3S 6. $757 \mathrm{TE}-07$ 603NEO3S $6.710 E-97 \quad 603 N 0035$ 6.620E-07 603NOO3S $6.578 \mathrm{E}-07$ 603N003S 6.538E-07 603NO03S 6. $501 E-07 \quad 603 \mathrm{Ng} 35$ 6. $466 E-07$ 603NOO3S 5.107E-07 728JAOLLS 5.914E:-07 726JAO2LS 5. $803 \mathrm{E}-07$ 728JAO2LS 5.630E-07 728JAO2LS 5.542E:-07 726JAO2LS 5. 362 E 07 728JAOELS 5. 283 E -07 728JAOZLS .210E-07 728JAO2LS $5.073 E-07$ 728JAOLLS 5. $009 \mathrm{E}-07$ 72BJAO2LS 4.987 - 77 72BJAOLS $4.811 E-07$ 7 BJADLS $4.754 E-07$ 720JACLL $4.698 E-07$ 728JAO2LS $4.625 E-07$ 728JAN2LS $4.572 E-07$ 728JAC2LS $4.519 E-07$ 728JAO2LS 4.453E-07 728JAO2LS 


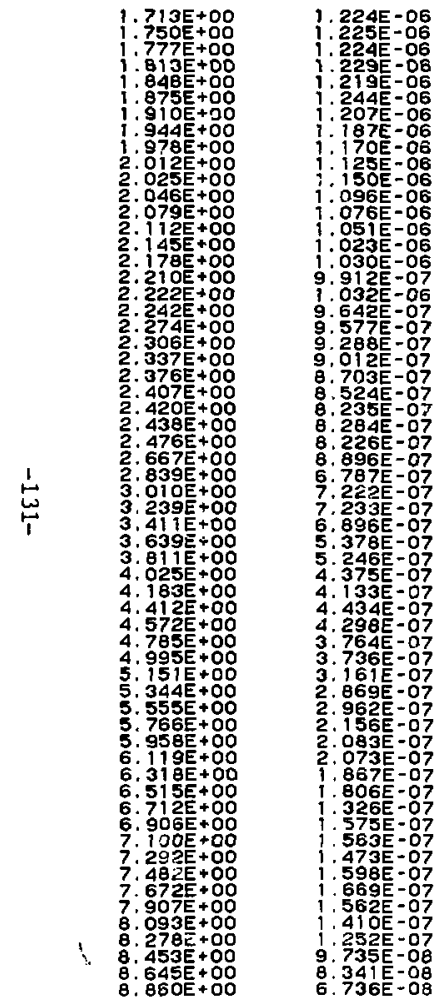

\begin{tabular}{|c|c|}
\hline 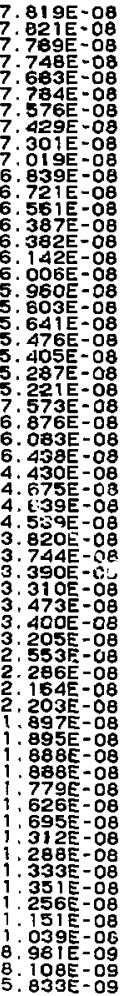 & 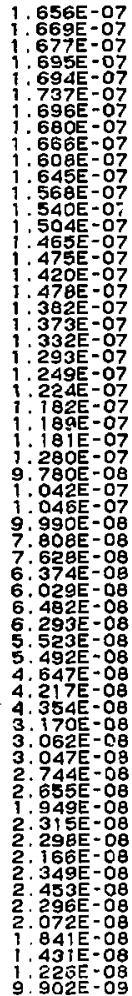 \\
\hline
\end{tabular}
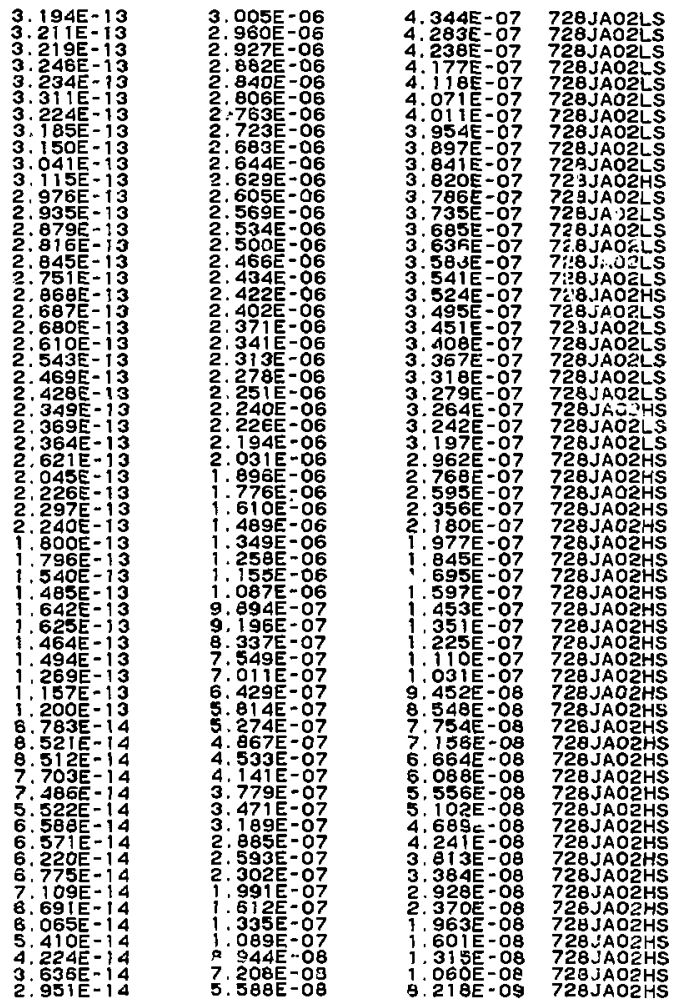

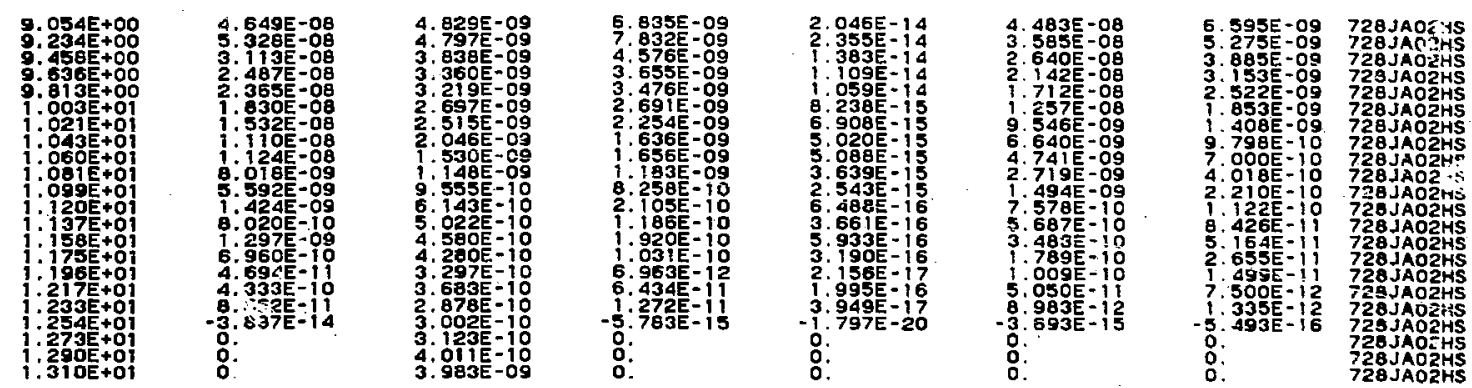


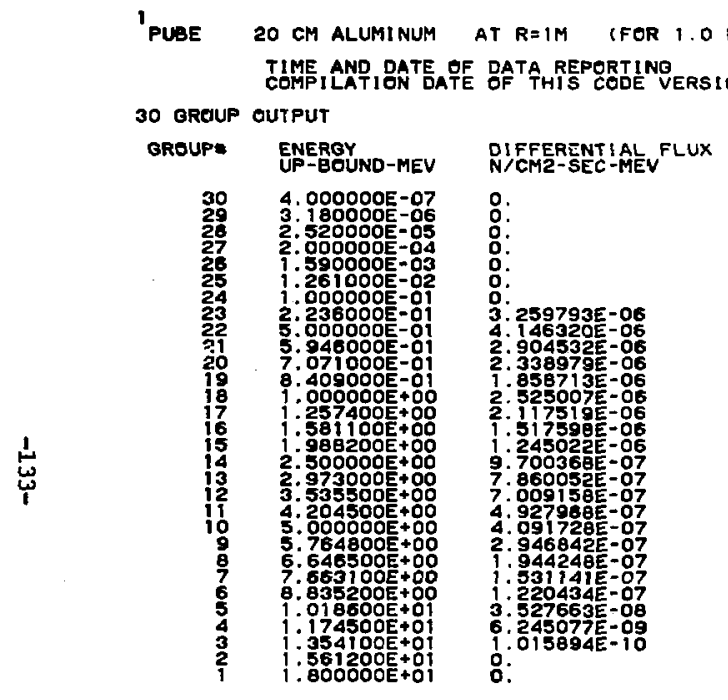

$10 / 14 / 770 \begin{array}{r}14: 47: 078 \\ 16.05 .47\end{array} \quad 119 / 77$

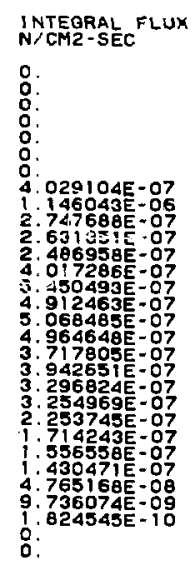

FLUX PER UNIT LETHAFTY

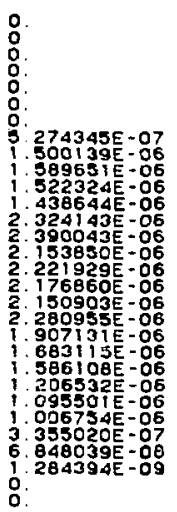


$10 / 14 / 770 \quad 15.00: 24 R \quad 10 / 17,77$ ENEROY (NEUT/CMR-SEC-MEV)

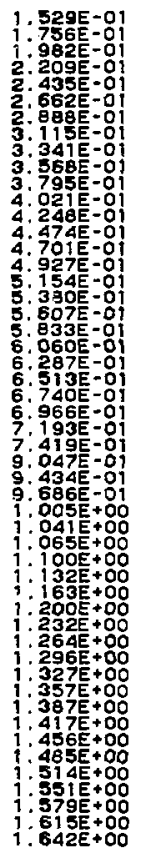

DEL - PHI

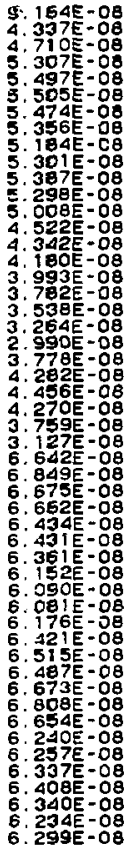

(MRIHR-MEV)

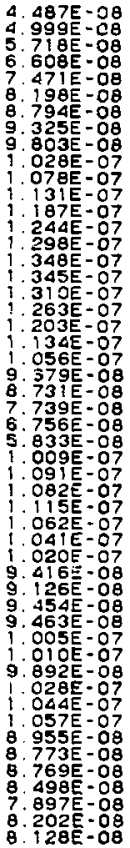

(ERG KERMA T-SEC-MEV)

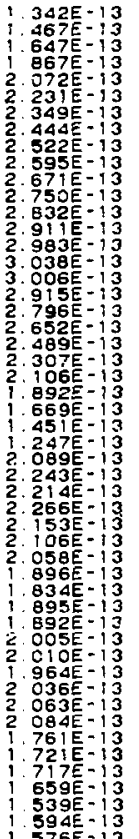

(NETEGRAL - SES -

7 100E-05 $7.014 \mathrm{E}-\mathrm{OE}$ 6. $966 \mathrm{E}-\mathrm{C} 6$ 6 ด62E- 06 6. $009 \mathrm{E}-06$ 6. $755 \mathrm{E}-\mathrm{OE}$ 6. $703 E-06$ 6. $6525=06$ 6. $5525-05$ 6. $504 E^{-06}$ 6 . $457 \mathrm{E}-06$ 6. 4 1 6 3245-06 6. $244 E-O G$ 6. $200 \mathrm{E}-06$ 6. $143 \mathrm{E}-06$ 6 1 $15 \mathrm{E}-06$ $6.069 \mathrm{E}-06$ 6. $069 \mathrm{O}-06$ . $034 E-06$ . $869 \mathrm{EE}-06$ . 44 - 06 $777 \mathrm{E}-06$ $7565-06$ $726 E-06$ 676E- 06 $648 E-06$ 648E-06 $5985-06$ ST2E-06

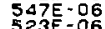
$499 E-06$ $474 E-06$ $444 E-06$ $.424 E-06$ $305 E-065$ $363 E-r_{1} 6$ $34 i E .06$
INT-OOSE

9 169E-OP 9. $346 \mathrm{E}-\mathrm{O} 7$ 9 IISE-O? 9. O99E-0? $9796-07$ 9. 037 E -07 9 1 $4 \mathrm{E}-07$ 8 9gok-0?

$8.939 E-07$

\& 912E-0?

8 883E-0?

$8.853 E-07$

8. $792 \mathrm{E} \cdot 0$ ?

$863 E \cdot 07$

8. $735 \mathrm{E} \cdot \mathrm{a} 7$

8. 684 - 07

8 .

8. 62 ze -07

605E-07

8. 46 但-07

8. 421 E -07

8. $393 \mathrm{E}-07$

353E-07

$249 E-07$

8. $253 \mathrm{E}-0$ ?

$222 E-07$
$193 E-07$

$815 \mathrm{AE} \cdot 07$

8 129E-a?

O97E-07

8 OJ4E- 07

\& OYaE-a?

941E-07

7 903E-07

$7.877 \mathrm{E}-07$

820E-O7

$7.768=07$

7. 768:-0?
FILE-TO

6.0 NoO2s 5 i CNOOzS 6) ONOO2S $5:$ ONOD2S - IONOOZS inOO2S bingoes ? i inoDs 61 ONOOES 610 NOO2S 610 NOO2S $6: 0$ NOC2S 6 i ONOO2S 6:ONOO2S EI ONOOZS 610 NoO2S GiONOO2S IONOO $610 \mathrm{oO} 2 \mathrm{~s}$ 6 ONOO2S 6 : ONOOZS 71 OJAO2LS $718 J A O 2 L S$ $718 J A O 2 L S$ 7) 7) $718 \mathrm{JAO2LS}$

$?$. $\rightarrow 18 J a O Z L S$ $718 J A O 2 L S$ 7 I JAOZLS $718.5 A O 2 L S$ 7 a AOLLS $718 J A O 2 L$ 7 . $718 \mathrm{JAO2LS}$ 

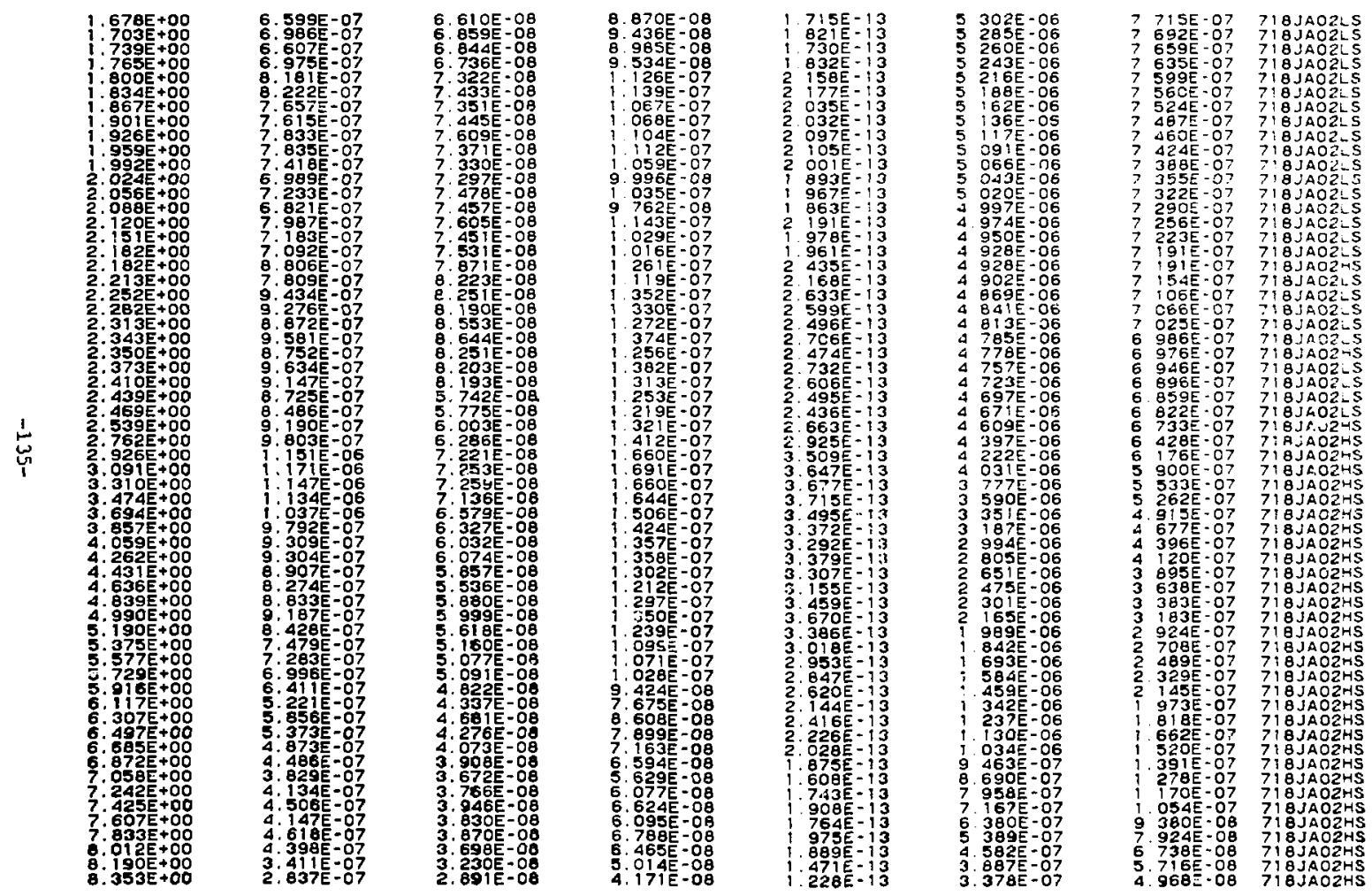


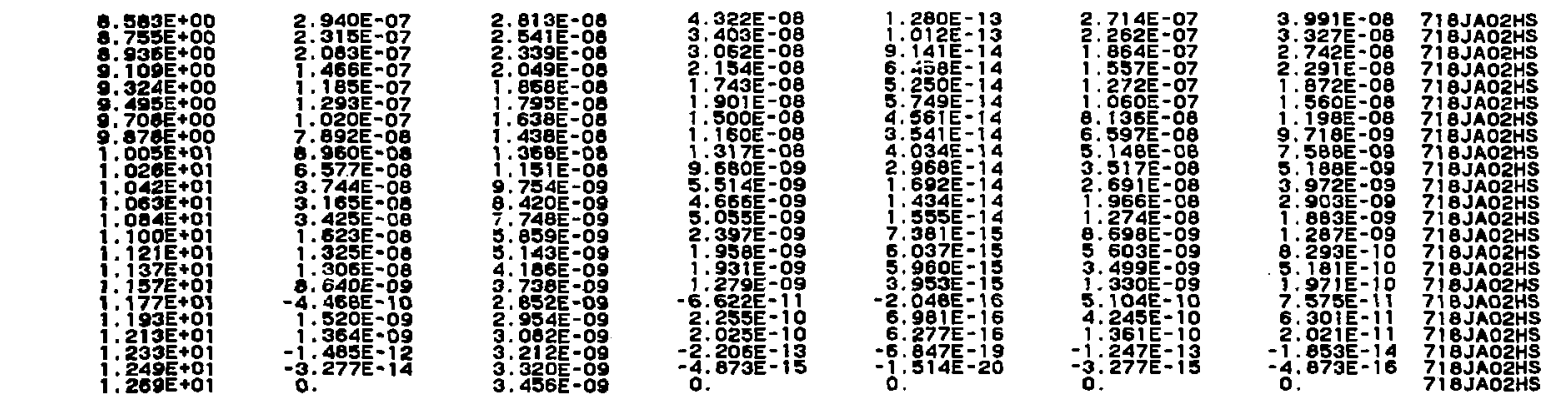




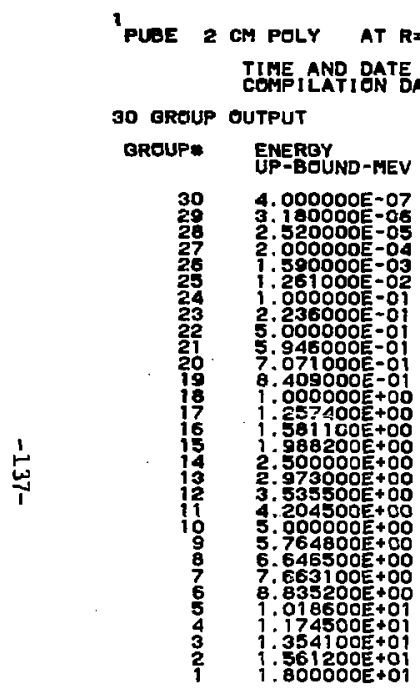

(FOR I. O N/SEC)

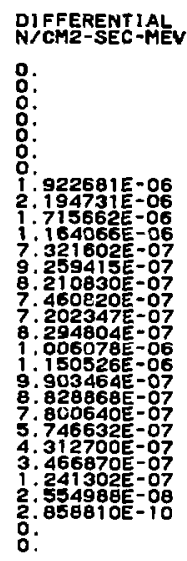

INTEGRAL FLUX

0

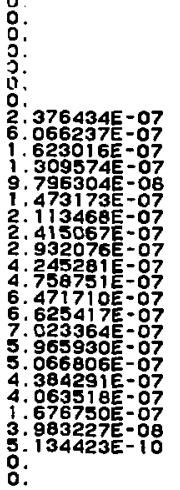

FLUX PER UNIT LETHARGY

o.

o.

o.

3. $110898 E-07$

7. $940537 \mathrm{E}-07$

9. $389818 \mathrm{E}-07$

666920 -

8. $522829 E-07$

.

$285367 E-06$

651437 -

744105

$3.8326415-0$

4. $1986175-06$

3.566159E-O6

3. $08565 \mathrm{E}-06$

1.

2. $001672 E=07$

o. 
5 CM PELY AT R=IM (FUR 1.O N/SEC) TIME AND OATE OF DATA REPORTINQ

ENEROY PHI

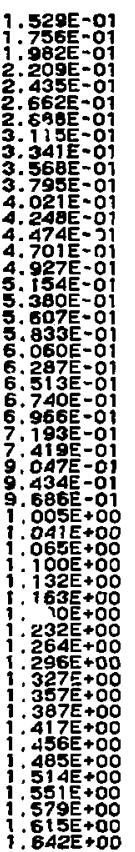

6. $840 \mathrm{E}-08$

$3.169 \mathrm{ge}-\mathrm{Oe}$

4.216E-OB

$4.246 \mathrm{k}-08$

$4.141 \mathrm{E}-\mathrm{O}$

3. $975 \mathrm{E}-0 \mathrm{0}$

3. $79 \mathrm{kE}-08$

3. $203 E-08$

3. $020 \mathrm{E}-08$

$2.845 E-08$

2. $690 \mathrm{~g}=08$

2.442E $=08$

. $333 \mathrm{E}$

2.234E-O8

2. 059 -08

$1975-08$

$1.980 \mathrm{E}-08$

$1.633 \mathrm{E}-08$

1. $492 \mathrm{E}-08$

$5.4900-08$

.561E-OB

$5.522 \mathrm{E}-08$

5. 461 E-

$5.438 E-08$

$5.436 \mathrm{E}-0 \mathrm{~B}$

5. $150 \mathrm{E}=08$

. $143 E-08$

$5.280 E-08$

5. $207 \mathrm{k}=08$

$5.439 \mathrm{E}-0 \mathrm{0}$

$503 E-08$

5. 311 E- 08

5. $306 \mathrm{E}-\mathrm{OB}$

$5.409 \mathrm{E}-0$

$5.406 \mathrm{E}-\mathrm{O}$

$5.152 \mathrm{E}-08$
$5.20 \mathrm{BE}-0 \mathrm{~B}$
$4.069 \mathrm{E}-0$
$10 / 14 / 77$ U 15:01:30R 10/17/77

(MR'HRE-MEV)

(ERG/GM-SEC-MEV)

(NNTEGT/CML-SEC)

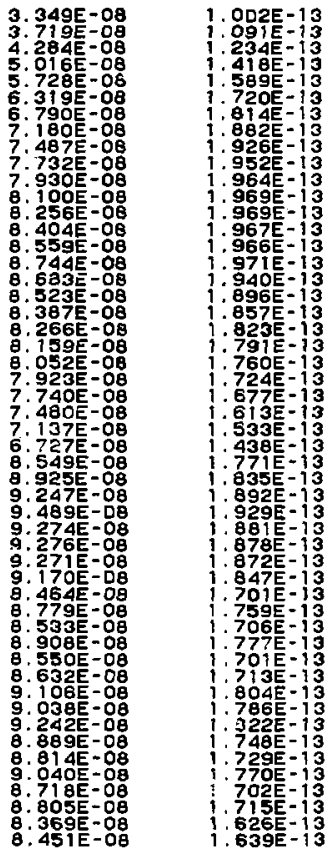

5. $444 E-06$

5. $312 \mathrm{ZE}-06$

$5.343 \mathrm{E}-06$

5. 304 E $=06$

.

$5.181 \mathrm{E}-06$

5. 1 A1E-06

5. 064 E 06

5. $0295-06$

$4.963 \mathrm{E}-06$

4.932 E-06

4. $903 \mathrm{E}-06$

4. $875 \mathrm{E}-06$

$4.823 \mathrm{E}-06$

4. $799 \mathrm{E}-06$

$4755-06$

$4.752 \mathrm{E}^{\circ}=06$

. $7309 \mathrm{E}-06$

4. $699 \mathrm{E}-06$

$4.670 \mathrm{O}=06$

$4.653 \mathrm{E}-\mathrm{O} 6$

$4.5285-06$

. 477 E-06

$4.47 \mathrm{E}=06$

$4.400=06$

. $373=-06$

$4.326 E=06$

4. $300 \mathrm{E}=06$

$255 E-066$

$4.232 E-06$

4. $211 E-06$

$4.1775-05$

4. 119E-06

4. YOOE-O

$4.080 E-06$

$4.054 E=06$

3.:12E-05
(NT-DGSE

FILE-IO

7. $019 E-07$

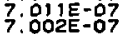

6.991 -07

6. $965 \bar{E}-07$

6. $950 \mathrm{E}-07$

$6.935 E-07$

6.910 -O7

. $903 \mathrm{E}=07$

6. $865 \mathrm{EE}-07$

6.827 -07

6. 8001-07

6. $789 \mathrm{E}-07$

$6.749 \mathrm{E}-07$

. 7 I

$6.693 E-07$
6.6744 .07

6. 656E-07

. $6211-07$

6. 60sE-07

. $465 \mathrm{E}-07$

6. $4315-07$

6. 374 E-07

. $318 E-07$

$6.256 \mathrm{E}-07$

6.2229E-07

6. 169 -07

6. $141 E-07$

6.113E-57

$6.060 \mathrm{E}-0$ ?

$6.005 E-07$

5.970 - 07

.944E-O

. $69 \mathrm{EE}-07$

$5.8611=07$
$5.8305-07$
$5.8072-07$
609Neozs

6ognoos

6o9kdo2s

6ugnoo2s

oozs

GogNeO2s

609 NoDes

Gognoozs

6ogneozs

6ogndozs

609no02s

6ognoo2s

6ogndoozs

609 NoO2s

609NaO

609Na02s

609 Nodes

$603 N 0025$

609 NOO2S

609 Nod2s

609No02S

7 BJAOBLS

71 JACZLS

7 lijA

71 OJAO3LS

7 I JAOZLS

71 BSAOBLS

71 JAO3LS

71 BJAOBLS

7183 AOЗLS

71 BJAOZLS

7 I JAO3LS

71 BJAO3LS

71 JAO3LS

7 I JAAOBLS

7 IIBJAOZLS 

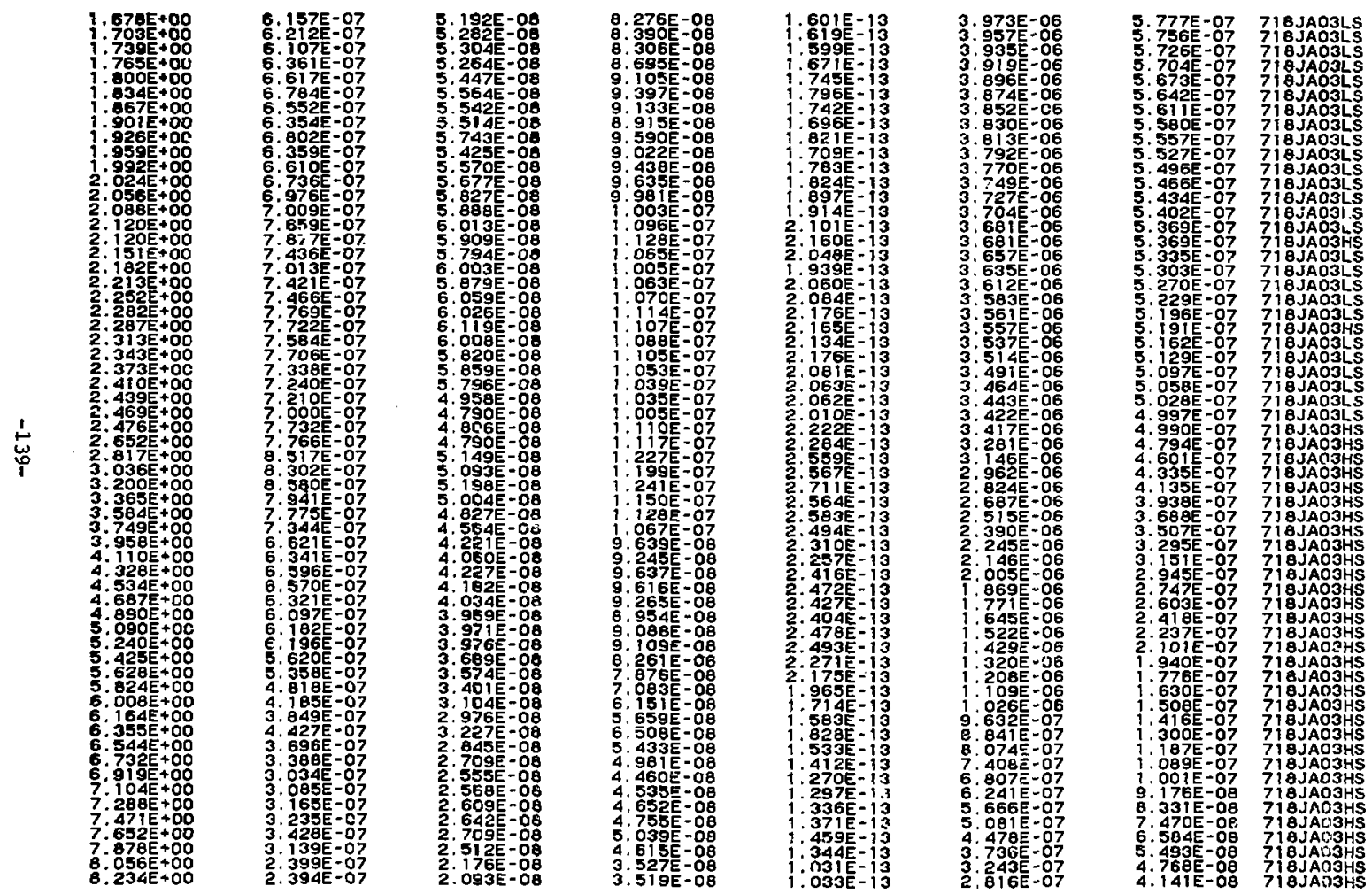

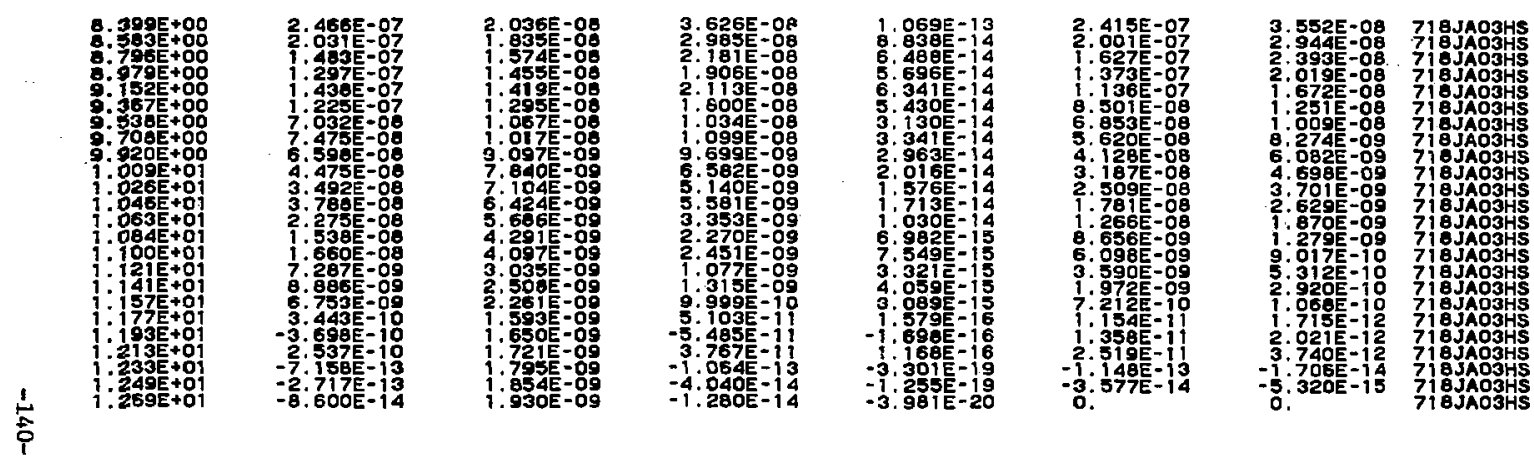

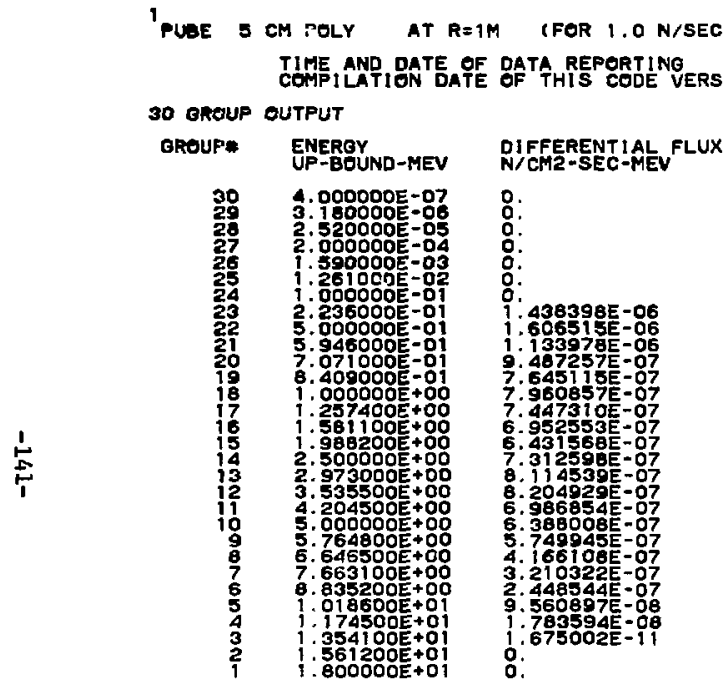

$10 / 14 / 77$ U 15:01:30R 10/17/77

INTEGRAL FLUX
N/CMR-SEC

o.

a.:

o:

:.

$1.777860 \mathrm{e}-07$

$4.4404085=07$
$1.0727435=07$

.

$1.266572 E-07$

$1.916938 \mathrm{E}-07$

2.25041 -

3.742588E-07

4. $615273 \mathrm{E}=07$

5.674205E -07

3.67325 E -07

3. $263613 \mathrm{~K}-07$

1.869939E-

3.780623E-08

::
FLUX PER UNIT LETHARGY

ㅇ.

o.

:

327328E-07

. $812371 \mathrm{E}=07$

5. $174781 E=07$

7. $327571 \mathrm{E}-07$

$4057795-07$

9.867410E-07

147 J

.220543E-06

.

230

3. $094850 \mathrm{E}-06$

296921E-06

O19841E-OG

. $092987 \mathrm{E}-07$

2. $117705=10$

o. 
$10 \mathrm{CM} \mathrm{POLY}$ AT R=1M (FOR $1.0 \mathrm{~N} / \mathrm{SEC}$ )

TIME AND DATE OF DATA REPORTING

$$
10 / 14 / 77 \text { U 15:02:48R } 10 / 17 / 77
$$

ENEROY (NEUT/CHE-SEC-MEV) DEL-PHI

DOSE

1. 529E-01

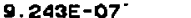

$4.622 E-08$

9. $243 E-07$

9. 351 - -07

$1.056 E-06$

2.435E-01

.662E-01

115E-01

$341 E-01$

. $7985-01$

$4.248 E-01$

$4.474 E-01$

4.701E-01

. 15 든-01

- 3BOE-01

. $333 E-01$

$\underset{1}{1}$

$1.128 E-06$

1. 100 E 06

$1.028 E-06$

9. 867 -

9. 041 - 07

8.655E-07

..2975-0 7

7. $683 \mathrm{~B}-07$

7. 437 J -07

7. $230 \mathrm{E}-07$

7. 0 6. 4 E-07

6. $975 \mathrm{E}=07$

6. 647 등-07

$6.494 E-07$

5. $9975-07$

. $740 \mathrm{E}-\mathrm{O}$

6.96

7. 193E-01

7. $419 E-01$

Q76E-O

. $345 E-01$

$9.996 E-01$

. 037 F + OO

. $098 \mathrm{~B}+\infty \mathrm{O}$

$132 E+\infty 0$

. 202E+00

. $236 E+00$

$258 E+00$

$334 E+00$

$366 \mathrm{E}+00$

, 397E + 420

$458 E+00$

$498 E+00$

329E +00

595E+ 00

$624 E+\infty 0$
$661 E+00$

5. $627 E-07$

.963E-07

. 80́ํㅡㄴ 07

5. $330 \mathrm{OE}-07$

5. 113 13E-07

$4.917 \mathrm{E}-07$
$4.671 \mathrm{E}-07$

4. 462 E- 07

4. 564E-07

. 389 $430=07$

4.412E-07

4. $397 \mathrm{E}-07$

$4.412 E-07$

4. 459 - 07

4. $31 \mathrm{BE}=07$

4. $2205-07$

4. $168=-07$

3. $3008=07$
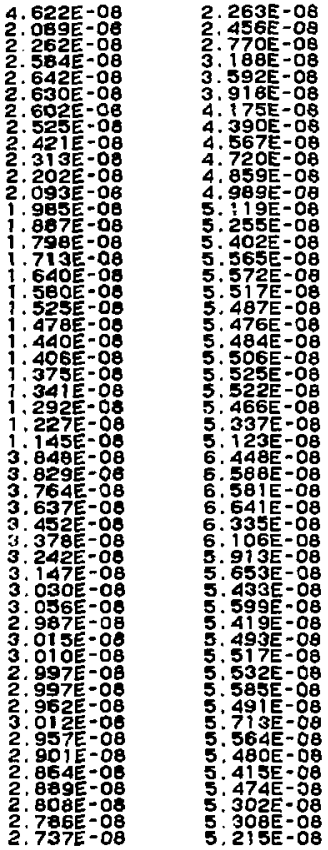

(ERG/GM-SEC-MEV)

(NTIEGRAL

(NT -DESE

FILE-ID

2. 263E-08 $\quad 6.768 E-14 \quad 3.159 E-06$

$7.977 E-14 \quad 3.116 E-06$

3. $093 \mathrm{E}-06$

3. $043 \mathrm{E}-06$

1. 065E-14

$1: 115 E-13$

1 . 175E-13

. 203E-13 2.921E-06

. ¿2 $21 E-133$ 2. $899 E-06$

$1.230 E-13 \quad 2.858 \mathrm{E}-06$

$1.241 E-13 \quad 2.839 E-06$

$1.245 E-13 \quad 2.803 E-06$

. 227E-13 $2.786 E-06$

.207E-13 $2.753 E-06$

$1.204 E-13 \quad 2.737 E-06$

$1.202 E-13 \quad 2.706 E-06$

. $196 \mathrm{E}-13 \quad 2.692 \mathrm{E}-06$

$146 E-13$

. 096E- i3

$1.335 \mathrm{E}-13 \quad 2.650 E-06$

349E- 13

$.351 \mathrm{E}-13$

$.285 E-13$

1. $194 \mathrm{E}-13$

1 : $092 \mathrm{E}-13$

1. $.0832=-13$

$1.096 E-13$

$1.106 E-13$

1. $125 E-13$

$1.074 E-13$

1. $0598=13$

1. olo

2. 5385-06

2. 522 E-06

2. $480 \mathrm{E}-06$

2. $4665-06$

. $44 \mathrm{EE}-06$

2. 41 作-06

2. $400 \mathrm{E}-06$

2. $375 \mathrm{E}-06$

. $342 \mathrm{E}-06$

2. $328 \mathrm{E}-06$

2.314E-06

$287 \mathrm{E}-05$

2. $270 \mathrm{E}-06$

$2.246 E-06$

2.230E-06

4.010E-07 607NeO2S

$.005 \mathrm{E}-07$ 607NG02S

$3.9921-07$ 607Noozs

. $9805-07$ SO7NOOS

$3.976 \mathrm{E}-07 \quad 67 \mathrm{NOO2S}$

3. $367 \mathrm{E}-07$ 607NGD2S

3. 357 -07

3. $947 E-07$

3. $926 \mathrm{E}-07$

$3.915 \mathrm{E}-07$

3. $903 \mathrm{E}-07$

3. $879 \mathrm{E}-07$

3. $867 \mathrm{E}-07$

3.842E=07

3. $829 \mathrm{E}=07$

3. $805 \mathrm{E}-07$

$3.792 E-07$

.

$3.755 E-07$

3. 742 E -07

3. $731 E-07$

$3.635 E-07$

3. $617 \mathrm{ZE}-07$

3.574E-07

$3.530 E=07$

3.513E- 07

3. $493 E-0$

3. $454 \mathrm{E}-07$

3. $436 E-07$

. 394 -

3. $382 \mathrm{E}-07$

3. $364 E-07$

3. 347 E:-07

3. उ12E-07

3. $290 \mathrm{E}-07$

3. 258 E -07

3. 222 -07

$607 N 0025$

07 No02s

$607 \mathrm{NJO}^{2}$

on

O7NOO2S

607NoO2s

607 NoO2S

607No02s

607NoO2S

6o7ngoes

6o7noges

607 No2s

G07N002S

607NODES

7 20SAOSLS

720JAU5LS

7 20JAOSLS

720JAOSLS

$720 J A O 5 L S$

$720 J A O 5 L S$

$720 J A O S L S$

$720 J A 05 L S$

2OJAOSLS

720JAOSLS

20JAOSLS

$720 \mathrm{JAOSLS}$

$720 J A O S$

72014

$720 J A O 5 L S$

TEOJAOSLS

$720 J A O 5 L S$ 

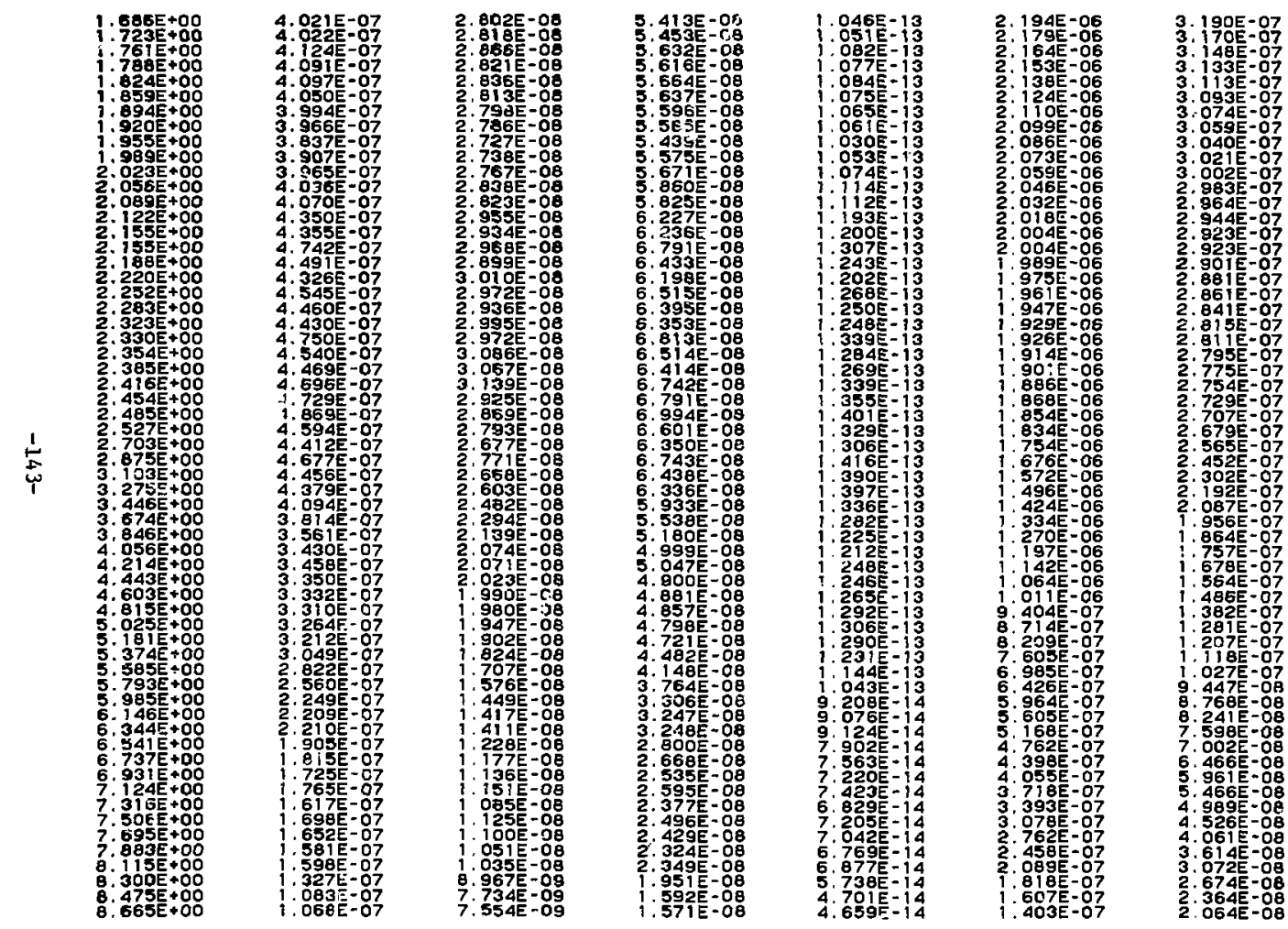

720JAOSLS $720 \mathrm{JAOSLS}$ $720 J A O S L S$ $720 \mathrm{TAOSLS}$ 720 JAOSLS 720 720 JAOSLS 7 OOJAOSLS $720 \mathrm{JAOSLS}$ $7203 A 05$ $720 \mathrm{JAOSLS}$ $720 \mathrm{JAOSHS}$ $720 J A O 5 L$ 720 JAO5LS $720 \mathrm{JAOSLS}$ 720JAOSL 7. 720 $720 j A 05$ LS $720 \mathrm{JAO} L \mathrm{LS}$ $720 \mathrm{JAOSLS}$ 7205 $720 \mathrm{JA05HS}$ 72OJAOSHS $720 \mathrm{JAOSHS}$ $720 J A 05$ SS $720 \mathrm{JAO5HS}$ $7205 i$ i. $720 J A O S H S$ $720 J A O 5 H E$ 720 JaOStís 720JAASHS 720JAOSHS $720 J A O S H S$ $720 J A O S H S$ 720 $720 J A 05 H$ $720 J A O S H S$ 7 72JAO5HS $720 J A O S H S$ $720 J A O S H S$ 7 720JAOSHS $720 J A O 5 H S$ $720 J A 05 H S$ $720 J A 05 H S$ $720 \mathrm{JOOSHS}$

720 JAOSHS 

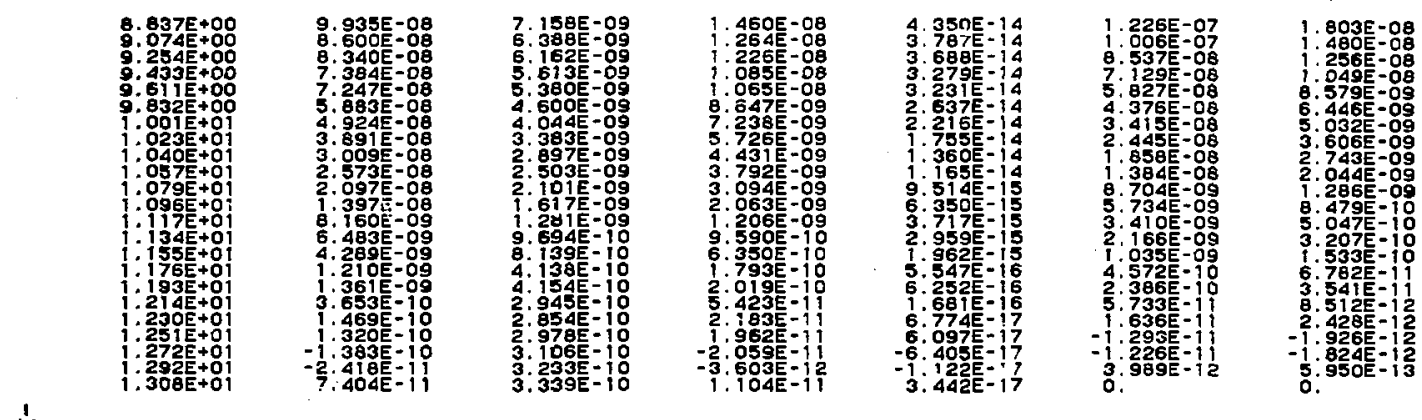

$720 \mathrm{JAOSHS}$ 20JAOSHS $720 \mathrm{JAOSHS}$ $720 \mathrm{JAOSHS}$ 7ZOJAOSHS $720 \mathrm{JAOSHS}$ 720 AOOSHS $7205 A O 5 H S$ $720 \mathrm{JAOSHS}$ $720 J A O S H S$ $720 J A O S H S$ $720 \mathrm{JAOSHS}$ 720 JAOSHS 7 TOJAOSHS $720 J A O 5 H S$ TEOJAOSHS 


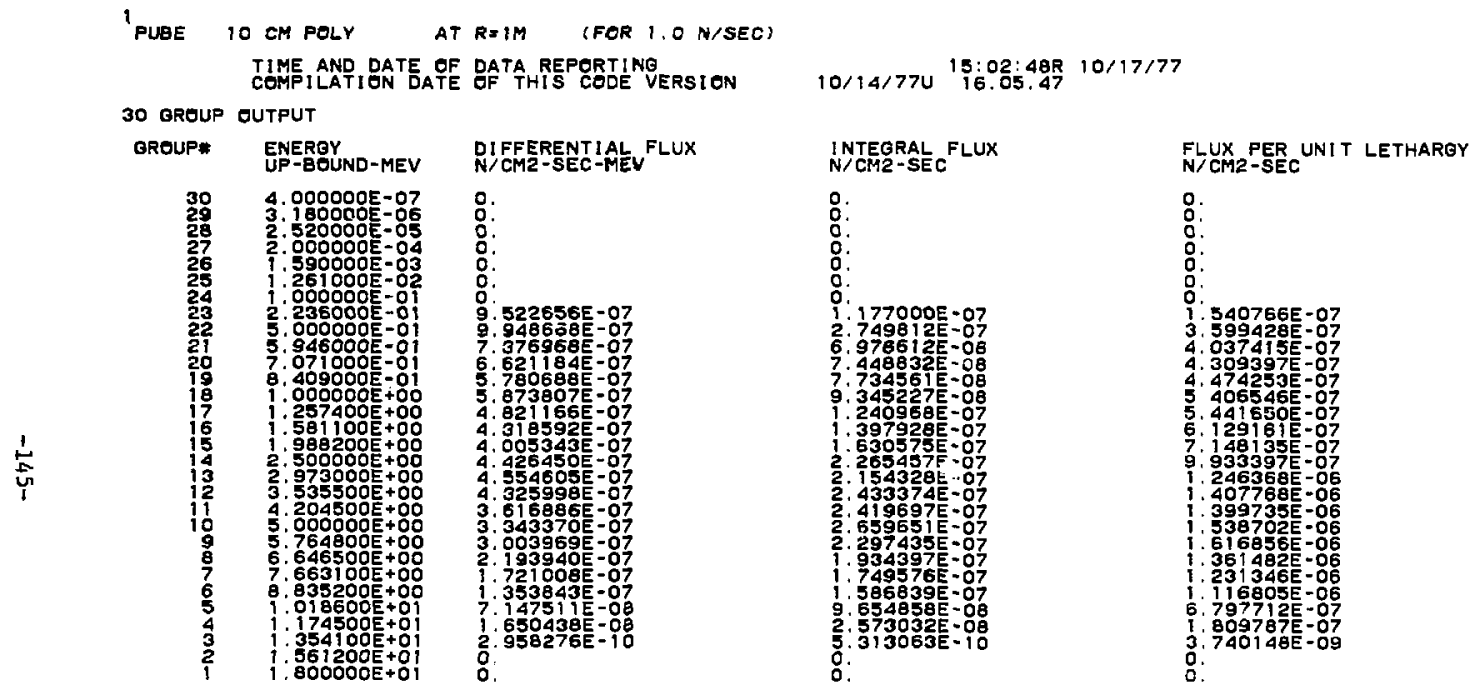

